\title{
Modelling Pn wave speeds beneath the central North Island, New Zealand
}

\author{
Anya Mira Seward
}

A thesis submitted to Victoria University of Wellington, as fulfillment for a

Doctor of Philosophy in Geophysics, 2008

Seismology

28-08-2008

Institute of Geophysics,

School of Geography, Environmental and Earth Sciences

Victoria University of Wellington

Te Whare Wānanga o te Upoko o te Ika a Māui

Wellington, New Zealand 


\section{ABSTRACT}

A new method of modelling Pn-wave speeds is created. The method allows the predominant wavelength features of P-wave speeds in the uppermost mantle to be modelled, as well as estimating values of mantle anisotropy and irregularities in the crust beneath stations, using least-square collocation.

A combination of National Network seismometers, local volcanic seismic monitoring networks and temporary deployments are used to collect arrival times from local events, during the period of 1990-2006. The dataset consists of approximately 11200 Pn observations from 3000 local earthquakes at 91 seismograph sites.

The resulting model shows distinct variations in uppermost mantle Pn velocities. Velocities of less than $7.5 \mathrm{~km} / \mathrm{s}$ are found beneath the back-arc extension region of the Central Volcanic Region, and under the Taranaki Volcanic Region, indicating the presence of water and partial melt. The region to the east shows extremely high velocities of $8.3-8.5 \mathrm{~km} / \mathrm{s}$, where the $\mathrm{P}$-waves are traveling within the subducting Pacific slab. Slightly lower than normal mantle velocities of $7.8-8.1 \mathrm{~km} / \mathrm{s}$ are found in the western North Island, suggesting a soft mantle. Pn anisotropy estimates throughout the North Island show predominately trench parallel fast directions, ceasing to nulls in the west. Anisotropy measurements indicate the strain history of the mantle.

For the observed upper mantle Pn velocity of $7.3 \mathrm{~km} / \mathrm{s}$ is one of the lowest seen in the world. Ray-tracing modelling indicate that this region extends to depths of at least $65 \mathrm{~km}$, suggesting an area of elevated heat $\left(700-1100^{\circ} \mathrm{C}\right)$ at Moho depth. Elevated temperatures can be caused by the presence partial melt ( $0.4 \%$ to $2.1 \%$ depending on the amount of water present).

Beneath the western North Island, the observed slower than normal mantle velocities, indicate a material of lowered shear modulus, susceptible to strain deformation. 
However, anisotropy estimations in this region, show no significant anisotropy, suggesting that this is a region of young mantle that hasn't had time to take up the signature of deformation. These observations can be explained by a detachment of the mantle lithosphere through a Rayleigh-Taylor instability more than 5 Ma. 


\section{ACKNOWLEDGEMENTS}

Firstly thanks must go out to my supervisors, Euan Smith and Tim Stern. Euan's patient guidance and encouragement have always been at the ready to help me move forward when things were standing still or heading backwards. Tim's excitement about results and the big picture always sprung up when I need that little bit more encouragement.

A special thanks goes out to Mark Henderson, who has been at my side, or usually my computer, for this whole wild journey. He has always been there for idea bouncing and brain storming; interpreting the "I want to do this... but the computer doesn't understand me", and always having the patience to sit down and help sort it out. I would like to sincerely thank Mark for all his help, especially in the writing of the modelling codes.

The Marsden Fund of New Zealand, was principal sponsor of this research. Their financial support was very much appreciated. Financial support for the completion and advertising (i.e attendance of conferences) of this project was also given by Tim Stern, and Victoria University of Wellington submission scholarship. Their help was also very much appreciated.

Most of the data used for this study were obtained through the GeoNet earthquake catalogues. I would like to extend a special thanks to Kevin Fenaughty, for always being happy to help when I needed data, and the GeoNet technicians, for keeping the catalogue up to date, so I didn't have to do too much additional picking of arrival times. 
Much appreciation is given to a long list of colleagues and friends, for their help, ideas, distractions, laughs, sweat and encouragement throughout this whole process, including:

(1) The fieldwork crew, namely... Euan Smith, Martha Savage, Mark Henderson, Erik Ewig and Sonja Greve.

(2) The work environment crew: (in addition to those already named), Adrian Benson, Tim Stern, John Townend, Wanda Stratford, Michelle Salmon, Sandra Bourguignon, and many more that have passed in and out of the department.

(3) The distraction crew: Scott Paterson, Suzannah Toulmin, Danny Clarke, Bronwyn O'Keefe, Jess Johnson, Stacey Dravitzki, and many many more.

(4) The encouragement crew: (include those already named) my family and friends, near and far. The lovely flatmates who have put up with my stresses over the years, namely, Nora Patterson, Michelle Wong-She, Hannah Lake, and Paul Frost.

You have all contributed to the success of this project in some way. THANK YOU! 


\section{CONTENTS}

Abstract $\quad$ iii

Acknowledgements $\quad$ V

Table Of Contents vii

List Of Figures $\quad$ xiii

List Of Tables $\quad$ xvii

\section{Chapters}

1 Introduction and Tectonic setting 1

1.1 Background . . . . . . . . . . . . . . . . . . . . . . 1

1.1.1 Subduction Zone Settings . . . . . . . . . . . . . . . . . 1

1.2 Tectonic setting of New Zealand . . . . . . . . . . . . . . . . . . . 3

1.2.1 Tectonics of the North Island . . . . . . . . . . . . . 7

1.3 Investigations into geophysical properties of the North Island . . . . . . 8

1.3.1 Uppermantle velocity studies . . . . . . . . . . . . . . 10

1.4 Thesis objectives $\ldots \ldots \ldots \ldots \ldots$. . . . . . . . . . . . . . . . . . 12

1.4.1 Pn velocity studies . . . . . . . . . . . . . . . . . 14

1.5 Thesis Outline . . . . . . . . . . . . . . . . 15 
2.1 Introduction . . . . . . . . . . . . . . . . . . . 17

2.2 Traditional Pn tomographic method . . . . . . . . . . . . . . . . 18

2.2.1 Limitations of traditional tomography . . . . . . . . . . . 19

2.3 Least-squares Collocation $(\mathrm{LSC}) \ldots \ldots \ldots$

2.3.1 Advantages of least-squares collocation . . . . . . . . . . . . 22

2.4 Modelling the uppermost mantle . . . . . . . . . . . . . 22

2.4.1 Slowness Modelling . . . . . . . . . . . . . . . . 23

2.4.2 The Mantle Covariance . . . . . . . . . . . . . . . . . . 25

2.4.3 Pn anisotropy estimation . . . . . . . . . . . . . 26

2.4.4 The Crustal Covariance . . . . . . . . . . . . . 27

2.5 Mantle slowness estimation summary . . . . . . . . . . . . . . . . . . . 29

3 Data Selection $\quad 31$

3.1 Introduction . . . . . . . . . . . . . . . . . . . . . 31

3.2 North Island Seismic Network . . . . . . . . . . . . . . . . . . 31

3.2.1 Western North Island Passive Seismic Experiment . . . . . . . . 32

3.2.2 Coromandel Peninsula deployment . . . . . . . . . . . . . . 35

3.2 .3 Station locations . . . . . . . . . . . . . . 36

3.3 North Island Seismicity . . . . . . . . . . . . . . . . . . . . 36

3.4 Ray-path geometry . . . . . . . . . . . . . . . . . . 39

3.4.1 Hypocentre derivation . . . . . . . . . . . . . . . . . 40 40

3.4.2 Picking of event arrival times . . . . . . . . . . . . . . 40

3.5 Two-Station method . . . . . . . . . . . . . . . . . . 41

3.6 Event selection . . . . . . . . . . . . . . . . . . . . . . . . 43 
4.1 Model Resolution . . . . . . . . . . . . . . . . . . . . . . 45

4.1 .1 Ray Path coverage . . . . . . . . . . . . . . . . 45

4.1.2 Creating a synthetic input model . . . . . . . . . . . . . 47

4.1 .3 Resolution of model . . . . . . . . . . . . . . . . . . . . . . . 48

4.1.4 Discussion of synthetic model resolution . . . . . . . . . . . 50

4.2 Uncertainty estimations . . . . . . . . . . . . . . 51

4.2 .1 Picking Errors . . . . . . . . . . . . . . . . . . . . 51

4.2.2 Mislocation of epicentres ............... 51

4.3 Input Parameters . . . . . . . . . . . . . . . . . . . . . 57

4.3.1 Mantle properties ................ 57

4.3 .2 Crustal properties . . . . . . . . . . . . . . . . 59

4.3 .3 Summary of Inputs . . . . . . . . . . . . . . . . . . 60

4.4 Results and Discussion . . . . . . . . . . . . . . . . . . 60

4.4.1 Crustal delay term estimates . . . . . . . . . . . . . 67

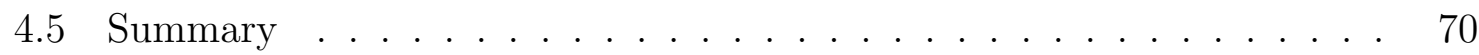

4.5.1 Modelling Resolution . . . . . . . . . . . . . . . . . . . 70

4.5.2 Modelling inputs ... . . . . . . . . . . . . 70

4.5.3 Uncertainties . . . . . . . . . . . . . . . . . . 71

4.5.4 Modelling Results . . . . . . . . . . . . . . . . . . . . . . . . 71

5 Upper Mantle Anisotropy $\quad 73$

5.1 Causes of Anisotropy . . . . . . . . . . . . . . . . . . . . . . 74

5.2 Measuring Seismic Anisotropy . . . . . . . . . . . . . . . . . . . . 75 
5.2.1 Shear wave splitting method . . . . . . . . . . . 75

5.2.2 Estimating Pn anisotropy _.............. . 76

5.2 .3 Pn vs SKS Anisotropy . . . . . . . . . . . . . . . 77

5.2.4 Estimating station term Anisotropy . . . . . . . . . . . . 78

5.3 Anisotropy beneath the North Island . . . . . . . . . . . . . . . . 80

5.3.1 Anisotropy estimates from SKS splitting beneath the North Island 80

5.3.2 Pn anisotropy results . . . . . . . . . . . . . . 81

5.4 Resolution of estimated $\mathrm{Pn}$ anisotropy . . . . . . . . . . . . . 82

5.4.1 The Western North Island . . . . . . . . . . . . . . . . . 83

5.5 Summary ............................. 86

6 Depth Modelling $\quad 87$

6.1 Central Low Velocity Zone . . . . . . . . . . . . . . . . . . . . 87

6.2 Velocity-Depth gradient . . . . . . . . . . . . . . 88

6.3 Depth extent estimation . . . . . . . . . . . . . . 88

6.4 Previous Estimates of depth extent of the central Low Velocity Zone . . 89

6.4.1 Depth estimation from Haines (1979) Data . . . . . . . . . . 89

6.4.2 Depths estimation from Reyners et al (2006) Tomography . . . 89

6.5 Depth estimation process . . . . . . . . . . . . . . . 90

6.5.1 Event offset and station separation . . . . . . . . . . 90

6.5.2 Circular ray-path estimation . . . . . . . . . . . . 93

6.5.3 Macray $^{T M}$ modelling of LVZ . . . . . . . . . . . . . . . 93

6.6 Summary ............................... 96 
7.1 Summary of observations . . . . . . . . . . . . . . . . . . 99

7.1 .1 Western North Island . . . . . . . . . . . . . . . . . . . 100

7.1.2 Taranaki Volcanic Region . . . . . . . . . . . . . . . . . 100

7.1.3 Central Volcanic Region . . . . . . . . . . . . . . . . 100

7.1 .4 Eastern North Island . . . . . . . . . . . . . . . . . . . . 100

7.1.5 North Island crustal observations . . . . . . . . . . . . . . . . . 101

7.2 Tectonic Implications from Pn wave speeds . . . . . . . . . . . . . . . . 101

7.2.1 Effect on mantle velocities of temperature, melt fraction and water content . . . . . . . . . . . . . . . 102

7.3 Regional discussion . . . . . . . . . . . . . . . . . . . . . . 107

7.3.1 Western North Island . . . . . . . . . . . . . . . 107

7.3.2 Taranaki ........................... 109

7.3.3 The Central Volcanic Region . . . . . . . . . . . . . . . 110

7.3 .4 Eastern North Island . . . . . . . . . . . . . . . . . . . . 111

8 Summary and Conclusions $\quad 113$

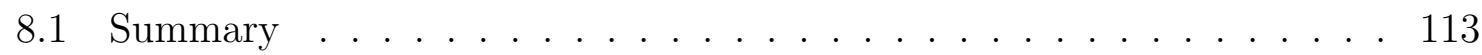

8.1.1 Modelling Method . . . . . . . . . . . . . . 113

8.1.2 Principal Mantle observations . . . . . . . . . . . . . . . . . . 114

8.1.3 Crustal observations . . . . . . . . . . . . . . . 115

8.2 Conclusions and possible future work . . . . . . . . . . . 115

8.2.1 Conclusions ......................... 115

8.2.2 Development of modelling algorithm . . . . . . . . . . . 116 


\section{Appendices}

A.1 List of Variables . . . . . . . . . . . . . . . . . . . . . 135

A.1.1 Seismic tomography . . . . . . . . . . . . . 135

A.1.2 Slowness modelling . . . . . . . . . . . . . . . 135

A.1.3 Ray Geometry . . . . . . . . . . . . . . . . . . 136

A.2 Derivation of equation $2.8 \ldots \ldots \ldots \ldots \ldots$

B Station List

C Fieldwork

C.1 Temporary Deployments . . . . . . . . . . . . . . . . . . . 145

C.2 Equipment. . . . . . . . . . . . . . . . . . . . 145

C.3 Installation and Servicing _. . . . . . . . . . . . . . . . . 147

C.4 Site selection . . . . . . . . . . . . . . . . . . . . . . . 148

C.5 Processing of raw data . . . . . . . . . . . . . . . . . . . 151

C.6 List of Events used from temporary deployment . . . . . . . . . . . . . 152

D Picking errors

E Modelling Codes

E.1 ImpEQcalc . . . . . . . . . . . . . . . . . . . . . . 157

E.2 MARCOV ............................ 160 
E.2.1 Classes . . . . . . . . . . . . . . . . . . . 160

E.2.2 Functions . . . . . . . . . . . . . . . . . 160

E.3 MAR . . . . . . . . . . . . . . . . . . . . . . . . . 161

E.3.1 Defining parameters: . . . . . . . . . . . . . . . 161

E.3.2 Covariance function: . . . . . . . . . . . . . . . . . . . 162

E.3.3 Calculation of velocity estimate: . . . . . . . . . . . . . 163

E.3.4 Plotting results: . . . . . . . . . . . . . . . . . . . 173

$\begin{array}{lll}\text { F } & \text { Station Term Anisotropy } & 175\end{array}$

$\begin{array}{lr}\text { G Depth Modelling } & 179\end{array}$

G.1 Ray Paths through a medium with a depth dependent velocity gradient 179

G.1.1 Linear change of velocity with Depth - Circular Ray-paths . . . 179

G.1.2 Depth penetration estimation . . . . . . . . . . . . 181

H JGR - Paper

H.1 Models of the upper mantle beneath the central North Island, New Zealand, from speeds and anisotropy of sub-horizontal P-waves (Pn) . . 183 


\section{FIGURES}

1.1 Back arc Setting . . . . . . . . . . . . . . . . 2

1.2 Back-arc Basins of the World . . . . . . . . . . . . . . . . 3

1.3 Tectonic Setting of New Zealand . . . . . . . . . . . . . . . . . 4

1.4 Reconstruction of New Zealand, King $2000 \ldots \ldots$. . . . . . . . . . 5

1.5 Tectonic setting of the North Island . . . . . . . . . . . . . . 6

1.6 Schematic of the subducting boundary beneath the North Island . . . . 7

1.7 Summary of crustal velocity observations throughout the North Island . 9

1.8 Upper mantle velocity model of New Zealand, Haines (1979) . . . . . . 11

1.9 Cross-section of subduction, central North Island . . . . . . . . . . . . 12

2.1 Flowchart of modelling method . . . . . . . . . . . . . . . . 23

2.2 Schematic of mantle anisotropy . . . . . . . . . . . . . . 26

2.3 Causes of crustal inhomogeneities . . . . . . . . . . . . . . . 28

3.1 Location of the New Zealand National Seismograph Network sites, North

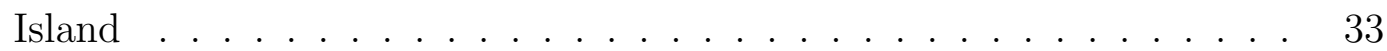

3.2 The WNIPSE temporary deployment, Waikato, Nov. 2004 to April 200534

3.3 The Coromandel temporary deployment Nov. 2005 to May 2006 . . . . 35

3.4 Benioff zone beneath the North Island . . . . . . . . . . . . . . . . . 37

3.5 New Zealands shallow seismicity between 1990-2000 . . . . . . . . . . . 38 
3.6 Schematic of the refracted ray paths f . . . . . . . . . . . . . . . . . . 39

3.7 Schematic of the two-station method . . . . . . . . . . . . . . . . . . . . 42

4.1 Ray-paths ............................ 46

4.2 Ray-paths density . . . . . . . . . . . . . . . . . . . . 47

4.3 Modelling Resolution . . . . . . . . . . . . . . . . . 50

4.4 Schematic of epicentral mislocation effect . . . . . . . . . . . . . 53

4.5 Pn lateral velocity variations across the North Island . . . . . . . . . 61

4.6 Synthetic upper mantle velocity beneath the North Island . . . . . . . 63

4.7 Regions of various $\mathrm{Pn}$ velocities . . . . . . . . . . . . . 64

4.8 Station delay terms . . . . . . . . . . . . . . . . . . . . . . 68

4.9 Crust-Mantle systems coupling test . . . . . . . . . . . . . . . . . . 69

5.1 Schematic of cracks and inclusions under stress . . . . . . . . . 75

5.2 Schematic of SKS splitting . . . . . . . . . . . . . 76

5.3 Crustal inhomogeneities . . . . . . . . . . . . . . . . . . . . 79

5.4 SKS splitting measurements beneath the North Island . . . . . . . . . . 80

5.5 Resultant Pn anisotropy for the Central North Island . . . . . . . . . . 83

5.6 Resolution of Anisotropy measurements . . . . . . . . . . . . . . 84

5.7 Summary of anisotropy observation . . . . . . . . . . . . . . . 85

6.1 Refraction geometry ...................... 88

6.2 Haines depth estimate . . . . . . . . . . . . . . . . . . . . . . . . 90

6.3 Reyners et al (2006) tomography . . . . . . . . . . . . . . . 91

6.4 Velocity from events at different offset . . . . . . . . . . . . . . . . . 92 
6.5 Ray depth penetration with various vertical velocity gradients . . . . . 93

6.6 The CVR - low velocity zone . . . . . . . . . . . . . . . . . 94

$6.72 \mathrm{D}$ cross-section of $\mathrm{LVZ} \ldots \ldots \ldots \ldots$

6.8 Stations and events within the LVZ . . . . . . . . . . . . . . . 96

6.9 MAR model of central LVZ profile . . . . . . . . . . . . . . . . . . . 97

7.1 Relationship between Melt, Temperature and Velocity . . . . . . . . . . 104

7.2 Range of Temperatures of uppermantle beneath the CVR . . . . . . . 105

7.3 Relationship of velocity, temperature, melt and water in the CVR . . 106

7.4 Rayleigh-Taylor Instability . . . . . . . . . . . . . . . . . . . . . 109

C.1 Site setup for a short period seismometers . . . . . . . . . . . 146

C.2 Site burial . . . . . . . . . . . . . . . . . . . 147

C.3 Sensor insulation . . . . . . . . . . . . . . . . . . . . 148

C.4 Geology of the Waikato . . . . . . . . . . . . . . . . . . . 149

C.5 Geology of the Coromandel Peninsular . . . . . . . . . . . . . . . 150

C.6 Data Processing Process . . . . . . . . . . . . . . . 151

G.1 Circular ray path schematic . . . . . . . . . . . . . . 180

G.2 Estimates of depth penetration with linearly varying vertical velocity gradient . . . . . . . . . . . . . . . . . . 182

Please note: all maps are in NZMG. This is a conformal mapping projection with minimum scale error, commonly used for national surveys of New Zealand.

Reference: http://www.linz.govt.nz

or: Reilly, W.I. (1973), A conformal mapping projection with minimum scale error, Survey Review XXII, 168, 57-71 


\section{TABLES}

3.1 WNIPSE deployment station list . . . . . . . . . . . . . . . . 32

3.2 Coromandel deployment station list . . . . . . . . . . . . . . . . . . 36

3.3 Standard North Island velocity-depth model . . . . . . . . . . . . . . . 41

4.1 Summary of picking uncertainties . . . . . . . . . . . . . 51

4.2 Probabilistic vs Geometric uncertainty estimates . . . . . . . . . . . . 58

4.3 Summary of crustal delay times . . . . . . . . . . . . . . . 67

4.4 Input parameters for modelling the uppermost mantle beneath the North Island . . . . . . . . . . . . . . . . . . . . 70

6.1 Summary of depth estimates . . . . . . . . . . . . . . . . . . 97

7.1 Summary of Pn results . . . . . . . . . . . . . . . . . . . . . . 99

B.1 List of station . . . . . . . . . . . . . . . . . . . . . 140

C.1 WNIPSE events . . . . . . . . . . . . . . . . . . . . 152

C.2 CORO events . . . . . . . . . . . . . . . . . 153

D.1 Picking uncertainties . . . . . . . . . . . . . 156

F.1 Station Term Anisotropy . . . . . . . . . . . . . . . . . 176 
XX 
CHAPTER 1

\section{INTRODUCTION AND TECTONIC SETTING}

\section{$1.1 \quad$ Background}

\subsubsection{Subduction Zone Settings}

Subduction zones are convergent plate boundaries where a dense cooler oceanic plate subducts beneath the lighter oceanic or continental plate (fig 1.1). The sinking of the dense slab provides the driving forces for Plate Tectonics (Davies 1999). As the plate descends into regions of higher pressure and temperature, its cool lithosphere emits water and other material into the lithosphere of the overriding plate, increasing the percentage of water and melt in the upper mantle beneath the overlying crust. The combination of water and melt beneath a continental crust, generally results in a surface expression of volcanic and island arcs, caused by the upsurge of warm fluids towards the surface. The dynamics of the subduction systems vary from region to region around the globe, due to a combination of various factors, including: (1) The geometry and age of the subducting slab (e.g Billen (2008); Sdrolias and Muller (2006)), (2) The composition, age, and density of the overriding plate (e.g King (2001)) and (3) The speed of subduction and trench migration (e.g. Doglioni et al. (2007)).

Plate interaction in the subduction process often generates back-arc regions (Heuret and Lalleman 2004) (fig 1.2). Back-arc basins are defined as regions of extension at convergent plate margins where rifting develops on the overriding plate. The occurrence of an extensional stress regime adjacent to an area of major convergence, accretion and 


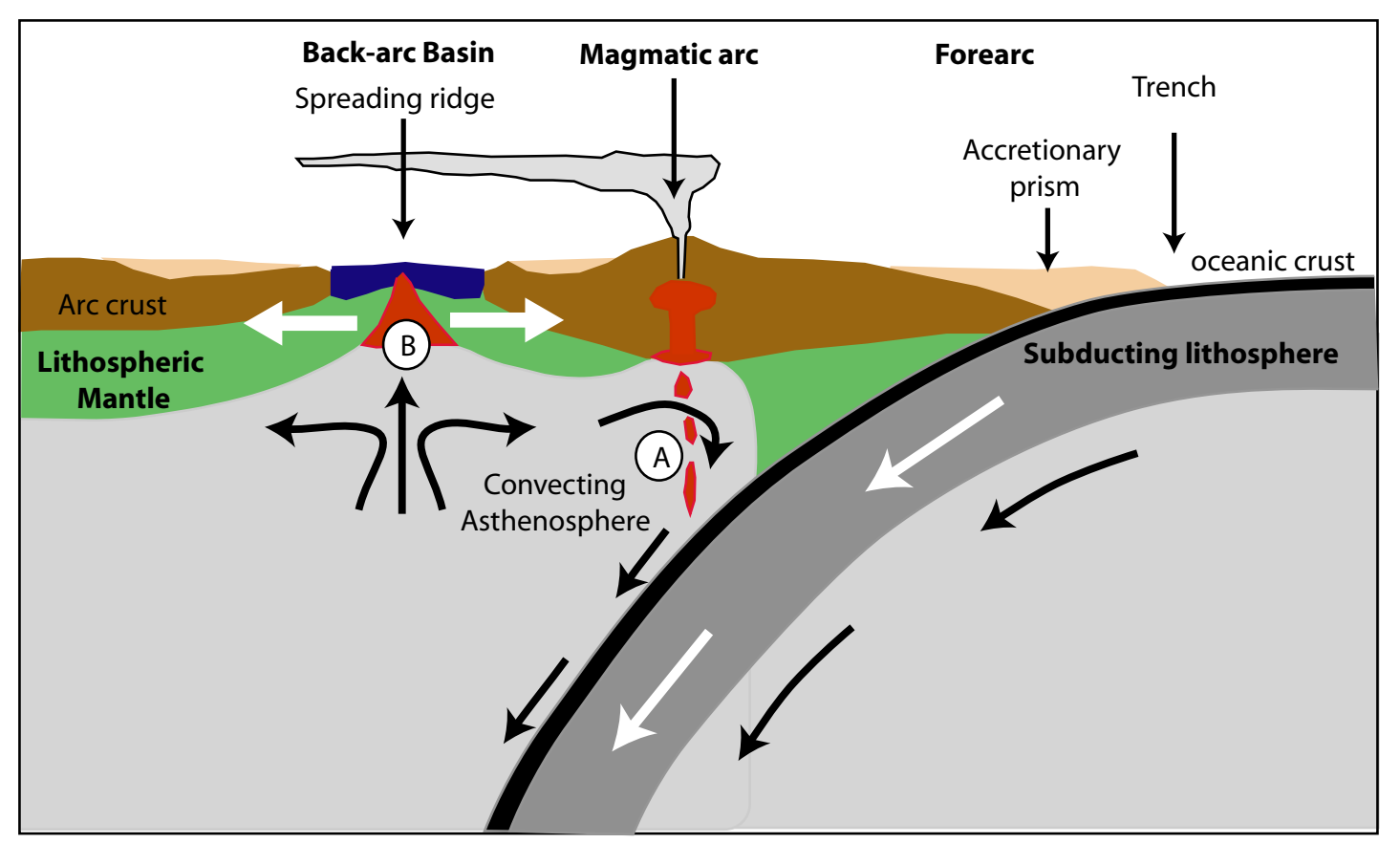

Figure 1.1 Cross section through the shallow part of a subduction zone showing the relative positions of the active magmatic arc and back-arc basin, where the white arrow represent the plate motions, and black arrows indication the asthenospheric motion. $\mathbf{A}$ and $\mathbf{B}$ represent regions of melt generation, A due to water diffuses from subducting lithosphere, and $\mathbf{B}$ from stretch of the crust and rising of melt.

thrusting has often been considered counterintuitive.

Back-arc regions vary in deformation style and structure from compressional regions with thickened crust to regions of active extensional rifting (Uyeda and Kanamori (1979); Uyeda (1982)). There are two main types of Back-arc: (1) back-arc extension (e.g. The Mariana arc and the Central Volcanic Region) or (2) back-arc compression (e.g. The Chilean arc). The formation of an extensional regime or a compressive regime is related to a particular behaviour of the slab with respect to the upper plate. Backarc stress correlates with slab dip, i.e. back-arc spreading is observed for steep dips, whereas back-arc shortening / compression occurs only for shallow dips (Lallenmand et al. 2005). There are many other factors that play an important role in the formation of back-arc regions. All back-arc systems have similar measurable characteristics such as, high heat-flow, high seismic attenuation and low Pn velocities (Currie and Hyndman 


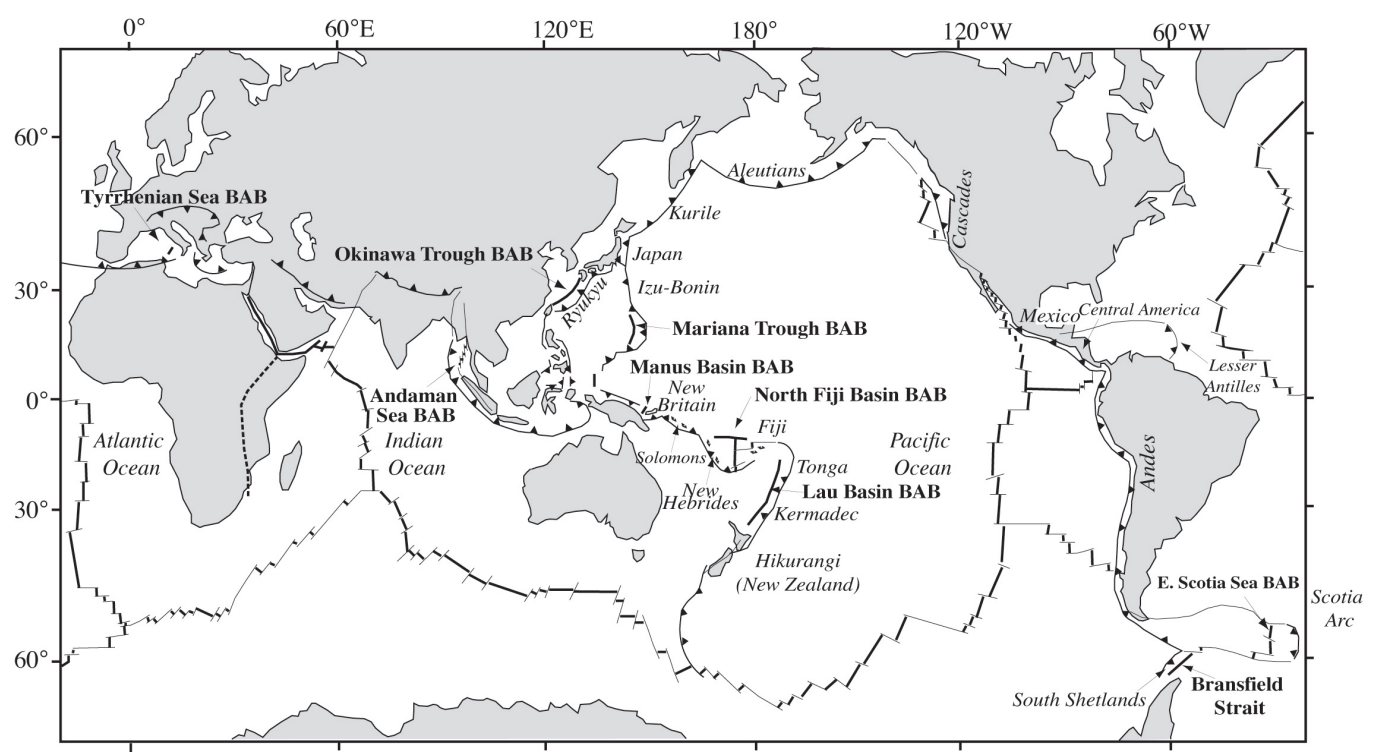

Figure 1.2 Location of back-arc basins around the World, black lines indicate plate boundaries. Back-arc basins are labeled in bold.

2006). Basins are also often found to be elevated with respect to their surroundings (Sclater 1972).

\subsection{Tectonic setting of New Zealand}

New Zealand is situated on the boundary between the Pacific and Australian Plates, and is divided into two main island, North and South (fig 1.3). The plate boundary changes character through New Zealand. Beneath the North Island, the Pacific Plate is subducting obliquely under the Australian Plate at $41 \mathrm{~mm} / \mathrm{yr}$ off the coast of Hawkes Bay (fig 1.5) increasing to $45 \mathrm{~mm} / \mathrm{yr}$ further north, adjacent to the East Cape (fig 1.5) (DeMets et al. (1990);(1994)). At the southern tip of the South Island, the subduction regime has reversed to where the Australian Plate is subducting beneath the Pacific Plate at approximately $38 \mathrm{~mm} / \mathrm{yr}$ (fig 1.3) (DeMets et al. 1990). These two different subducting regimes are joined through the central South Island by the Alpine Fault, which accommodates the plate motion with a dextral strike-slip system (Walcott 1998).

Relative plate motion has recently been modelled by King (2000), where the Aus- 


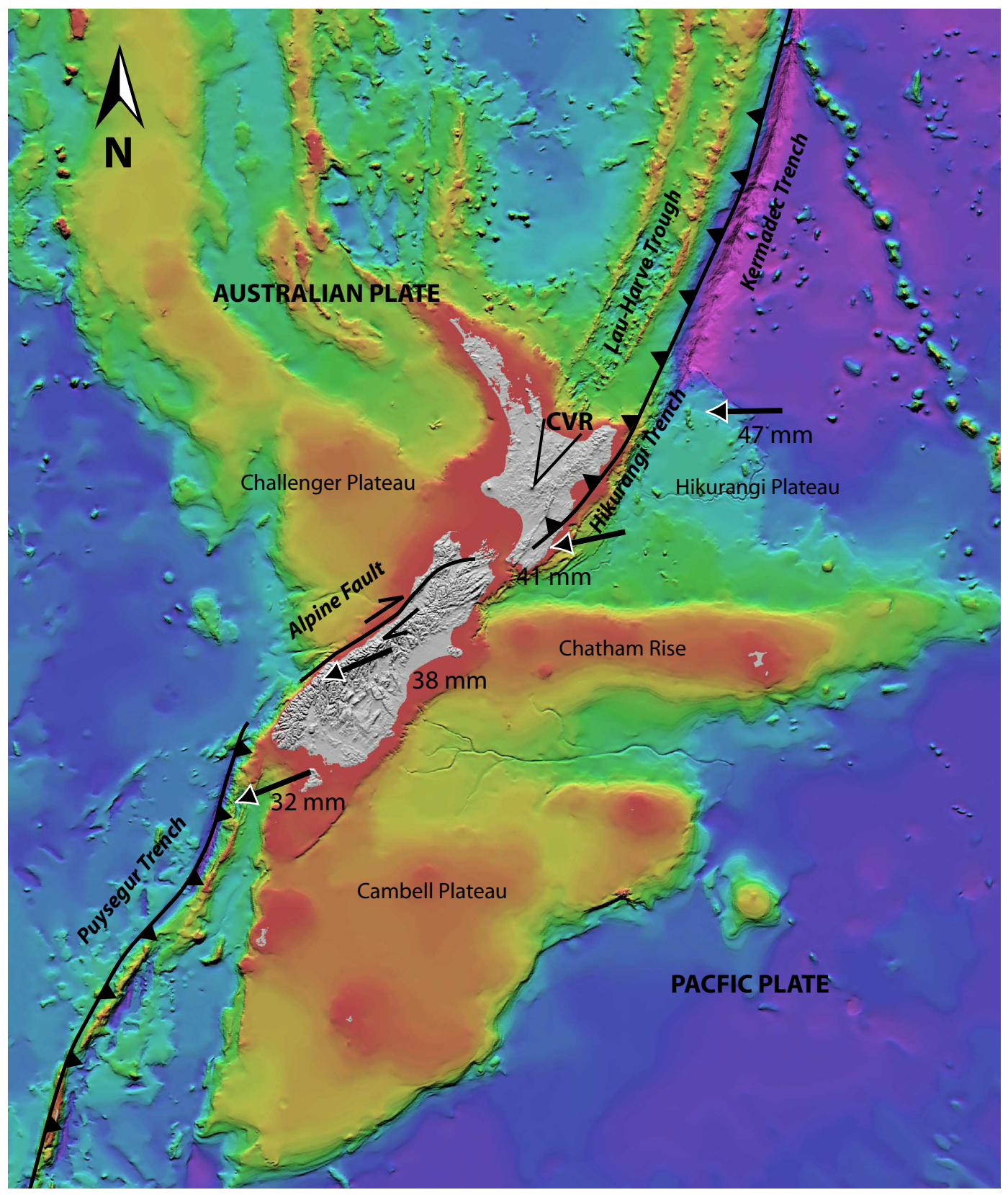

Figure 1.3 Tectonic setting of New Zealand, from NIWA bathymetry. Arrows indicate the direction of the Pacific Plate motion relative to the Australian, calculated from DeMets (1990). 

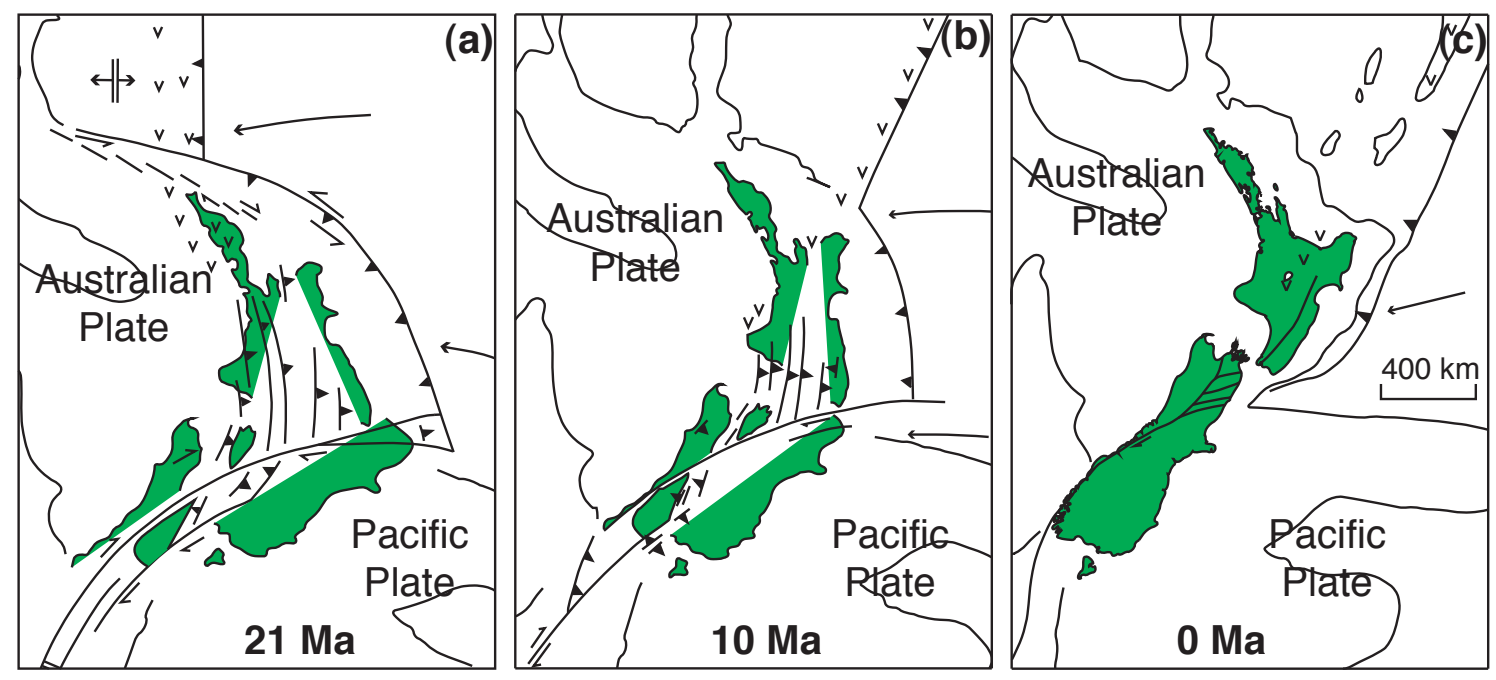

Figure 1.4 Reconstruction of New Zealand, King, 2000. (a) shows a snapshot at $21 \mathrm{Ma}$, where there is evident shortening across the North Isalnd. (b) shows a snapshot at $10 \mathrm{Ma}$, indicating the rotation of the eastern North Island and shortening in the western and southwest North Island. (c) Shows the current setting of New Zealand

tralian and Pacific Plates have been mapped out over the past 40 million years. Late Tertiary plate boundary systems (fig 1.4) through the North Island, show an onset of subduction around the late Oligecene (30-34 Ma), causing compression and tectonic shortening in the Australian Plate. The rotation of the East coast of the North Island, relative to the Australian Plate could be the reason we observe a back-arc system in the centre of the North Island. Relative motion between the plates was predominately strike slip from 25 to $6.4 \mathrm{Ma}$ (Walcott 1998) becoming more convergent in recent times. In the early Pliocene (4-5 Ma), compression switched to extension (King 2000). The plate motion has resulted in the rotation of the eastern North Island relative to the west of $c a 6^{\circ}$ per Ma (Walcott 1987).

Paleomagnetic measurements predict a rotation rate of $6.5^{\circ} / \mathrm{Ma}$ (Mumme et al. 1989), which is in agreement with volcanic arc migration data (7/Ma) (Kear (1994); Skinner (1986)). Current GPS observations show a clockwise surface rotation of $3.6^{\circ} / \mathrm{Ma}$ (Wallace et al. 2004). 


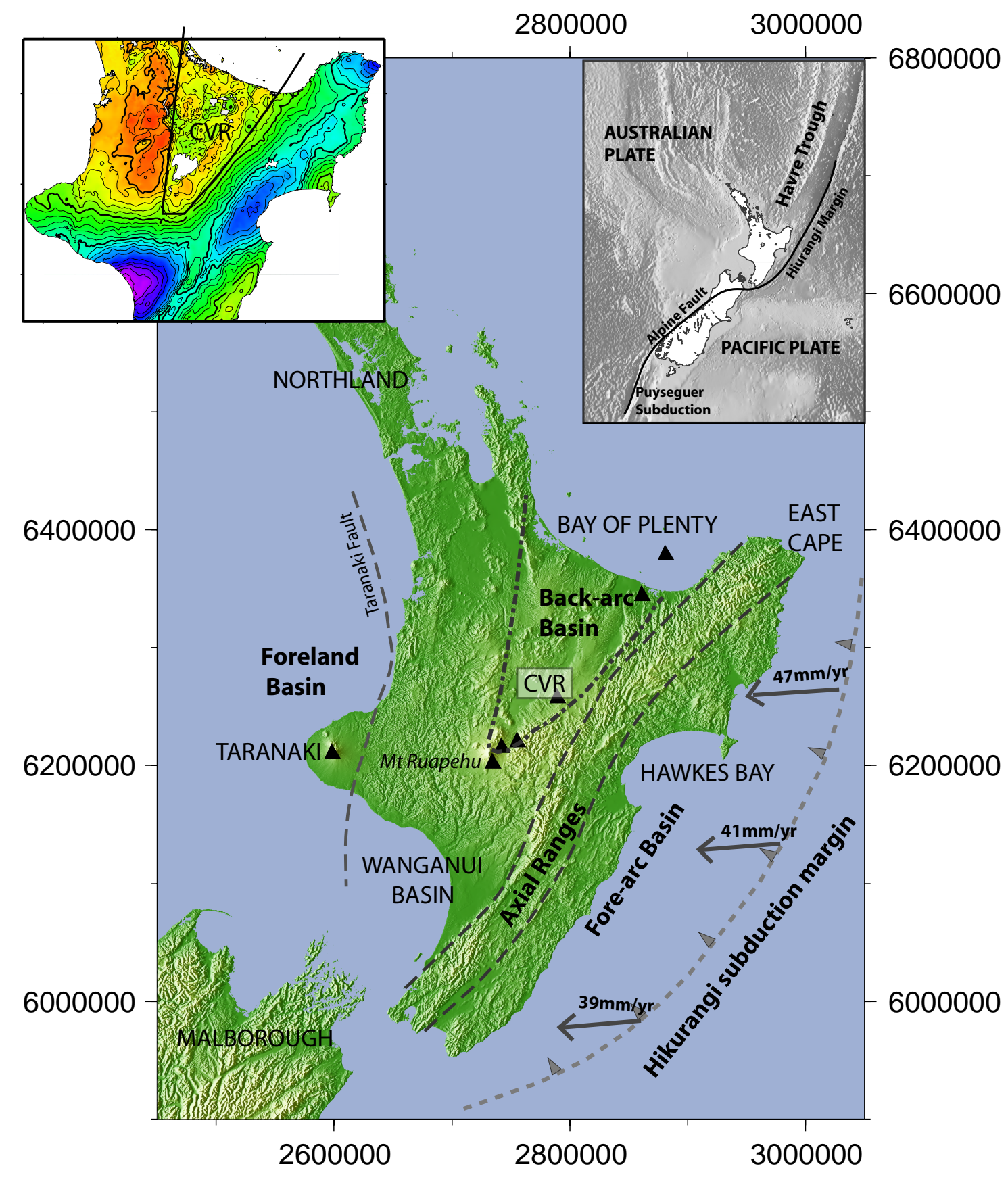

Figure 1.5 Tectonic setting of the North Island, New Zealand. The subduction of the Pacific Plate beneath the Australian Plate off the east coast, results in volcanism and back-arc spreading within the Central Volcanic Region (CVR). All plate convergence vectors have been calculated from DeMets (1990). Insert right: the plate tectonic setting of New Zealand. In the north the Pacific Plate is subducting beneath the Australian Plate commencing the Hikurangi subduction front. In the South Island, the subduction is reversed, with the Australian Plate subducting beneath the Pacific Plate at the Puysegur subducting front. These subduction zones are connected through the Alpine Fault. Insert left: Isosatic gravity map of the central North Island (Reilly et al. 1977). 


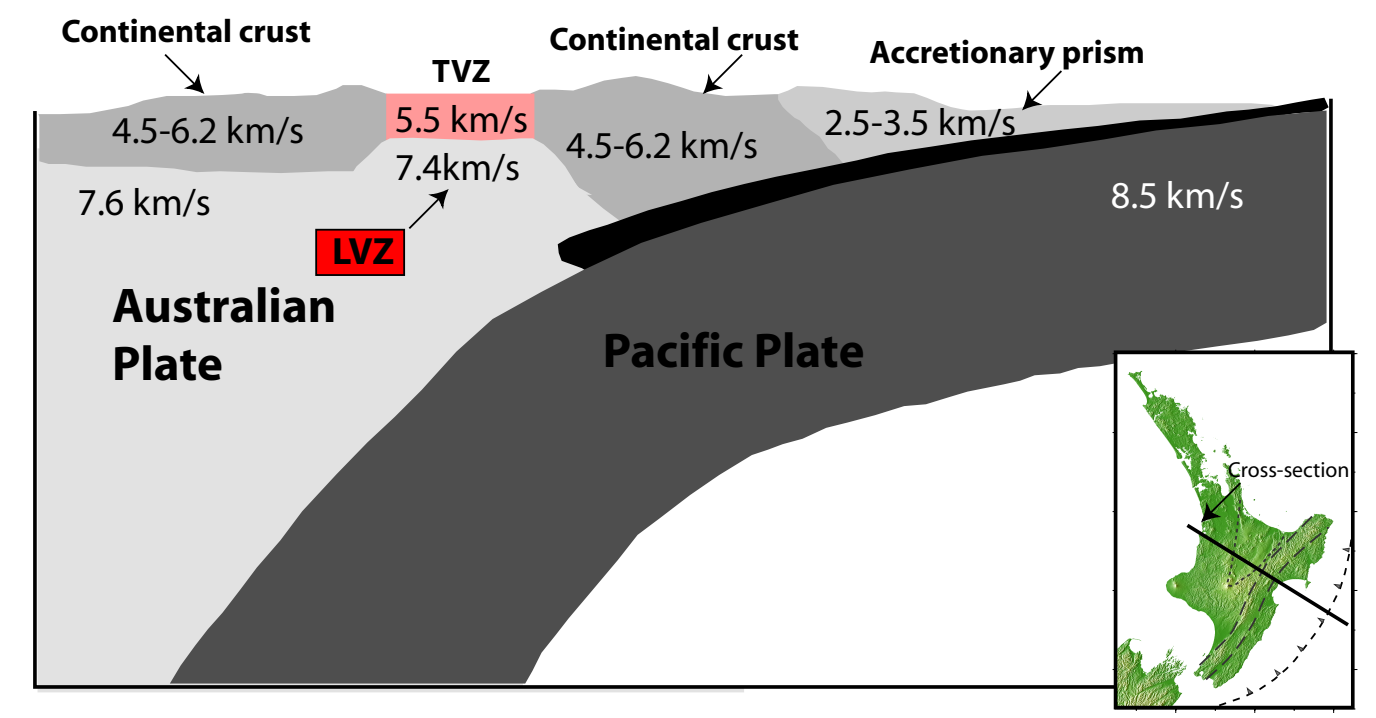

Figure 1.6 Schematic of a subduction Zone beneath a nominal cross-section (insert) of the North Island. The Pacific Plate subducts beneath the Australian Plate at an average rate of $43 \mathrm{~mm} / \mathrm{yr}$, reaching a depth of approximately $80 \mathrm{~km}$ beneath the Central Volcanic Region (CVR). Velocities are averaged values measured by Stratford and Stern (2004);(2006), Harrison and White (2006), Reyners et al. (2006). The black layer is the oceanic crust of the subducting Pacific Plate.

\subsubsection{Tectonics of the North Island}

The tectonic regime of the Hikurangi subduction zone (fig 1.6) is described as extensional in the north, and compressional towards the south (Stern et al. 2006). The change from compressional to extesional deformation is evident from the thinning of the continental crust from $35 \mathrm{~km}$ in the south to $20 \mathrm{~km}$ in the north (Nicol and Wallace 2007) and is thought to be due to the southern part of the margin being currently locked (Reyners et al. (1997); Wallace et al. (2004)).

This change in plate motion, combined with plate coupling forces along the plate 
interface, has resulted in back-arc extension in the continental lithosphere (Stern and Davey (1987); Reyners et al. (1997)). Back-arc extension extends from the Bay of Plenty southwards to the active volcanic region of Tongariro and Ruapehu (fig 1.5)(Beanland and Haines (1998); Reilley (1990)).

\subsection{Investigations into geophysical properties of the North Is- land}

New Zealand provides a great opportunity to study plate boundary deformation processes, due to its location on a continental mass above the plate boundary. It is also one of the few places on Earth where a spreading back-arc region is located on land (Hatherton 1970). The unique setting of the North Island is accompanied by elevated heat output (Pandey 1981) and extremely high eruption rates in the extensional Central Volcanic Region (CVR), making it one of the hottest and most productive magma generating regions on Earth (Wilson et al. 1995). A series of recent studies highlight the significant role of melt on geophysical properties, such as velocities, attenuation and anisotropy across the North Island (Stratford and Stern (2004);(2006); Salmon et al. (2005); Greve and Savage (2006); Stern et al. (2006)).

The Central Volcanic Region (CVR) is the apparent continuation of the Lau-Havre Trough (Karig 1970) into continental New Zealand. The wedge shaped Central Volcanic Region (CVR) is characterised by negative gravity anomalies (fig 1.5) (Reilly et al. (1977); Stern (1982)), thin crust (fig 1.7)( Stern and Davey (1987); Stern et al. (1987)), active andesitic and rhyolitic volcanism (Calhaem 1973) and extension of 5-12 mm/yr as determined by GPS measurements (Wallace et al. 2004).

Seismic exploration over the past 25 years has provided in depth information on the characteristics of the crust throughout the North Island (fig 1.7). These characteristics can be split into two domains (Stern et al. 2006). (1) Northland and the CVR generally have thinner crust, between 20 - $25 \mathrm{~km}$ thick (Horspool et al. (2006); Stern and Davey (1987); Stratford and Stern (2004)(2006)), compared to (2) regions to the east of 
the Axial Ranges (i.e. East Cape, Hawke Bay, Wairarapa) and to the south (e.g. Wanganui Basin and Wellington), which tend to have thicker crust (of up to $45 \mathrm{~km}$ depth) (Bannister et al. (2004); Ewig and Stern (2006); Reyners et al. (1999); Savage (1998); Stern et al. (1992)).

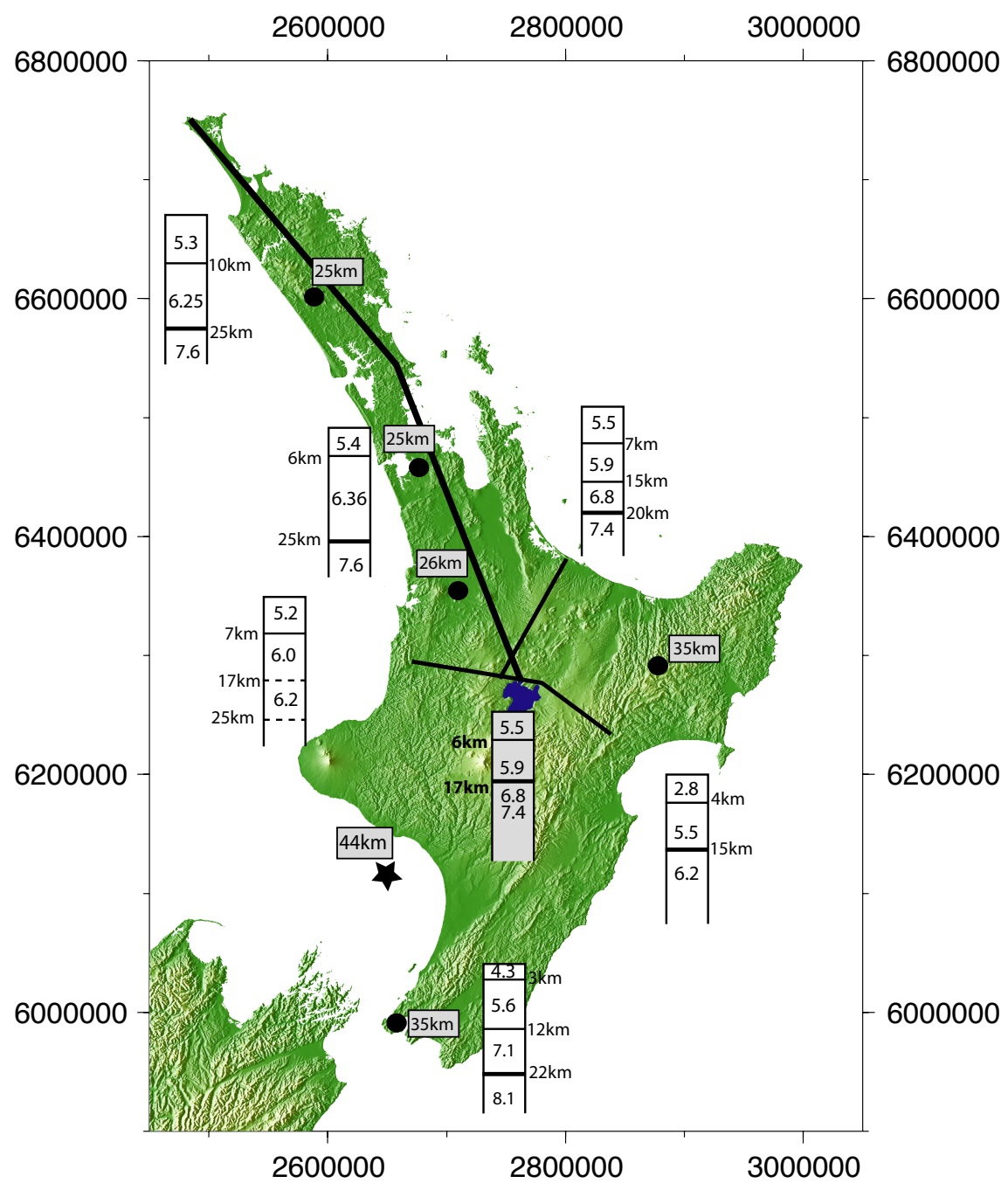

Figure 1.7 Summary of crustal seismic structure of the North Island. Velocity profiles are from refraction surveys of Stern et al., 1987 (Northland Profile), and Reyners et al. (1999) (East coast profiles), and Chadwick (1997) (Southern North Island). Spot measurements of crustal thicknesses are from receiver functions (Horspool et al. (2006); Bannister et al. (2004); Savage (1998)) The star represents the Moho depth estimate of the Wanganui Basin (Ewig and Stern 2006) 


\subsubsection{Uppermantle velocity studies}

The existence of lateral inhomogeneity in seismic wave velocities within the upper mantle beneath New Zealand has been known for some time. It was first published by Hamilton (1969) while determining the location of the epicenter of the 1966 Gisbourne earthquake. He noted that the P-wave travel time residuals along the northeastsouthwest axis of New Zealand were higher than normal. Hamilton determined P-wave velocities to be on average $8.29 \pm 0.07 \mathrm{~km} / \mathrm{s}$. Time residuals at stations to the southwest of the island were near zero, while at western and northwestern stations the residuals were as high as +2 or +3 seconds. This indicates that the $\mathrm{P}$ velocity is faster along the paths travelling southwest of the epicentre than it is for those travelling west or northwest.

The lateral inhomogeneity within the upper mantle was looked at more closely by Haines (1979). He used local crustal earthquakes recorded at National Network seismograph stations active in 1971 to map the variations in both $\mathrm{Pn}$ and $\mathrm{Sn}$ wave speeds beneath continental New Zealand. The resulting model split New Zealand into 10 regions of assumed constant velocity structure (fig 1.8), in which $\mathrm{Pn}$ velocities range from $7.4 \mathrm{~km} / \mathrm{s}$ beneath the central North Island, to $8.7 \mathrm{~km} / \mathrm{s}$ beneath Nelson, in the northern South Island. Within the North Island alone, Pn velocities range from $8.5 \mathrm{~km} / \mathrm{s}$ along the east coast, to $7.4 \mathrm{~km} / \mathrm{s}$ within the CVR, and $7.8-7.9 \mathrm{~km} / \mathrm{s}$ along the west coast. There is no Sn observations for the central and western regions of the North Island.

High Pn velocities to the east of the North Island are consistent with seismic velocities within a subducting oceanic lithosphere (Haines (1979); Smith (1977)). The boundary between the northernmost east coast and the rest of the eastern region, determined by Haines (1979) corresponds to the presence of a steep gravity gradient anomaly (Reilly 1965). The western and central North Island, and Cook Strait all have $\mathrm{P}$ velocities of less than $8.1 \mathrm{~km} / \mathrm{s}$. The boundary between the western North Island and Cook Strait region is poorly determined, while the boundary between the western 


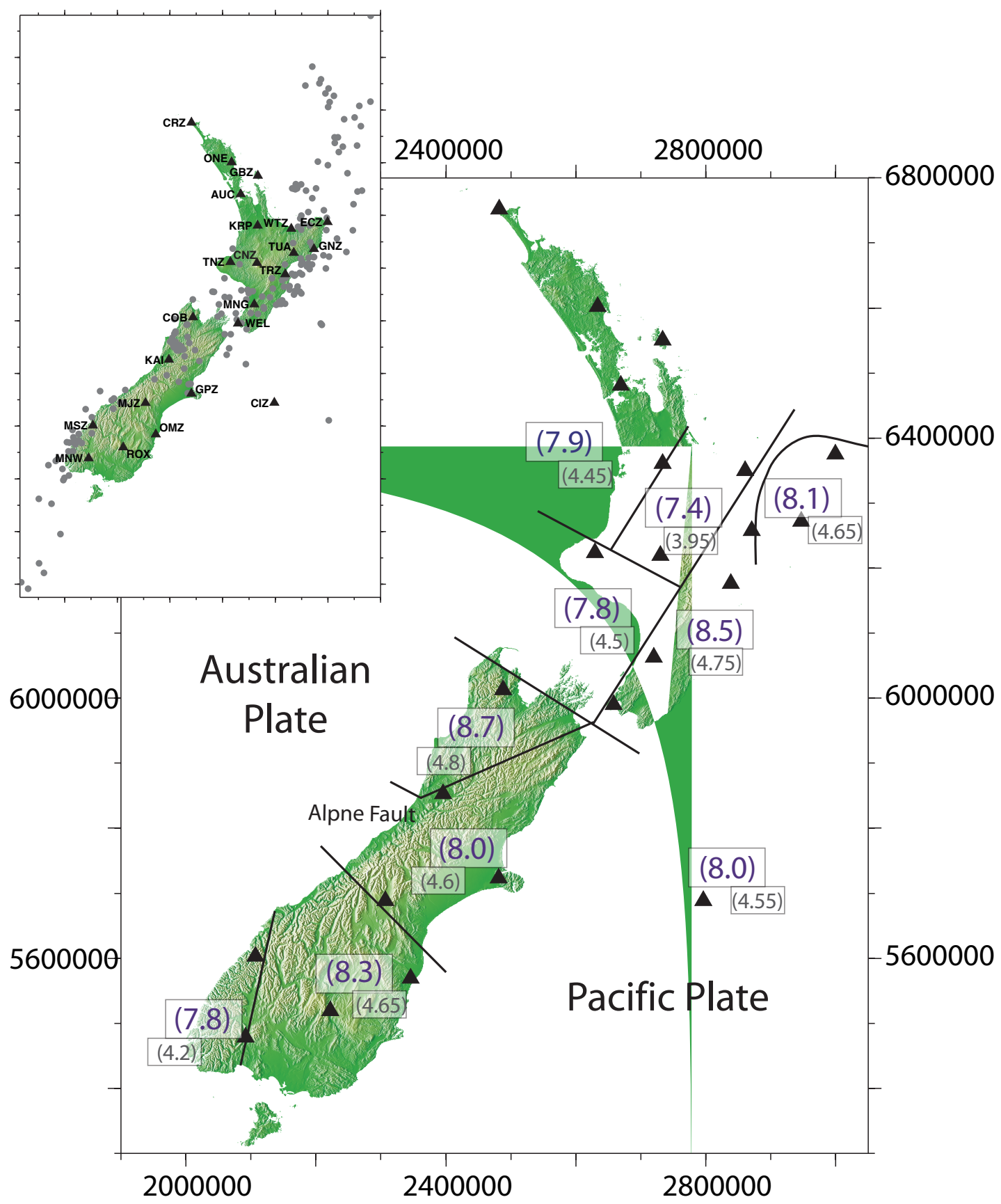

Figure 1.8 Upper mantle velocity structure beneath New Zealand, basedon Pn and Sn velocity observation, Haines 1979. insert Data used in Haines 1979 investigation into uppermantle velocities beneath New Zealand

and central region coincides with a high-frequency attenuation zone (Mooney 1970). Based on the Vp/Vs ratios observed, Haines (1979) determined that the uppermost mantle beneath the central North Island must contain pockets of melt, resulting in 
mantle derived volcanism. The ratio seen in the western North Island is consistent with smaller proportions of melt, although it could be due to a presence of heat alone. Stratford (2006) determined a temperature anomaly of $280^{\circ} \mathrm{C}$ for the upper mantle beneath the western North Island, with only $0.1 \%$ melt, whereas beneath the Central North Island, a temperature anomaly of $300^{\circ} \mathrm{C}$ and $1.4 \%$ melt were determined from observed $\mathrm{Pn} / \mathrm{Sn}$ velocity ratios.

Recent tomographic models of the North Island (Reyners et al. 2006) show similar velocities to those observed by Haines (1979) at depths between $32 \mathrm{~km}$ and $40 \mathrm{~km}$. A P-velocity of $8.5 \mathrm{~km} / \mathrm{s}$ is observed in the subducting slab to depths up to $300 \mathrm{~km}$ (fig 1.9). The mantle of the subducting plate is seen at shallow depth on the east side of the North Island, neighboured by a region of low seismic P-velocity of $7.4-7.6$ $\mathrm{km} / \mathrm{s}$ beneath the CVR, interpreted by Reyners et al. (2006) as being a region of high temperature and high melt content.
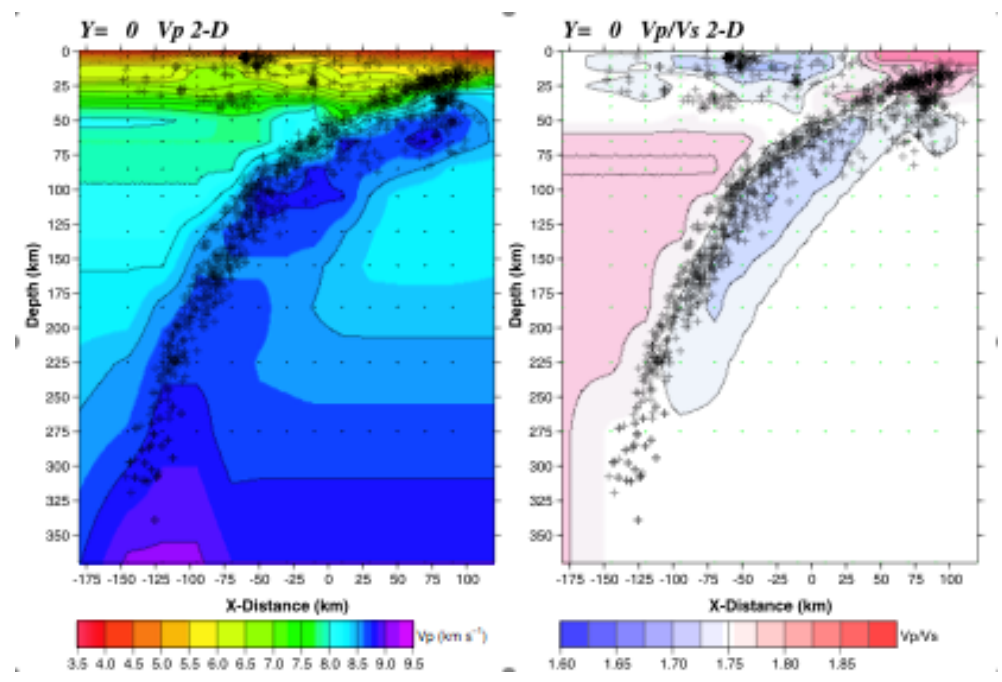

Figure 1.9 Cross-section of Vp tomography across the center of the North Island (left), and Vp/Vs ratio (right) imaged by Reyners et al. (2006)

\subsection{Thesis objectives}

The central North Island of New Zealand represents a rare example of back-arc spreading impinging on continental lithosphere. In the central North Island, the back-arc 
extension began approximately $5 \mathrm{Ma}$, and is still very active today. This is a very rare phenomenon. Back-arc spreading is well documented in oceanic environments, but is rarely seen in continents. It has been argued that the Basin and Range province in Nevada, USA, is a continental back-arc spreading centre active 25 My ago. The central North Island of New Zealand is a unique setting in which we are able to study the properties of an active back-arc spreading region from the land.

This study focuses on the properties of the uppermost mantle beneath the central North Island, New Zealand, deduced from seismic Pn velocities. Knowledge of the upper mantle is needed to understand many tectonic processes. Seismologists have known for some time that earthquake waves which transverse the upper mantle beneath the central North Island are subjected to severe attentuation (Eiby 1959) and travel at anomalously slow velocities (Haines 1979).

It is largely concurred that the driver of volcanism within a back-arc basin is water (and other volatiles) driven off the subducted slab. Water hydrates the mantle rocks and lowers the melting temperature. Typically, P- and S-wave speed drops with increasing temperature and partial melt content. Thus, waves from shallow earthquakes that have travelled through the upper mantle, known as Pn and Sn phases, provide an ideal tool for studying the properties of the uppermost mantle.

The central North Island is well placed to use lower crustal earthquakes for this study. Many earthquakes occur in the offshore Bay of Plenty, and Hawkes Bay and there is also a good cluster down in the Marlborough area of the South Island (fig 1.5). However to the west there are few.

This project aims to use these earthquakes as energy sources for waves which transverse the uppermost mantle. Their arrivals are detected at seismic stations spread throughout the North Island, and then used to estimated the variations in mantle velocities dependent on the direction from which the energy arrives.

A new modelling method will be created as an alternative to traditional tomographic methods. This new procedure utilises the method of least-squares collocation, 
used previously in GPS and gravity modelling. Pn velocities are modelled as a continuous surface, taking in to consideration the presence of mantle anisotropy, variations in crustal thickness and velocity structure beneath the recording stations and errors associated with picking and random noise.

\subsubsection{Pn velocity studies}

The seismic structure of the uppermost mantle provides constraints on mantle minerals, thermal properties, composition and tectonic history of the lithosphere. Typically, P-wave speeds are unique for each mineral composition, decreasing with increased

temperature and partial melt content. Pn has been used to study properties of the uppermost mantle, in conjunction with tomography to map variations over regional and global distances.

Pn wave phases are defined by Aki and Richards (1980) as the first arrivals of a crustal source beyond the distance of $100-200 \mathrm{~km}$. The notation Pn is used in other seismological text books (e.g Fowler (1990); Lay and Wallace (1995)) for the upper-mantle head wave at the crust-mantle boundary.

Many long-range refraction studies since 1950 have taken a more numerical approach in defining Pn as the wave which generally has a phase velocity between 7.8 $8.3 \mathrm{~km} / \mathrm{s}$ (e.g Herrin and Taggart (1962)). More recent studies, indicate that upper mantle velocities detected around the globe, in fact, range from $7.1 \mathrm{~km} / \mathrm{s}$ to $9.0 \mathrm{~km} / \mathrm{s}$ (Dziewonski and Anderson 1981), with a global average of $8.09 \mathrm{~km} / \mathrm{s}$ (Christensen and Mooney 1995).

At close distances, $\leq 200 \mathrm{~km}$, Pn waves act much like a mantle head-wave, which evolves into a mantle turning wave with increased distance (e.g. Aki and Richards (1980)). Most studies have ignored effects of the mantle velocity gradient and treated Pn are as a pure head wave at all distances, as we do in this study. A few studies, such as Hearn et al. (2004), have allowed for the error introduced by a turning wave, by adding a time delay term that is unique to each observation. The error introduced 
is minimal. Chapter 6, outlines a number of studies done to estimate the depth extent of the ray paths. The resulting time error introduced is less than that resulting from picking errors and is therefore compensated for in the modelling algorithm.

Pn velocities are dependent on the tectonic setting. For example, upper mantle velocities beneath stable plate interiors, such as eastern North America, Europe, China and southern Africa, are in the range of $7.9 \mathrm{~km} / \mathrm{s}$ to $8.4 \mathrm{~km} / \mathrm{s}$ (e.g Hearn (1996); (1999); Pei et al. (2007); Phillips et al. (2005); Qiu et al. (1996)). Those Pn velocities seen beneath mountain ranges and plateaus, such as the Rockies, the Himalayas, and Tibetan Plateau range between $7.7 \mathrm{~km} / \mathrm{s}$ and $8.2 \mathrm{~km} / \mathrm{s}$, slightly lower than those seen in stable plate interiors (e.g. Holt and Wallace (1990); Beghoul and Barazangi (1989)). Those mantle velocities seen in active extensional regions, such as plate boundaries / subduction zones(Calvert et al. (2000)), mid-ocean ridges (e.g. Canales et al. (2000)) and back-arc spreading regions (e.g. Haines (1979); Iwasaki (1990); Ribe (1989)) are as low as $7.4-7.8 \mathrm{~km} / \mathrm{s}$. A maximum range of mantle velocities for modelling worldwide is thus between $7.1 \mathrm{~km} / \mathrm{s}$ and $9.0 \mathrm{~km} / \mathrm{s}$.

\subsection{Thesis Outline}

A new method of modelling upper mantle wave speeds has been developed using the method of least-squares collocation. It utilises the Pn phase travel times from local earthquakes, arriving at pairs of stations throughout the North Island to map the uppermost mantle beneath the North Island of New Zealand. An introduction into how the new method approaches the modelling problem is discussed in the next chapter (Chapter 2: Modelling Method).

Chapter 3 (Data Selection) discusses the network of seismic stations in the North Island, the pattern of seismicity and how the appropriate events are selected.

Chapter 4 (Modelling Resolution and Results) covers how well our modelling algorithm can resolve features of the upper mantle with the data set available. How uncertainties can be estimated and distinguished from mantle features are discussed 
in addition to what realistic input parameters are appropriate for modelling the uppermost mantle. Results are discussed and related to the tectonic environment of the North Island.

Chapter 5 (Upper mantle Anisotropy) discusses the importance of taking anisotropic effects into account when modelling the upper mantle velocities. Characteristics of mantle anisotropy from around the world are discussed and combined with observations of anisotropy beneath the North Island of New Zealand. Probablistic bounds for the modelling procedure are estimated and discussed. Results are compared to anisotropy observed through SKS splitting measurements, and tectonic implications are discussed.

Chapter 6 (Depth Modelling) attempts to resolve the depth of the anomalously low velocity observed in the central North Islands' central back-arc spreading region. Several different approaches are discussed and compared. A new 2D velocity - depth profile is created along the axis of the CVRs low velocity zone. Travel time estimations from the model are then re-run through the modelling code to test the realism of the velocity - depth profile. Results suggest that the low velocity zone reaches depths of up to $80 \mathrm{kms}$.

Chapter 7 (Uppermost mantle structure beneath the North Island) combines the observations of Pn velocity, anisotropy and depths estimates into a discussion of properties and characteristics of the uppermost mantle beneath the North Island.

Chapter 8 (Conclusions) summaries the main observations and conclusions of this study.

The appendices A-H, provide additional information on derivations of equations used in the modelling procedure (appendix A), a complete list of stations used (Appendix $B)$, the temporary deployments of two seismograph arrays (Appendix $C)$, determination of errors (Appendix D), the modelling method and codes (Appendix E), list of station term anisotropy estimates (Appendix $F$ ) and methods used and tests for determining the depth penetration of observations (Appendix $G$ ). A copy of the paper summarizing this project, submitted to JGR, is included (Appendix $H$ ). 
CHAPTER 2

\section{MODELLING METHOD}

\section{$2.1 \quad$ Introduction}

A common problem in earth science is that a finite number of observations are collected and then used to model a continuous earth. In this project, the upper mantle velocity structure beneath the central North Island of New Zealand is modelled by producing a continuous model from earthquake arrival times at a finite number of seismic stations throughout the North Island.

Continuous models are beneficial as they allow for the detection of outliers and abnormal observations, and therefore allow their removal or down-weighting, to produce a more robust estimate of the real situation. Continuous models also allow the introduction of a priori spatial information, and allow estimates of signal at locations where there are no discrete data observed.

The approach to a modelling solution usually involves introducing strong constraints into the model. The model is then inverted by minimising the differences between the model and the measurements. Fitting an arbitrary smooth surface to discrete measurements will not produce an accurate description of the measurement surface, rather it will produce a filtered interpretation. A difficulty arises when interpreting values at particular locations. If a value is estimated for a specific point, it will not be arbitrarily accurate, rather it will be specified to a precision based on the model. This situation can be improved by including an estimate for the spatial variability of the true surface. 
Fitting a parameterised surface to measurements is defined as deterministic modelling. This means an implicit assumption is made that if we could sample the velocity with absolute accuracy at a finite number of points in a region, then we would know the values of the velocity at every other point. The number of parameters required to achieve a good fit is often prohibitive, as is the difficulty in designing the model. This type of model is based on very broad assumptions. The earth is unlikely to behave exactly as predicted and thus the results are unlikely to simulate reality. Instead we need to add an element of uncertainty, or non-regularity, the stochastic approach. In such a model, it is assumed that no matter how many observations are obtained, there will always be room for uncertainty and error in the measurements.

One step towards a fully stochastic model is a semi-stochastic model. In this type of modelling the unpredictability of the earth is factored into the model, but estimates are still predominately parameters for a standard deterministic model. The stochastic part of the model is introduced in the form of psuedo-observations.

A fully stochastic approach allows point estimate values to be measured, i.e. it is possible to say that at a point the measurement will be within a relatively well defined confidence interval. The deterministic approach will always be limited by its simplicity, but it will often have better precision. Precision does not represent true accuracy, rather it is the propagation of a particular set of zero error assumptions through the modelling procedure. The stochastic approach is more forgiving of modelling inaccuracy and therefore will be more realistic to the true earth system. We therefore attempted to model the uppermost mantle beneath the North Island by combining these two approaches.

\subsection{Traditional Pn tomographic method}

Regional mantle velocities are traditionally modelled through the use of gridded tomographic methods. This is often done through the inversion of P- and S- wave travel times. 
Gridded seismic tomography, on a regional scale, usually follows the following steps:

(1) Split upper mantle beneath study area into a set of $2 \mathrm{D}$ or $3 \mathrm{D}$ cells

(2) Flat-layered earth-model with initial estimates of average crustal velocity and thickness, and average mantle velocity.

(3) Use LSQR (Least-SQuare Residual) algorithm (e.g. Paige and Saunders (1982)) to solve the linear-system of equations

(4) Add smoothness constraints, to reduce effects of outliers and unevenness of ray-paths (e.g. Lees and Crosson (1989); Liang et al. (2004)) OR using damped leastsquares.

Travel times for Pn waves are traditionally modelled as:

$$
T_{i j}=\alpha_{i}+\beta_{j}+\gamma_{i j}+\sum_{k} \delta x_{i j k} s_{k}
$$

Where $\alpha$ and $\beta$ represent the travel time along the crustal legs of the ray-path in the neighbourhood of the source $(i)$ and receiver $(j)$, respectively. Travel time for the mantle leg of the raypath is obtained by summing products of raypath segments associated with each model node at Moho depth, $\delta x_{i j k}$, with the average mantle lid slowness of each cell, $s_{k} . \gamma_{i j}$ is a correction for the effect of the a depth dependent velocity gradient in the mantle along a ray-path.

\subsubsection{Limitations of traditional tomography}

Using many travel time measurements and raypath integrals requires a least - squares inversion to estimate the best mantle slowness model. However, estimating velocities in a material through the use of travel-time differences and least - squares methods, applied to a gridded model, usually results in the problem of an underdetermined system of equations. This is because the simplified model of acoustic propagation assumes an infinitely thin ray. If such a ray transverses a medium which is parameterised by a finite number of nodes, whose spatial influence is finite (e.g. Thurber and Aki (1987)), then 
some individual node points or cells are likely to have little or no ray path coverage.

There are a number of possible solutions to this problem. For example, the velocities at some node-points can be fixed at a constant value, or the solution can be damped around an initial starting value (Aki and Richards 1980). Pseudo-observations can be introduced into the inversion, usually in the form of regularisation. These would have the effect of causing neighbouring node points to interact (a modelling assumption of inter-point correlation) and can be used to force a bulk behaviour onto the material. An example of this, from geodesy, is the minimum strain model used in crustal velocity estimation (Beavan and Haines 2001).

To produce fine control in the degree of spatial correlation requires a large number of densely packed node points and numerous pseudo-observations. When the gridding of the node points is fine, the number of parameters in the estimation is then large. Furthermore, if the gridding of the node points is fine with respect to the distance over which the node points are strongly correlated then the number of pseudo-observations also becomes large. This can be demonstrated by considering the case of a $2 \mathrm{D}$ grid of ten by ten node points corresponding to one hundred parameters in the inversion. If there exists significant correlation between each point and every other point, then we must include 4950 (combinations of two from 100 point grid) additional equations (pseudo-observations) in the inversion.

For the North Island, considering the region between $173^{\circ} E-179^{\circ} E(\mathrm{NZMG}$ : $2500000-300000 \mathrm{E}$ ) and $35^{\circ} S-42^{\circ} S$ (NZMG: $6000000-6600000 \mathrm{~N}$ ) we would need 672 node points to sample the region at $0.25^{\circ} \times 0.25^{\circ}$ grid spacing. This would result in the need for 225456 pseudo-observations to be inverted.

A method that overcomes the difficulties of a large number of parameters and pseudo-observations is least - squares collocation (Moritz 1972). 


\subsection{Least-squares Collocation (LSC)}

Moritz (1972) developed the method of least-squares collocation (LSC) where measurements are modelled in two parts.

(1) Deterministic Part : usually closely fits the measurements.

(2) Stochastic Part : consists of allowances for measurement noise and a signal.

The signal is the uncertainty in the deterministic part of the modelling procedure that must be reasonably well characterised by a signal covariance function.

In least-squares collocation (LSC) the pseudo-observations are collected and compressed into a data covariance matrix, which is a model for the expected similarity of slowness values at pairs of points in space. This then results in two parts to the model; the deterministic model, which would produce the precise set of parameters if a finite number of error-free observations were available, and a stochastic part consisting of the sum of measurement noise and the difference between the deterministic model and the expected reality. In general, the stochastic part can only be known exactly if infinitely many observations are available. In practice, the covariance matrix is determined for the observation errors and added to the signal covariance determined from a spatial covariance function. The deterministic part of the model is placed into a design matrix.

The basic generalised form of LSC is of the form:

$$
\mathbf{l}=M \mathbf{p}+s+n
$$

where $\mathbf{l}$ is a vector of the observations, $\mathbf{p}$ is a vector of parameters, and $s$ and $n$ are random variables corresponding to the signal and noise in the measurements, respectively. $M$ is a known rectangular matrix, in our case, a matrix differencing station arrival times, and $\mathbf{p}$ is the average slowness. We are able to estimate the signal at pseudo-observation points through the use of a covariance matrix $C$. Thus the measurement $l$ consists of a deterministic part $M \mathbf{p}$ and two random parts $s$ and $n$. 


\subsubsection{Advantages of least-squares collocation}

The use of least - squares collocation for modelling provides additional advantages over standard fully parameterised modelling. The first advantage is that prior knowledge of the system can be introduced. For example, we can reasonably assume that the mantle P-wave velocities will be within a particular range (e.g. $7.0-9.0 \mathrm{~km} / \mathrm{s}$ ). The second advantage, as discussed earlier, is that, even though structure is imposed on the modelling procedure through the amount of variability assigned (variance/covariance) to each part of the data, these are not rigid constraints. As the amount and quality of data increases, this can overcome the preconceived model formulation, and then the results will tend to reflect more and more the actual signal of the data. Third, in traditionally parameterised modelling, if the number of model parameters exceeds the number of observations, or if the observations do not constrain certain parameters, then the inversion will fail unless pseudo-observations or damping are incorporated into the solution. This problem is avoided with the collocation method, where the parameters are always over-determined.

\subsection{Modelling the uppermost mantle}

We approach the problem of modelling the uppermost mantle beneath the North Island, by using Pn phase arrivals at the available stations over the time period of $1990-2000$, with addition data from November 2004 - March 2005 and November 2005 - May 2006 (see next chapter for more detail of data collection, and processing), and assumed characteristics of upper mantle properties (fig 2.1). Arrival times are differenced for pairs of stations inline with an earthquake epicenter. Time differences and mantle characteristics are combined through a two-dimensional integration of the inter-point covariance function (Gaussian Quadrature). 


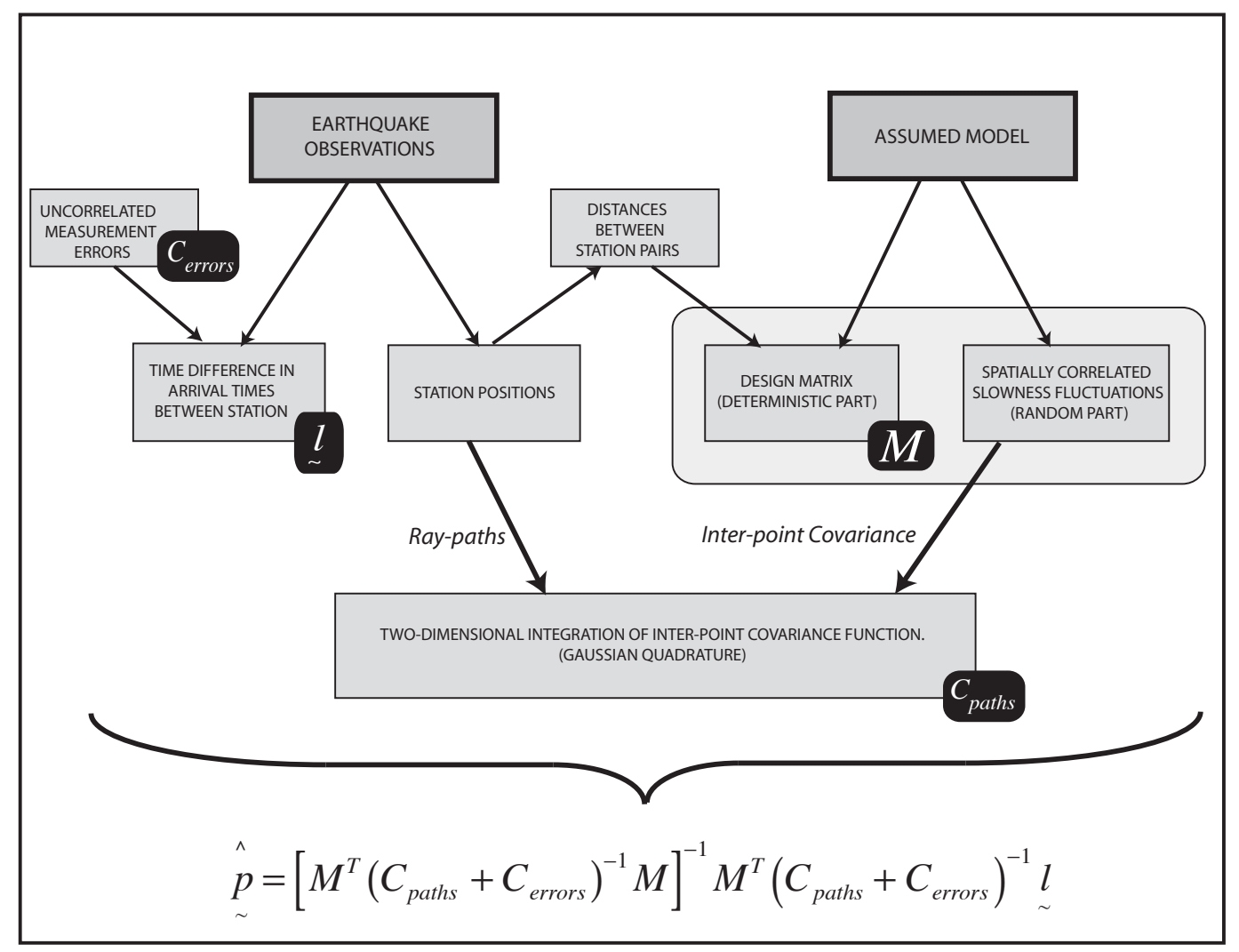

Figure 2.1 Flowchart outline the approach used to model the upper mantle using Pn wave phases.

\subsubsection{Slowness Modelling}

Observed travel time differences represent the effect on velocity of a variety of properties associated with the material through which the seismic energy traverses.

$$
l_{A B}=\left(\Delta_{B Q}-\Delta_{A Q}\right) S_{a v}+\alpha_{Q}+\left(\theta_{A Q}-\theta_{B Q}\right)^{\text {mantle }}+\left(\phi_{A}-\phi_{B}\right)^{\text {crust }}+\xi^{\text {meas }}
$$

$l_{A B}$ is the observed travel time difference, $\Delta_{B Q}$ and $\Delta_{A Q}$ are the distances between the epicentre (Q) and stations $\mathbf{B}$ and $\mathbf{A}$, respectively; $S_{a v}$ is the average slowness (modelled by the deterministic model), $\alpha_{Q}$ represents the contribution from uncertainty in the location of the earthquake origin. $\theta_{A Q}$ and $\theta_{B Q}$ are path integrals of slowness from 
earthquake to the stations though the mantle, and $\phi_{A}$ and $\phi_{B}$ are crustal terms that take into account differences in crustal velocities and thicknesses in the neighbourhod of stations $\mathbf{A}$ and $\mathbf{B}$. $\xi^{\text {meas }}$ are uncertainties associated both with the data and the modelling parameters.

A simple model is used for converting the observations into a design matrix $\mathbf{M}$ and modelling parameters, $\mathbf{p}$. In the following equations, $\boldsymbol{l}$ is the vector of observations $l_{A B}$.

$$
\begin{aligned}
& \mathbf{M p}=\boldsymbol{l}+\mathbf{E} \\
& \operatorname{cov}(\mathbf{E})=\mathbf{C}_{\text {tot }}=\mathbf{C}_{\text {meas }}+\mathbf{C}_{\text {mant }}+\mathbf{C}_{\text {crust }}
\end{aligned}
$$

The formulation is based on the Gauss-Markov model shown in EQ(2.4), where $\mathbf{E}$ combines the uncertainty in the measurements (i.e $\left.\mathbf{C}_{\text {meas }}=\operatorname{cov}\left(\xi^{\text {meas }}\right)\right)$, mantle $\left(\mathbf{C}_{\text {mant }}\right)$ and crustal $\left(\mathbf{C}_{\text {crust }}\right)$ modelling parameters. The design matrix, $\mathbf{M}$, encapsulates the deterministic components of the model, which in this case consists of $(n)$ distance differences between pairs of stations and the epicentres of the earthquakes.

So, the design matrix is the effect of the average slowness on each of the time differences, $\boldsymbol{l}$.

$$
\boldsymbol{l}=\left(\begin{array}{c}
t_{B 1}-t_{A 1} \\
t_{B 2}-t_{A 2} \\
\vdots \\
t_{B n}-t_{A n}
\end{array}\right)
$$

The parameter vector, $\mathbf{p}$, will therefore contain only one element, the average slowness $\left(\widehat{S_{a v}}\right)$. The observation vector, $\boldsymbol{l}$ (EQ 2.3), contains the differences in travel times between pairs of stations from each single earthquake. The total covariance $\left(\mathbf{C}_{\text {meas }}+\mathbf{C}_{\text {mant }}+\mathbf{C}_{\text {crust }}\right)$ is the sum of three seperate random processes. The first is the measurement covariance, $\mathbf{C}_{\text {meas }}$, related to the accuracy with which the Pn arrivals are picked. Since the measurements are differences between arrival time observations, the covariance matrix contains off diagonal terms. The signal covariance, $\mathbf{C}_{\text {mant }}$, contains 
information about the assumed slowness structure of the mantle. $\mathbf{C}_{\text {crust }}$, is the covariance structure of the crust. The inversion of the model (EQ2.4) is performed exactly as any normal weighted least-square inversion.

$$
\underline{\hat{\mathbf{p}}}=\left[\mathrm{M}^{\mathrm{T}} \mathrm{C}_{\text {tot }^{-1} \mathrm{M}}\right]^{-1} \mathrm{M}^{\mathrm{T}} \mathrm{C}_{\text {tot }}{ }^{-1} l
$$

\subsubsection{The Mantle Covariance}

The location of useable events and stations means that any features with wavelengths smaller than the minimum station-event separation (here $50 \mathrm{~km}$, see chapter 3: Data Selection) will be difficult to detect and model. The signal covariance $\mathbf{C}_{\text {mant }}$ thus primarily represents longer wavelength features. This is modelled through the use of a covariance function (EQ 2.7) that describes the correlation of the slowness at any two points in the mantle $\left(x_{A}\right.$ and $\left.x_{B}\right)$, through the correlation distance $(D)$ and the expected magnitude of the maximum deflection $\left(Y_{m}\right)$ of the slowness from the average value.

$$
\mathbf{C}_{\text {mant }}\left(\mathbf{x}_{B}, \mathbf{x}_{A}\right)=Y_{m} \exp \left(-\frac{\left|\mathbf{x}_{B}-\mathbf{x}_{A}\right|^{2}}{D^{2}}\right)
$$

However, instead of modelling pairs of points, we are actually modelling pairs of line segments linking stations and earthquakes, i.e. the integral of the slowness along ray paths. So the covariance between time measurements (EQ 2.8) will actually be a double integral of the covariance function between the location of station $\mathbf{B}\left(\mathbf{s}_{B}\right)$ and the epicentre of the earthquake $(\mathbf{q})$, and between the location of station $\mathbf{A}\left(\mathbf{s}_{A}\right)$ and the epicentre (q) (see Appendix A for derivation).

$$
\operatorname{Cov}_{\text {mpath }}\left(\mathbf{s}_{B}, \mathbf{s}_{A}, \mathbf{q}\right)=\int_{s_{B}}^{q} \int_{s_{A}}^{q} \mathbf{C}_{\text {mant }}\left(\mathbf{x}_{\mathbf{B}}, \mathbf{x}_{\mathbf{A}}\right) d x_{B} d x_{A}
$$

As there is no analytical solution, the integral in (EQ 2.8) must be done numerically involving integration of the error function (EQ 2.7). Because the wavelength of the 
inter-point covariance (a function of $D$ ) is long, it is possible to do a sufficiently accurate Gauassian quadrature using relatively few points. This was tested with a variety of divisions, and it was found that with 16 Gaussian nodes the signal was resolved sufficiently for a mantle slowness wavelength of $20 \mathrm{~km}$. This means that an accurate mantle covariance matrix can be generated in only a few minutes for a few thousand observations. For more accuracy, however, each ray was numerically integrated with a 32-point quadrature.

\subsubsection{Pn anisotropy estimation}

To infer uppermost mantle anisotropy from Pn travel times is difficult since variations in anisotropy must be distinguished from lateral variations in velocity. However, the problem can be vastly simplified by the assumption that mantle anisotropy is symmetrical about $180^{\circ}$, and can be described by a $2 \theta$ azimuth variation (fig 2.2) (Hearn 1996).

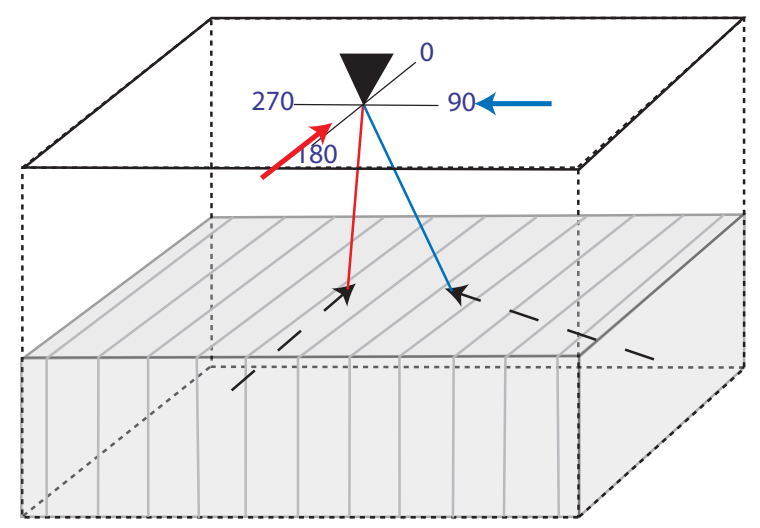

Figure 2.2 Schematic of the effect of mantle anisotropy. Anisotropic effects in the mantle can be modelled as being dependent on the azimuth of the arriving ray. Since both rays arriving from the left and the right will take longer to travel through the anisotropic material than rays raying in and

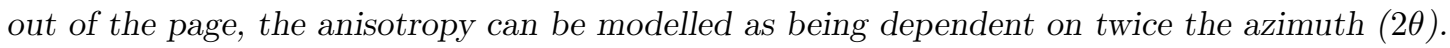

Anisotropic mantle slowness can be approximated by adding two terms to the mantle covariance. The two anisotropic terms are functions of sine and cosine of twice the 
ray-path azimuth (Eberhart-Phillips and Henderson 2004), as shown in (EQ 2.9):

$$
S^{\prime}(\theta)=S_{0}+A \cos (2 \theta)+B \sin (2 \theta)
$$

where $S_{0}, A$ and $B$ are spatially correlated variables, with covariances calculated through path integrals between stations and earthquakes.

\subsubsection{The Crustal Covariance}

The crustal terms are assumed to be correlated at a smaller length-scale than the mantle. Instead of performing integration along ray paths in the crust, only point values are used. These point values correspond to the crustal delays for each station and are of the form

$$
C_{t c}=Y_{c} \exp \left(-\frac{\left|\mathbf{x}_{B}-\mathbf{x}_{A}\right|}{D}\right)
$$

with $D$ values of $10 \mathrm{~km}$, and $\mathbf{x}_{A}$ and $\mathbf{x}_{B}$ are coordinate positions of station $\mathbf{A}$ and station $\mathbf{B}$, respectively. If the crust-mantle interface is dipping or there is local inhomogeneity in the crust around the station, then it is expected that there will be some anisotropic variations in the crustal delay. For a single path, this is modelled to first order in $\theta$ as:

$$
\begin{aligned}
& C_{\text {crust }(\text { sin })}=\sin (\theta) \operatorname{Cov}_{t c} \sin (\theta)^{T} \\
& C_{\text {crust }(\cos )}=\cos (\theta) \operatorname{Cov}_{t c} \cos (\theta)^{T}
\end{aligned}
$$

where $\theta$ is the vector of azimuthal angles from which the ray approaches a station. So the total crustal covariance is estimated by:

$$
\operatorname{Cov}_{\text {crust }}=C_{t c}+C_{\text {crust }(\text { sin })}+C_{\text {crust }(\text { cos })}
$$

The station delays $\left(C_{\text {crust }}\right)$ represent the combined effect of the crustal thickness 
(a)

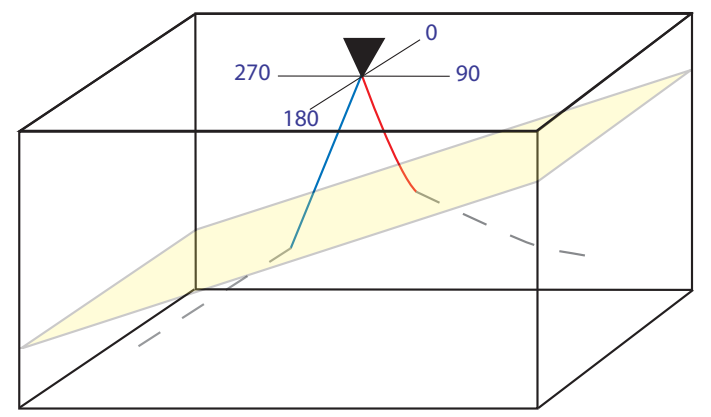

(b)

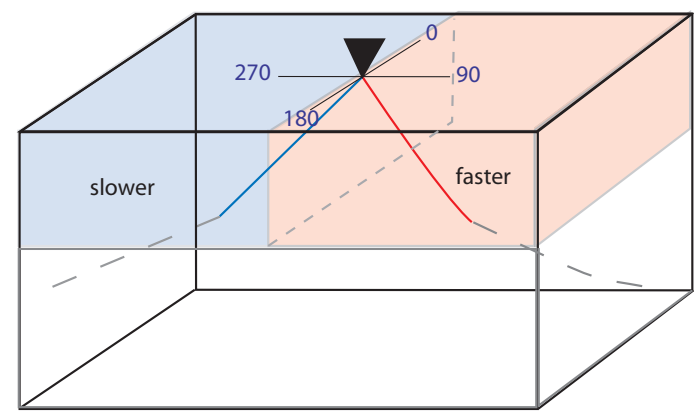

Figure 2.3 Schematic of the effect of: (a) a dipping Moho, and (b) the presence of inhomogeneities in the crust, in the neighbourhood beneath the receiving station. A ray arriving at the station from the right will arrive sooner than one arriving from the left. The effects of crustal anisotropy can be modelled as function of azimuthally dependent signal.

and crustal velocity. Crustal thickness and crustal velocity cannot be independently determined from the delay times. However, by making assumptions approximate values for the relative variations in crustal thickness and crustal velocity can be found. E.g. for a crust with a constant velocity of $6.3 \mathrm{~km} / \mathrm{s}, 1 \mathrm{~s}$ of relative delay time indicates about $10.4 \mathrm{~km}$ of additional crust thickness. For a $40 \mathrm{~km}$ constant thickness crust, 1s of delay corresponds to a change in crustal velocity of $6.2-6.6 \mathrm{~km} / \mathrm{s}$.

Another factor affecting station delay terms is systematic picking errors at the station. These could occur due to a clock error, timing errors or phase identification errors that repeatedly occur at a given station. 


\subsection{Mantle slowness estimation summary}

-The upper mantle slowness is modelled as a horizontally varying random surface, fluctuating about some baseline, or average value.

- The spatial covariance of the random surface is assumed to be of the form:

$$
C(d)=A \exp \left(\frac{-d^{2}}{D^{2}}\right)
$$

where $\mathrm{d}$ is the horizontal distance between two points in the upper mantle, $\mathrm{A}$ is the magnitude of the variability of the slowness, and D is the correlation distance, which can be considered to be the smoothness of the surface.

- The covariance of the slowness is integrated along pairs of seismic ray paths to produce the covariance of the time measurements due to mantle slowness uncertainties alone.

- The uncertainties due to measurement error and mantle variability are combined into a single measurement of uncertainty. This is used as the covariance in the weighted least-square estimation procedure following the principles of least-square collocation.

-Parameters in the least-squares estimation are simply the average mantle slowness.

- The residuals from the inversion are a combination of estimates for the measurement errors and for the fluctuations of the mantle slowness about the average. The mantle slowness at each horizontal point in the mantle can be extracted through the use of the equation

$$
S(p)=C_{s m}(p) C_{T}^{-1} \mathbf{r}+S_{a v}
$$

where $S$ is the slowness at a point $p, C_{s m}$ is the covariance between the signal point and each ray-path, $\mathbf{r}$ is the residual, and $S_{a v}$ is the overall average slowness of the mantle (Moritz 1972). 
CHAPTER 3

\section{DATA SELECTION}

\subsection{Introduction}

The uppermost mantle beneath the central North Island, is modelled using travel-time differences between seismic stations. A combination of National Network seismometers, local volcanic seismic monitoring networks and temporary deployments are used to collect arrival times from local events, during the period of 1990-2006. Travel time differences from earthquakes lying roughly along the straight-line intersection of station pairs are used.

The resulting dataset consists of approximately 11200 Pn observations from 3000 local earthquakes at 93 seismograph sites.

\subsection{North Island Seismic Network}

The New Zealand National Seismograph Network (NZNSN) consists of 42 sites (Jan 2007 (GeoNet 2008)) located with approximately $100 \mathrm{~km}$ spacing throughout New Zealand with additional arrays established at places of geophysical significance (e.g. volcanically active regions). Throughout the North Island there are, currently operating, 18 NZNSN sites interspersed with 34 volcano-seismic monitoring and regional networks sites (fig 3.1). Over the past 30 years, sites have been established at various locations, and either still remain or have been moved. In this project events between January 1990 and December 2000 have been used, in addition to arrival times from a 
total of 78 nationally monitored seismograph sites active over time.

To sample the uppermantle beneath the central North Island, the NZNSN seismographs in the west of the island were too few for our needs. We therefore deployed two seismograph arrays in the western North Island. The first deployment, WNIPSE (Western North Island Passive Seismic Experiment), was located in the Waikato, central-west North Island. The second deployment, CORO was located further north, along a northsouth line down the western coast of the Coromandel Peninsular (See Appendix C).

\subsubsection{Western North Island Passive Seismic Experiment}

Between November 2004 and April 2005, 13 seismometers were deployed in two arrays in the Waikato region of the western North Island (fig 3.2). One line stretched from Whitehall (East of Hamilton) in the north to west of Pio Pio in the south. The other line stretched west from Te Kawa to Raglan on the coast (CWNIPSE), completing the CNIPSE line deployed in 2001(Henrys et al. (2003); Greve and Savage (2007)).

Table 3.1

Location of temporary WNIPSE deployment

\begin{tabular}{|c|cc|cc|c|c|c|c|}
\hline \hline Station & Lat & Lon & $\mathbf{E}$ & $\mathbf{N}$ & start & end & sensor & logger \\
\hline \hline COWA & -38.249 & 175.32 & 2713243 & 6325824 & 10-NOV-04 & 28-MAR-05 & Marks-L4 & Reftek130 \\
HULA & -37.879 & 175.554 & 2734820 & 6366324 & 8-NOV-04 & 26-MAR-05 & Marks-L4 & Reftek72A \\
MUIA & -38.018 & 175.47 & 2727086 & 6351111 & 9-NOV-04 & 28-JAN-05 & Marks-L4 & Reftek130 \\
SUTA & -38.087 & 175.517 & 2730977 & 6343294 & 9-NOV-04 & 28-MAR-05 & Marks-L4 & Reftek130 \\
WATA & -38.406 & 174.846 & 2671325 & 6309451 & 10-NOV-04 & 29-MAR-05 & Marks-L4 & Reftek130 \\
WLKA & -38.335 & 175.216 & 2703894 & 6316587 & 6-NOV-04 & 29-MAR-05 & Marks-L4 & Reftek130 \\
\hline FLYC & -37.900 & 174.935 & 2680360 & 6365414 & 9-NOV-04 & 11-NOV-05 & CMG-40T & Orion \\
PEAC & -37.837 & 174.863 & 2674204 & 6372476 & 7-NOV-04 & 6-AUG-05 & CMG-40T & Orion \\
PUKC & -38.135 & 175.287 & 2710604 & 6338559 & 4-NOV-04 & 5-AUG-05 & CMG-40T & Orion \\
STEC & -38.113 & 175.241 & 2706680 & 6341124 & 4-NOV-04 & 12-NOV-05 & CMG-40T & Orion \\
VERC & -38.009 & 175.043 & 2689624 & 6353054 & 6-NOV-04 & 6-AUG-05 & CMG-40T & Orion \\
WULC & -38.186 & 175.384 & 2718980 & 6332647 & 3-NOV-04 & 5-AUG-05 & CMG-40T & Orion \\
YTFC & -38.035 & 175.134 & 2697466 & 6349951 & 5-NOV-04 & 11-NOV-05 & CMG-40T & Orion \\
\hline \hline
\end{tabular}

There were two main reasons for the WNIPSE deployment (Western North Island Passive Seismic Experiment). CWNIPSE was deployed by Sonja Greve to complete the CNIPSE line across the central North Island, for an investigation into the anisotropy variation in the mantle (Greve 2008). The CNIPSE project was deployed from January 


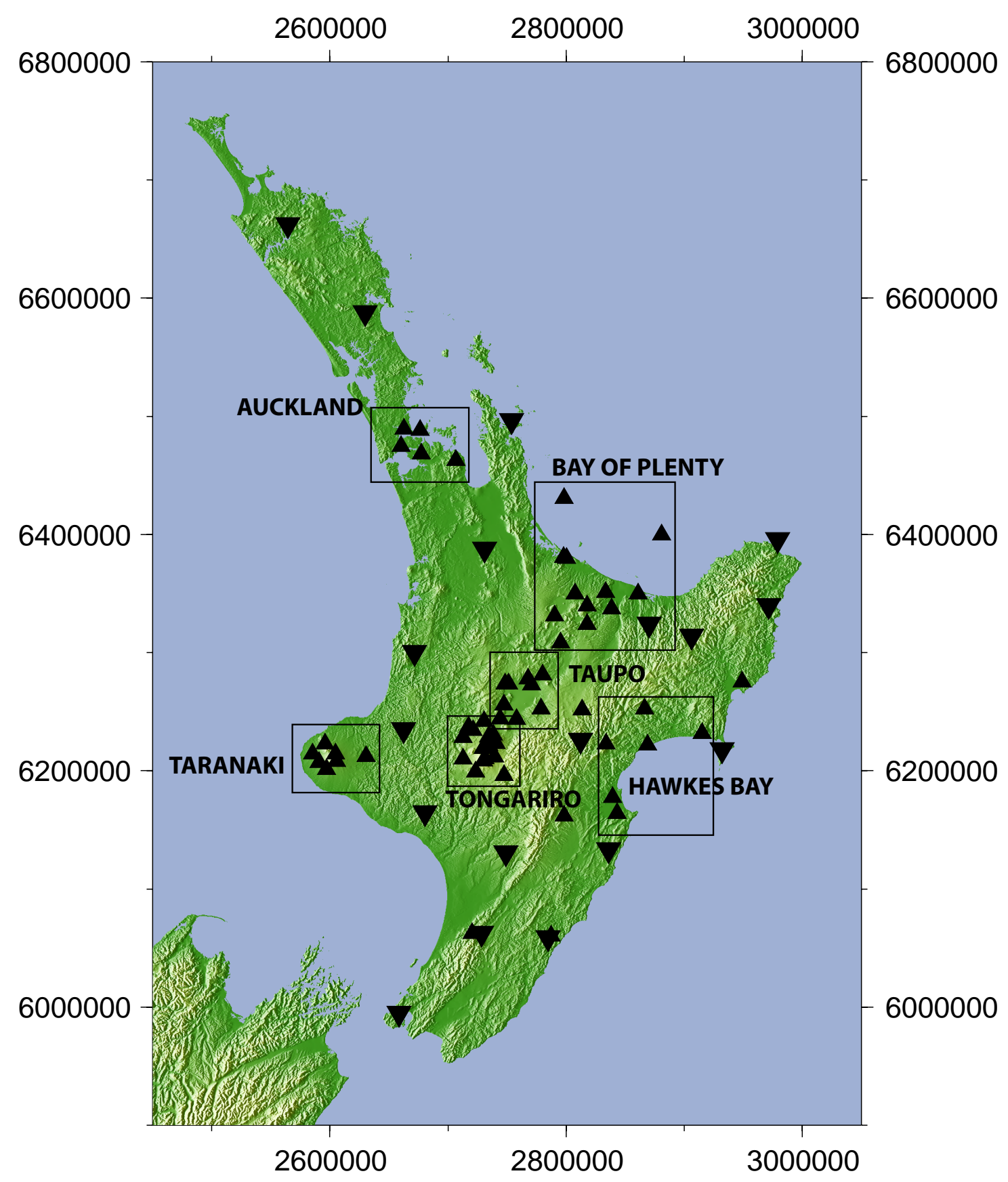

Figure 3.1 The Seismograph network of the North Island (1990-2000). Black inverted triangles show the sites of the New Zealand National Seismograph Network (NZNSN), while the smaller black triangles show the locations of the volcano-seismic monitoring networks throughout the North Island. 


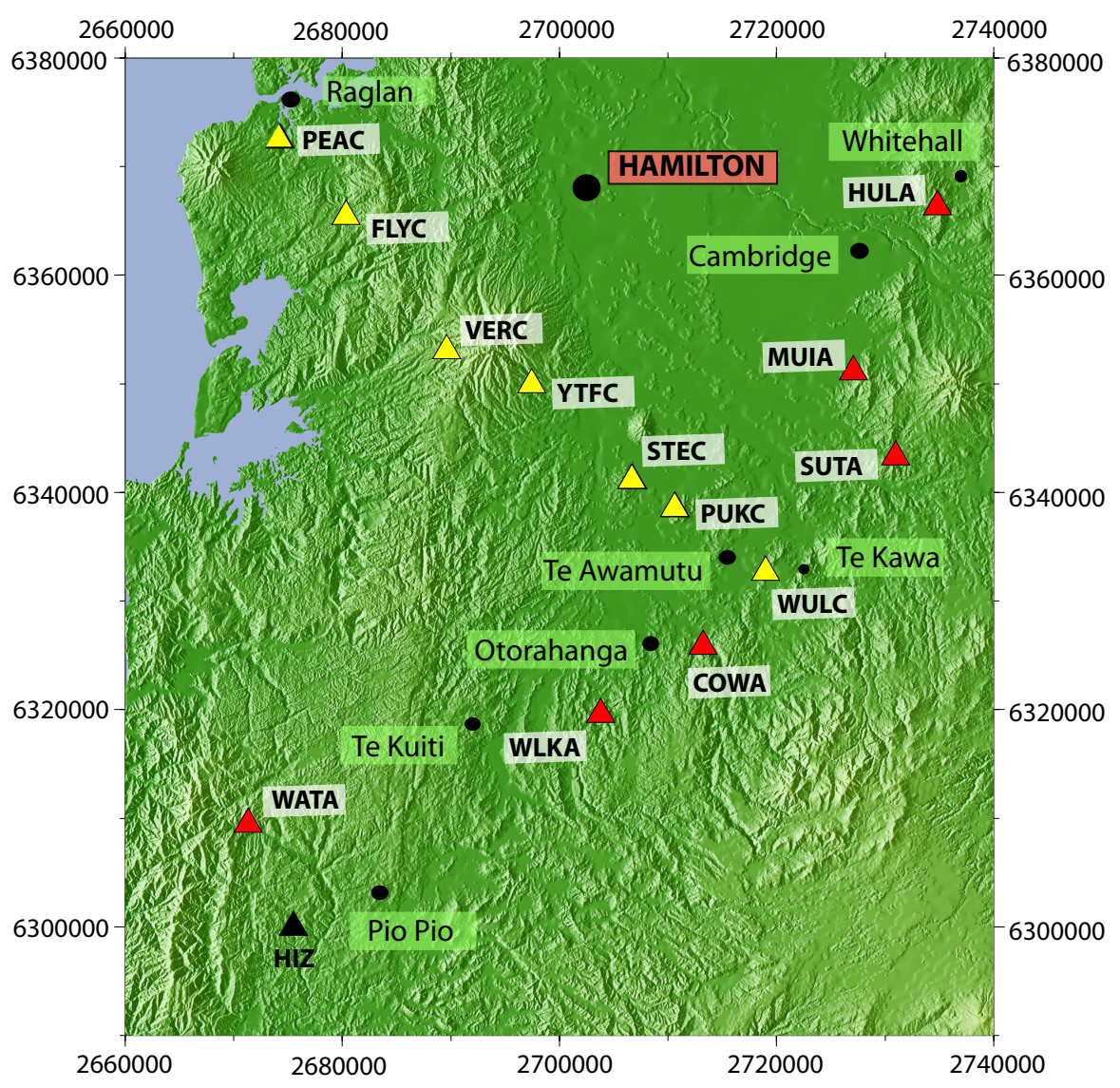

Figure 3.2 Locations of the WNIPSE deployment sites in the Waikato, from November 2004 to April 2005. Yellow triangles represent those sites of the CWNIPSE deployment, completing the CNIPSE line. Those red triangles are those deployed for greater ray coverage beneath the central North Island. Black triangles represent the location of permanent sites.

8th to June 27th 2001, as an international investigation (University of Leeds, Victoria University of Wellington, GNS Science)(Henrys et al. 2003) into the North Island subduction system. It included 74 portable digital seismographs, arranged in a finely spaced (10 km separation) cross-section line from Napier, on the east coast, to Te Kawa (fig 3.2), as well as a closely spaced grid throughout the central North island.

The second line (north-east to south-west Waikato), was deployed purely to increase the number of seismometers in this region. The sites were chosen primarily on the access to basement rocks (i.e. greywacke) (figC.4). 


\subsubsection{Coromandel Peninsula deployment}

The Coromandel region is a peninsula adjacent to the Northland/Auckland region of New Zealand's North Island (fig 3.3). Between November 2005 and May 2006, 6 seismometers were deployed in a north-south profile down the western coast of the Coromandel Peninsula (fig 3.3). Sites are located only along the west coast, as this is where most of the exposed basement greywacke can be found (fig C.5).

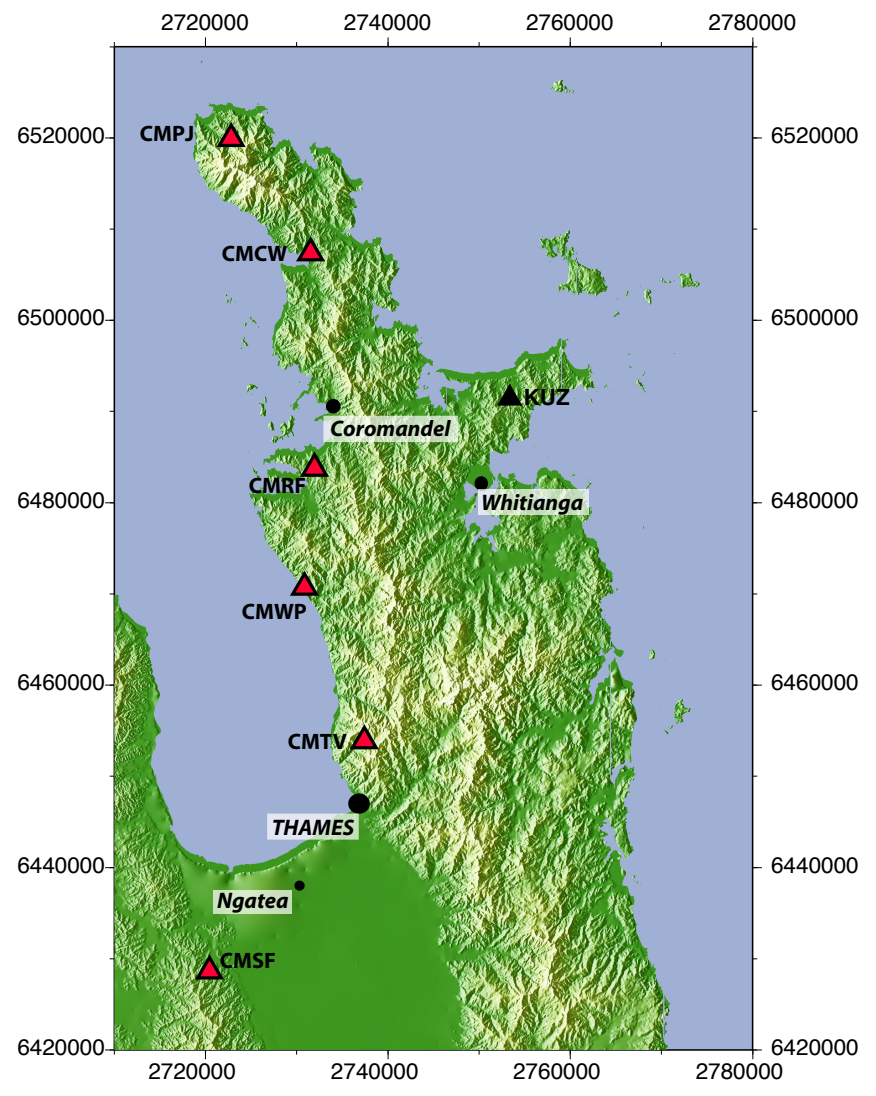

Figure 3.3 Location of the CORO deployment sites down the Coromandel Peninsula, from November 2005 to May 2006, represented by the red triangles. Black triangle represent the location of the permanent seismograph sites. 
Table 3.2

Location of temporary Coromandel deployment

\begin{tabular}{|c|cc|cc|c|c|c|c|c|}
\hline \hline Station & Lat & Lon & E & N & elev & start & end & sensor & logger \\
\hline \hline CMCW & -36.609 & 175.471 & 2731546 & 6507441 & 15 & 7-NOV-05 & 28-MAY-06 & Marks-L4 & Reftek130 \\
CMPJ & -36.498 & 175.370 & 2722790 & 6519970 & 145 & 7-NOV-05 & 27-MAY-06 & Marks-L4 & Reftek130 \\
CMRF & -36.822 & 175.483 & 2731947 & 6483816 & 220 & 8-NOV-05 & 28-MAY-06 & Marks-L4 & Reftek130 \\
CMSF & -37.321 & 175.371 & 2720431 & 6428702 & 105 & 9-NOV-05 & 29-MAY-06 & Marks-L4 & Reftek130 \\
CMTV & -37.089 & 175.554 & 2737414 & 6453962 & 346 & 9-NOV-05 & 29-MAY-06 & Marks-L4 & Reftek130 \\
CMWP & -36.939 & 175.475 & 2730850 & 6470791 & 29 & 8-NOV-05 & 28-MAY-06 & Marks-L4 & Reftek130 \\
\hline \hline
\end{tabular}

\subsubsection{Station locations}

The NZNSN stations used for the study are those that were active between 1990 and 2000, at various times, and those stations active within the North Island during the deployments described above. This resulted in a total of 114 stations that were used in the algorithm (Appendix B).

\subsection{North Island Seismicity}

The North Island is situated above the oblique subduction of the Pacific Plate beneath the Australian Plate, which results in earthquakes, volcanoes and active deformation (fig 1.5). The Wadati-Benioff zone beneath the North Island (fig 3.4) delineates the seismically active part of the Pacific plate. The deep earthquakes marking the Hikirangi Benioff zone extend into the northern South Island.

Local crustal events were used to study the uppermost mantle velocity structure beneath the North Island of New Zealand (fig 3.5). Many earthquakes occur in the offshore Bay of Plenty to the north of the Island. There is also a cluster of events that occurs in the Marlborough region to the south. The east coast of the North Island is the most seismologically active region of New Zealand, providing a great source of lower crustal events. Unfortunately to the west of the North Island there are few events, meaning that reversal observations are seldom obtainable. Reversal observations are important as they more easily allow the detection of mantle anisotropy, and any dipping 


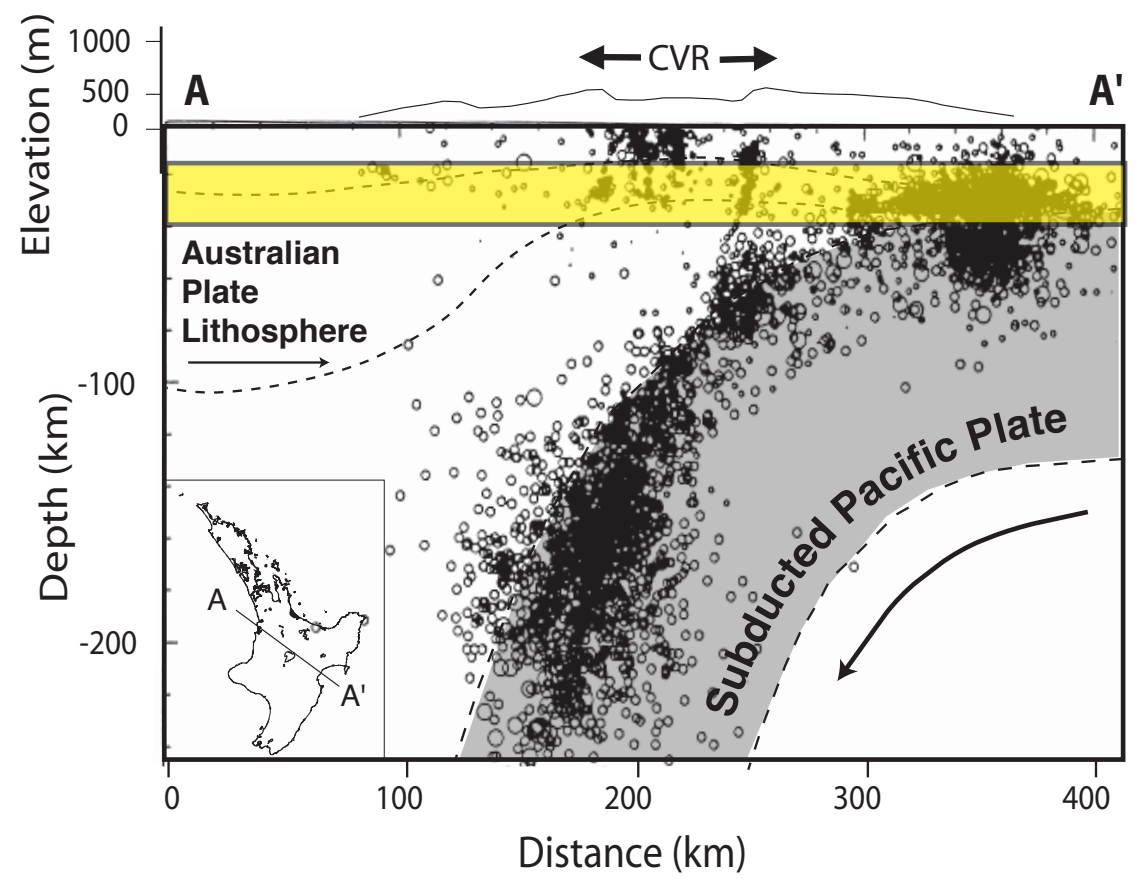

Figure 3.4 The Benioff zone beneath the North Island, adapted from Stratford (2004). Earthquake hypocentres (Anderson and Webb 1994) are shown as open circles, size dependent on magintude. Yellow zone represent the depth range of earthquakes in which we are interested.

boundary layers.

The Central Volcanic Region is marked by an alignment of shallow crustal earthquakes that trends northeast from Mt Ruapehu. This alignment lies along the eastern margin of the CVR coincident with the active volcanic front marked by recent volcanism between Mt Ruapehu and White Island (fig 3.5).

A band of shallow (15 - $40 \mathrm{~km}$ depth) seismicity runs east-west from Mt Ruapehu towards Mt Taranaki, indicating a particularly active lower crust in this region. Other shallow events are mostly located off the east coast of the North Island, where the subducting plate is dipping shallowly (fig 3.4). 


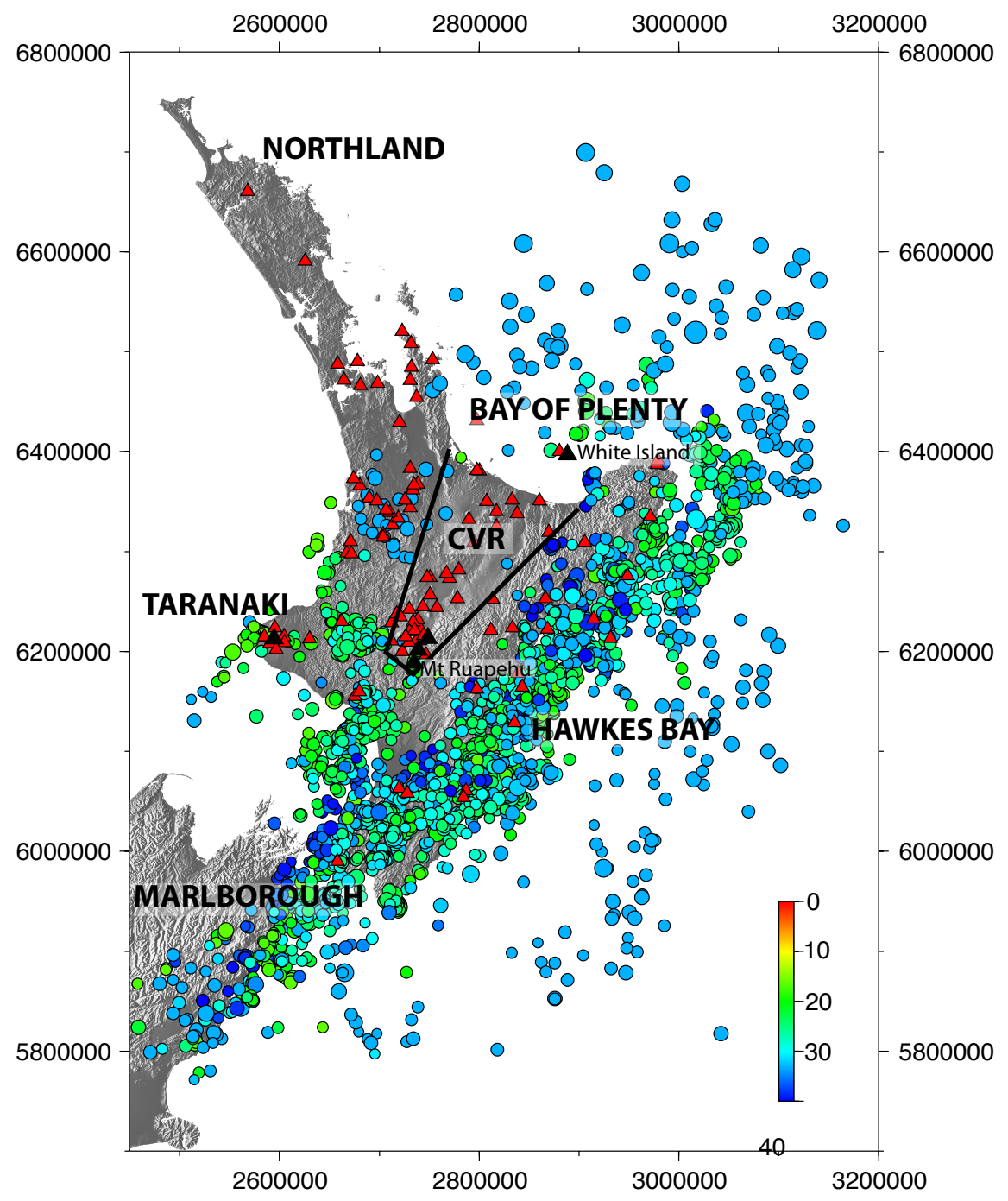

Figure 3.5 New Zealand shallow seismicity, hypocentres at depths between 16 - $40 \mathrm{~km}$, from the GeoNet catalogue 1990-2000. Circles vary in size relative to magnitude, and colour based on depth. Red triangles represent seismic stations throughout the North Island, and the Black triangles indicate the locations of active volcanoes. 


\subsection{Ray-path geometry}

A Moho refracted ray path can be described in three portions: the source to mantle leg, the ray-path through the mantle, and the leg from the mantle to the receiver (fig 3.6). The arrival time $T_{i}$ of a refracted ray can be broken up into (EQ 3.1):

$$
T_{i}=T_{o}+\alpha_{o}+\frac{\Delta_{i}-\left(\delta_{o}+\delta_{i}\right)}{V_{a i}}+\alpha_{i}
$$

Where $T_{o}$ is the origin time determined from the initial locating model, $\Delta_{i}$ is the distance between epicenter and station, $\delta_{o}$ and $\delta_{i}$ represent the horizontal distance between the focus and the point with which the ray pierces the Moho boundary, and the horizontal distance between the stations and the refraction point at the Moho. $\alpha_{o}$ and $\alpha_{i}$ are time estimates of variations between the velocity/depth model and the true velocity structure in the proximity of the focus and the receiver, respectively. $V_{a i}$ can be thought of as the apparent velocity with which the ray travels below the Moho between the piercing points.

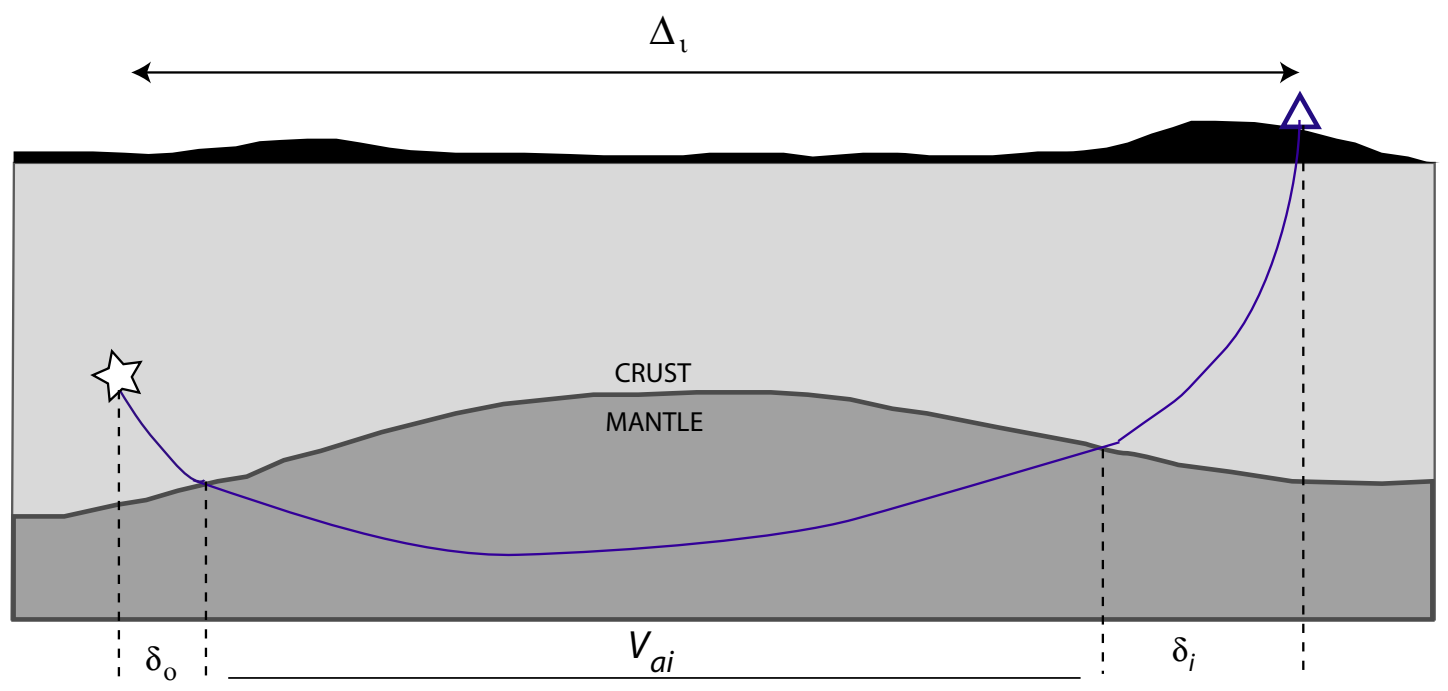

Figure 3.6 Schematic of a theoretical ray path between an event focus and a station. 


\subsubsection{Hypocentre derivation}

Event hypocentres are determined using Pn and Sn phases or first-arriving crustal P and S phases. New Zealand is split into four different velocity-depth structures (table 3.3) (Maunder 2001). Most of New Zealand is assumed to follow the New Zealand standard profile, consisting of a crustal P-velocity of $5.5 \mathrm{~km} / \mathrm{s}$ to a depth of $12 \mathrm{~km}$, underlain by a crust velocity of $6.5 \mathrm{~km} / \mathrm{s}$ to a depth of $33 \mathrm{~km}$, which is assumed to be the Moho boundary, underlain by a mantle P velocity of $8.1 \mathrm{~km} / \mathrm{s}$. In the North Island, the Taupo Volcanic Region and the Wellington region each have their own velocity profiles, based on models by Stern and Davey (1987) and Robinson (1986), respectively. Beneath the Moho defined by these models, velocities are smoothly merged with those of the Jeffreys-Bullen Tables (Jeffreys and Bullen 1958). It is self evident that inaccuracies in the earth model will map into errors in event timing and location. The effect of this on the model is looked at later in section 4.2.2.

\subsubsection{Picking of event arrival times}

GeoNet seismographs are equipped with GPS receivers for timing, which are accurate to nanoseconds.

In the picking procedure digital seismograms are displayed on high-resolution graphic monitor screens under the control of CUSP (Caltect-USGS Seismic Processor) interactive software, for an analyst to select phase onset times. Weights are initially assigned to phase arrival times by the analyst according to the apparent precision of the measurement. The weight of the reading is further modified by the location program, which, after every iteration, weights the residuals used to adjust the trial origin (GeoNet 2008).

Picking procedures used for observation at temporary sites are outlined in Appendix C. 5 . 
Table 3.3

Four different velocity/depth structures are used to calculate travel-times of rays passing through and immediately beneath the crust in different parts of the country

\begin{tabular}{|l||c|c|}
\multicolumn{3}{|c|}{ (Maunder 2001) } \\
\hline \hline MODEL & $\begin{array}{c}\text { UPPER DEPTH } \\
\text { BOUNDARY }(\mathrm{km})\end{array}$ & $\begin{array}{c}\mathrm{Vp} \\
(\mathrm{km} / \mathrm{s})\end{array}$ \\
\hline \hline NZ standard & 0.0 & 5.5 \\
& 12.0 & 6.5 \\
& 33.0 & 8.1 \\
\hline Wellington & 0.0 & 4.40 \\
& 0.4 & 5.63 \\
& 5.0 & 5.77 \\
& 15.0 & 6.39 \\
& 25.0 & 6.79 \\
& 35.0 & 8.07 \\
& 45.0 & 8.77 \\
\hline Taupo & 0.0 & 3.00 \\
& 2.0 & 5.30 \\
& 5.0 & 6.00 \\
& 15.0 & 7.40 \\
& 33.0 & 7.78 \\
& 65.0 & 7.94 \\
& 96.4 & 8.08 \\
\hline Clyde & 0.0 & 4.4 \\
& 0.5 & 6.0 \\
& 12.0 & 6.5 \\
& 33.0 & 8.1 \\
\hline \hline
\end{tabular}

\subsection{Two-Station method}

As most of the lower crustal earthquakes occur outside the limits of the seismograph network, the two-station method is utilised. The two-station method uses observations of arrival times at pairs of stations from a single earthquake, roughly aligned with the station pair (fig 3.7). This method removes the need for exact origin times of earthquakes and reduces the dependence on the velocity model used for the locating of the epicentre.

The basic two-station method assumes that the Pn travel time for distances between stations is linearly dependent on $\Delta_{A B}$, i.e. it has an insignificant horizontal velocity 
(a)

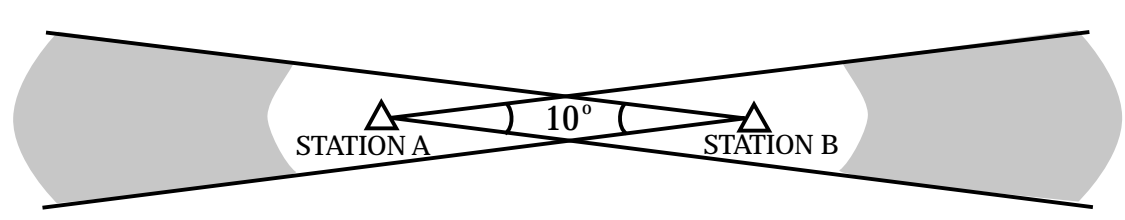

(b)

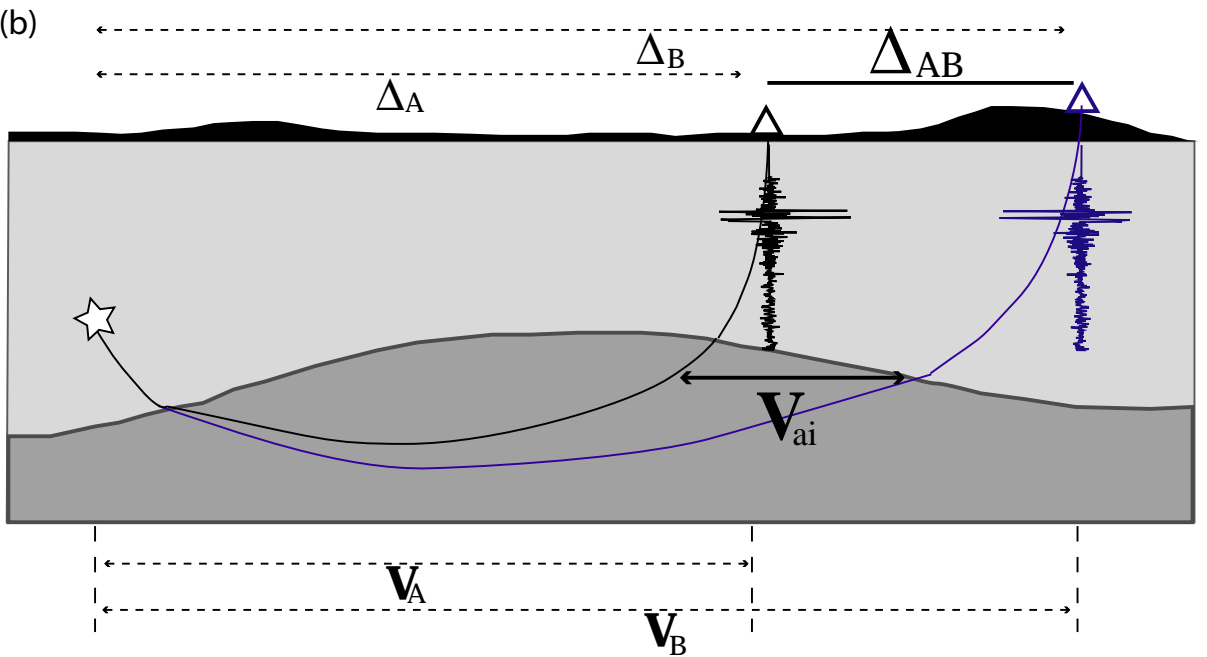

Figure 3.7 Schematic of the two-station method.(a) Shows the allowed offset of an event from the azimuth aligning station pairs. (b) Shows a theoretical raypath of a Pn wave from an event to stations $\mathbf{A}$ and $\mathbf{B}$.

gradient. We therefore use the two-station method, as described by Haines (1979), to develop event selection criteria and apply a more complex algorithm to model the horizontal variations in upper mantle $\mathrm{P}$-wave velocities.

As events seldom occur exactly in line with station pairs, we allow a window of $10^{\circ}$ from the direct azimuth joining the stations (fig $3.7 \mathrm{a}$ ) .

The arrival times, $t_{A}$ and $t_{B}$, of the Pn refracted upper mantle phase at two stations, $\mathbf{A}$ and $\mathbf{B}$, are related to the distances, $\Delta_{A}$ and $\Delta_{B}$, from the epicentre to the stations according to the equation:

$$
t_{B}-t_{A}=\frac{\Delta_{B}-\Delta_{A}}{V_{a i}}+\left(\alpha_{B}-\alpha_{A}\right)
$$


Where $V_{a i}$ is the apparent velocity of waves traveling in the upper mantle, and $\alpha_{B}$ and $\alpha_{A}$ represent the delay times for the crustal neighbourhood beneath stations $\mathbf{B}$ and $\mathbf{A}$, respectively.

Equation 3.2 on its own is too simple to be used in modeling the upper mantle, in that it does not allow for variations in crustal velocity and thickness beneath individual stations, or horizontal velocity gradients in the uppermost mantle. It is therefore used to develop event selection criteria and a more complex algorithm is used to model the horizontal variations in upper mantle $\mathrm{P}$-wave velocities.

\subsection{Event selection}

At the beginning of this chapter a crude statement of the criteria for membership in a set of data was given. Event observations are refined to those that satisfy the following criteria (adjusted from Haines, (1979)):

(1) Earthquakes initially located by 6 or more observations

(2) Magnitudes of 3.5 or greater, to ensure clear P arrival picks.

(3) Hypocentres located at depths of 16 to $40 \mathrm{~km}$ with offsets from the closest station of $50 \mathrm{~km}$ or more, to ensure that the first arrivals will be a Pn phase. Based on the New Zealand Standard model (table: 3.3), offsets of $39.3 \mathrm{~km}$ and $40.7 \mathrm{~km}$ for Pn and Sn phases, respectively, are needed for a refracted Moho ray from an event originating at $16 \mathrm{~km}$ depth. By using a minimum offset of $50 \mathrm{~km}$ we account for the variation in the North Island crustal thickness.

(4)An epicentre located within $10^{\circ}$ of the azimuth between stations, to ensure that the wave from different earthquakes traverse approximately the same material. 
(5)Travel time differences with error uncertainities of $\geq 0.2 \mathrm{~s}$ are removed.

Our dataset consists of approximately 11200 Pn observations from around 3000 local events, at 78 national stations between 1990 and 2000 (GeoNet 2008), and 19 VUW temporary deployment stations between 2004 and 2006. 
CHAPTER 4

\section{MODELLING RESOLUTION AND RESULTS}

\subsection{Model Resolution}

In the last few years, tomographic inversion methods have become increasingly popular as a means to provide images of the internal structure of the Earth at different scales (e.g. Zhao (2004); Foulger et al. (2001); Wittlinger et al. (1996); Zelt and Barton (1998); Hearn and Ni (1994); Hearn (1996); (1999)). A difficulty commonly encountered with such methods is determining the reliability of the images obtained. In other words, how closely does the resulting model resemble the actual Earth structure. The usual method to test reliability, is to create artificial inputs to the modelling procedure and examine the output.

To test the resolution of the MAR modelling algorithm (see Appendix E) a known velocity input is created and tested with the available ray-path coverage. In this case a conventional checker-board test is used to examine the resolution. The synthetic data consist of an alternating pattern of positive and negative anomalies, which are inverted using the same method applied to obtain the measurements of Pn velocities. The raypath geometry of the observations is used, and realistic noise is added to the synthetic data through the use of the measurement covariance matrix.

\subsubsection{Ray Path coverage}

The dataset consists of approximately 11200 ray-paths (fig 4.1 ) from approximately 3000 local earthquakes, recorded at 93 seismic stations throughout the North Island 


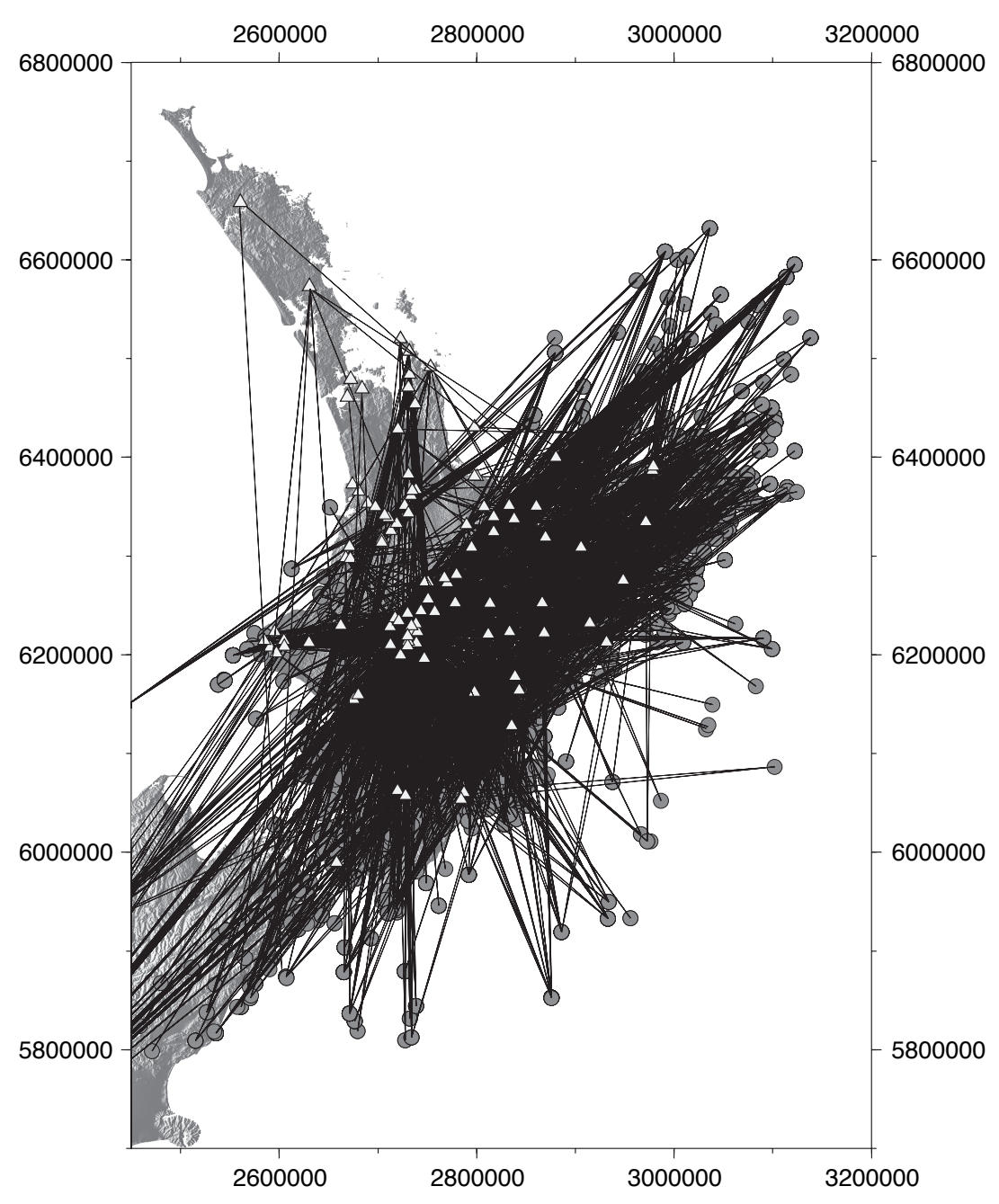

Figure 4.1 Figure showing the raypaths used in this dataset. All raypaths match the event selection criteria defined in section 3.6, for all station pairs. Grey circles represent earthquakes, white triangles are North Island seismic stations.

(see chapter 3 for more detail). This results in an average of approximately 200-400 rays per $10 \mathrm{~km}^{2}$, over the majority of the North Island, reaching a maximum density of 1487 rays in proximity to Mt Ruapehu (fig $\mathbf{4 . 2}$ ). 


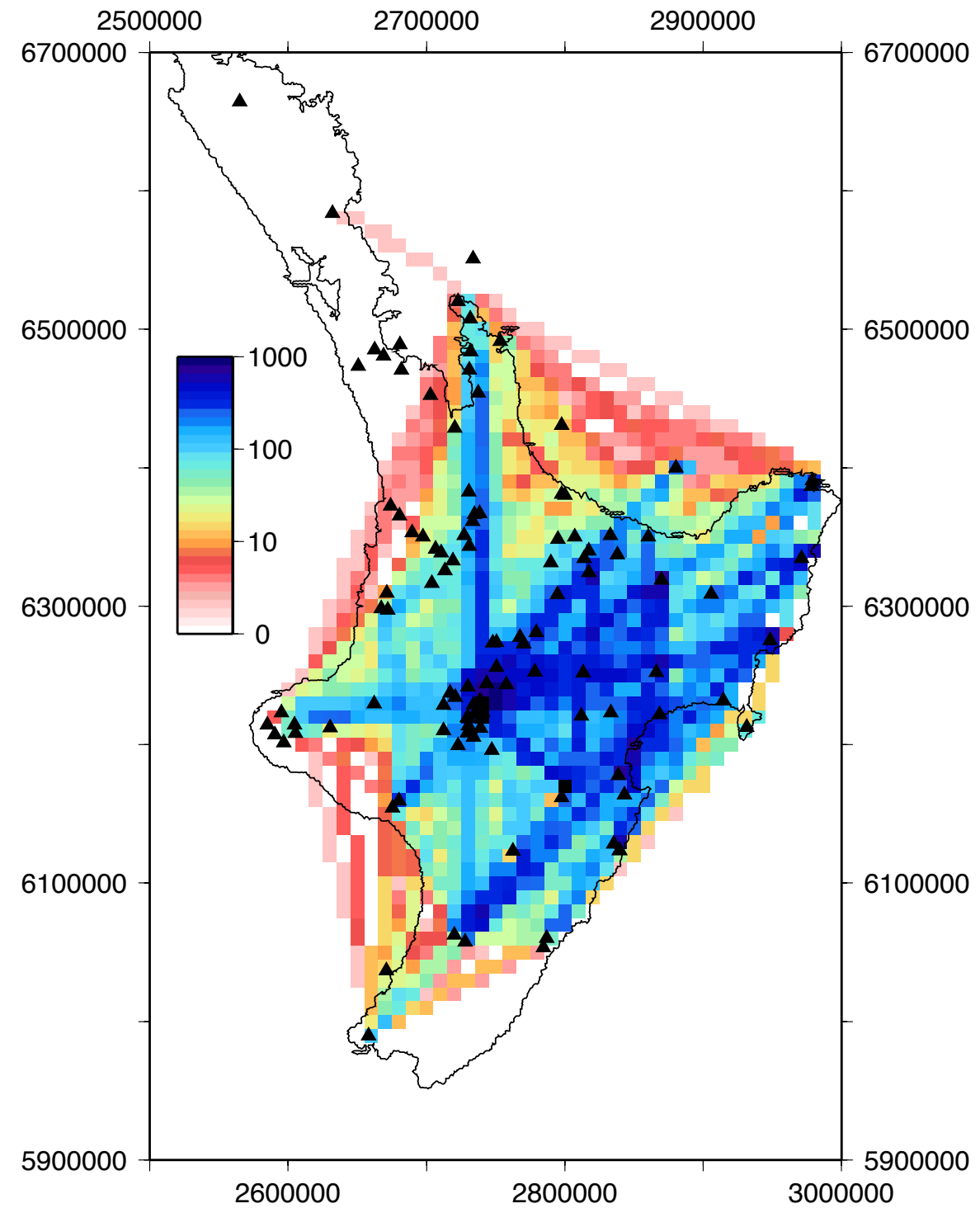

Figure 4.2 Inter-station ray density.

\subsubsection{Creating a synthetic input model}

In order to create a checker-board pattern we use sinusoidally varying slowness in both the eastern $(x)$ and the northern $(y)$ directions.

$$
S=S_{o}+k \sin \left(\omega_{1} x\right) \sin \left(\omega_{2} y\right)
$$


Which is equivalent to:

$$
S=S_{o}+\frac{k}{2}\left(\cos \left(\omega_{1} x-\omega_{2} y\right)-\cos \left(\omega_{1} x+\omega_{2} y\right)\right)
$$

where $S_{o}$ is the average slowness, $k$ is the amplitude of the oscillations, $\omega$ is the wavenumber, subscription (1 and 2) allow different values for east and north direction, and $x$ and $y$ are the distances in the east and north directions, respectively. In this case, the slowness is analytically integrated along the geometry of the ray-paths.

Only where there is good ray coverage, will the resulting model match the input checkerboard in both wavelength and amplitude (fig 4.3). Elsewhere, the modelling procedure will attempt to smooth the result to an average velocity estimated for the region.

\subsubsection{Resolution of model}

The input sinusoidal pattern has an amplitude of $\pm 0.015 \mathrm{~s} / \mathrm{km}$ relative to a background velocity of $8.0 \mathrm{~km} / \mathrm{s}\left(S_{0}=0.125 \mathrm{~s} / \mathrm{km}\right)$. This results in a mantle P-velocity variation ranging from $7.1 \mathrm{~km} / \mathrm{s}$ to $9.0 \mathrm{~km} / \mathrm{s}$, which are realistic limits for the uppermost mantle (see Pn discussion, section 1.4.1). Several different mantle wavelengths were tested, but only realistic mantle anomaly wavelengths of $50 \mathrm{~km}$ to $150 \mathrm{~km}$ are discussed (see discussion on realistic mantle anomaly wavelength (section 4.3.1)).

Several synthetic models with different wavelengths were tested to determine the minimum wavelength of mantle features that can be resolved with our ray-path coverage. As shown in figure 4.3, much of the central region is resolved well at most correlation distances. However smoothing occurs where ray-path coverage becomes more sparse. 
(a) Synthetic input wavelength

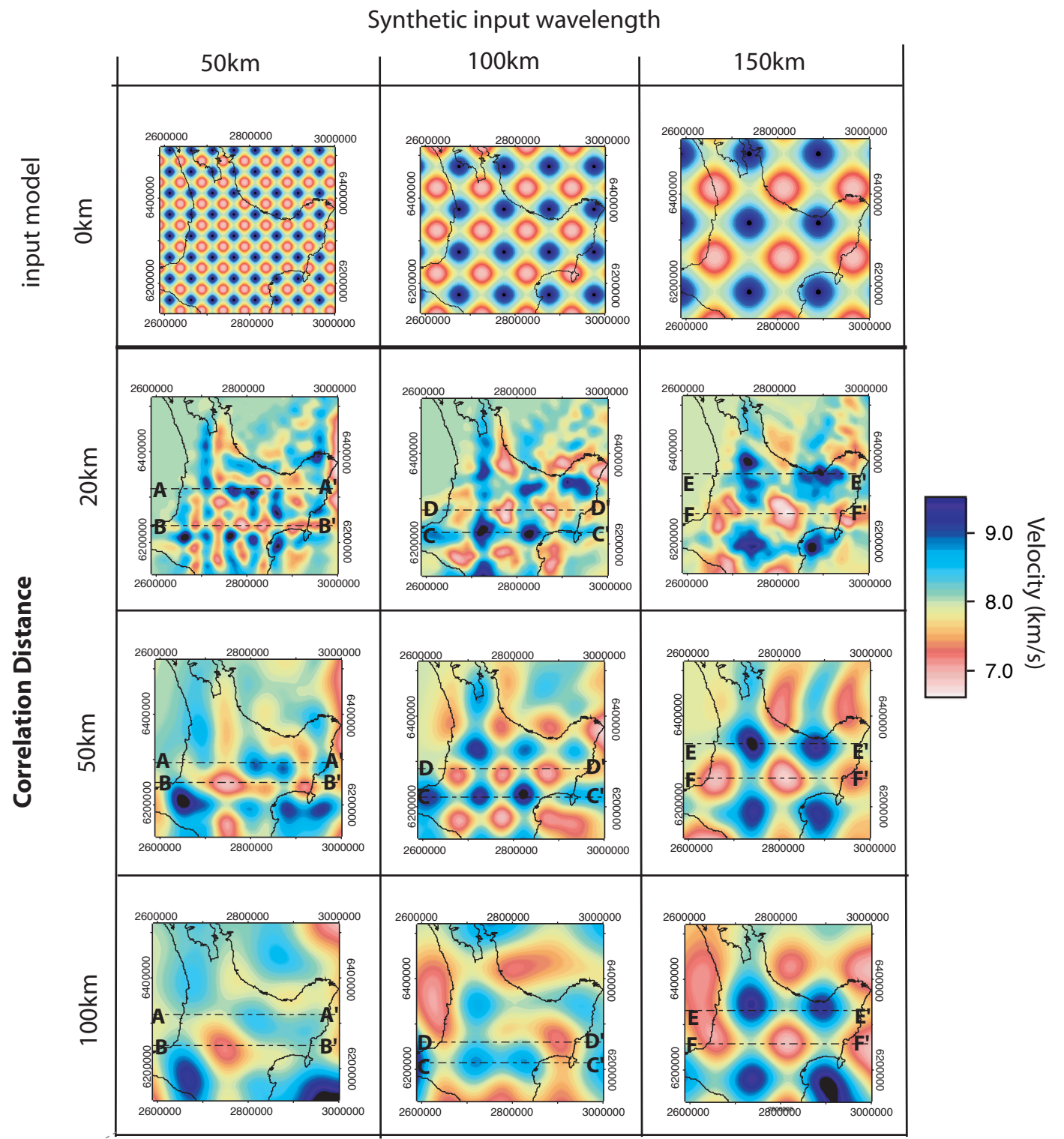

(b)

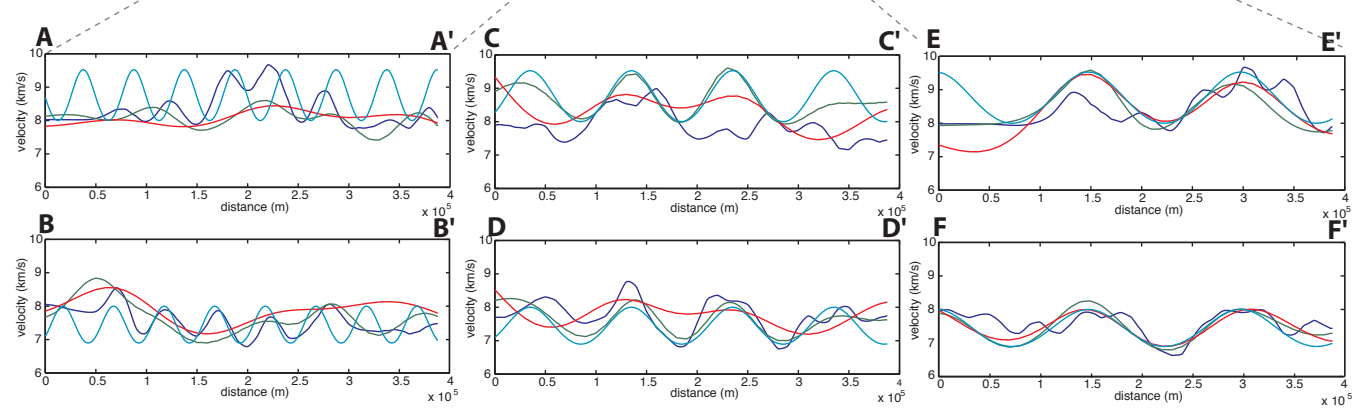


Figure 4.3 Modelling resolution. Input synthetic checkerboard models of various wavelengths (50 $\mathrm{km}, 100 \mathrm{~km}, 150 \mathrm{~km}$ ) were run through the modelling code with a variety of correlation distances. (a) the resultant models of the checkerboard at various correlation distances. Colours vary with velocity, red are lower speeds, while blues are faster. (b) Shows the amplitude resolution of the checkerboard along profiles $A-A^{\prime}, B-B^{\prime}, C-C^{\prime}, D-D^{\prime}, E-E$ ', and $F-F^{\prime}$ shown in figure (a). Light blue shows the amplitude of the input. Dark blue represents resolution with a correlation distance of $20 \mathrm{~km}$, green represents the correlation distance of $50 \mathrm{~km}$, and red represents a correlation distance of $100 \mathrm{~km}$.

\subsubsection{Discussion of synthetic model resolution}

The correlation distance (D) is an assigned length scale defining the distance over which the slowness behaves similarly. The larger the correlation distance, the smoother the resulting model will appear, whereas smaller correlation distances will result in residuals that are more susceptible to noise in the model and to errors in picked arrival times. The effect of smoothing is particularly noticeable in the north and west of the North Island (fig 4.3).

The $20 \mathrm{~km}$ correlation distance resolves all the synthetic anomalies but is also very susceptible to the effect of noise (fig 4.3) and ray-path distribution, resulting in a distorted image. The $50 \mathrm{~km}$ correlation distance does not adequately resolve the features of the $50 \mathrm{~km}$ mantle wavelength, but does resolve the anomalies of the $100 \mathrm{~km}$ and $150 \mathrm{~km}$ wavelengths. Anomalies of wavelength $150 \mathrm{~km}$ or greater are resolved well at any correlation distance smaller than the wavelength of the anomaly.

The amplitudes of the anomalies (fig $4.3 b$ ) are generally well resolved in the centers of the profile lines $\left(\mathbf{A A}^{\prime}, \mathbf{B B}^{\prime}, \mathbf{C C}^{\prime}\right.$, etc ...). This coincides with the region where there is better raypath coverage. At either edge of the profile lines the input amplitudes are less well resolved, due to insufficient ray coverage.

The ideal wavelength for the best imaging seems to be approximately half the wavelength of the anomalous features. 


\subsection{Uncertainty estimations}

\subsubsection{Picking Errors}

Measurement uncertainties were estimated by comparing the arrival pick-times in the GeoNet catalogue with re-picked arrival times for the same events. 15 events from the year 2000 were re-picked at 21 of the 26 active stations (table D.1). Of 65 re-picked observations, the average variation from the catalogued arrivals was $0.032 \mathrm{~s}$ with a maximum of $0.117 \mathrm{~s}$.

Table 4.1

\begin{tabular}{|l|c|}
\multicolumn{2}{l}{ Summary of picking uncertainties } \\
\hline \hline maximum difference & $0.117 \mathrm{~s}$ \\
average difference & $0.032 \mathrm{~s}$ \\
median & 0.026 \\
variance & 0.0018 \\
standard deviation & 0.03 \\
\hline \hline
\end{tabular}

We assume that with $95 \%$ confidence the picking measurement is within $0.06 \mathrm{~s}$ of the derived value. Since we are looking at difference between station pairs we need to multiply the $95 \%$ confidence for a single station by $\sqrt{2}$, which means that the $95 \%$ confidence bound per observation is in fact $0.085 \mathrm{~s}$.

\subsubsection{Mislocation of epicentres}

When using the earthquake catalogue, it is important to be aware that the estimated position of an earthquake epicentre outside of the seismic network can be very inaccurate. The uncertainty of earthquake epicentres, outside of a dense seismic network can be on the order of tens of $\mathrm{km}$ (Nicholson et al. 2004). We calculated the effect that this uncertainty has on the modelling algorithm.

Each earthquake is initially located by at least 6 arrival observations, and the standard velocity model used for locating epicentres (fig 3.3). It is evident that inaccuracies 
in the earth model used for locating events will map into the event timing and epicentral / hypocentral location. The need for an exact origin time is eliminated in the choosing of the input events and differencing (i.e. the two-station method).

Depths of earthquake hypocentres are often difficult to determine. Generally this will not affect the model, as travel times between station pairs are being modelled. Care does have to be taken if a earthquake hypocentre has been located within the lower crust but is in fact in the upper mantle. These observations are eliminated by calculating the apparent velocity before the data is put through the algorithm. Otherwise, rough observations are observed as outliers within the modelling algorithm, and down-weighted or eliminated when appropriate.

There are two ways in which to approach the problem of travel time biasing: (1) the geometrical approach; or (2) the probabilistic approach. Both are described below.

\section{The geometrical approach}

The basic two-station method, assumes the geometry of ray-paths to be a straight line through the two stations. Hence the uppermost mantle velocity between the two

stations ( $\mathrm{A}$ and $\mathrm{B}$ ) is only a function of the path $\mathrm{AB}$ rather than the total path. This eliminates the mislocation effect of the focus on the velocity estimate. However, if we use the complete ray-path, from source to both receivers, the actual velocity will be that estimated through differencing of station observations, which will include the effect of epicentral mislocations. The epicentral distances $d_{A}$ and $d_{B}$, are calculated from the initial velocity model (table 3.3), and are therefore susceptible to errors due to the simplifications in that model.

In this section, we refer to the distance between stations $\mathbf{A}$ and $\mathbf{B}$ and the event epicenter $(\mathbf{Q})$, determined from an initial velocity model, as $d_{A}$ and $d_{B}$, respectively. The true ray-paths between epicenter and stations are referred to be $d_{A}{ }^{\prime}$ and $d_{B}{ }^{\prime}$ (fig $4.4)$.

To test a combination of epicenter and two station locations, we can calculate a 


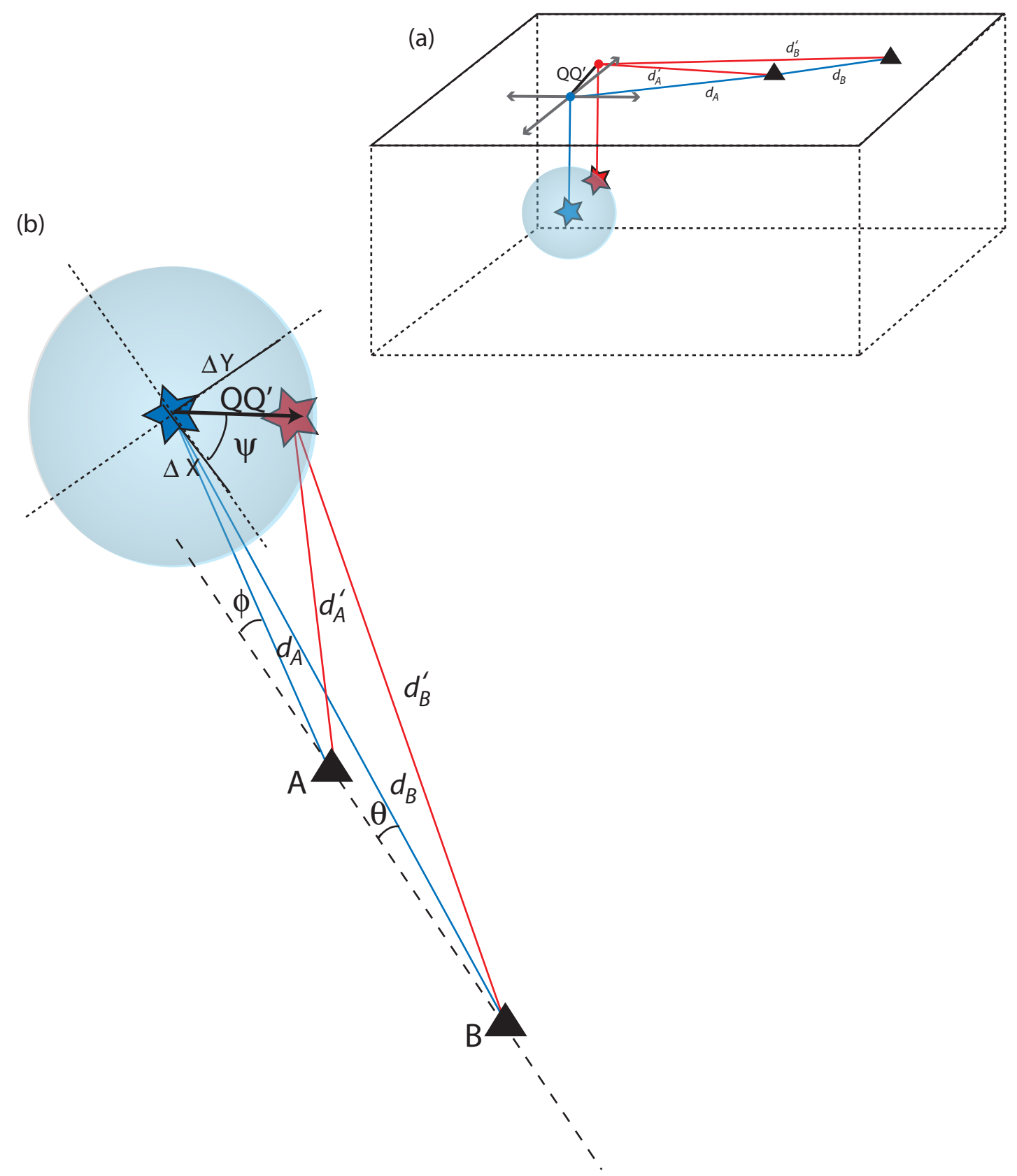

Figure 4.4 Highly exaggerated schematic of the epicentral mislocation $Q Q$ ' on the geometries that are used to determine Pn velocities. (a) shows a $3 D$ representation of the geometrical problem, where (b) shows the $2 D$ birds-eye view. 
maximum expected difference between $d_{A}{ }^{\prime}-d_{B}{ }^{\prime}$ and $d_{A}-d_{B}$, given some circle of maximum error around the epicenter.

\section{The probabilistic approach}

The distance to an earthquake epicenter $\left(x_{Q}, y_{Q}\right)$ from a station located at $(x, y)$ can be calculated by

$$
d=\sqrt{\left(x_{Q}-x\right)^{2}+\left(y_{Q}-y\right)^{2}}
$$

This can be expanded into a Taylor series as a function of the East $(x)$ and North $(y)$ errors $\left(\xi_{x}\right.$ and $\left.\xi_{y}\right)$, which are perturbations of $x_{Q}$ and $y_{Q}$.

$$
d \approx d_{o}+A_{1} \xi_{x}+A_{2} \xi_{y}+A_{3} \xi_{x}^{2}+A_{4} \xi_{y}^{2}+\ldots
$$

where $d$ is the true length between the earthquake epicenter and the station and $d_{o}$ is the length calculated from the positions derived using the standard New Zealand velocity model (table 3.3). $A_{n}$ are the coefficients of the expansion, where

$$
\begin{array}{c|c}
A_{1}=\frac{\partial d}{\partial x_{Q}}=\frac{x_{Q}-x}{d} & A_{2}=\frac{\partial d}{\partial y_{Q}}=\frac{y_{Q}-y}{d} \\
A_{3}=\frac{1}{2}\left(\frac{\partial^{2} d}{\partial x_{Q}{ }^{2}}\right)=\frac{1}{2}\left(\frac{1}{d}-\frac{\left(x_{Q}-x\right)^{2}}{d^{3}}\right) & A_{4}=\frac{1}{2}\left(\frac{\partial^{2} d}{\partial y_{Q}{ }^{2}}\right)=\frac{1}{2}\left(\frac{1}{d}-\frac{\left(y_{Q}-y\right)^{2}}{d^{3}}\right)
\end{array}
$$

To second order, the first moment of the measurements is

$$
\bar{d}=\langle d\rangle=\left\langle d_{o}\right\rangle+A_{1}\left\langle\xi_{x}\right\rangle+A_{2}\left\langle\xi_{y}\right\rangle+A_{3}\left\langle\xi_{x}^{2}\right\rangle+A_{4}\left\langle\xi_{y}{ }^{2}\right\rangle
$$

We assume $\left\langle\xi_{x}{ }^{2}\right\rangle=\left\langle\xi_{y}{ }^{2}\right\rangle=\sigma^{2}$, where $\sigma^{2}$ is the epicentral error variance.

The expected values of the elements of the Taylor expansion are:

$$
\begin{array}{c|c}
A_{1}\left\langle\xi_{x}\right\rangle \simeq 0 & A_{2}\left\langle\xi_{y}\right\rangle \simeq 0 \\
A_{3}\left\langle\xi_{x}{ }^{2}\right\rangle \simeq A_{3} \sigma^{2} & A_{4}\left\langle\xi_{x}{ }^{2}\right\rangle \simeq A_{4} \sigma^{2}
\end{array}
$$


So

$$
\left(A_{3}+A_{4}\right) \sigma^{2}=\frac{1}{2}\left(\frac{2}{d}-\frac{\left(x_{Q}-x\right)^{2}}{d^{3}}-\frac{\left(y_{Q}-y\right)^{2}}{d^{3}}\right)=\frac{\sigma^{2}}{2 d}
$$

The mean of the distance differences now becomes:

$$
\overline{\Delta d}=\Delta d_{o}+\frac{\sigma^{2}}{2}\left(\frac{1}{d_{B}}-\frac{1}{d_{A}}\right)
$$

where $d_{B}$ is always greater than $d_{A}$. This shows that there will be a distributional bias, such that the mean distance difference $\overline{\Delta d}$ is less than the distance difference calculated.

The variance of the distribution $s^{2}$ can be estimated by a forth order Taylor expansion of:

$$
s^{2}=\left\langle\left(d_{B}-d_{A}-\left\langle d_{B}-d_{A}\right\rangle\right)^{2}\right\rangle
$$

resulting in a variance of

$$
s^{2}=2 \sigma^{2}\left(1-\frac{d_{B}}{d_{A}}+\frac{\tau l_{A B}}{d_{A} d_{B}}\right)+\frac{\sigma^{4}}{2}\left(\frac{1}{d_{B}}-\frac{1}{d_{A}}\right)^{2}
$$

where $l_{A B}$ is the straight line distance between stations and $\tau$ is the distance to the epicenter from station B, resolved onto the straight line between the stations.

The above equations for the bias (mean distance difference) and the approximate (4th order expression) variance of the distribution have been tested for epicentre location errors up to $20 \mathrm{~km}$ and for all applicable epicentre and station separation distance combinations, and found to be accurate to within $\sim 10 \%$ of randomly generated data (see table 4.2).

To produce a single measure of inaccuracy for the distance difference, the mean and 
variance may be combined:

$$
u=\sqrt{\left(\overline{\Delta d}-\Delta d_{o}\right)^{2}+s^{2}}
$$

If these uncertainties were not modelled correctly in the least-square adjustment it is probable that it would result in a bias in the slowness estimates. The uncertainty (EQ 4.12) is multiplied by the average slowness to get a time uncertainty. Rather than trying to model such uncertainties, which are from a non-normal distribution, we simply eliminate any observations where

$$
S_{a v} \times u>2 \xi
$$

where $S_{a v}$ is the average mantle slowness, $u$ is the measure of inaccuracy and $\xi$ is the picking error. Therefore observations will be eliminated if inaccuracy is much greater that the measurement errors.

\section{Comparison between Geometric and Probabilistic estimations}

Table 4.2 is a comparison of the probabilistic and geometric approaches to determining the effect of epicentral mislocation. $D_{A}$ and $D_{B}$ are distances from station $\mathrm{A}$ and station $\mathrm{B}$, respectively, to the epicentre resolved onto the line AB. In this table, the effect of the worst case scenario is examined, i.e. when the opening angle, $\theta$, is at its maximum, $10^{\circ}$. The resulting epicentral offset from line $\mathrm{AB}$ is shown in the third column (Epi). The epicentre is assumed to be located with a one standard deviation uncertainty of $10 \mathrm{~km}$ in the east and north directions.

To test the accuracy of both the geometric and probabilistic estimation, a random number generator test was done, using the MatLab function randn. A hundred thousand random epicentre locations where generated and $d_{A}^{\prime}$ and $d_{B}^{\prime}$ were calculated. The average deviation of the distance difference, $d_{B}^{\prime}-d_{A}^{\prime}$ vs. $d_{B}-d_{A}$, and standard deviation, are shown in columns $4\left(R_{\cdot a v}\right)$ and $5\left(R_{\cdot s d}\right)$. These numerical calculations are 
almost identical to the values calculated from EQ $4.13\left(P_{a v}\right)$ and EQ $4.11\left(P_{s d}\right)$. The total error $\left(P_{t o t}\right)$ is calculated through EQ 4.12 , and divided by $8 \mathrm{~km} / \mathrm{s}$ to approximate the associated time error $\left(P_{T-\text { error }}\right)$.

In the geometric case, a search was performed to find the greatest difference between $d_{B}^{\prime}-d_{A}^{\prime}$ and $d_{B}-d_{A}$, resulting in a maximum positioning error given in column G.pos-error. The search was restricted to a circle around the located epicentre with a radius encompassing the $95 \%$ confidence region, as calculated from the Chi-square distribution. Again, this distance is divided by $8 \mathrm{~km} / \mathrm{s}$ to estimate a timing error (column $\left.C_{T-\text { error }}\right)$.

Note that the geometric error is based on a 95\% confidence circle, and the probabilistic error is based on 1 s.d. error in the epicenter location. The final column shows the ratio of errors determined through the probabilistic and geometric approach. The ratio shows that for short path length $\left(d_{B} \leq 100 \mathrm{~km}\right)$ the probabilistic error is greater than the geometric error, whereas at larger path lengths the time ratio is much smaller. The main reason for this result is that the geometrical approach is an over-simplification of the location uncertainties. For this reason, the probabilistic method was used to select usable events.

\subsection{Input Parameters}

\subsubsection{Mantle properties}

\section{Velocity range}

A maximum range of upper mantle velocities from modelling worldwide is between $7.1 \mathrm{~km} / \mathrm{s}$ and $9.0 \mathrm{~km} / \mathrm{s}$ (see chapter 1: Pn wave phase for more detail), and as we are looking at a small area of diverse tectonic settings, we allow the same range of velocities to be present within the North Island, New Zealand. 


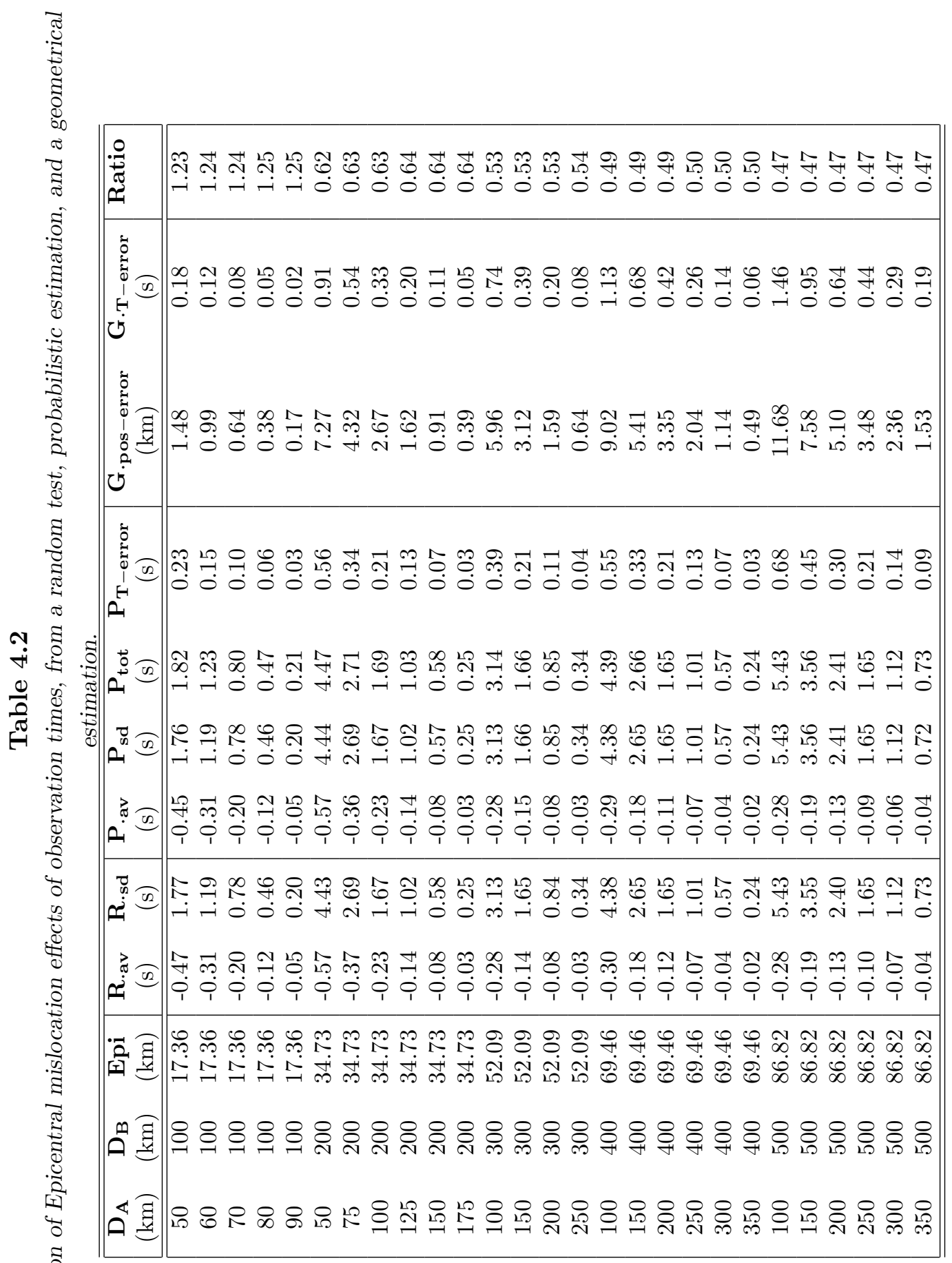




\section{Anomaly wavelength}

Tomographic Pn studies to image upper mantle velocities have been done at various scales worldwide. Most of the global Pn models reveal upper mantle anomalies with wavelengths between c.a. $350 \mathrm{~km}$ and $550 \mathrm{~km}$ (e.g. Pei et al. (2007); Al-Lazki et al. (2004); Hearn (1996);(1999); Hearn et al. (2004); Calvert et al. (2000)). Those studies looking at locally smaller regions, such as Northwestern Italy (Di Stefano et al. (1999); Parolai et al. (1997)) or the central Tien Shan, China (Xu et al. 2007), for example, have managed to resolve upper mantle anomalies of between 50 - $150 \mathrm{~km}$ wavelength, using a model grid spacing of $25 \mathrm{~km}$ by $25 \mathrm{~km}$. The detection of smaller wavelength features appears to be difficult, and is either due to the amplitude of the signal at these wavelengths or to modelling limitations.

With the effects of mantle material mixing through convection, features of larger wavelengths are more likely to exist than those of small wavelengths. We therefore assume that the minimum likely resolvable wavelength of the upper mantle with our station spacings and New Zealands seismicity, is between 50 and $150 \mathrm{~km}$ beneath the North Island. GPS measurements show that the majority of the deformation in the North Island happens over a length scale of $200 \mathrm{~km}$ (Wallace et al. 2004), meaning that if we wanted to successfully model similar length scales in the mantle, we would need to model the deformation distance to approximately half of this length (i.e. $50-150 \mathrm{~km}$ range).

\subsubsection{Crustal properties}

Crustal properties are estimated through the use of station time delay terms. Variations beneath stations are estimated by consistent time delays seen beneath an individual station. Crustal thicknesses range from a maximum thickness of $\geq 40 \mathrm{~km}$ beneath the Wanganui Basin to the southwest of the CVR, to a minimum of $16-20 \mathrm{~km}$ beneath the CVR (see Chapter 1 for crustal properties). Velocity profiles vary between 3 distinct regions (fig 1.7) the western region, the CVR, and the east coast. 
From the crustal velocity profiles in figure $\mathbf{1 . 7}$, and assuming a critically refracted ray at the crust-mantle boundary, by applying Snells law of refraction to the rays travelling through the crust, a maximum time differences due to different crusts should not exceed $1.5 \mathrm{~s}$. We therefore set this as the maximum likely delay time for the crust.

\subsubsection{Summary of Inputs}

- A Pn velocity range is bounded by a minimum and maximum of $7.1 \mathrm{~km} / \mathrm{s}$ and $9.0 \mathrm{~km} / \mathrm{s}$. Resulting in a slowness range of $0.111-0.141 \mathrm{~s} / \mathrm{km}$.

- A mantle correlation distance of $100 \mathrm{~km}$ is assumed.

- A crustal correlation distance of $10 \mathrm{~km}$ is assumed.

- A maximum delay time variation due to variations in crustal thickness and station elevation of station pairs is calculated to be $1.5 \mathrm{~s}$.

- Picking errors are not likely to be any larger than $0.1 \mathrm{~s}$ and events with possible mislocation errors of $0.2 \mathrm{~s}$ or greater are removed during processing.

\subsection{Results and Discussion}

The slowness estimates are calculated through the continuous function EQ 2.14, which is sampled at regular intervals, and modelled by fitting a surface through these points.

Our results (fig 4.5) for a correlation distance of $100 \mathrm{~km}$ show that the Pn velocity in the uppermost mantle beneath the North Island varies from velocities of less than $7.4 \pm 0.1 \mathrm{~km} / \mathrm{s}$ in the centre to $8.5 \pm 0.2 \mathrm{~km} / \mathrm{s}$ in the east, with an overall average of $8.0 \mathrm{~km} / \mathrm{s}$. The North Island can be split into three distinct regions, based on the upper mantle seismic velocities :

(1) The western North Island

(2) The volcanic regions (i.e the Central Volcanic Region (CVR) and the Taranaki 


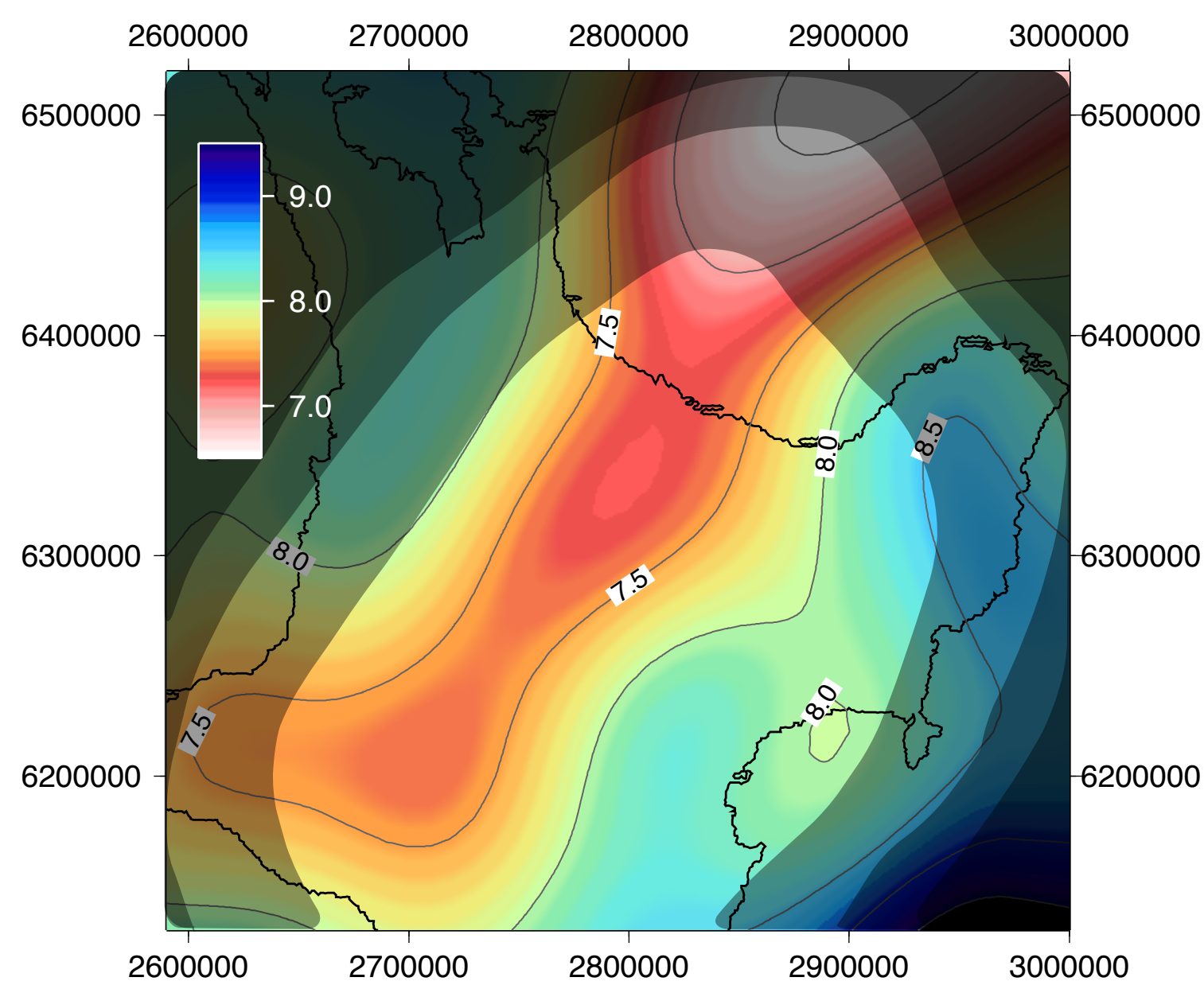

Figure 4.5 The Pn velocity estimated from our modelling algorithm, with an average Pn velocity of $8.0 \mathrm{~km} / \mathrm{s}$. Mantle correlation distance is $100 \mathrm{~km}$. Warmer (red) colours represent slower velocities and cooler (blue) colours represent higher velocities. Dark shading represents how well the region is resolved. The region with no shading is resolved to $\pm 0.1 \mathrm{~km} / \mathrm{s}$; first degree of shading represents \pm 0.2 $\mathrm{km} / \mathrm{s}$; second degree of shading represents $\pm 0.3 \mathrm{~km} / \mathrm{s}$; and the darkest shade represents uncertainties of greater than $\pm 0.4 \mathrm{~km} / \mathrm{s}$.

Volcanic Region

(3) The eastern North Island.

The western North Island is generally considered to be a region of slightly lower than normal mantle velocities (Haines 1979), high attenuation (Salmon et al. 2003), and a thin crust of $25 \mathrm{~km}$ (Stern and Davey 1987). The high velocities observed in the east are attributed to the subducted slab (Reyners et al. (2006); Haines (1979)). The observed low velocities are in the proximity of the active volcanic regions of the North Island, i.e. the CVR and Mt Taranaki to the west, and are assumed to be indicative of high 
heat and melt content (Hammond and Humphreys 2000). Mt Taranaki is chemically distinct from the volcanoes within the CVR. It is a high-K andesite volcano, whereas the CVR volcanoes are low-K andesite volcanoes. The results (fig 4.5) show what appears to be a continuous low-velocity region within the upper mantle between the two active volcanic systems.

To test the resolution of this feature a synthetic model (fig 4.6) was created based on the observed results, with a distinct low velocity beneath Mt Taranaki $(7.5 \mathrm{~km} / \mathrm{s})$, a continuous low-velocity region beneath the CVR $(7.4 \mathrm{~km} / \mathrm{s})$, and high velocities along the east coast $(8.5 \mathrm{~km} / \mathrm{s})$. The synthetic data were then run through the modelling algorithm with the ray density, correlation distance, error allowances, anisotropic properties and crustal term allowances used to produce figure 4.5. The results obtained from the synthetic input are very similar to results obtained from the real data. The continuous low velocity between the CVR and Taranaki persists indicating that our model can not determine whether the CVR and Taranaki are part of the same upper mantle anomaly or are distinct. As the chemistry indicates unique volcanic systems, they will be discussed separately.

Therefore the North Island is split into four distinct regions (fig 4.7).

(1) The western North Island

(2) The Taranaki Volcanic Region

(3) The Central Volcanic Region

(4) The eastern North Island.

\section{(1) The western North Island}

Christensen and Mooney (1995) define a normal uppermost mantle velocity as being between 8.0 and $8.2 \pm 0.2 \mathrm{~km} / \mathrm{s}$, with a global average of $8.09 \mathrm{~km} / \mathrm{s}$. Velocities of between $7.9 \pm 0.1$ and $8.2 \pm 0.2 \mathrm{~km} / \mathrm{s}$ are seen west of the CVR, from north of the Taranaki volcanic region. These velocities are indicative of low-to-normal mantle 

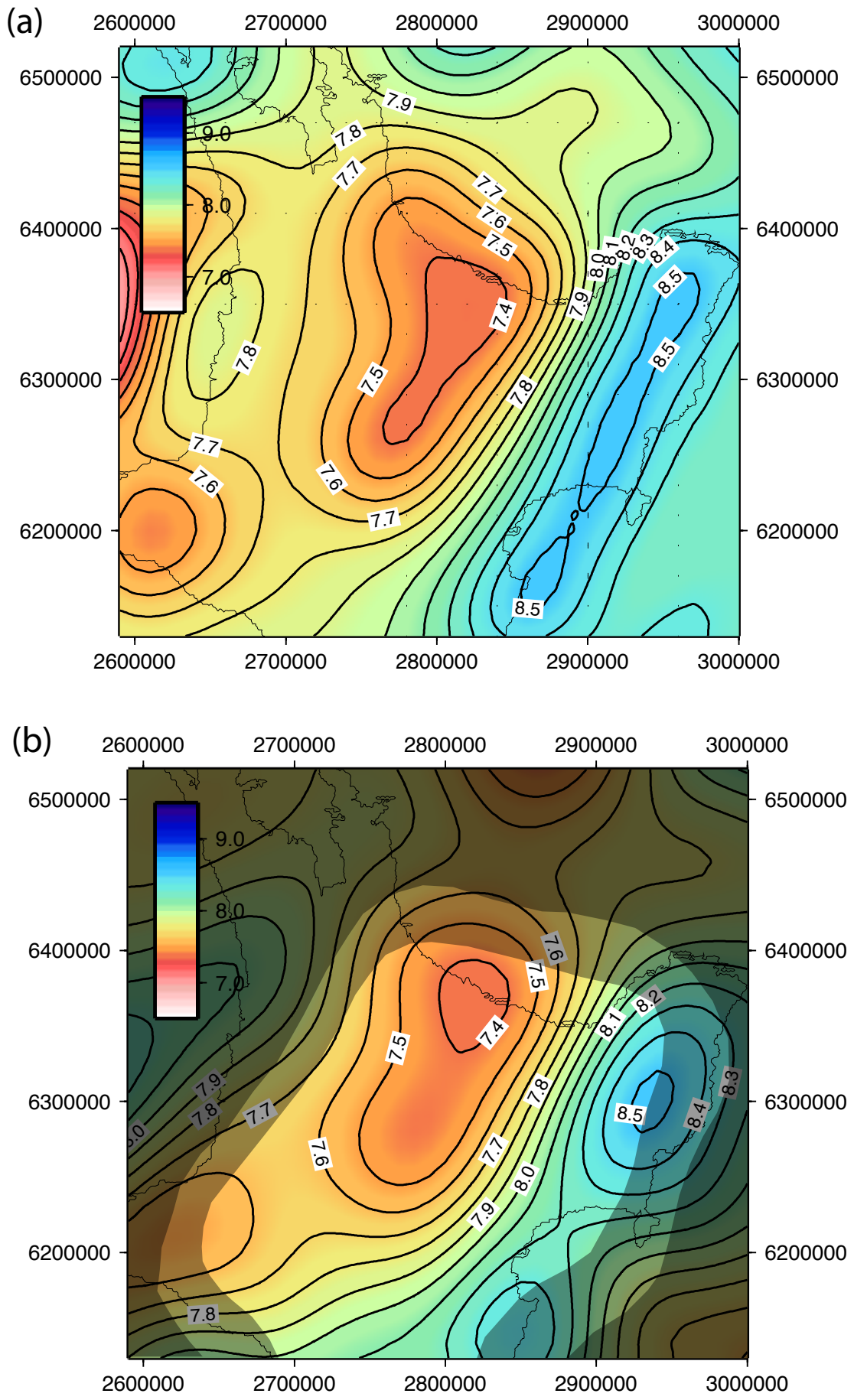

Figure 4.6 (a) Synthetic model of upper mantle velocities structure beneath the North Island, based on interpretation of upper mantle model. (b) shows the results when the synthetic is run through the modelling algorithm. Note that the low velocity beneath the CVR and Taranaki again appears joined. The region with no shading is resolved to $\pm 0.1 \mathrm{~km} / \mathrm{s}$; first degree of shading represents \pm 0.2 $\mathrm{km} / \mathrm{s}$; second degree of shading represents $\pm 0.3 \mathrm{~km} / \mathrm{s}$; and the darkest shade represents uncertainties of greater than $\pm 0.4 \mathrm{~km} / \mathrm{s}$. 


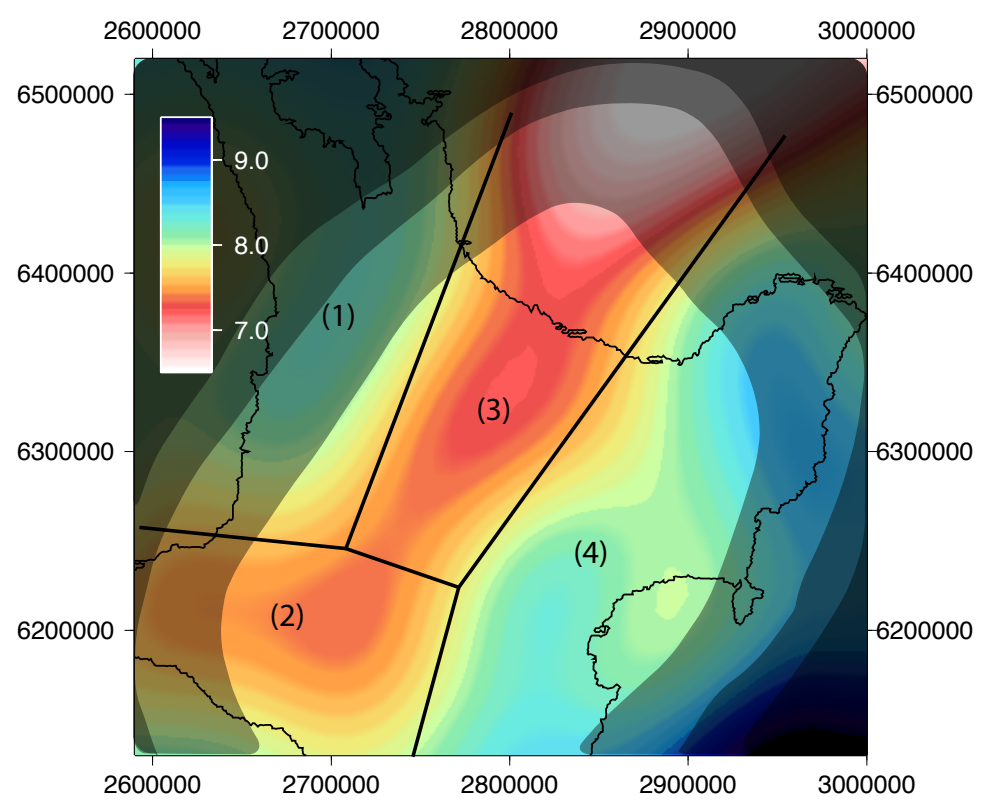

Figure 4.7 The resultant velocity model from our modelling algorithm (fig 4.5), with an average Pn velocity of $8.0 \mathrm{~km} / \mathrm{s}$. The North Island can be split into four distinct regions based on mantle Pn velocity: (1) the northwestern North Island, (2) the Taranaki Volcanic Region, (3) the central volcanic Region, and (4) the eastern North Island. Warmer (red) colours represent slower velocities and cooler (blue) colours represent higher velocities. Dark shading represents how well the region is resolved. The region with no shading is resolved to $\pm 0.1 \mathrm{~km} / \mathrm{s}$; first degree of shading represents $\pm 0.2 \mathrm{~km} / \mathrm{s}$; second degree of shading represents $\pm 0.3 \mathrm{~km} / \mathrm{s}$; and the darkest shade represents uncertainties of greater than $\pm 0.4 \mathrm{~km} / \mathrm{s}$.

velocities.

\section{(2) The Taranaki Volcanic Region}

Around Mt Taranaki (formerly Mt Egmont), Haines (1979) found a Pn-velocity of 7.8 $\mathrm{km} / \mathrm{s}$, consistent with a slightly lower than normal mantle velocity. We detect velocities of $\leq 7.5 \pm 0.1 \mathrm{~km} / \mathrm{s}$. Sherburn et al. ((2005); (2006)) report a low velocity, $7.2 \mathrm{~km} / \mathrm{s}$, at a depth of $35 \mathrm{~km}$ from both their 1D and 3D velocity tomography studies of $\mathrm{Mt}$ Taranaki. Reyners et al. (2006), also found a region of lower velocities in the Taranaki region surrounded by velocities of $8.0 \mathrm{~km}$ at depths between $35-50 \mathrm{~km}$.

The boundary between the Taranaki low velocity region and the region to the north roughly coincides with a line between Mt Taranaki and Mt Ruapehu, the Taranaki- 
Ruapehu Line (TRL). The TRL was initially identified as a broad zone of seismicity, which marks the juxtaposition of thin crust $(25 \mathrm{~km})$ to the north against an average crustal thickness of $32-36 \mathrm{~km}$ to the south (Stern and Davey 1987). More recently, Salmon (2007) measured a change in not only crustal thickness across this line, but also distinct variations in both seismic attenuation and mantle resistivity, suggesting that the boundary extends into the upper mantle. We note a distinct variation in upper mantle Pn velocity in this region. However, the modelling parameters do not allow determination of the exact position, but suggest that the change in velocity is also related to the other changes seen across this line.

\section{(3) The Central North Island (CVR)}

The Central Volcanic Region has extreme low measured upper mantle velocity, $\leq 7.5$ $\pm 0.1 \mathrm{~km} / \mathrm{s}$, bordered by rapid changes (over $50 \mathrm{~km}$ ) to velocities of $8.0 \mathrm{~km} / \mathrm{s}$ to both the east and the west. Velocities this low were also detected by Haines (1979). Similar low velocities have been detected by regional seismic refraction surveys (NIGHT (Henrys et al. 2003); and MorC (Benson et al. 2006)), causing debate over whether these velocities are indeed mantle ((Stratford and Stern 2004); (2006)) or anomalously high velocity crust (Harrison and White 2006). Our Pn results agree with the interpretation of this region having anomalously low velocity upper mantle. For a ray travelling from east to west beneath the CVR, it must travel at greater than Moho depths to reach the westernmost stations (see chapter 6 for more discussion on the depth of the observed low velocity zone). Therefore, the region with velocity $\leq 7.5 \mathrm{~km} / \mathrm{s}$ must be mantle material as the ray paths must extend to depths greater than Moho for all travel paths traversing the CVR.

The velocities seen beneath the CVR are on average $10 \%$ lower that those expected for a normal mantle. Low Pn velocities are associated with mantle material near its solidus temperature (Montagner 1994). Such low velocities are often associated with regions of high heat flow around the globe, such as mantle upwelling (Keller et al. 
(1994); Pei et al. (2006); Xu et al. (2007); Appendix B) or hotspots (Bjornsson et al. 2005). Velocities much lower than $7.8 \mathrm{~km} / \mathrm{s}$ may even require a small amount of partial melt (Hearn 1999). Laboratory studies by Hammond and Humphrey (2000) suggest that $2 \%$ melt inclusions can produce a decrease in Pn velocities of $10 \%$. The presence of melt beneath the CVR would also explain the high attenuation seen primarily in S-waves travelling through this region (Salmon et al. 2006), and why Sn picks have large errors, if an arrival time can be measured at all.

Another explanation for low velocity is the presence of water (Tatsumi and Eggins (1995); Ulmer (2001); Kelley et al. (2006)) in the upper mantle generated from the subducted oceanic lithosphere. Dehydration of subducting slab is responsible for volcanism and therefore must cause a significant amount of water to infiltrate the mantle wedge (Peacock (1990); Arcay et al. (2006)). This water would be manifested in the form of $\mathrm{OH}$ bounded in the minerals of the mantle wedge (e.g. Karato (2003)).

\section{(4) The eastern North Island}

Below the eastern North Island, Pn velocities are greater than $8.1 \pm 0.1 \mathrm{~km} / \mathrm{s}$ reaching localised maxima of greater than $8.5 \pm 0.2 \mathrm{~km} / \mathrm{s}$. These high velocities can be attributed to the subducted oceanic plate. Subducting slabs are generally found to be considerably denser than the overriding plate, and therefore will have a high $\mathrm{P}$-wave velocity. Haines (1979) detected Pn velocities between $8.1 \mathrm{~km} / \mathrm{s}$ and $8.5 \mathrm{~km} / \mathrm{s}$ in the east, which he also attributed to the subducted oceanic lithosphere of the Pacific Plate. Reyners et al. (2006) resolve a Vp in the slab of on average $8.4 \mathrm{~km} / \mathrm{s}$ with localised maximum of $9.0 \mathrm{~km} / \mathrm{s}$ through 3D tomography in this region.

Both Reyners et al. (2006) and Haines (1979) detect the lower velocities beneath the East Cape region (North), while their maxima are about and south of Hawke Bay. Our results (fig 4.7) show an average seismic velocity within the slab of $8.3 \pm 0.18 .5 \pm 0.2$ $\mathrm{km} / \mathrm{s}$, and a localised minimum of $8.0 \mathrm{~km} / \mathrm{s}$ below the Wairoa Basin, Hawke Bay. The Wairoa Basin is a large fore-arc basin, $250 \mathrm{~km}$ long and $80 \mathrm{~km}$ at its widest, filled with 
sedimentary rocks dating back to the Cainozoic (Walcott 1987), overlain by fine grained bentonitic clays, which is then overlain by more than $4 \mathrm{~km}$ of siltstones and mudstones from the Pliocene (Kingma 1965). This large accumulation of sediments results in a higher crustal delay term than those in the surrounding region. This relatively large time residual may not be resolvable in our modelling algorithm, and is in fact mapped as a slower mantle anomaly beneath the Wairoa Basin. The synthetic model (fig 4.6) with a continuous high seismic velocity $(8.5 \mathrm{~km} / \mathrm{s})$ slab located along the east coast, also shows a decrease in seismic velocity to $8.2 \mathrm{~km} / \mathrm{s}$ beneath the Wairoa Basin, indicating that this could also be an artefact of the assumed mantle wavelength.

\subsubsection{Crustal delay term estimates}

Station terms are estimated as consistent time errors beneath each station relative to all the other stations. The resulting relative delay times are shown in figure 4.8. Four different crust types coinciding with the mantle segregations can be seen. In the eastern North Island (section 3)we see later arrivals, whereas those in the western North Island (section 1) are seen to be relatively early, consistent with thicker crust in the east than in the west. From the crustal velocity profiles in fig 1.7, and assuming a critically refracted ray at the crust-mantle boundary, this difference should be approximately $1.4 \mathrm{~s}$. The model estimates are on average $1.3 \mathrm{~s}$ earlier in the west and in the east.

Table 4.3

\begin{tabular}{|l|c|c|}
\multicolumn{3}{c}{ Summary of crustal delay times } \\
\hline \hline Section & Region & Range of Delay Time (s) \\
\hline \hline$(1)$ & Northland & $-1.9 \longleftrightarrow-0.9$ \\
& western NI & $-1.0 \longleftrightarrow+0.4$ \\
& Taranaki & $-1.2 \longleftrightarrow-0.2$ \\
\hline$(2)$ & CVR & $-0.7 \longleftrightarrow+0.7$ \\
\hline$(3)$ & eastern NI & $+0.4 \longleftrightarrow+1.2$ \\
\hline$(4)$ & southern NI & $-0.2 \longleftrightarrow+0.4$ \\
\hline \hline
\end{tabular}

The station terms estimated for the CVR (section 2) show some variability, but are all small oscillations about the mean crustal time delay. This is not surprising with 


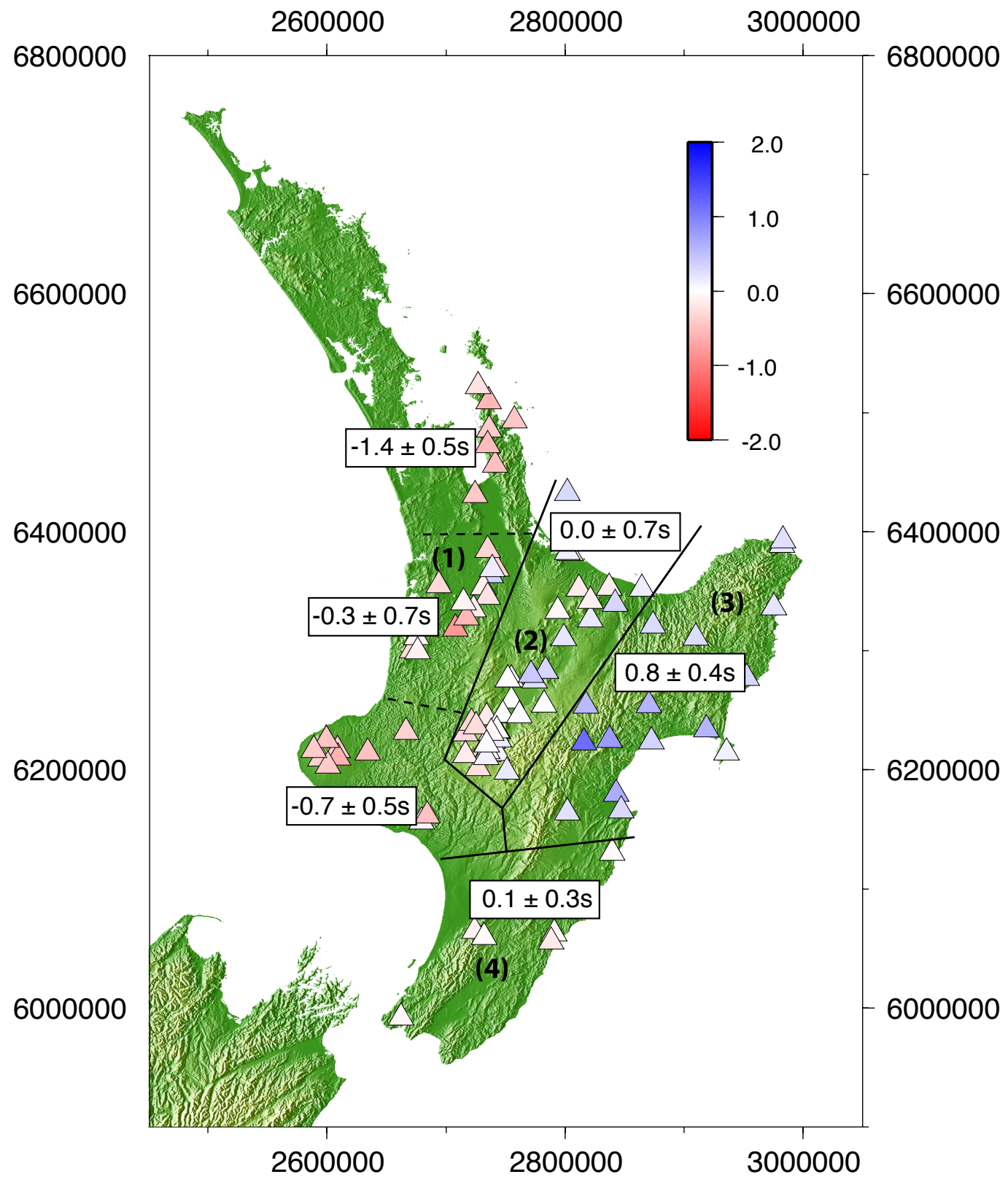

Figure 4.8 Station delay for Pn travel times. Warmer (reds) colours indicate less time spent in the crust, while blues indicate lower crustal travel times. Reds suggest faster or thinner crust than blues. Note stated numbers represent the range of delay magnitudes within a region. 


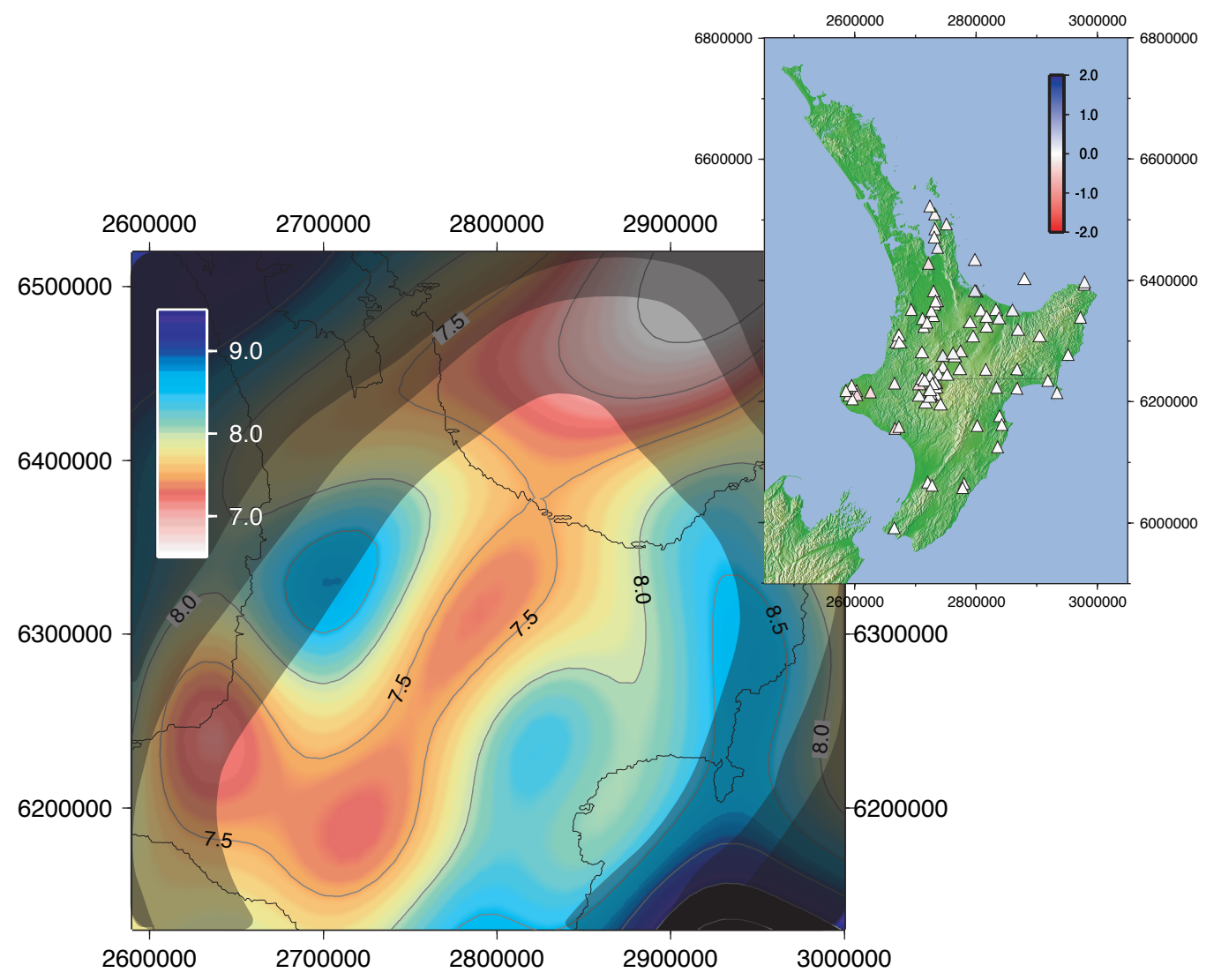

Figure 4.9 Testing the crust-mantle coupling within the modelling algorithm. The resulting model and station delay terms, when testing the crust-mantle interaction of the modelling algorithm. Station delay terms of - $0.7 \mathrm{~s}$ were assigned to those stations in the western North Island, allowing the algorithm to estimate the mantle velocities and the oscillation of station delay terms from the mean delay time. The resulting mantle model is similar to those observed when station terms have no tight constraints. This suggests that there is minimal interaction between the mantle and crustal systems.

the variability of the crust within this zone (e.g. geothermal fields, ash deposits, etc.) and the uncertainty in the measurements themselves.

Those crustal terms observed in the Taranaki region, in combination with the lower than previously observed mantle velocities, led to a closer investigation into the possibility of crust-mantle coupling in the modelling algorithm. The feed-back between the station delay terms and mantle velocities was tested by setting the station delays to fixed values estimated from the crustal profile (fig 1.7). It was then observed that the low mantle velocities were persistent (fig 4.9), suggesting that there is minimal 
interaction between the mantle and crustal parts of the modelling.

Those crustal delay values seen in the south of the North Island (section 4) are not well resolved, as this region is not primarily being modelled. This has resulted in the inversion smoothing the delays to approximately zero.

\subsection{Summary}

\subsubsection{Modelling Resolution}

Section 4.1.1 shows that the location of earthquakes and stations throughout the North Island provides a good coverage and density of ray-paths over most of the central regions. The resolution of the modelling algorithm was tested with a synthetic checker board input model. By using the ray-path coverage provided by the event - station distribution, the resolution of the checker board was good. Amplitudes of checker board anomalies were well resolved within the majority of the central North Island. Amplitudes and gradients were lost / smoothed towards the edge of the ray-path coverage where resolution started to fail.

\subsubsection{Modelling inputs}

The probabilistic bounds used as input in the modelling code are summarized in table (4.4).

Table 4.4

Input parameters for modelling the uppermost mantle beneath the North Island

\begin{tabular}{c}
\hline$V_{\text {range }}=7.1-9.0 \mathrm{~km} / \mathrm{s}$ \\
$S_{\text {range }}=0.111-0.141 \mathrm{~s} / \mathrm{km}$ \\
$\lambda_{\text {mantle }}=100 \mathrm{~km}$ \\
$\lambda_{\text {crust }}=10 \mathrm{~km}$ \\
$\delta t_{\text {crust }}=1.5 \mathrm{~s}$ \\
measurement error $u=0.1 \mathrm{~s}$ \\
\hline \hline
\end{tabular}




\subsubsection{Uncertainties}

Miscellaneous errors in the signal are estimated in terms of picking errors and timing errors due to the mislocation of the epicentres of events. The probabilistic bounds for the picking errors are based on observed differences between the catalogued arrival times and those that have been repicked. The maximum picking error is seen to be $0.12 \mathrm{~s}$, which is then set as the maximum bound for modelling.

The error in timing associated with the mislocation of an event epicentre, was estimated through two approaches, (1) the geometric approach and (2) the probabilistic approach. The resulting timing errors from both approaches were seen to not differ to much and the cut-off was set to $0.1 \mathrm{~s}$ for modelling.

\subsubsection{Modelling Results}

The North Island can be split into four distinct regions.

- The western North Island - velocities of $7.9 \pm 0.1-8.2 \pm 0.2 \mathrm{~km} / \mathrm{s}$

- The Taranaki Volcanic Region - velocities of $\leq 7.5 \pm 0.1 \mathrm{~km} / \mathrm{s}$

- The Central Volcanic Region - velocities of $7.4 \pm 0.1 \mathrm{~km} / \mathrm{s}$ with regions of $\leq 7.3$ $\mathrm{km} / \mathrm{s}$

- The eastern North Island - velocity of $8.1 \pm 0.1-8.5 \pm 0.2 \mathrm{~km} / \mathrm{s}$

Station delay term, indicate similar sectioning of the crust can be made. 
CHAPTER 5

\section{UPPER MANTLE ANISOTROPY}

Pn travel times are affected not only by lateral variations in crust and mantle velocities, but also by anisotropy within the material through which the wave travels. Anisotropy is the property of being directionally dependent, as opposed to isotropy, where properties are the same in all directions (Stein and Wysession 2003). Seismic waves in an anisotropic medium will travel at different velocities depending on their propagation direction and/or their polarisation.

Anisotropy was first utilised in tectonic studies by Hess (1964) and Raitt et al. (1969); (1971). These early studies showed that the anisotropic fast axis within the oceanic lithosphere lies parallel to the spreading direction. Since then, many studies have used seismic anisotropy to examine regional tectonics beneath both the oceans and continents (e.g. Bamford et al. (1979); Savage and Silver (1993); Savage (1999); Silver (1996); Montagner and Tanimoto (1991)and references therein).

It is important to note that if the upper mantle velocity structure is modelled without the effects of anisotropy, anisotropic anomalies could be mapped as artificial isotropic velocity perturbations. In this chapter, Pn anisotropy is estimated and modelled for the uppermost mantle beneath the central North Island. These results are compared to anisotropy measurements obtained from the splitting of S-waves across the central North Island (Greve and Savage (2007); Audoine et al. (2004); Morley et al. (2006)). 


\subsection{Causes of Anisotropy}

Seismic anisotropy indicates an ordered medium, thought to be the a direct indicator of past deformation due to stress and strain leaving a signature on the deformed material (Savage (1999); Ribe (1992)). In the mantle, deformation can cause lattice-preferred orientation of single crystals in material (Mainprice and Silver (1993); Mainprice et al. (2000); Nicolas and Christensen (1987)). The alignment of minerals is the main source of anisotropy in the lower crust and the mantle of the earth. Within the upper crust, anisotropy is more likely to be caused by layered material (Backus 1962) or aligned cracks (Kendall 1994) and inclusions of material within a medium (Karki et al. (2001); Crampin (1994); Crampin (1984)). Each of the above situations will cause a seismic wave to travel faster in one direction than another.

The link between upper mantle anisotropy and mantle tectonics is predominantly thought to be the preferred alignment of olivine crystals due to creep (Ribe 1992). Most minerals are naturally anisotropic; however combining several minerals into a rock creates a generally isotropic medium, unless deformed. Olivine is the most dominant mineral in the upper mantle, and is highly susceptible to anisotropy (e.g. Verma (1960)). In numerous investigations, the relationship between deformation and the lattice-preffered orientation of olivine crystals has been studied (e.g. Hess (1964); Gueguen and Poirier (1980); Kern (1993); Mainprice and Nicolas (1989); Ismail and Mainprice (1998)). It is thought that during deformation (under finite strain) the fast axes of olivine aligns with the longest axes of the strain ellipsoid (Ribe 1992), leading to lattice-preferred orientation (LPO). This will then result in waves travelling faster along the axes of maximum strain, than waves travelling in any other direction.

The main cause for anisotropy in the crust is the presence and formation of cracks and inclusions due to stress (Kendall 1994). Inclusions and cracks align perpendicular to minimum compressive stress orientation, as those perpendicular to maximum compressive stress close (Crampin 1994) (fig 5.1). Fast polarisation is parallel to the cracks and therefore parallel to maximum compressive stress ((Crampin 1984); (1994)). 


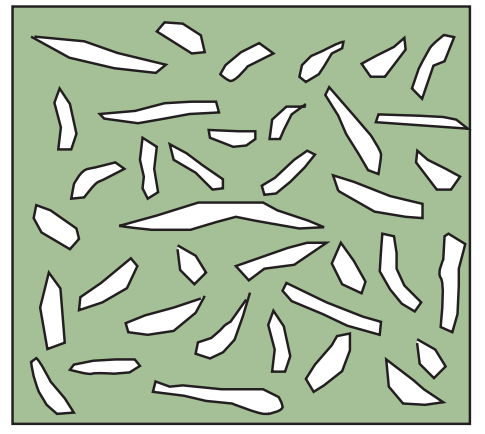

Unstressed material

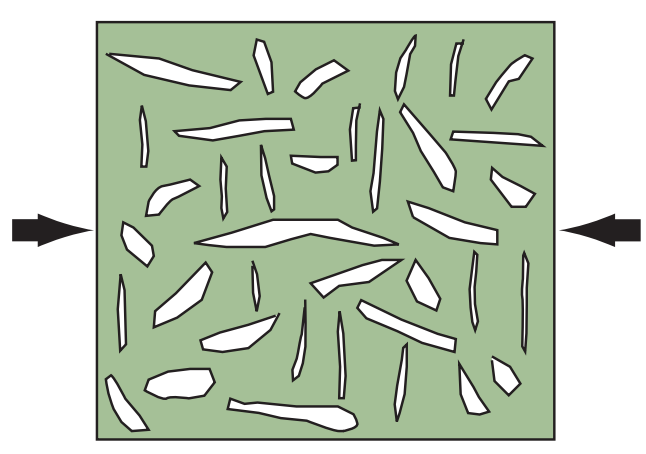

Stressed material

Figure 5.1 In an isotropic material, cracks and inclusions are generally randomly orientated. However when that material under goes stress, the cracks roughly aligned with the maximum stress close, while those parallel remain open.

The anisotropy strength depends on the velocity contrast between the cracks and the main medium.

\subsection{Measuring Seismic Anisotropy}

\subsubsection{Shear wave splitting method}

When an $\mathrm{S}$ wave enters in an anisotropic medium, it is split into two distinct waves: a fast wave (S1), polarised in the fast direction which depends both on the medium and the direction of propagation, and a slow wave (S2), polarised perpendicular to S1 (fig 5.2). The shear wave splitting can be characterised by the two parameters $\delta t$, the delay time between the S1 and $\mathrm{S} 2$, and $\phi$, the direction of polarisation of the fast component. The parameters $\phi$ and $\delta t$ can be related, respectively, to the direction of main stress (or strain) of the anisotropic medium and to the length of the anisotropic path as well as to the strength of anisotropy.

Measurements of upper mantle anisotropy from SKS splitting have been published for regions all around the globe where 3-component seismograms are deployed (e.g. Silver (1996); Savage (1999), and references therein).

To study mantle anisotropy, core-refracted phases such as SKS, SKKS or PKS are 


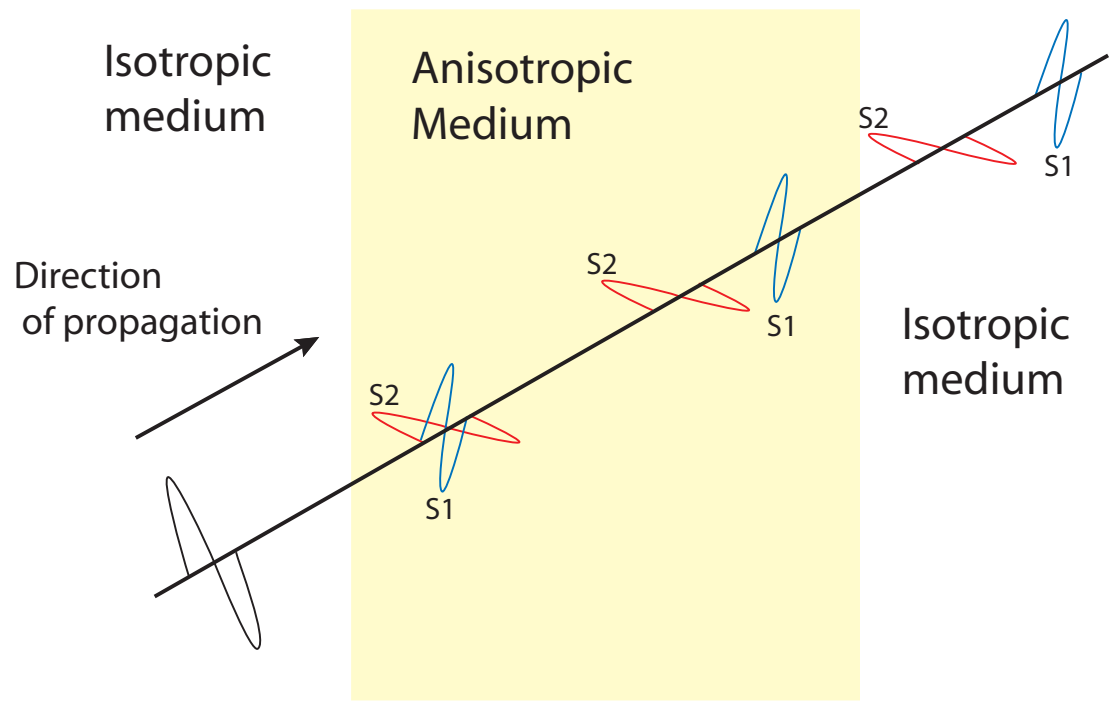

Figure 5.2 An initially polarized shear wave splits into a fast and slow wave as it propagates through an anisotropic medium.

usually used. Their steep incident angle provide good lateral resolution, but not good depth resolution. They respond to anisotropic media anywhere between the outer core and the recording station. Additional information is needed to constrain the exact location of the anisotropy.

\subsubsection{Estimating Pn anisotropy}

Observation of Pn anisotropy is becoming a more common practice in Pn tomography studies around the World, e.g Smith and Ekström (1999); Hearn and Ni (1994), Hearn (1996), Hearn (1999); Pei et al. (2007);

With P-waves, ansiotropy is evident by different speeds depending on the propagation direction of the wave, with the fastest direction aligned with the axis of maximum extension in the mantle (Ribe 1992).

Pn anisotropy is generally measured as a percentage difference between maximum and minimum observed P-velocity (Ribe 1992), dependent on the azimuth of the ar- 
riving wave.

$$
\left|A_{P n}\right|=\frac{\left(V_{\max }-V_{\min }\right)}{V_{a v}}
$$

where $V_{\max }$ and $V_{\min }$ are the maximum and minimum seismic velocities, respectively, and $V_{a v}$ is the average seismic velocity over the region.

In order to determine the azimuthal dependence of the anisotropic medium, a slightly more complex calculation is needed, based on the perturbation theory (Smith and Ekström 1999). The angular dependence of the P-wave velocity has been shown to exhibit a $2 \theta$ variation (Hearn 1996) (fig 2.2), and the effect on slowness $S(\theta)$ can be estimated through

$$
S(\theta)=S_{o}+A \cos (2 \theta)+B \sin (2 \theta)
$$

where $S_{o}$ is the average slowness of the region, and $A$ and $B$ are spatially correlated variables with covariances calculated through path integrals between stations and earthquakes, and $\theta$ is the back azimuth. The magnitude of anisotropy can be calculated by:

$$
A_{P n}=\frac{\sqrt{A^{2}+B^{2}}}{S_{o}}
$$

And the direction of fastest / or slowest propagation is given by:

$$
\phi=\frac{1}{2} \arctan \frac{B}{A}
$$

\subsubsection{Pn vs SKS Anisotropy}

Lab experiments by Christensen (1966) show that for an olivine rich rock, maximum S-wave anisotropy of $8.11 \%$ and a maximum P-wave anisotropy of $8.5 \%$ are detected.

SKS propagates at near vertical incidence, while Pn propagates subhorizontally. 
Studies of velocities of waves propagating through olivine as a function of direction show that for transverse anisotropy the SKS fast direction is the same as the direction of fastest P wave propagation (Christensen 1984). Hence SKS anisotropy orientation can be compared to that of Pn. However, unlike Pn data, which measures the anisotropy within the uppermost layer of the mantle, SKS data measures the vertically integrated anisotropy throughout the mantle.

By combining observations of S-wave and P-wave anisotropies, information about the location of the anisotropic medium can be deduced.

\subsubsection{Estimating station term Anisotropy}

The focus of this project is primarily the uppermost mantle beneath the North Island. However, using $\mathrm{P}$-wave arrival times requires the effect of crustal inhomogenieties to be taken into account. The anisotropy of the crust, i.e. aligned cracks or inclusions, cannot directly be determined; however the effect of directionally dependent fast ray propagation can. Figure 2.3 illustrates that rays travelling to a station through the crust could travel through a region of faster crustal material (fig $\mathbf{2 . 3 a}$ ) or a region of thinner crust (fig $\mathbf{2 . 3 b}$ ).

The effect of a sloping Moho boundary and first order crustal inhomogeniety beneath each station is approximated with a station term anisotropy, and is modelled as an azimuthally dependent signal term (EQ 5.5). The crustal anisotropy due to aligned cracks and inclusions, will be dependent on $2 \theta$, the effect of which is included in the estimation of station term anisotropy $(C(\theta))$, but can not be independently solved for.

$$
C(\theta)=\alpha \sin \theta+\beta \cos \theta+\gamma
$$

where $\theta$ is a column vector of the azimuth with which the ray approaches the station, $\alpha$ and $\beta$ are parameters dependent on the time at various azimuths and $\gamma$ is the average time delay beneath an individual station. $\alpha, \beta$, and $\gamma$ are correlated through a covariance function and then differenced for each ray at each station (see appendix $F$ ). 


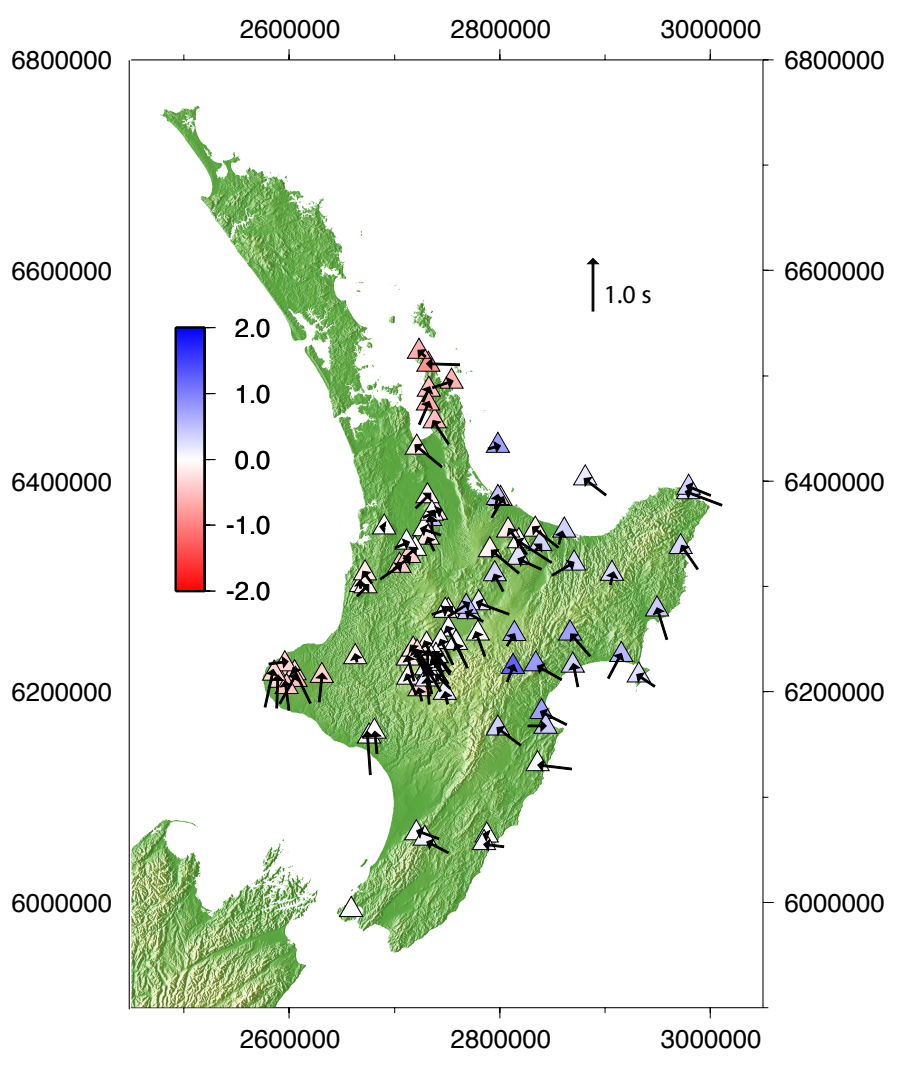

Figure 5.3 Estimations of crustal inhomogeneities, arrows indicate direction of fastest approach.

The resulting estimates of crustal inhomogeneities, which includes the effect of crustal anisotropy are shown in figure $\mathbf{5 . 3}$ (and table F.1; Appendix F). There does not appear to be a consistent fast direction over the Island, although the CVR does seem to show a fairly consistent north-west fast direction. It is important to note that most of the stations do not receive rays from a wide variety of azimuths, the majority arriving from the south or east. There are a few originating in the Bay of Plenty to the North, but none arriving from the west or northwestern regions. The incomplete range of arrival azimuths may result in biasing the direction of fastest arrivals. 


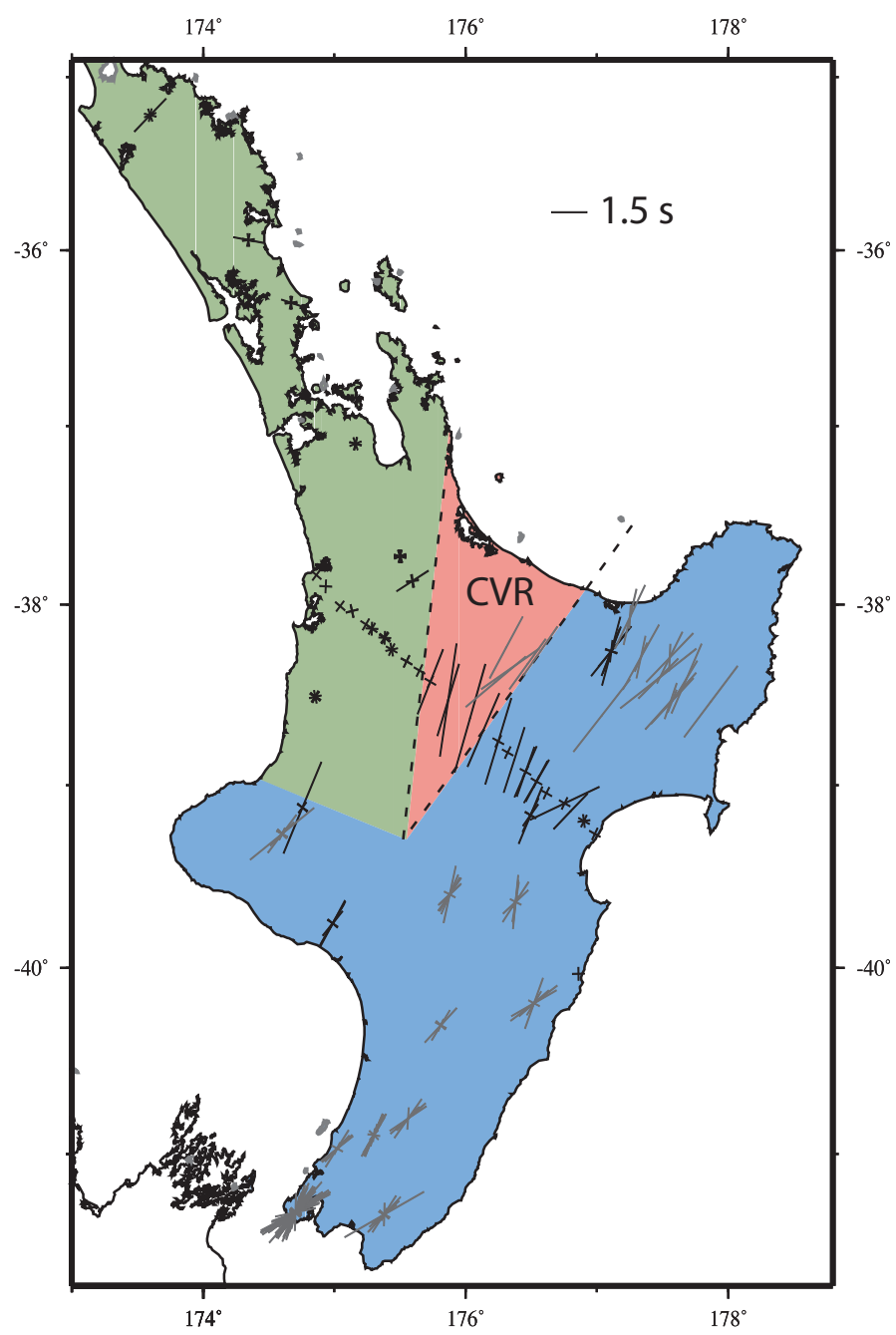

Figure 5.4 Observed SKS splitting measurements beneath the North Island, from Greve and Savage, 2006. Blue region represents regions of 2-3 s delay times, Pink represents high delay region of up to $4.5 \mathrm{~s}$, and the green region represents the area where no apparent anisotropy is seen.

\subsection{Anisotropy beneath the North Island}

\subsubsection{Anisotropy estimates from SKS splitting beneath the North Island}

Recent studies by Greve (2008), Morley et al. (2006), and Audoine et al. (2004) show strong lateral anisotropic changes across the central North Island, identified by shearwave splitting measurements. The observations divide the central North Island into three distinct anisotropic regions (fig 5.4). 
(1) The forearc region of the subduction zone in the east, with shear-wave splitting times between 2-3 s for teleseismic rays (?), resulting in a trench parallel fast polarisation. From local shear-waves (Morley et al. 2006) splitting delay times of $0.3 \mathrm{~s}$ are observed in this region.

(2) The back-arc spreading region of the Central Volcanic Region, with anomalously high delay times of up to $4.5 \mathrm{~s}$ for teleseismic rays (?), with trench parallel fast polarisation. From local shear-waves, trench-normal fast directions are observed (Morley et al. 2006) with an average delay of $0.35 \mathrm{~s}$.

(3) The western North Island (far back-arc region of the subduction zone system), where no apparent anisotropy is measured (?).

These regions of observed differences in anisotropy correlate well with changes in attenuation (Salmon et al. 2005), velocity (Haines 1979), gravity and heat flow (Stern et al. 2006). These changes are attributed mainly to the influence of the hot, melt and volatile-rich mantle wedge under the CVR and small-scale convection processes or vertical flow under the western North Island. The western boundary of the CVR marks a change between high anisotropy in the mantle wedge to apparent isotropy under western North Island (?). Trench-parallel subslab mantle flow contributes about 2-3 s of delay time, observed in the forearc region and the CVR.

\subsubsection{Pn anisotropy results}

Our modelling algorithm estimates a Pn anisotropy percentage over the North Island and plotted every $50 \mathrm{~km}$ (see chapter 2). The results (fig 5.5) show a fairly consistent trench parallel fast direction over the majority of the eastern and central North Island. The exception is the western region, where apparent nulls or insignificant anisotropy are observed. These results are in general agreement with SKS splitting direction observed by ?. The magnitude of anisotropy differs in the various regions. The maximum anisotropy detected is $9.8 \%$ in the forearc region. However we find that the magnitude of anisotropy is dependent on the range of accepted input values. 
The maximum anisotropy bound was set to $10 \%$ in the results shown in figure $\mathbf{5 . 5}$, based on the observation of anisotropy for P- and S- waves to be similar for Olivine (Christensen 1966), and a maximum of $10 \%$ observed by Audoine et al. (2004) for Swave anisotropy in the North Island. It is important to note that the maximum bound is not a rigid constraint, but rather a probabilistic one. This means that if there is sufficient evidence in the data to show that there is an anisotropy of $15 \%$, the software would allow an anisotropy of $15 \%$.

It is interesting to note that if the maximum mantle anisotropy is restricted to $5 \%$, the direction of ansiotropy remains consistent, but resolves the maximum anisotropy to $5.1 \%$. If we allow the maximum anisotropy to be $20 \%$ the model resolves its maximum anisotropy to be $19 \%$, with its direction remaining consistent. This suggests that the model is unable to constrain the magnitude of the anisotropy very well, however, the ray-path coverage is sufficient to resolve the direction of fast orientation.

\subsection{Resolution of estimated Pn anisotropy}

There will always be a trade off between Pn velocity anomalies and anisotropic effects when modelling the uppermost mantle. Figure $\mathbf{5 . 6}$ shows the resolution / tradeoff between a known anisotropic structure (fig 5.6 left column) and upper mantle velocities. It can be seen that with the resolution available from the ray-path coverage, the majority of both the amplitude and direction of anisotropy is resolved. Small perturbations are caused in the upper mantle velocity structure (fig $\mathbf{5 . 6}$ right column), resulting in a maximum of $0.1 \mathrm{~km} / \mathrm{s}$ velocity variation over the regions of good resolution. The direction and magnitude of anisotropy are mostly consistent within the region of good resolution, but the direction does tend to turn at the limits of resolution (fig $\mathbf{5 . 6}$ shaded region) 


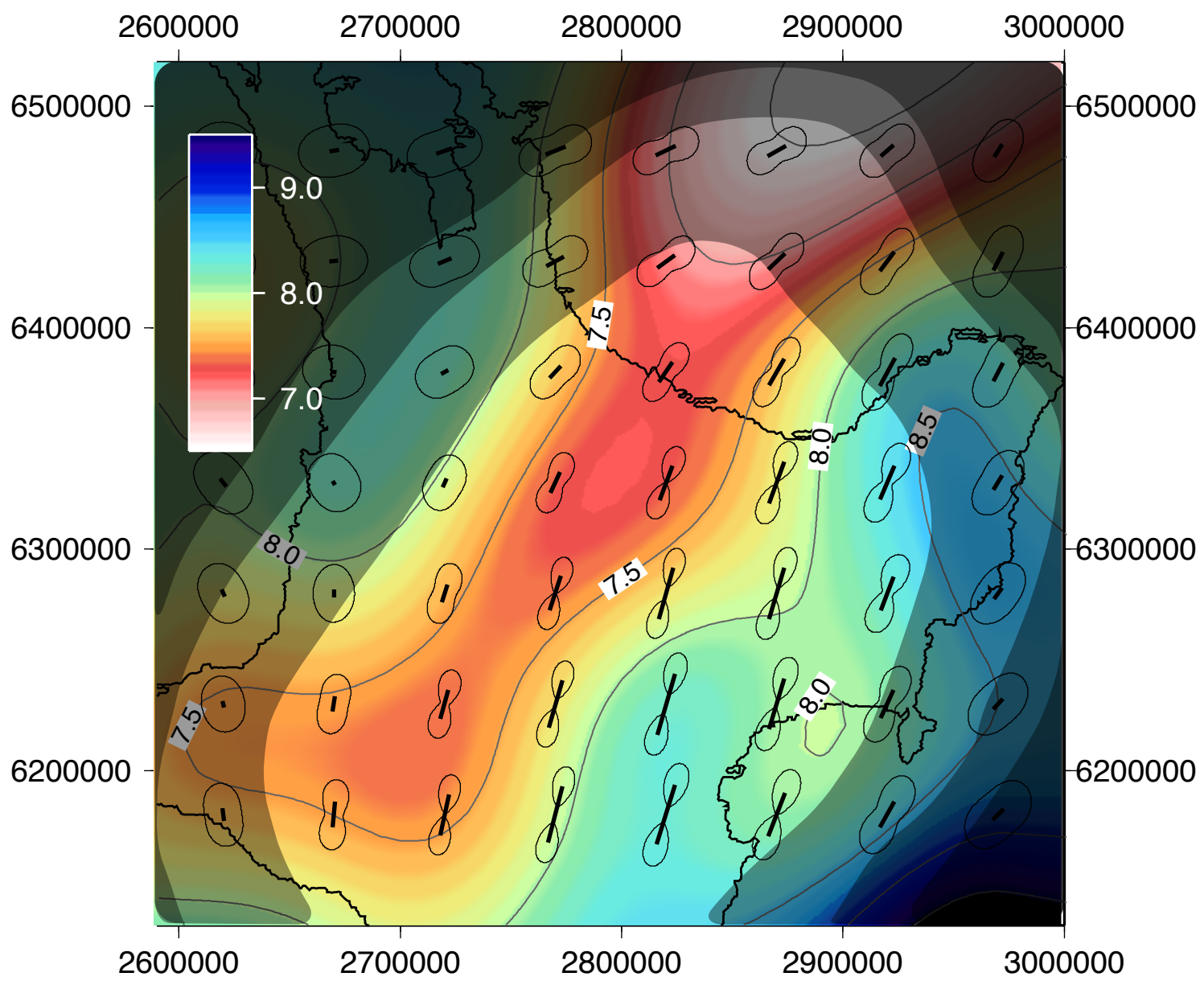

Figure 5.5 Pn anisotropy beneath the Central North Island, based on a maximum allowed anisotropy of $10 \%$, and a maximum velocity variation between $7.1-9.0 \mathrm{~km} / \mathrm{s}$. The Pn anisotropy shows relative anisotropy though the values are not constrained. The region with no shading is resolved to \pm 0.1 $\mathrm{km} / \mathrm{s}$; first degree of shading represents $\pm 0.2 \mathrm{~km} / \mathrm{s}$; second degree of shading represents $\pm 0.3 \mathrm{~km} / \mathrm{s}$; and the darkest shade represents uncertainties of greater than $\pm 0.4 \mathrm{~km} / \mathrm{s}$.

\subsubsection{The Western North Island}

The observations of null measurements in the west presents an interesting puzzle. Results of Pn velocities indicate that this is a region of relatively low shear modulus, compared to the global average (Christensen and Mooney 1995), suggesting that the region is susceptible to strain deformation. Reconstruction of New Zealand tectonic deformation (King 2000) (fig 1.4), shows that the western North Island underwent 50-100 km of shortening during the Miocene. If anisotropy is a direct indicator of past deformation history (Ribe 1992), then why do we not detect any in this region? 

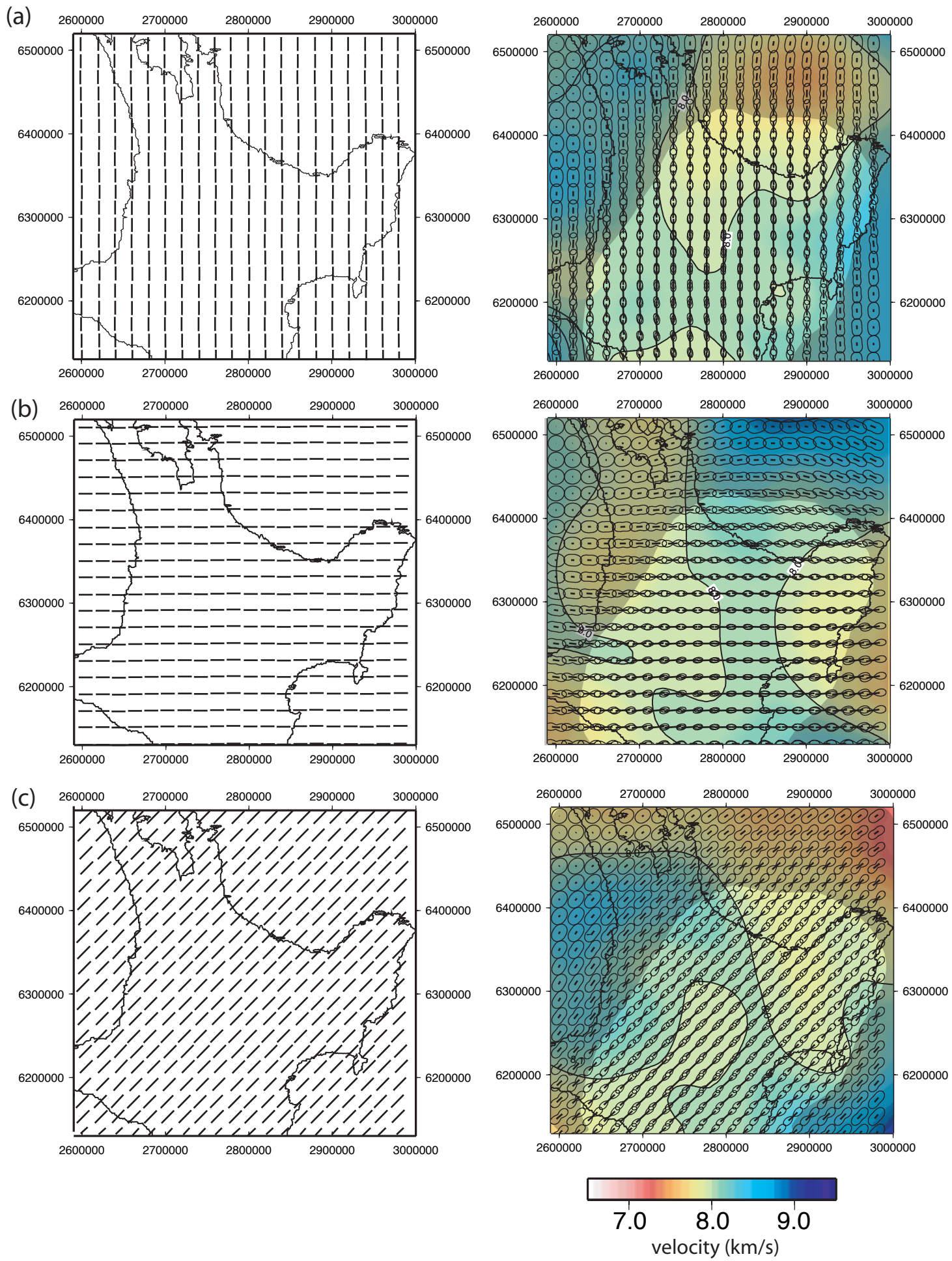

Figure 5.6 Resolution of Pn anisotropy observations. Left column input synthetic anisotropy fast direction, magnitude 10\%, Right column resolution of modelling algorithm MAR for strong anisotropy. (a) synthetic $N-S$ fast direction anisotropy. (b) synthetic $E-W$ fast direction anisotropy (c) synthetic NE-SW fast direction anisotropy (trench parallel for the North Island). Regions of velocities varying from $8.0 \mathrm{~km} / \mathrm{s}$, indicate regions of velocity / anisotropy tradeoff. Note they are mostly in regions of less resolution, based on ray coverage. In regions of good resolution, anisotropy is resolved well in both magnitude and direction. Shading shows the limit of good resolution. 


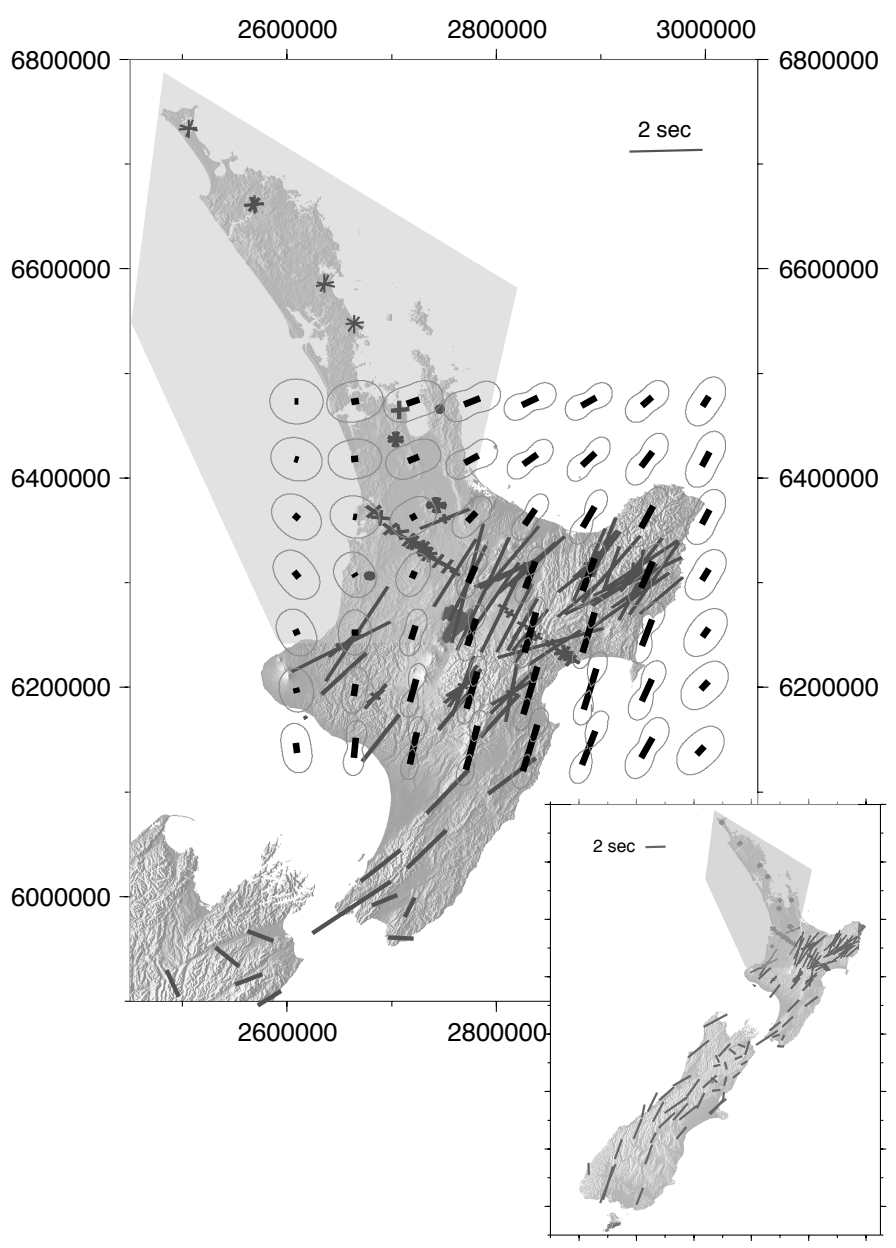

Figure 5.7 Summary of anisotropy beneath the North Island, from SKS splitting measurements (?; Morley et al. (2006); Audoine et al. (2000); Duclos (2005)) and Pn anisotropy estimates (modelled here). Shaded region represents the region where no significant anisotropy is measured (wester North Island). insert Summary of anisotropy beneath New Zealand. 
One possible explanation proposed by Reyners et al. (2006) is the presence of a well-developed return flow within the mantle wedge. This would result in a vertical anisotropy, which would not be detected with SKS splitting. However, Pn observations would detect a horizontal flow along the lid. Our results do not find any significant anisotropy in this region.

Another explanation is proposed by Stern et al. (2006), and discussed in more detail in section 7.3 .

\subsection{Summary}

The Modelling Algorithm (MAR) has difficulty determining the magnitude of Pn anisotropy which is strongly dependent on the maximum that is set. The ratio of anisotropy magnitudes across the island remain consistent, despite maximum input allowance. The direction in which the rays travel fastest is consistent and in agreement with previously observed anisotropy in the region. The crustal anisotropy cannot be separated from the effects of variations in Moho depth and slope.

Observations of Pn anisotropy across the North Island are in general agreement with previous anisotropy studies (fig 5.7), primarily showing trench parallel fast direction over the eastern and central regions, and isotropic uppermantle beneath the western North Island. These observations suggest that:

(1) The subducting slab, in the east, consists of anisotropic material, which has stronger anisotropy than other material beneath the North Island in the uppermost mantle;

(2) the majority of anisotropy detected by SKS splitting measurements is beneath the depth of penetration of Pn anisotropy measurements, but consistent in direction, suggesting the detected anisotropy is due to mantle flow within the wedge;

(3) Null measurements in the west suggest the presence of a new mantle with no remanent strain history. 
CHAPTER 6

\section{DEPTH MODELLING}

\subsection{Central Low Velocity Zone}

The Central Volcanic Region has the lowest measured Pn velocity, $\leq 7.4 \pm 0.1 \mathrm{~km} / \mathrm{s}$, seen around the world. Other back-arc regions generally have mantle velocities between $7.5 \mathrm{~km} / \mathrm{s}$ and $7.8 \mathrm{~km} / \mathrm{s}$ (e.g Iwasaki (1990), Ribe (1989)). The region of $7.3-7.5 \mathrm{~km} / \mathrm{s}$ beneath the central North Island has sparked debate over whether this material is of crustal (Harrison and White 2006) or mantle origin (Stratford and Stern 2004).

Harrison and White (2006) argue that below the upper crust, there is a layer of heavily intruded or underplated mafic lower crust with velocities of $6.9-7.3 \mathrm{~km} / \mathrm{s}$, to a depth of $30 \mathrm{~km}$. This is underlain by the mantle wedge consisting of velocities from $7.4-7.8 \mathrm{~km} / \mathrm{s}$ to a depth of $100 \mathrm{~km}$.

If there is a crust beneath the CVR at a depth of $30 \mathrm{~km}$, it would mean that the crust beneath the CVR is thicker than that of the western North Island, which is inconsistent with rifting and stretching of the back-arc region. Stratford and Stern $(2004,2006)$ argue that velocities of $7.3 \mathrm{~km} / \mathrm{s}$ in the lower crust is unreasonable in a area of high heat flow and volcanic activity, and that it is more likely to be perturbed upper mantle containing some partial melt.

This chapter discusses several different approaches to estimate the depth extent of apparent low velocity zone beneath the CVR. 


\subsection{Velocity-Depth gradient}

The velocity-depth gradient is estimated from local tomography studies of the North Island. Reyners et al. (2006) detected a change in velocity of $0.2 \mathrm{~km} / \mathrm{s}$ over a depth of $20 \mathrm{~km}$ in the central North Island, suggesting a gradient of $0.01 \mathrm{~km} / \mathrm{s} / \mathrm{km}$. Stratford and Stern (2004) showed a change in velocity of $0.1 \mathrm{~km} / \mathrm{s}$ at a depth of $15 \mathrm{~km}$ beneath the Central Volcanic Region, indicating a gradient of approximately $0.006 \mathrm{~km} / \mathrm{s} / \mathrm{km}$. We therefore test velocity-depth gradients between $0.005 \mathrm{~km} / \mathrm{s} / \mathrm{km}$ and $0.01 \mathrm{~km} / \mathrm{s} / \mathrm{km}$ to estimate the depth extent of the low velocity zone (LVZ).

\subsection{Depth extent estimation}

In the MAR algorithm (see Appendix E), ray-paths are modelled as head-waves, where in reality they are most likely to be turning rays (fig 6.1). A head-wave is one that reaches a boundary at the critical angle (dependent on the velocity contrast between layers), and travels immediately below the interface and is refracted back to the surface at the same angle $\left(\theta_{c}\right)$. In the next sections we attemp to determine the depth to which these turning rays reach.

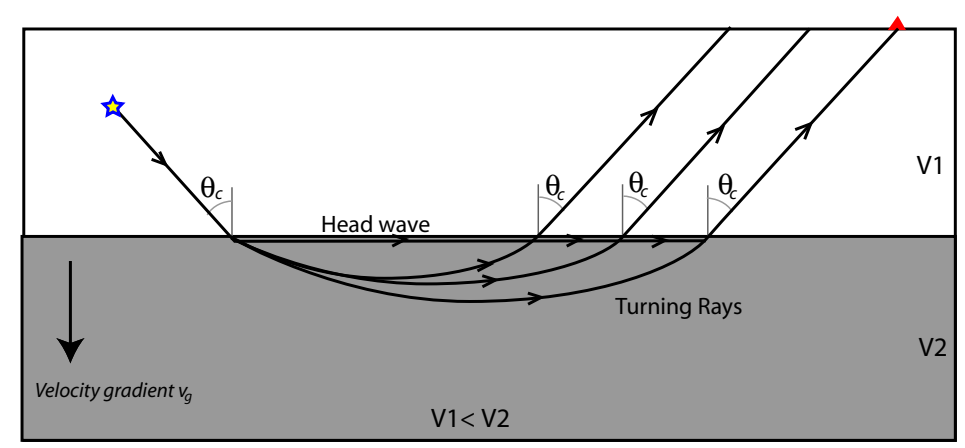

Figure 6.1 Schematic of refracted ray paths. Most refracted arrivals, traverse a region with a vertically varying velocity gradient, causing them to be turning rays. 


\subsection{Previous Estimates of depth extent of the central Low Velocity Zone}

\subsubsection{Depth estimation from Haines (1979) Data}

Haines (1979) reported a velocity of $7.4 \mathrm{~km} / \mathrm{s}$ beneath the central North Island on the basis of earthquake travel times between pairs of stations. Offsets for crustal earthquakes along the central Low Velocity Zone (LVZ) from seismograph stations were up to $750 \mathrm{~km}$. If this ray detected the $7.4 \mathrm{~km} / \mathrm{s}$ layer, it would require that the low velocity layer extends to a depth of at least $80 \mathrm{~km}$ (fig 6.2 (Stratford and Stern 2004)).

\subsubsection{Depths estimation from Reyners et al (2006) Tomography}

From the dense CNIPSE array deployed in 2001, Reyners et al. (2006) inverted arrival times of earthquakes and shots for both hypercentre locations and 3D $V p$ and $V p / V s$ structure beneath the central North Island. Their results show the presence of a 7.4 $\mathrm{km} / \mathrm{s}$ velocity region from $32 \mathrm{~km}$ depth beneath the CVR to a maximum depth of 65 $\mathrm{km}$ immediately west of the Taupo caldera (fig 6.3). This region is interpreted to be due to a significant volume of partial melt, produced by the reaction of fluid released by the dehydrating subducted Pacific Plate into the convecting mantle wedge.

In Reyners et al. (2006) the $7.4 \mathrm{~km} / \mathrm{s}$ region is not apparent at depths less than 32 km, as has been detected by others (Stratford and Stern (2004, 2006); and Harrison and White (2006)). This is most likely due to weakly constrained crustal structure and sparse grid node spacing. 


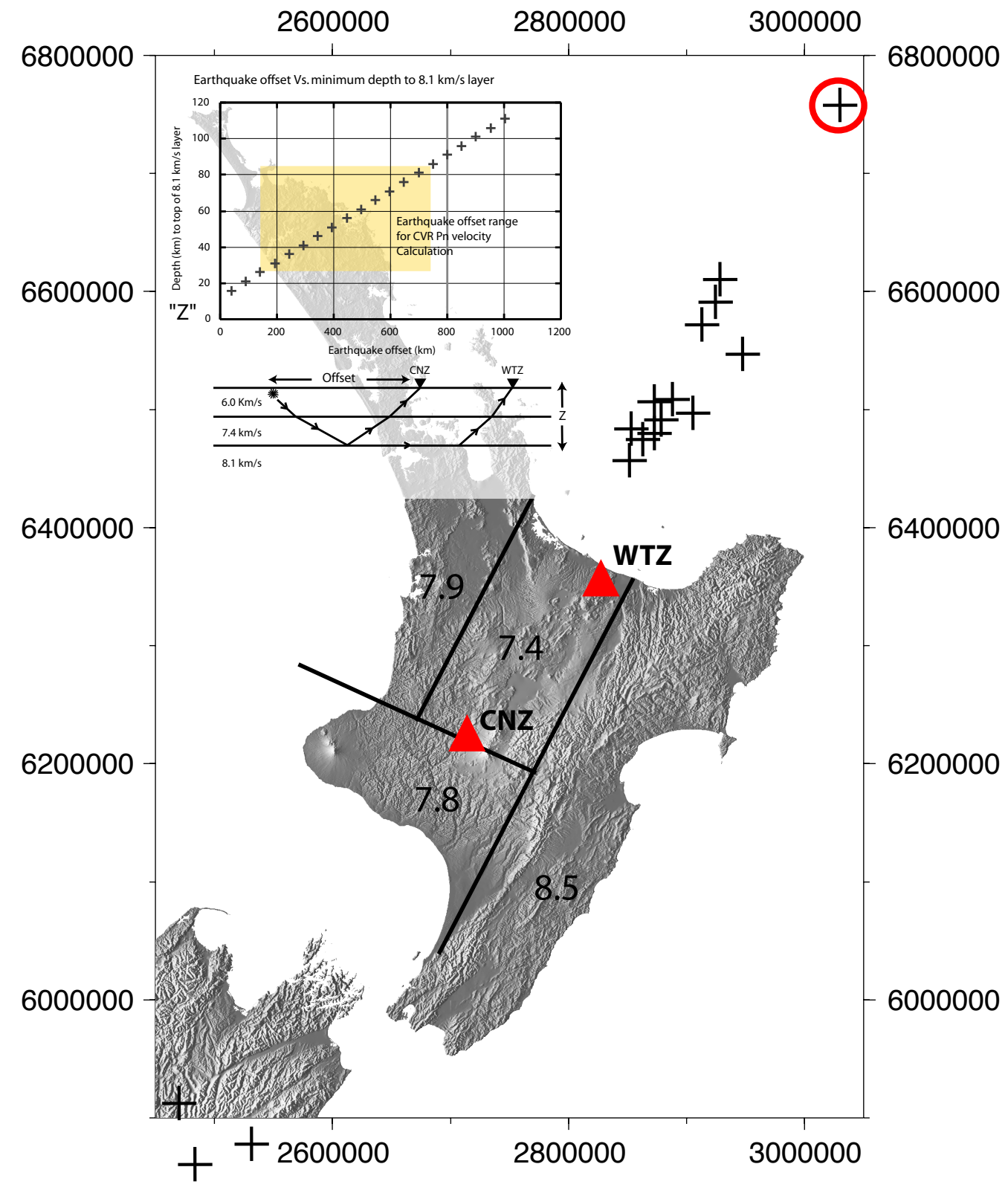

Figure 6.2 Adapted from Stratford 2004.

\subsection{Depth estimation process}

\subsubsection{Event offset and station separation}

Travel times have been modelled (Chapter 4), in this study, assuming that the Pn waves have been traveling as true head-waves, where in reality they will be refracted into the 


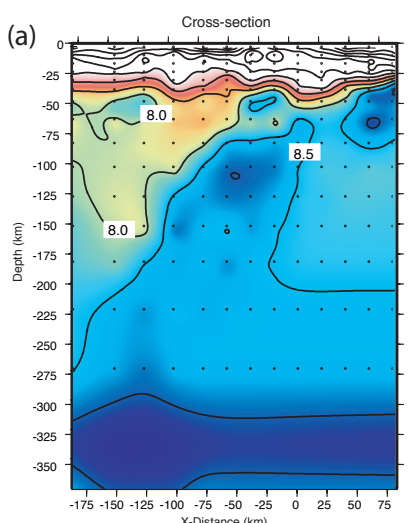

(d)

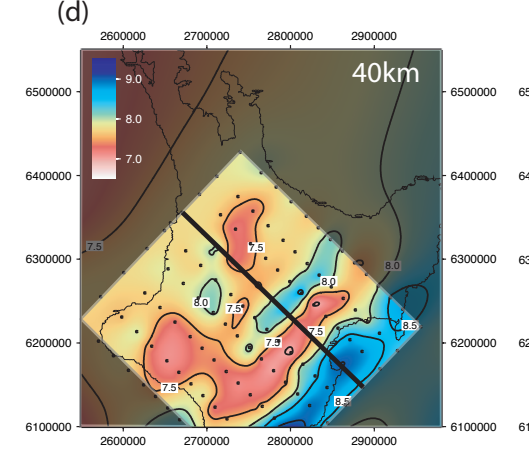

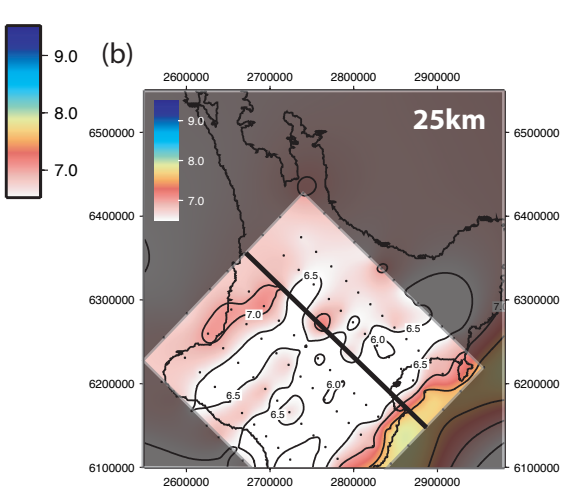

(e)

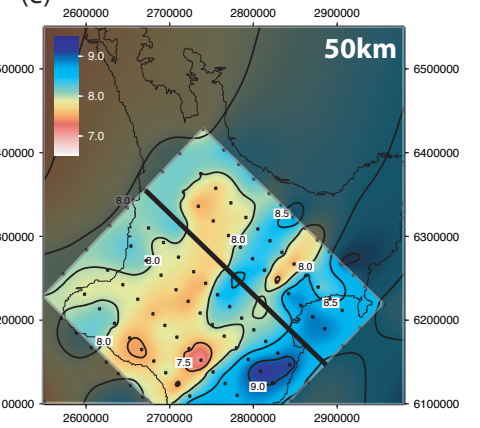

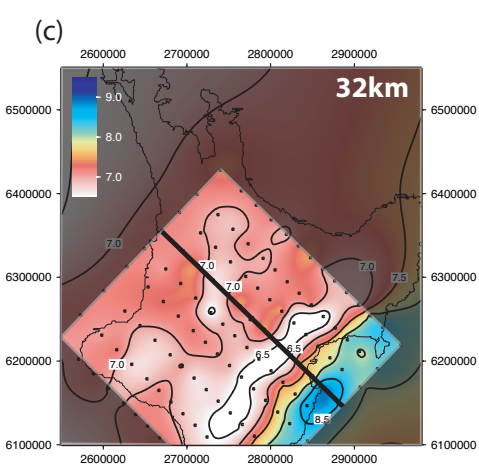

(f)

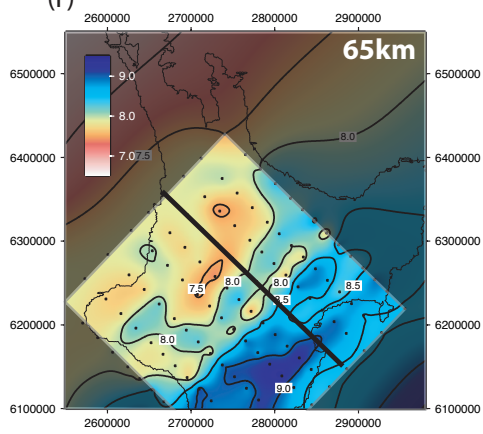

Figure 6.3 Depth slices from Reyners et al (2006) tomography. Colour scale has been adapted to correspond with the colour scale used in the MAR algorithm. (a) is a $2 D$ cross-section of Vp across the central region of the North Island. Profile line is marked on (b)-(f) by the thick solid black line. (b) - (f) are depth slices of the 3D tomograpy at depths of $25 \mathrm{~km}, 32 \mathrm{~km}, 40 \mathrm{~km}, 50 \mathrm{~km}$ and $65 \mathrm{~km}$, respectively.

mantle lid and travel at a depth dependent on their origin offset. Estimates based on the standard New Zealand velocity model (table 3.3) (Maunder 2001), suggest that for offsets of $c a .300 \mathrm{~km}$ from the furthest station, rays reach depths of approximately $40 \mathrm{~km}$ beneath the surface. As a first approach, the observations were split into two groups, those station pair observations with event offsets greater than $300 \mathrm{~km}$ for both stations and those with event offsets of less than $300 \mathrm{~km}$. Both groups consisted of approximately 1200 observations, providing similar resolution within the LVZ.

Figure 6.4 shows the results from these subgroups. The first thing to notice is that the region of $7.4 \mathrm{~km} / \mathrm{s}$ is apparent in (b), which suggests that this region extends to depths greater than $40 \mathrm{~km}$. This reinforces the Stratford and Stern (2004) interpretation of this zone being mantle, as the normal crust is a maximum of $35 \mathrm{~km}$ thick 

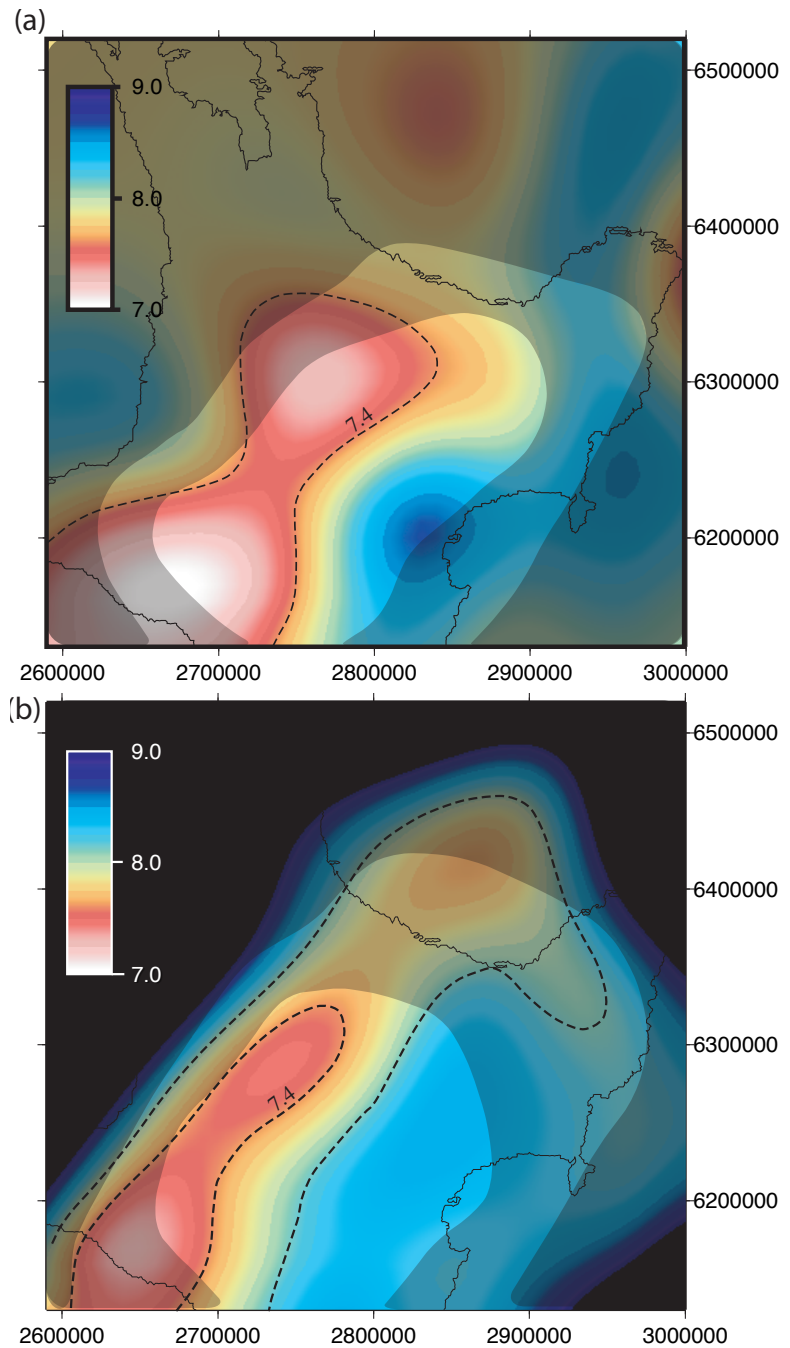

Figure 6.4 Inferred depth slices representing wave speeds above and below $40 \mathrm{~km}$ depth. (a) Shows mantle velocities created from events between 50 - $300 \mathrm{~km}$ offset from nearsest station, assumed to penetrate no deeper than $40 \mathrm{~km}$ depth. (b)Shows mantle velocities from event at offsets greater than $300 \mathrm{~km}$ from the nearest station, inferred to penetrate at depths greater than $40 \mathrm{~km}$. Black shading represents uncertainty associated with accuracy of the model.The region with no shading is resolved to $\pm 0.2 \mathrm{~km} / \mathrm{s}$; first degree of shading represents $\pm 0.3 \mathrm{~km} / \mathrm{s}$; and the darkest shade represents uncertainties of greater than $\pm 0.4 \mathrm{~km} / \mathrm{s}$.

in all models of the central North Island. The event with greatest offset in this data set is $600 \mathrm{~km}$, suggesting a maximum depth being sampled of $70 \mathrm{~km}$, using the same depth estimation method as used on Haines (1979) data by Stratford and Stern (2004) (discussed above). 


\subsubsection{Circular ray-path estimation}

Another method commonly used to estimate depth penetration is by assuming a 2 layer model. In this case, a crust of constant velocity and thickness overlying an upper mantle with a linearly varying velocity is used. This will result in straight raypaths in the crustal layer, and circular bending rays in the mantle. A constant crust, of velocity $6.0 \mathrm{~km} / \mathrm{s}$ and thickness $22 \mathrm{~km}$, is assumed to realistically represent the velocity structure beneath the CVR (Stratford and Stern 2004). It was found that with realistic mantle velocity gradients $(0.005-0.01 \mathrm{~km} / \mathrm{s} / \mathrm{km})$ and an uppermost mantle velocity of between $7.4-8.0 \mathrm{~km} / \mathrm{s}$, a ray will not penetrate to depths greater than $80 \mathrm{~km}$ for the event offsets within the dataset (fig 6.5) (seeAppendix $G$, for details). This would result in a maximum time difference of $0.2 \mathrm{~s}$ between stations pairs.

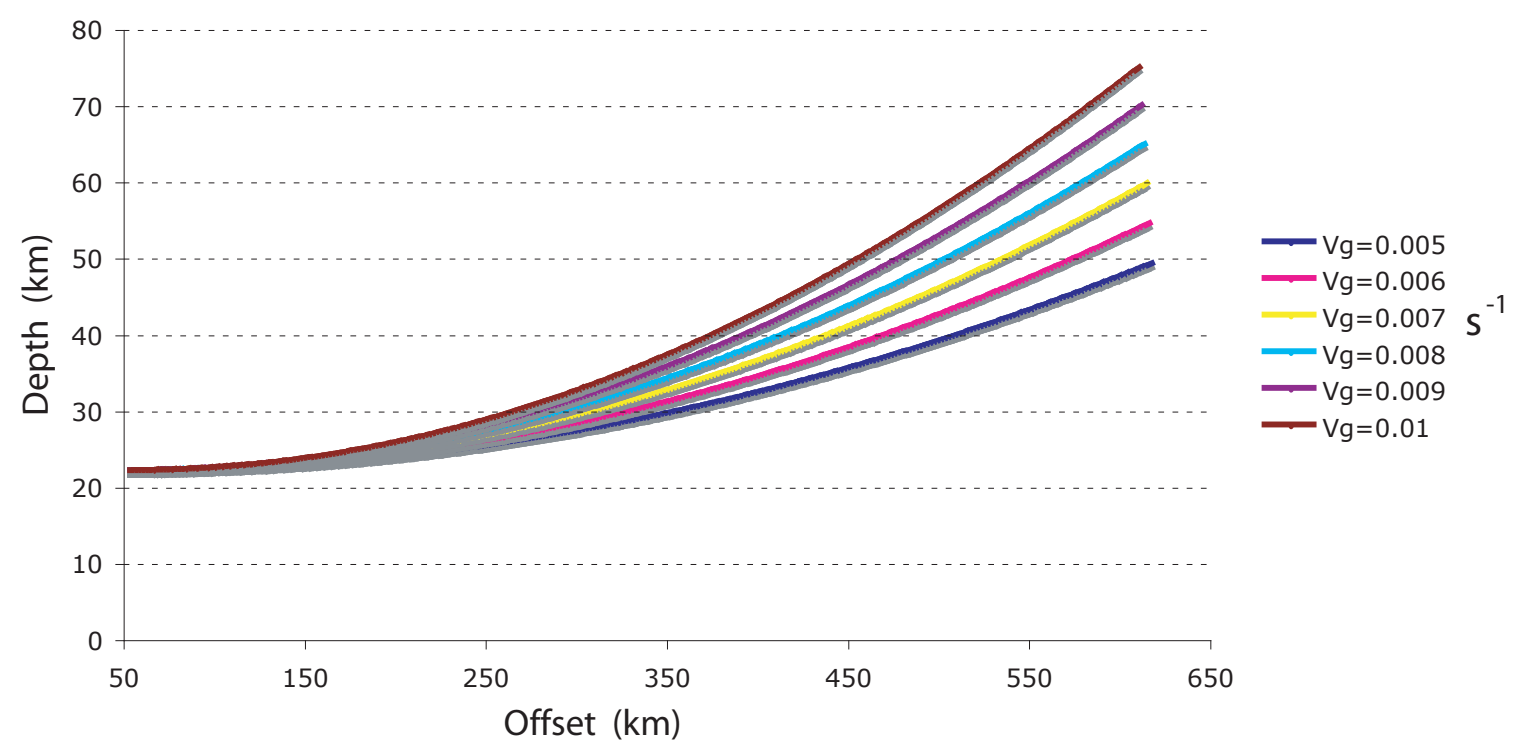

Figure 6.5 Test of velocity gradient on depth penetration of rays transversing layer with upper most Pn-velocity of $7.4 \mathrm{~km} / \mathrm{s}$

\subsubsection{Macray ${ }^{T M}$ modelling of LVZ}

Forward modelling ray-tracing was carried out for a 2D NE-SW profile line along the axis of the central LVZ (fig 6.6) using the Macray ${ }^{T M}$ software of Luetgert (1988). The ray-tracing algorithm for forward modelling is based on zero-order asymptotic ray 
theory developed by Cerveny et al. (1977) for the theoretical response of a laterally heterogeneous medium.

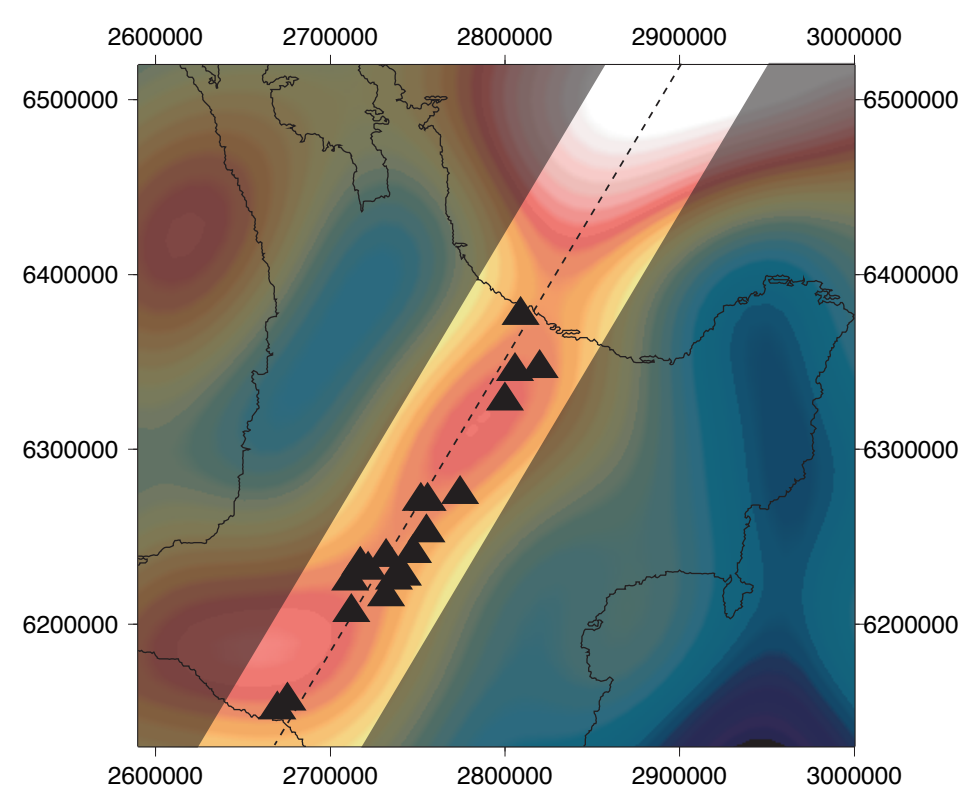

Figure 6.6 Low Velocity Zone beneath the central North Island.

Travel time for a refracted ray is calculated by:

$$
T=\frac{r}{V_{2}}+\frac{\delta z}{V_{1} \cos (\theta)}
$$

where $T$ is the total travel time, $\delta z$ is thickness of the layer, $V_{1}$ is the velocity in layer $1, V_{2}$ is the velocity in layer $2, \theta$ is the incidence angle, and $r$ is the travel path length in layer 2 (Lay and Wallace 1995). When a vertical gradient exists within a layer, a turning wave is produced. Travel time for a turning ray is calculated by:

$$
\delta T(a b)=\frac{1}{V_{g}} \ln \frac{\sin \left(\theta_{b}\right)\left(1+\cos \left(\theta_{b}\right)\right)}{\sin \left(\theta_{a}\right)\left(1+\cos \left(\theta_{a}\right)\right)}
$$

where $V_{g}$ is the velocity gradient and $\theta_{a}$ and $\theta_{b}$ are the ray inclinations to the vertical at depths $a$ and $b$ in the layer (Lay and Wallace 1995).

Coordinates of 26 events and 18 stations within the central LVZ were projected onto a 2D profile line (fig $\mathbf{6 . 7}$ ) parallel to the axis of the observed low velocity region. 
The initial 2D model was based on velocity-depth profiles estimated from the results of tomographic modelling in the northern South Island (Eberhart-Phillips et al. 2005), and central and southern North Island (Reyners et al. 2006). The 2D profile consists of 6 layers, with average velocities of $5.2 \mathrm{~km} / \mathrm{s}$ for the uppermost crust, underlain by a layer of average $5.6 \mathrm{~km} / \mathrm{s}$, and a lower crustal layer of $6.4 \mathrm{~km} / \mathrm{s}$. The low velocity layer of interest consists of velocities ranging from $7.3 \mathrm{~km} / \mathrm{s}$ to $7.5 \mathrm{~km} / \mathrm{s}$ at the base, with an average of $7.4 \mathrm{~km} / \mathrm{s}$ and a vertical velocity gradient ranging from $0.003-0.01 \mathrm{~s}^{-1}$.

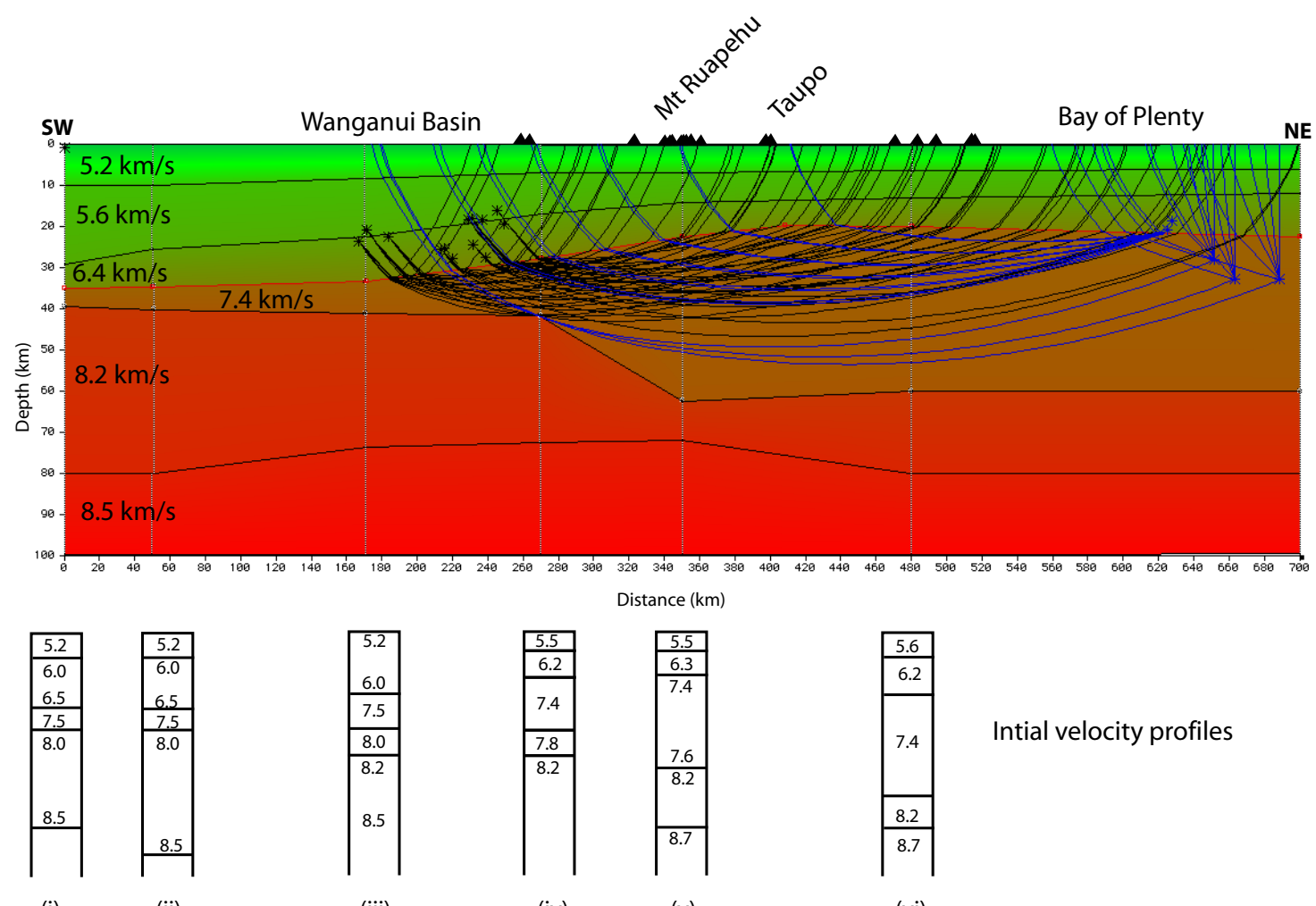

Figure 6.7 $2 D$ depth profile of the Low Velocity Zone of the CVR observed in fig 6.6. Profiles (i) - (vi) are initial velocity profiles estimated from previous tomography. ( (i) \& (ii) (Eberhart-Phillips et al. 2005); (iii), (iv), (v) \& (vi) (Reyners et al. 2006))

The resultant rays from earthquakes do not reach depths greater than $60 \mathrm{~km}$, so we are unable to say if the LVZ layer extends deeper than this from the available data. 


\section{MAR inversion of Macray ${ }^{T M}$ traveltimes}

Travel time differences, event locations and station positions projected on to the profile line (fig 6.8) were run through the MAR algorithm. The resultant mantle surface (fig 6.9) shows an average mantle velocity along the line of $7.4 \mathrm{~km} / \mathrm{s}$ increasing to $7.5 \mathrm{~km} / \mathrm{s}$ towards the southern end of the profile.

The results show that the MAR algorithm can successfully extract the mantle velocity from a known input. The agreement in the results from MacRay traveltimes (fig 6.9) and the observed traveltimes (see insert, fig 6.9), show that the 2D model accurately represents the structure of the LVZ.
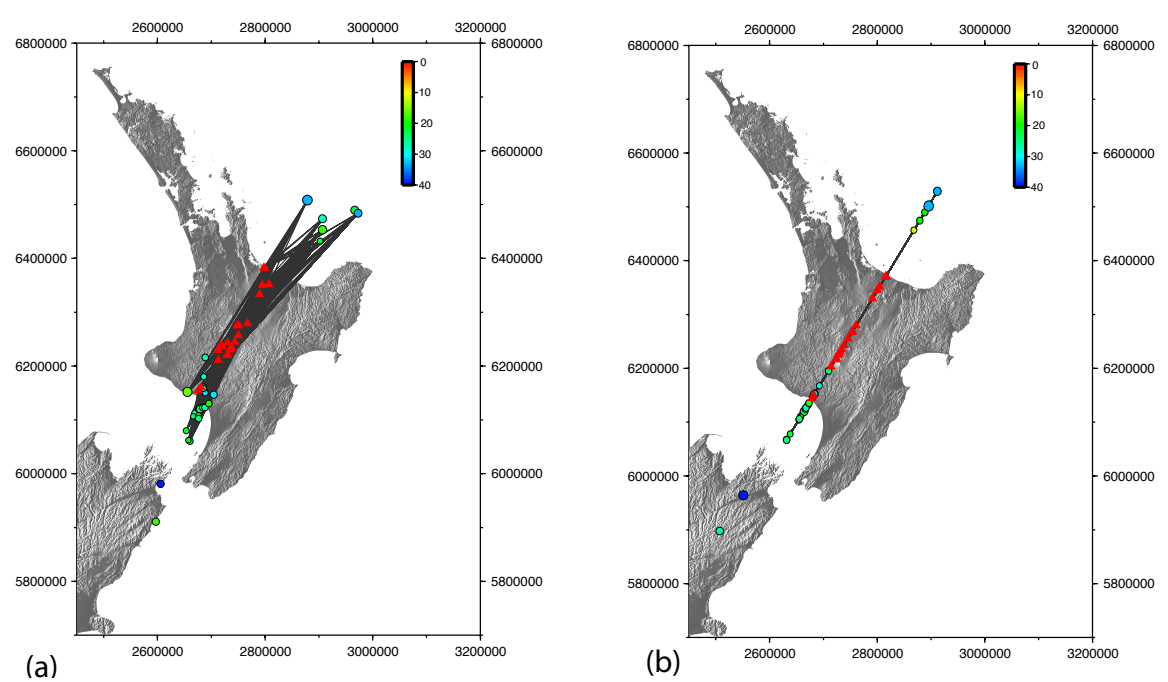

Figure 6.8 Figure of events and stations aligned within the Low Velocity Zone, used to estimate the depth to which this zone reaches (fig 6.6). (a) shows events and stations true position within the $L V Z$, where (b) shows the projected locations of events and stations along the $2 D$ profile line used for depth modelling

\subsection{Summary}

Each of the above depth estimation techniques and data (summarized in table 6.1), indicate that this low velocity material beneath the central North Island extends to depths greater than $40 \mathrm{~km}$, reaching a maximum depth of $c a .65-80 \mathrm{~km}$. This suggests 


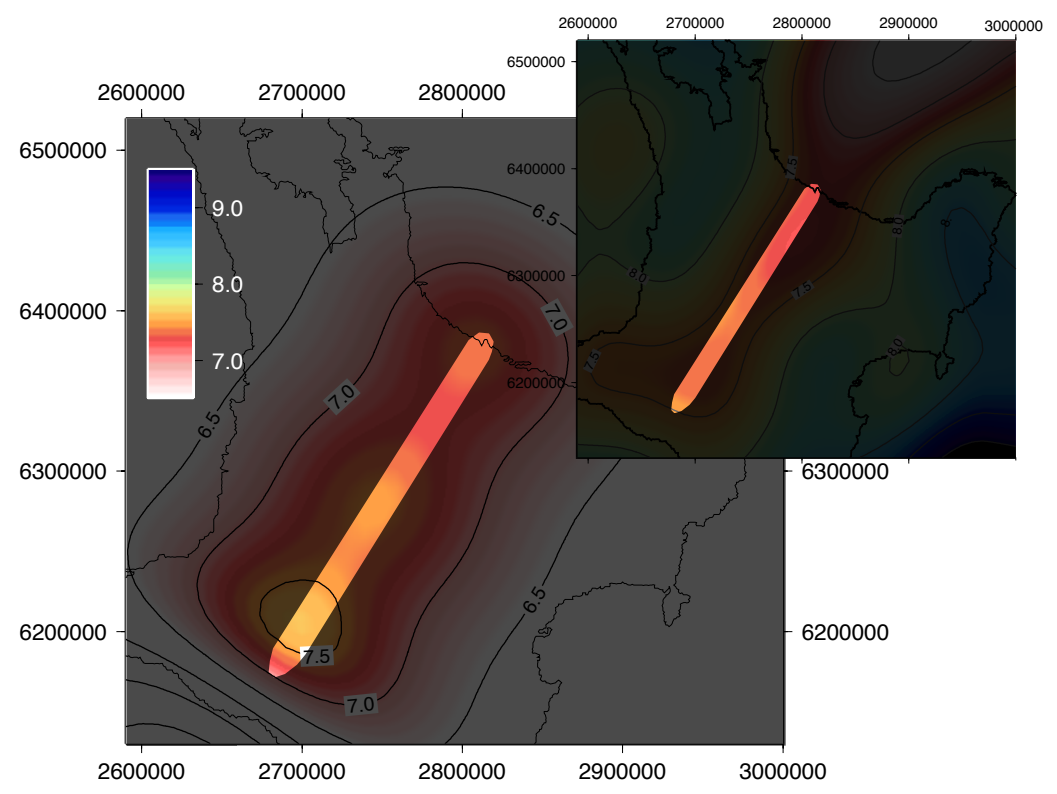

Figure 6.9 Resultant model from MAR, of observations calculated from differencing MacRay ${ }^{T M}$ travel times along the central LVZ profile line. Insert shows the results from the complete dataset within the region of resolution of the profile line.

that the low velocity material extends well into the mantle lithosphere and therefore is likely to be of mantle origin.

Table 6.1

Summary of depth estimates for LVZ discussed in this chapter

\begin{tabular}{|l|c|}
\hline \hline Model Estimate & Depth estimate \\
\hline \hline Haines Data & $\leq 80 \mathrm{~km}$ \\
\hline Reyners et al $(2006)$ & $\leq 65 \mathrm{~km}$ \\
\hline Event and station separation & $40 \mathrm{~km} \leq \mathrm{D} \leq 70 \mathrm{~km}$ \\
\hline Constant mantle $V_{g}$ & $\leq 75 \mathrm{~km}$ \\
\hline 2D profile line & $\leq 60 \mathrm{~km}$ \\
\hline \hline
\end{tabular}

This LVZ exhibits velocity that are on average $10 \%$ lower than the global norm for mantle material. Laboratory studies by Hammond and Humphreys (2000) suggest that melt inclusions can produce a decrease in Pn velocities of $10 \%$ with just $2 \%$ of partial melt present. Another explanation for low mantle velocities near subduction zones, is the presence of water generated by the dehydration of the subducted slab 
(Peacock 1990).

Further discussion of the effect of temperature, melt and water on the reduction of Pn velocities is discussed in the next chapter (Chapter 7: Uppermost mantle structure beneath the central North Island) 


\section{DISCUSSION OF MANTLE STRUCTURE BENEATH THE NORTH ISLAND}

\subsection{Summary of observations}

Our results (fig 4.5, fig 5.5) show that the Pn velocity in the uppermost mantle beneath the North Island varies from velocities of less than $7.4 \pm 0.1 \mathrm{~km} / \mathrm{s}$ in the centre to velocities as high as $8.5 \pm 0.2 \mathrm{~km} / \mathrm{s}$ in the east, with an overall average of $8.0 \mathrm{~km} / \mathrm{s}$. Anisotropy estimations show a consistent trench parallel fast direction over most of the North Island, with the exception of the western region.

The North Island can be split into four distinct regions, based on the characteristic of Pn velocity and Pn anisotropy observations (fig 4.7).

(1) the western North Island

(2) the Taranaki Region

(3) the Central Volcanic Region (CVR)

(4) the eastern North Island.

Table 7.1

Summary of Pn results

\begin{tabular}{|l|c|c|}
\hline \hline Region & PnVelocity & Anisotropy \\
\hline \hline western NI & $7.9 \longleftrightarrow 8.2$ & null \\
Taranaki & $7.5 \pm 0.1$ & NS (uncertain) \\
CVR & $7.4 \pm 0.1$ & NNE-SSW (trench - parallel) \\
eastern NI & $8.1 \longleftrightarrow 8.5$ & NNE-SSW (trench - parallel) \\
\hline \hline
\end{tabular}




\subsubsection{Western North Island}

Pn-velocities of between $7.9 \pm 0.1-8.2 \pm 0.2 \mathrm{~km} / \mathrm{s}$ are seen west of the CVR. These velocities are indicative of slow-to-normal mantle velocities.

This region is not well resolved with the available raypath coverage, however, null or insignificant anisotropic measurements are apparent.

\subsubsection{Taranaki Volcanic Region}

Velocities in the neighbourhood of Taranaki are determined to be $\leq 7.5 \pm 0.1 \mathrm{~km} / \mathrm{s}$ from the MAR algorithm, in agreement with other local seismic velocity surveys (Sherburn and White (2005); (2006)).

Pn anisotropy in this region is not well constrained, with only a slight indication of a north-south fast direction. SKS splitting measurements across the TRL (Savage et al. 2007) show no overall consistency of fast anisotropic direction.

\subsubsection{Central Volcanic Region}

The Central Volcanic Region has the lowest measured mantle velocity, $\leq 7.4 \pm 0.1$ $\mathrm{km} / \mathrm{s}$, which extends to depths of at least $65 \mathrm{~km}$ (see chapter 6 ).

Pn anisotropy measurements in this region show a trench parallel fast direction, suggesting the flow of water-enriched mantle or partial melt is perpendicular to the spreading direction of the back-arc extension (Reyners et al. 2006).

\subsubsection{Eastern North Island}

Below the eastern North Island, Pn velocities are greater than $8.1 \pm 0.1 \mathrm{~km} / \mathrm{s}$ reaching a localised maximum of greater than $8.5 \pm 0.2 \mathrm{~km} / \mathrm{s}$. These higher velocities can be attributed to the subducted oceanic plate.

The highest measured value of mantle anisotropy is located beneath the southern part of the east coast region, which suggests that the anisotropy is most likely to 
be within the subducting plate. This trench parallel fast orientation of anisotropy is likely due to trench-parallel fossil anisotropy within the subducting plate (Reyners et al. 2006). These results are also consistent with SKS splitting measurements (?).

\subsubsection{North Island crustal observations}

Crustal delay terms are estimated as consistent time errors unique to each station. The resulting relative delay times are shown in figure 4.8. Four different crustal types can be seen. In the eastern North Island (3) we see late arrivals $(+0.4 \longleftrightarrow+1.2 \mathrm{~s})$, whereas those in the western North Island (1) are seen to be relatively early $(-1.0 \longleftrightarrow$ $+0.4 \mathrm{~s})$, consistent with thicker crust in the east than in the west. The station terms estimated for the CVR $(2)$ show some variability $(-0.7 \longleftrightarrow+0.7 \mathrm{~s})$, but are mostly small oscillations about the mean crustal time delay. Station delays to the south (4) are not well resolved, and are generally smoothed to about zero $(-0.2 \longleftrightarrow+0.4 \mathrm{~s})$.

Estimations of station delay times are generally in agreement with crustal velocity profiles calculated from local seismic experiments (fig 1.7). Maximum station pair crustal differences (fig 4.8) are estimated as $1.3 \mathrm{~s}$ from the modelling algorithm, and if calculated from the velocity profile in figure $\mathbf{1 . 7}$ the maximum difference between the eastern profile and western profile is $1.4 \mathrm{~s}$. These results suggest thinner / higher Vp crust in the west, a thicker / lower Vp crust in the east, while in the CVR there are very small time delays, indicating a slow crustal $\mathrm{Vp}$, in a thin crust.

\subsection{Tectonic Implications from Pn wave speeds}

The velocity of a mantle seismic wave is dependent on the pressure, temperature, melt fraction and water content of the region through which it propagates. Thus, by modelling the seismic velocity structure of a region, insight into the temperature, melt and water content can be obtained. 


\subsubsection{Effect on mantle velocities of temperature, melt fraction and water content}

Direct measurements of temperature is limited to the upper few kilometres of the Earth's crust. Estimates of temperatures at greater depths require indirect methods, such as surface heat flow and radiogenic heat production (e.g. Clauser and Huenges (1995)), mantle seismic velocity from refraction and tomography studies (e.g. Black and Braile (1982)) and thermobarometry studies of mantle xenoliths (e.g. Harder and Russell (2006)). Typical temperature ranges of the mantle lid range from $500^{\circ} \mathrm{C}$ to $900^{\circ} \mathrm{C}$ (Turcotte and Schubert (2002); Peacock (2003)). Studies of back-arc regions (Currie and Hyndman 2006) suggest a much higher range for the upper most mantle, $800-1400^{\circ} \mathrm{C}$.

Estimates of temperature and partial melt effects on seismic velocity in the mantle have largely been made in laboratory studies (Sato et al. (1989); Isaak (1992); Anderson et al. (1992)). For dry olivine, a velocity - temperature gradient of $-0.5 \mathrm{~m} / \mathrm{s} / \mathrm{K}$ is generally accepted (Isaak 1992), although gradients as steep as $-2.0 \mathrm{~m} / \mathrm{s} / \mathrm{K}$ have been estimated by Sato et al. (1989) for olivine beneath its solidus temperature.

These values are not appropriate for a wet subduction zone setting. The release of water into the upper mantle from the downgoing plate lowers the solidus temperature for olivine.

For back-arc regions, the relationship between velocity and temperature is shown, by Weins and Smith (2003), to be:

$$
\begin{aligned}
& \frac{\partial V_{p}}{\partial T} \approx-1.0 \mathrm{~m} / \mathrm{s} / \mathrm{K} \\
& \frac{\partial V_{s}}{\partial T} \approx-0.8 \mathrm{~m} / \mathrm{s} / \mathrm{K}
\end{aligned}
$$

where $V_{p}$ is the $\mathrm{P}$-wave speed, $V_{s}$ is the $\mathrm{S}$-wave speed, and $T$ is the temperature.

Partial melt $(\Phi)$ also has a reducing effect on Pn and Sn velocities. Based on laboratory studies of melt inclusions (Hammond and Humphreys 2000), velocity - partial 
melt gradients are:

$$
\begin{aligned}
& \frac{1}{V p} \frac{\partial V_{p}}{\partial \Phi} \approx-3.6 \% \\
& \frac{1}{V s} \frac{\partial V_{s}}{\partial \Phi} \approx-7.9 \%
\end{aligned}
$$

where $\Phi$ is the percent partial melt. The relationship between seismic velocity and melt fraction shows that $\mathrm{S}$-waves are affected at twice the rate of $\mathrm{P}$-waves, and are therefore a better indicator for the presences of melt.

Combining equations 7.1 and 7.2, the melt and temperature effects on velocity, ignoring the effect of water, can be estimated as follows.

$$
\delta V=\frac{\partial V}{\partial T} \delta T+\frac{\partial V}{\partial \phi} \delta \phi
$$

Figure 7.1 shows the relationship between melt fraction and temperature for a given $\mathrm{Vp}$ and $\mathrm{Vs}$. It is evident that the S-wave is reduced more quickly than the P-velocity as the melt fraction increases.

If we examine the case of the Central Volcanic Region of the North Island, where Pn velocities of $7.3 \pm 0.1 \mathrm{~km} / \mathrm{s}$ are observed, and assume a Sn velocity of $3.95 \mathrm{~km} / \mathrm{s}$ (observed by Haines (1979)), then temperature range of $600-1150^{\circ} \mathrm{C}$ and a melt fraction between 0.009 - 0.022 can be inferred (fig 7.2). However, it must be noted that small errors in velocities can result in large uncertainties in temperature and melt fraction estimates.

Previous studies into the upper mantle characteristics by Stratford (2006) infer a temperature range of between $700-900^{\circ} \mathrm{C}$ at approximately $25 \mathrm{~km}$ depth beneath the CVR. In chapter 6 , the depth extent of the low velocity region beneath the CVR was estimated to range to a depth of between 65 and $80 \mathrm{~km}$. It is therefore likely that the temperature range sampled is between $700-1100^{\circ} \mathrm{C}$. 

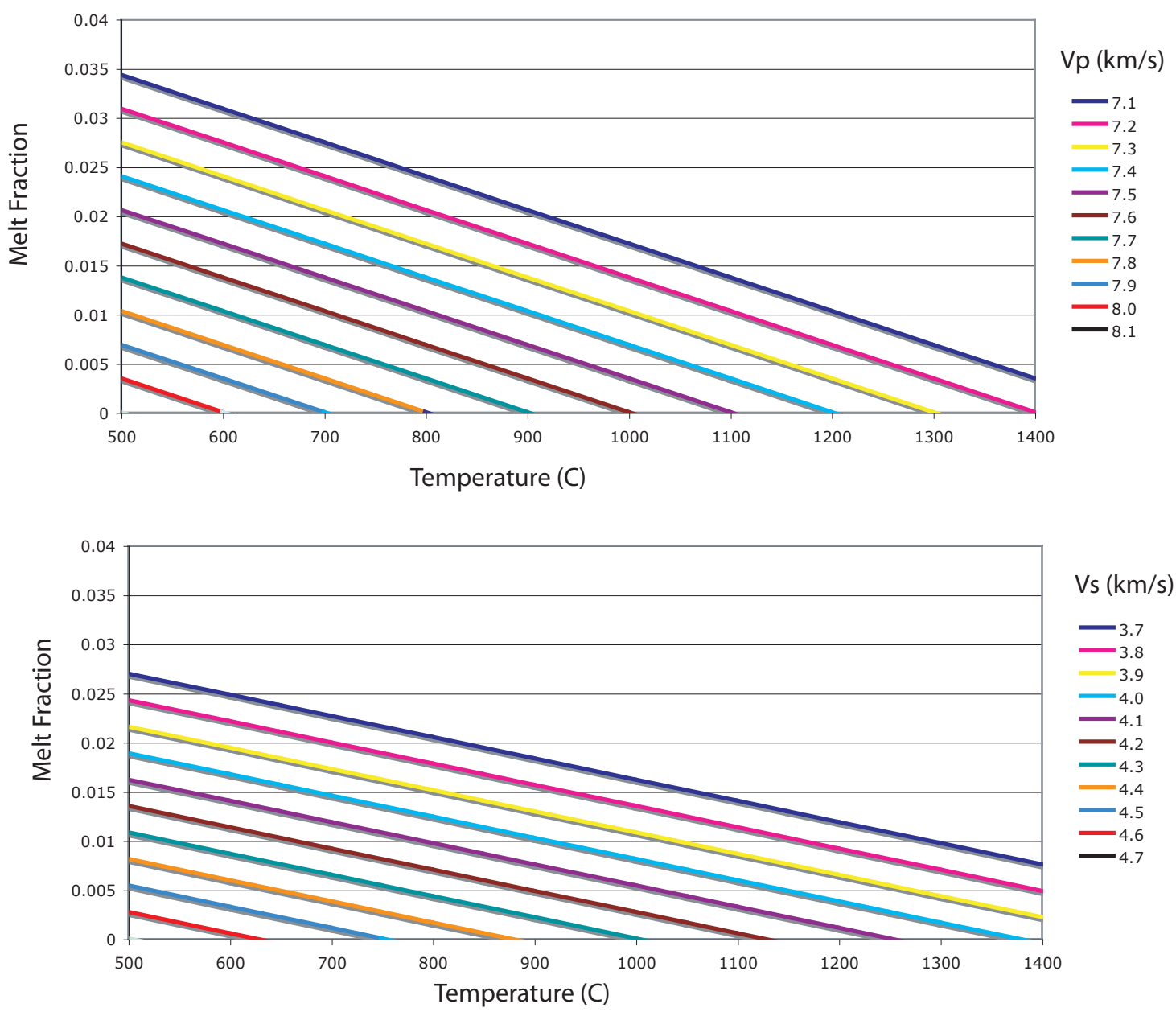

Figure 7.1 Upper: The relationship between temperature, melt and P-velocity. A reference velocity of $8.1 \mathrm{~km} / \mathrm{s}$ is assumed. Lower: The relationship between temperature, melt and S-velocity. A reference velocity of $4.7 \mathrm{~km} / \mathrm{s}$ is assumed.

Recent studies have turned to attenuation to understand the wet mantle in back-arc regions (Weins and Smith 2003). High attenuation seen below the Central Volcanic Region $\left(1000 / Q_{p}=5.0\right)$ is consistent with a hydrated mantle wedge at temperatures just above the solidus (Salmon 2007). At $30 \mathrm{~km}$ depth this equates to a temperature of about $1000^{\circ} \mathrm{C}$ (Salmon 2007) and is indicative of $2 \%$ melt.

\section{Effects of water}

Karato (2003) looks at the effects of water on seismic wave velocities in the upper 


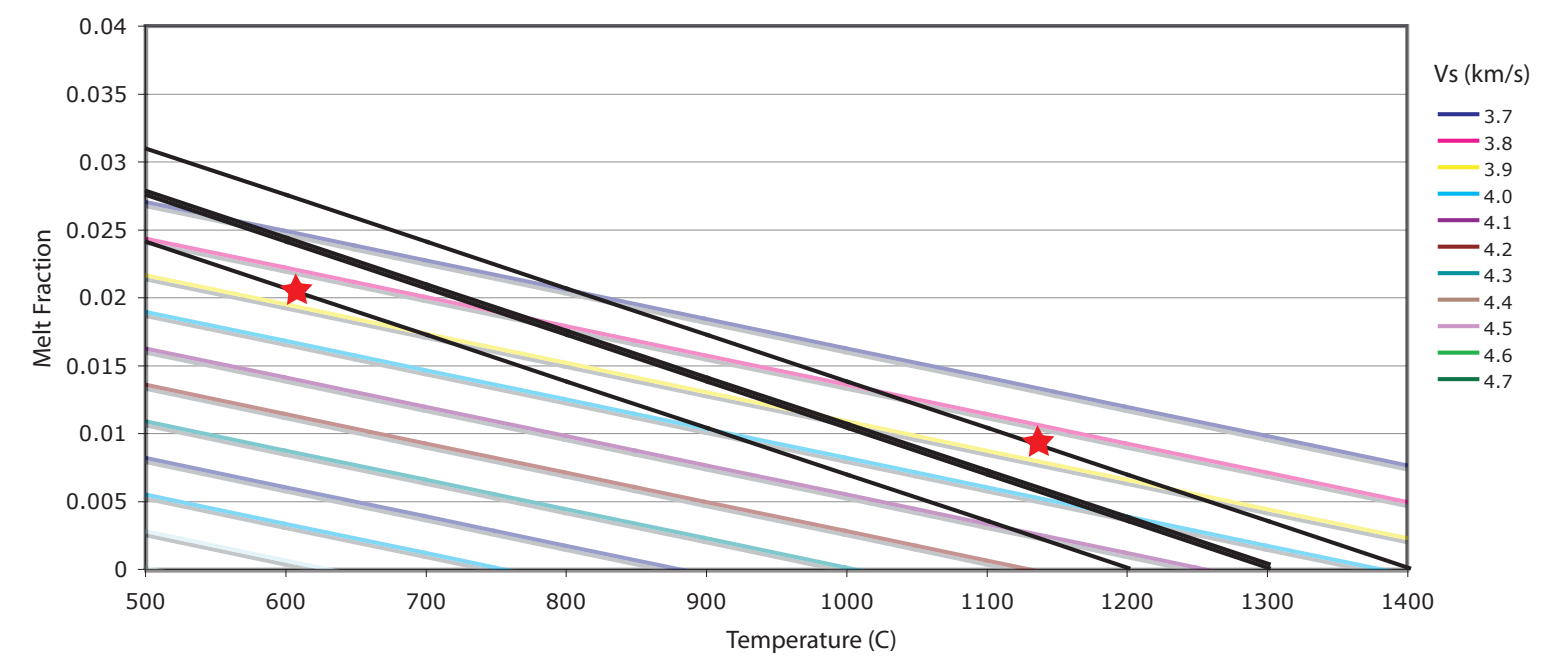

Figure 7.2 Temperature Range (between stars) in the upper mantle beneath the CVR can be estimated from the Velocity observations. Pn velocity of $7.3 \pm 0.1 \mathrm{~km} / \mathrm{s}$ (black lines) and a $\mathrm{Sn}$ velocity (coloured lines) of $3.95 \mathrm{~km} / \mathrm{s}$ Haines (1979) result in a temperature range of $600-1150^{\circ} \mathrm{C}$ in the uppermost mantle

mantle. When water is dissolved in silicates, some chemical bonds will be replaced with weaker bonds such as H-O. Seismic wave velocity $(V)$ is related to the bond strength and, hence, elasticity (elastic constant, $c$ ) through:

$$
V=\sqrt{\frac{c}{\rho}}
$$

where $\rho$ is the density of the material. Both density and elastic constant will be reduced by the incorporation of water. Karato and Jung (1998) calculate the relationship between seismic velocity and the change in bond strength from the introduction of water to be:

$$
\frac{\partial V}{V}=-A \partial \psi
$$

where $\partial \psi$ is the volume fraction of water, and $\mathrm{A}$ is a constant which depends on the mechanism of softening and the elastic constants (estimated to be 0.54 for P-waves, and 0.49 for S-waves for the upper mantle) (Karato and Jung 1998). 


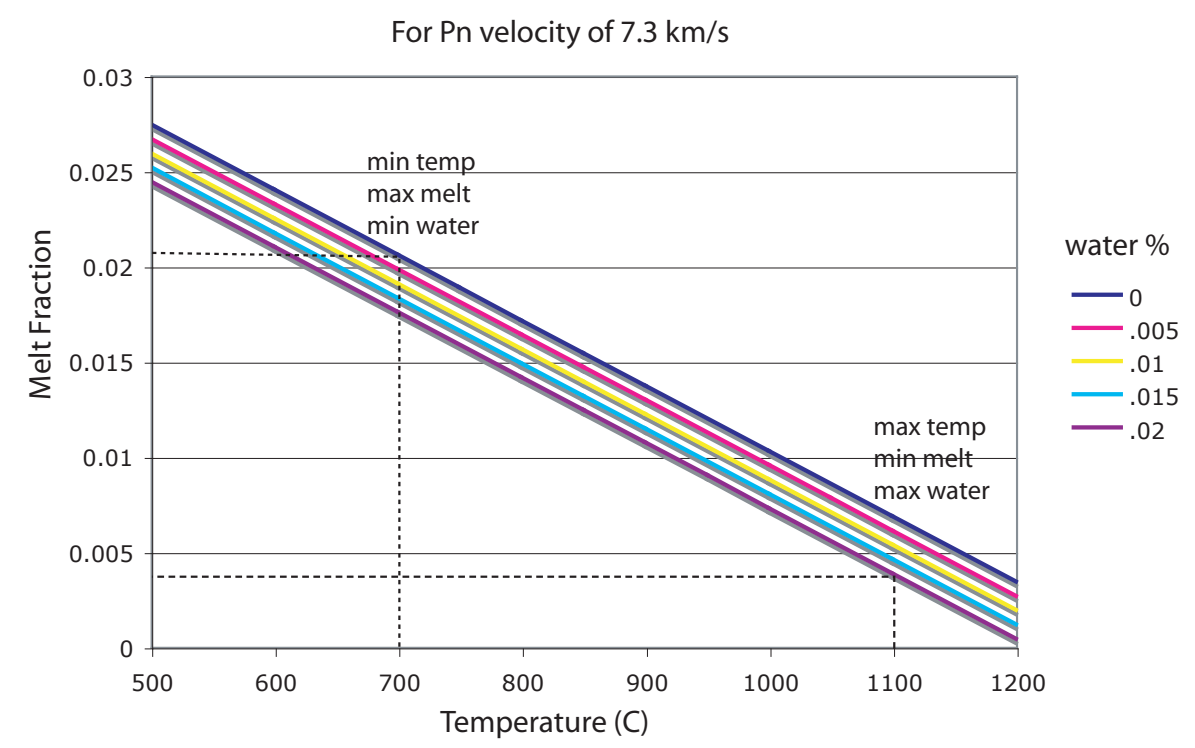

Figure 7.3 Relationship between, temperature, melt and water for the observed $V p$ of $7.3 \mathrm{~km} / \mathrm{s}$ in the Central Volcanic Region

Including the effect of bond-weakening by the introduction of water from the subducted slab in EQ 7.3, the change in mantle velocity can be estimated by,

$$
\delta V=\frac{\partial V}{\partial T} \delta T+\frac{\partial V}{\partial \phi} \delta \phi-A \partial \psi V
$$

A maximum volume fraction of water can be estimated by the change in velocity due to the introduction of water alone, i.e. no temperature or melt content increase.

$$
\delta V_{\max }=-A \partial \psi V
$$

The maximum volume fraction of water will not exceed $0.2 \%$, using the Karato and Jung (1998) estimates for A, and a minimum Vp of $7.3 \mathrm{~km} / \mathrm{s} . \delta V_{\max }$ is -800 for a normal mantle velocity of $8.1 \mathrm{~km} / \mathrm{s}$ that is assumed for the uppermost mantle region.

Figure 7.3, shows the minimum and maximum ranges for temperature ( $700-$ $\left.1100^{\circ} \mathrm{C}\right)$, melt fraction $(0.004-0.021)$ and volume water fraction $(0-0.02 \%)$. The 
exact relationship between water content and melt fraction is needed to refine these values. Unfortuntely, there is little known about the effect of water on melt fraction at these temperatures for uppermost mantle depths and pressures.

\subsection{Regional discussion}

The North Island of New Zealand offers a unique opportunity to study plate boundary deformation processes, due to its location on a continental mass above the boundary. The North Island provides one of the few places on Earth where a spreading backarc region is located on land (Hatherton 1970). The mantle velocities seen here are generally lower than elsewhere in similar tectonic settings. Observations of Pn velocities beneath other back-arcs generally range from $7.8 \mathrm{~km} / \mathrm{s}-8.2 \mathrm{~km} / \mathrm{s}$ (Currie and Hyndman 2006), whereas in the CVR Pn velocities of 7.4 or less are being observed at the Moho. It is therefore difficult to compare with other regions around the globe.

The presence of Hikurangi Plateau off the east coast of the North Island, may influence the amount of water within the mantle wedge or the angle or rate of the subducting plate. The benefit of modelling one aspect of the subduction regime, is that it generally provides constraints or information for kinematic models of the system as a whole

Below we discuss the four regions observed beneath the North Island and what could be inferred from their characteristics.

\subsubsection{Western North Island}

The results of modelling the uppermost mantle P- velocity and anisotropy in the North Island presents an interesting conundrum when looking at the western region, north of the Taranaki-Ruapehu line. The Pn wave speeds in this region suggest that the upper mantle has a lower shear modulus than the global average (Christensen and Mooney 1995) and is, therefore, susceptible to strain deformation. According to the tectonic 
reconstruction of New Zealand (King 2000), the western North Island underwent 50 - $100 \mathrm{~km}$ of shortening during the Miocene. If anisotropy is a direct indicator of deformation history (Ribe 1992), then why do we not detect any in this region?

An explanation proposed by Stern et al. (2006) is that we are observing a relatively young mantle ( $\leq 5 \mathrm{Ma}$ ) that hasn't had time to take up the signature of deformation.

\section{Rayleigh-Taylor instabilities}

The suggestion of a Rayleigh-Taylor instability beneath the western North Island (Stern et al. 2006) provides a possible explanation for observations of low mantle velocities, and the absence of anisotropy in the western North Island, as well as providing an explanation for abrupt changes in attenuation, crustal thickness and electrical resistivity seen across the Taranaki-Ruapehu-Line (Salmon 2007).

A Rayleigh-Taylor instability (fig 7.4) occurs any time a dense heavy fluid is being accelerated into a light fluid (Rayleigh 1883). In terms of mantle tectonics, the lithospheric mantle acts as the dense, heavy layer intruding into a warmer asthenospheric mantle. The process involves an initial uniform thickening of the lithosphere, which was seen in the North Island approximately 25-5 Ma (King 2000). With time the thickened mantle lid may become heavy and unstable, developing viscous properties and eventually a blob will develop, dropping off after time. After detachment of the instability, warm asthenosphere fills the ensuing gap, causing rapid uplift of the Earth's surface (Stern et al. 2006). In the western North Island peripheral extension of the crust was seen between 10-5 Ma in the Taranaki Basin (King and Thrasher 1992). Uplift occurred approximately 5 Ma, coinciding with the onset of volcanism (Stern et al. 2006).

The weakened lithosphere would cause the destruction of the original mantle strain record, resulting in little or no detectable anisotropy in the newly formed mantle, as observed with both Pn and SKS anisotropy measurements. 
(a)

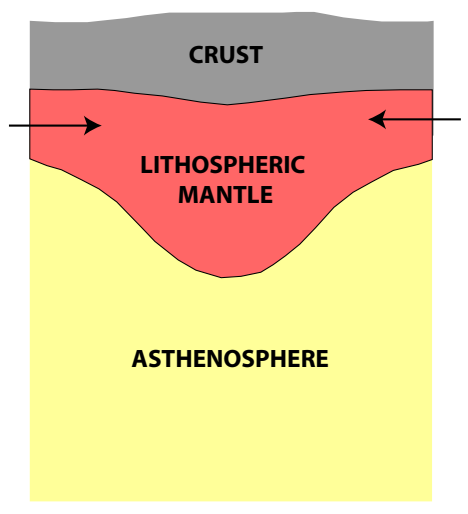

(b)

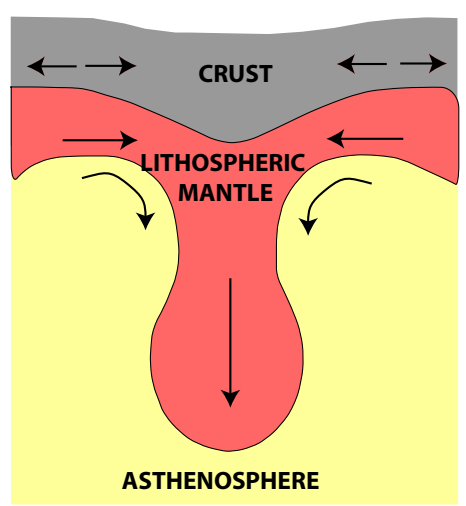

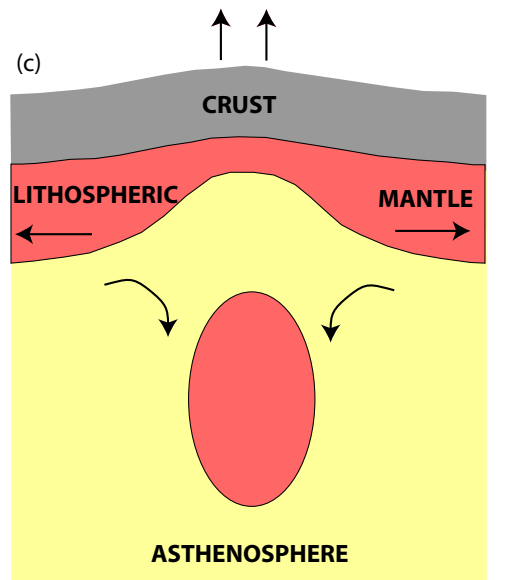

Figure 7.4 Cartoon illustrating the three general stages of a developing Rayleigh-Taylor Instability (adapted from Houseman and Molnar (1997))

\subsubsection{Taranaki}

Previous studies by Haines (1979) detected Pn velocities of $7.8 \mathrm{~km} / \mathrm{s}$ in the region of Mt Taranaki. More recent studies by Sherburn and White (2005), (2006) and Reyners et al. (2006), detect velocities as low as $7.2 \mathrm{~km} / \mathrm{s}$ at depths of $35-50 \mathrm{~km}$. The MAR algorithm estimates velocities of $\leq 7.5$, suggesting a temperature anomaly of $300^{\circ} \mathrm{C}$ (Stratford 2006), and $1.4 \%$ melt.

Chemically, Mt Taranaki is distinct from the volcanoes of the CVR. Why they are coeval is a question that has not yet been answered. Mt Taranaki is the active front of a south-wards migrating low-K andesitic volcanic range, and Mt Ruapehu is the southern most volcano in the CVR volcanic system. The line connecting these two volcanoes, the Taranaki-Ruapehu Line (TRL), has been of subject of recent studies (Salmon (2007); Stern et al. (2006)).

A distinct change in crustal thickness across the TRL, from $25 \mathrm{~km}$ in the North to $32-36 \mathrm{~km}$ in the south, is observed over a small horizontal distance $(\leq 30 \mathrm{~km})$ (Salmon 2007). Studies of seismic attenuation and magnetic resistivity over this line have shown that the uppermost mantle is disturbed in this region. It is this that may be the boundary between the low-velocity zone observed beneath Taranaki and the 
western North Island.

\subsubsection{The Central Volcanic Region}

The Central Volcanic Region has an extremely low measured upper mantle velocity, $\leq 7.4 \pm 0.1 \mathrm{~km} / \mathrm{s}$, bordered by rapid changes (over $50 \mathrm{~km}$ ) to velocities of $8.0 \mathrm{~km} / \mathrm{s}$ in both the east and the west. Similar velocities in this region were also detected by Haines (1979), Stratford and Stern (2004); (2006) and Harrison and White (2006). Harrison and White (2006) argue that below the upper crust there is a layer of $6.9-$ $7.3 \mathrm{~km} / \mathrm{s}$ of heavily intruded or under-plated mafic lower crust, to a depth of $30 \mathrm{~km}$. This is underlain by the mantle wedge consisting of velocities from $7.4-7.8 \mathrm{~km} / \mathrm{s}$ to a depth of $100 \mathrm{~km}$. Stratford and Stern (2004), (2006) argue that velocities of $7.3 \mathrm{~km} / \mathrm{s}$ in the lower crust are unreasonable in an area of known high heat flow and volcanic activity. If the crust in the CVR were $30 \mathrm{~km}$ thick, it would be thicker than the crust in the western North Island, which is inconsistent with subduction zone and rifting settings.

In Chapter 6, the depth extent of the low-velocity region seen beneath the CVR was investigated. Numerous approaches show that a region of seismic velocities between $7.3-7.5 \mathrm{~km} / \mathrm{s}$ are seen to depths of at least $65-80 \mathrm{~km}$, suggesting that a large region of upper mantle is altered by heat, melt and water caused by the subduction zone system.

From the above discussion of temperature, melt fraction and water content, the observed Pn velocity in the CVR could be caused by temperatures of between $700-$ $1100^{\circ} \mathrm{C}$, or a melt presence of $0.4-2.1 \%$, and a maximum water content of 0.02 .

Seismic anisotropy from both SKS splitting measurement (?) and Pn estimates show trench parallel fast directions, suggesting flow of melts in the mantle wedge. 


\subsubsection{Eastern North Island}

Below the eastern North Island, high velocities of $\geq 8.3 \mathrm{~km} / \mathrm{s}$ are seen in the upper mantle. These high velocities have been detected by many, e.g. Smith (1977), Haines (1979), Reyners et al. (2006), and are attributed to the subducting oceanic plate. It can be seen (fig 1.9) that the subducting slab is shallow beneath the eastern margin of the North Island, then starts to dip more steeply towards the western boundary of this region, beneath the CVR. The tomography of the subducted plate beneath the North Island, by Reyners et al. (2006) (fig 1.9), shows that the seismic P-velocity within the slab increases with depth, suggesting the release of water into the overriding plate. This water is then introduced into the mantle wedge beneath the CVR, resulting in the observed presence of melt and water within the uppermost mantle. 
CHAPTER 8

\section{SUMMARY AND CONCLUSIONS}

\subsection{Summary}

The principal focus of this thesis was to produce a velocity model of the uppermost mantle beneath the central North Island, using Pn wave phases. Information obtained from the modelling procedure has provided insight into uppermost mantle P-wave velocities, Pn anisotropy and crustal irregularities. This chapter summarises the key aspects of the modelling algorithm and its output.

\subsubsection{Modelling Method}

In calculating the uppermost mantle P-wave slowness, the observed data can be partitioned between mean slowness, variations in mantle slowness, the anisotropic effects in the mantle, and variations in combined crustal velocity and thickness beneath seismic stations. The key aspects of the modelling algorithm are summarised below.

- Upper mantle Pn velocities can successfully be modelled using the method of least-squares collocation.

- The main advantage of least-squares over traditional tomographic modelling is that no tight constraints or psuedo-observations are required.

- The total covariance matrix can be split into the sum of the mantle covariance, crustal covariance and an observation uncertainty covariance. 
- The mantle covariance function describes the correlation of the slowness between any two points in the mantle, through the correlation distance, and the expected deflection of the slowness from the average value.

- The crustal covariance is the correlation between points in the crust. The crustal covariance can be separated from mantle effects so there is minimal interaction between mantle and crustal systems. The interaction was tested by assigning station delay terms of $-0.7 \mathrm{~s}$ to the western North Island, principally making all the delay terms constant across the North Island. The model was re-run and resulted in little variation in the underlying mantle.

- The measurement uncertainty covariance is related to the picking precision.

\subsubsection{Principal Mantle observations}

The North Island can be split into 4 regions, based on the resulting Pn velocity and anisotropy estimations.

(1) The western North Island, where Pn velocities range from 7.9 to $8.2 \mathrm{~km} / \mathrm{s}$, with no apparent anisotropy.

(2) The Taranaki Volcanic Region, where Pn velocities of $\leq 7.5 \mathrm{~km} / \mathrm{s}$, and insignificant anisotropy with a slight suggestion of N-S fast direction.

(3) The Central Volcanic Region, where Pn velocities of $\leq 7.4 \mathrm{~km} / \mathrm{s}$, and trench parallel fast direction anisotropy. Investigation into the depth to which the low velocity zone reaches suggest at least $65-80 \mathrm{~km}$.

(4) The eastern North Island, where Pn velocities of $\geq 8.1 \mathrm{~km} / \mathrm{s}$, and strong trench parallel fast direction anisotropy, suggest that the cool subducting slab is being traversed. 


\subsubsection{Crustal observations}

Estimates of crustal delay times beneath each station are estimated through the modelling algorithm, and are in agreement with crustal travel times estimated from seismic profiles throughout the North Island.

\subsection{Conclusions and possible future work}

\subsubsection{Conclusions}

During this study, a new method for modelling Pn wave speeds was developed. This method utilised least-squares collocation, traditionally used in gravity and GPS surveys, to produce a continuous model of Pn velocity structure. The region of focus was the uppermost mantle beneath the central North Island of New Zealand. Travel time data was collect at pairs of stations, roughly in line with earthquake epicentres and then differenced to removed the dependence on an exact origin time and event location. This data was then run through the algorithm, where probabilistic bounds were placed on mantle and crustal characteristics. The resulting model consists to a continuous surface of mantle velocities and anisotropy, with point estimates of crustal travel time delays beneath the seismograph stations.

Based on these results, the North Island can be split into 4 main regions based on the Pn anisotropy and velocity results (fig 5.5). These 4 regions correspond with regions previously identified in several studies, primarily those of Haines (1979), Reyners et al. (2006), Stratford (2006) and Greve (2008) (see previous discussion on characteristics). This suggests that the algorithm developed is a successful alternative to traditional methods used to model Pn wave speed characteristics.

There are several advantages of this method over traditional 2D tomography. Firstly, the is no need for detailed knowledge of the velocity profile and nodal interaction that is required in gridded tomography. Our method relies on the signal within the data to be segmented into probabilistic bounds of velocity, anisotropy, crustal and error character- 
istics. Secondly, it is relatively quick, processing 11000 observations in a few minutes. And finally, it is independent of other velocity models used in locating earthquake epicentre.

\subsubsection{Development of modelling algorithm}

Having tested the method in the North Island, we are aware that of several key steps that will improve (and fully test) the algorithm and methods capability. Firstly, the lack of earthquakes off the west coast has left a void in raypath coverage. It would be ideal to test this algorithm further is a region of the world with full $360^{\circ}$ of azimuthal coverage, such as the the western US. This region has been model previously with 2D tomography (Hearn 1996), and has been shown to have great ray coverage, resulting in good resolution of both Pn velocity structure and Pn anisotropy.

It would also be a key advantage to test Sn velocity modelling through this algorithm. This was not fully tested / applied to the North Island of New Zealand, as most of the Sn signal is attenuated as the wave traverses the island. The behaviour of Sn wave phase can provide key insight into upper mantle properties and ideally should be included in the modeling algorithm to obtain a fuller understanding of region

Once the modelling algorithm has been fully tested and the modelling of the Sn wave phase has been included this method could be used as an alternative to traditional 2D tomographic method in all regions of the world. As each method of modelling has its own short comings, combining alternative techniques can often results in a more realistic understanding of mantles properties and dynamic processes. It would therefore be very interesting to combine Pn and Sn observations from both the North Island and the South Island to get a velocity map of the greater continental New Zealand region. 


\section{REFERENCES}

Aki, K. and Richards, P. (1980), Quantitive Seismology: Theory and Methods, W.H. Freeman, San Francisco.

Al-Lazki, A., Sandovol, E., Seber, D., Barazangi, M., Turkelli, N. and Mohamad, R. (2004), Pn tomographic imaging of mantle lid velocity and anisotropy at the junction of the Arabian, Eurasian and African plates, Geophysical Journal International 158(3): 1024-1040.

Anderson, H., Isaak, D. and Oda, H. (1992), High-Temperature elastic constant data on minerals relevant to geophysics, Reviews of Geophysics 30: 5790.

Anderson, H. and Webb, T. (1994), New Zealand seismicity: patterns revealed by the upgraded National Seismograph Network, New Zealand Journal of Geology and Geophysics 37(4): 477-493.

Arcay, D., Doin, M.-P., Tric, E., Bouquet, R. and De Capitani, C. (2006), Overriding plate thinning in subduction zones: Localized convection induced by slab dehydration, Geochemistry Geophysics Geosystems 7: 1-26.

Audoine, E., Savage, M. K. and Gledhill, K. (2000), Seismic anisotropy from local earthquakes in the transition region from subduction to a strike-slip plate boundary, New Zealand, Journal of Geophysical Research B: Solid Earth 105(B4): 8013-8033.

Audoine, E., Savage, M. K. and Gledhill, K. (2004), Anisotropic structure under a back arc spreading region, the Taupo Volcanic Zone, New Zealand, Journal of Geophysical Research B: Solid Earth 109(11): 1-21. 
Backus, G. (1962), Long-wave elastic anisotropy produced by horizontal layering, journal of Geophysical Research 67(11): 4427-4440.

Bamford, D., Jentsch, M. and Prodehl, C. (1979), Pn anisotropy studies in northern Britain and eastern and western United States, Geophysics journal of the Royal Astronomical Society 57: 397-429.

Bannister, S., Bryan, C. J. and Bibby, H. M. (2004), Shear wave velocity variation across the Taupo Volcanic Zone, New Zealand, from receiver function inversion, Geophysical Journal International 159(1): 291-310.

Beanland, S. and Haines, J. (1998), The Kinematics of active deformation in the North Island, New Zealand, determined from geological strain rates, New Zealand Journal of Geology and Geophysics 41: 311-323.

Beavan, J. and Haines, J. (2001), Contemporary horizontal velocity and strain rate fields of the Pacific-Australian plate boundary zone through New Zealand, Journal of Geophysical Research 106(B1): 741-770.

Beghoul, N. and Barazangi, M. (1989), Mapping high Pn velocity beneath the Colorado Plateau constrains uplift models, Journal of Geophysical Research 94(B6): 7083-7104.

Benson, A., T.A., S. and Bannister, S. (2006), Lower crust - upper mantle structure and bright reflectors under the Taupo Volcanic Zone, in N. Mortimer and L. Wallace (eds), Joint Geological society of New Zealand and New Zealand Geophysical Society Conference Launching International year of Planet Earth, Vol. 1, Geological Society of New Zealand Miscellaneous Publications 123A, p. 11.

Billen, M. (2008), Modelling the Dynamics of Subducting Slabs, Annual Reveiw of Earth and Planetary Science 36(1): 325-356.

Bjornsson, A., Eysteinsson, H. and M., B. (2005), Crustal formation and magma genesis beneath Iceland: Magnetotelluric constraints, Geological Society of America Special Paper 338 pp. 665-686. 
Black, P. and Braile, L. (1982), Pn velocity and cooling of the continental lithosphere, Journal of Geophysical Research pp. 10557-10568.

Calhaem, I. (1973), Heat flow measurements under some lakes in North Island, New Zealand, PhD thesis, Victoria University of Wellington.

Calvert, A., Sandvol, E., Seber, D., Barazangi, M., Vidal, F., Alguacil, G. and Jabour, N. (2000), Propagation of regional seismic phases (Lg and Sn) and Pn velocity structure along the Africa-Iberia plate boundary zone: tectonic implications, Geophysical Journal International 142(2): 382-408.

Canales, J., Detrick, R., Lin, J., Collins, J. and Toomey, D. (2000), Crustal and upper mantle seismic structure beneath the rift mountains and across a nontransform offset at the Mid-Atlantic Ridge $\left(35^{\circ} N\right)$, Journal of Geophysical Research 105.

Cerveny, V., Molotkov, I. and Psencik, T. (1977), Ray method in Seismology, University of Karlova, Prague, Czechoslovakia.

Chadwick, M. (1997), The 1991 Hikurangi margin seismic refraction experiment, $\mathrm{PhD}$ thesis, Victoria University of Wellington.

Christensen, N. (1966), Shear wave velocities in metamorphic rocks at pressures to 10 Kilobars., Journal of Geophysical research 71: 3549-355.

Christensen, N. (1984), The magnitude, symmetry and origin of upper mantle anisotropy based on fabric analysis of ultramafic teconites, Geophysics Journal of the Royal Astronomical Society 76: 89-111.

Christensen, N. and Mooney, W. (1995), Seismic velocity structure and composition of the continental crust : A global view, Journal of Geophysical research 100(B7): 9761-9788.

Clauser, C. and Huenges, E. (1995), Thermal conductivity of rocks and minerals, in T. Ahren (ed.), Rock Physics and Phase Relations: A handbook of Physical Constants, AGU, Washington D.C. 
Crampin, S. (1984), An introduction to wave propagation in anisotropic media, Geophysical Journal international 76(1): 17-28.

Crampin, S. (1994), The fracture criticality of crustal rocks, Geophysical Journal international 118: 428-438.

Currie, C. and Hyndman, R. (2006), The thermal structure of subduction zone back arcs, Journal of Geophysical Research 111: B08404.

Davies, G. (1999), Dynamic Earth, Cambridge University Press, New York.

DeMets, C., Gordan, R., Argus, D. and Stein, S. (1994), Effects of recent revisions to the geomagnetic reversal time scale on estimates of current plate motions, Geophysical Research Letters 21(20): 2191-2194.

DeMets, C., R.G, G., D.F., A. and S., S. (1990), Current plate motions, Geophysics Journal international 101: 425-478.

Di Stefano, R., Chiarabba, C., Lucente, F. and Amato, A. (1999), Crustal and uppermost mantle structure in Italy from the inversion of P-wave arrival times: geodynamical implications, Geophysical Journal International 139(2): 483498.

Dobrin, M. and Savit, C. (1988), Introduction to Geophysics Prospecting, McGraw-Hill, New York.

Doglioni, C., Carminati, E., Cuffaro, M. and Scrocca, D. (2007), Subduction kinematics and dynamic constraints., Earthscience Reviews 83(3-4): 125-175.

Duclos, M. (2005), Insight on the plate boundary deformation from seismic anisotropy in the New Zealand upper mantle, $\mathrm{PhD}$ thesis, Victoria University of Wellington.

Dziewonski, A. and Anderson, D. (1981), Preliminary reference Earth model, Physics of the Earth and Planetary Interiors 25(4): 297-356. 
Eberhart-Phillips, D. and Henderson, C. M. (2004), Including anisotropy in 3-D velocity inversion and application to Marlborough, New Zealand, Geophysical Journal International 156(2): 237-254.

Eberhart-Phillips, D., Reyners, M., Chadwick, M. and Chiu, J. M. (2005), Crustal heterogeneity and subduction processes: 3-D Vp, Vp/Vs and Q in the southern North Island, New Zealand, Geophysical Journal International 162(1): 270288.

Edbrooke, S. (2001), Geology of the Auckland area. Institute of Geological and Nuclear Sciences 1:250000 geological map 3, Institute of Geological and Nuclear Sciences Limited, Lower Hutt, New Zealand.

Edbrooke, S. (2005), Geology of the Waikato area. Institute of Geological and Nuclear Sciences 1:250000 geological map 4, Institute of Geological and Nuclear Sciences Limited, Lower Hutt, New Zealand.

Eiby, G. (1959), The Structure of New Zealand from Seismic evidence, International Journal of Earth Science 47(2): 647-662.

Ewig, E. and Stern, T. (2006), Lithospheric shortening and ductile deformation in a back-arc setting:Wanagnui Basin, New Zealand, in E. Trans (ed.), AGU Fall Meeting Suppliment, Vol. 87, Eos Trans., p. 52.

Foulger, G., Pritchard, M., Julian, B., Evans, J., Allen, R., Nolet, G., Morgan, W., Bergsson, B., Eriendsson, P., Jakobsdottir, S., Ragnarsson, S., Stefansson, R. and Vogfjord, K. (2001), Seismic tomography shows that upwelling beneath Iceland is confinded to the upper mantle, Geophysical Journal International 146(2): 504-530.

Fowler, C. (1990), The Solid Earth: an introduction to Global Geophysics, Cambridge University Press, Cambridge.

GeoNet (2008), The GeoNet Project - Monitoring geological hazards in New Zealand, website: http://www.geonet.org.nz . 
Greve, S. (2008), Deep Anisotropic Structure under the Central Volcanic Region, New Zealand, PhD thesis, Victoria University of Wellington.

Greve, S. and Savage, M. (2006), Strong Variations in Seismic Anisotropy across a Mantle Wedge, Hikurangi Subduction Zone, New Zealand, in E. Trans (ed.), $A G U$ Fall meeting, San Francisco.

Greve, S. and Savage, M. (2007), Modelling seismic anisotropy across the central Volcanic Region, in N. M. . L. Wallace (ed.), Geological Society of New Zealand and New Zealand Geophysical Society Joint Annual Conference, Geological Sciety of New Zealand Miscellaneous Publications 123A, Tauranga.

Gueguen, Y. and Poirier, A. (1980), Deformation of mantle rocks, Annual Review of Earth and Planetary Sciences 2(8): 119-144.

Haines, A. (1979), Seismic wave velocities in the uppermost mantle beneath New Zealand, N.Z. Journal of Geology and Geophysics 22(2): 245-257.

Hamilton, R. (1969), Seismological Studies of the gisbourne Earthquake Sequence, 1966, in R. Hamilton, G. Lensen, R. Skinner, O. Hall, A. Andrews, C. Strachan and G. O.M. (eds), Gidbourne Earthquake, New Zealand, March 1966, Vol. 194, New Zealand Department of Scientific and Industrial Research Bulletin, pp. $7-23$.

Hammond, W. and Humphreys, E. (2000), Upper mantle seismic wave velocity: Effects of realistic partial melt geometries, Journal of Geophysical Research 105(B5): 10975-10986.

Harder, M. and Russell, J. (2006), Thermal state of upper mantle beneath the Northern Cordilleran Volcanic Province (NCVP), British Columbia, Canada, Lithos 87: $1-22$.

Harrison, A. and White, R. S. (2006), Lithospheric structure of an active backarc basin: The Taupo Volcanic Zone, New Zealand, Geophysical Journal International 167(2): 968-990. 
Hatherton, T. (1970), Upper mantle inhomogeniety beneath New Zealand: surface manifestations, Journal of Geophysical Research 75: 269-284.

Hearn, T. M. (1996), Anisotropic Pn tomography in the western United States, Journal of Geophysical Research B: Solid Earth 101(4): 8403-8414.

Hearn, T. M. (1999), Uppermost mantle velocities and anisotropy beneath Europe, Journal of Geophysical Research B: Solid Earth 104(B7): 15123-15139.

Hearn, T. M. and Ni, J. (1994), Pn Velocities Beneath Continental Collision ZOnes: The Turkish-Iranian Plateau, Journal of Geophysical Research B: Solid Earth 117(2): 273-283.

Hearn, T. M., Wang, S., Ni, J. F., Xu, Z., Yu, Y. and Zhang, X. (2004), Uppermost mantle velocities beneath China and surrounding regions, Journal of Geophysical Research B: Solid Earth 109(11): 1-11.

Henrys, S., Reyners, M. and Bibby, H. (2003), Exploring the Plate Boundary Structure of the North Island, New Zealand, EOS 84(31): 289 294-295.

Herrin, E. and Taggart, J. (1962), Regional variations in Pn velocity and their effect on the location of epicenters, Bulletin of the Seismological Society of America 52(5): 1037-1046.

Hess, H. (1964), Seismic anisotropy of the uppermost mantle under oceans, Nature 203: 629-631.

Heuret, A. and Lalleman, S. (2004), Plate motions, slab dynamics and back-arc deformation, Physics of the Earth and Planetary Interior 149: 31-51.

Holt, W. and Wallace, T. (1990), Crustal thickness and upper mantle velocities in the Tibetan plateau region from the inversion of regional Pnl waveforms: Evidence for a thick upper mantle lid beneath southern Tibet, Journal od Geophysical research 95(B8): 12499-12525.

Horspool, N., Savage, M. and Bannister, S. (2006), Implications for intraplate volcanism and back-arc deformation in northwestern New Zealand, from joint 
inversion of receiver functions and surface waves, Geophysical Journal Interntional 166(3): 1466-1483.

Houseman, G. and Molnar, P. (1997), Gravitational (Rayleigh-Taylor) instability of a thickened boundary layer and its relavence for the thermal evolution of continental convergent belts, Journal of Geophysical Research 128: 125-150.

IRIS (2008), PASSCAL software, website: http://www.passcal.nmt.edu .

Isaak, D. (1992), High-Temperature elasticity of iron-bearing olivines, Journal of Geophysical Research 97: 1871-1885.

Ismaïl, W. and Mainprice, D. (1998), An olivine fabric database: An overview of upper mantle fabric and seismic anisotropy, Tectonophysics 296(1-2): 145-157.

Iwasaki, T. (1990), Crustal and uppermantle structure in the Ryukyu Island Arc deduced from deep seismic sounding, Geophysical Journal International 102(3): 631-651.

Jeffreys, H. and Bullen, K. (1958), British Association for the Advancement of Science, Gray-Milne Trust, London.

Karato, I. (2003), Mapping water content in the upper mantle, in J. Eiler (ed.), Inside the Subduction Factory, American Geophysical Union, Washington, DC.

Karato, S. and Jung, H. (1998), Water, partial melting and the origin of the seismic low velocity and high attenuation zone in the upper mantle, Earth and Planetary Interiors 51(1-3): 193-207.

Karig, D. (1970), Kermadec arc - New Zealand tectonic confluence, New Zealand Journal of Geology and Geophysics 13: 21-29.

Karki, B., Stixrude, L. and Wentzcovitch, R. (2001), High-pressure elastic properties of major materials of the Earth's mantle from first principles, Reviews of Geophysics 39(4): 507-534. 
Kear, D. (1994), A "least complex" dynamical model fro late Cenozoic volcanism in the North Island, New Zealand, New Zealand Journal of Geology and Geophysics 37: 223-236.

Keller, G., Mechie, J., Braile, L., Mooney, W. and Prodehl, C. (1994), Seismic structure of the uppermost mantle beneath the Keyan Rift, Tectonophysics 236(14): 201-216.

Kelley, K., Plank, T., Grove, T., Stolper, E., Newman, S. and Hauri, E. (2006), Mantle melting as a function of water content beneath back-arc basins, Journal of Geophysical Research $\mathbf{1 1 1 .}$

Kendall, J. (1994), Teleseismic arrivals at a mid ocean ridge: effects of mantle melt and anisotropy, Geophysical Research Letters 21(4): 301-204.

Kern, H. (1993), P- and S-wave anistropy and shear-wave splitting at pressure and temperature in possible mantle rocks and their relation to the rock fabric, Physics of the Earth and Planetary Interiors 78(3-4): 245-256.

King, P. R. (2000), Tectonic reconstructions of New Zealand: 40 Ma to the present, New Zealand Journal of Geology and Geophysics 43: 611-638.

King, P. R. (2001), Subduction zone: Observations and geodynamic models, Physics of the Earth and Planetary Interiors 127(1-4): 9-24.

King, P. and Thrasher, G. (1992), Post-Eocene development of Taranaki Basin, New Zealand, in J. Watkins (ed.), Geology and Geophysics of Continental Margins, American Association of Petroleum and Geology, Tulsa, USA.

Kingma, J. (1965), Geological Map Sheet 9: Gisbourne, Department of Scientific and Industrial Research, Wellington, New Zealand.

Lallenmand, S., Heuret, A. and Boutelier, D. (2005), On the relationship between slab dip, back-arc stress, upper plate absolute motion, and crustal nature in subduction zones., Geochemistry, Geophysics, Geosystems 6(9). 
Lay, T. and Wallace, T. (1995), Modern Global Seismology, Academic Press, San Diego.

Lees, J. and Crosson, R. (1989), Tomographic Inversion for Three-Dimensional Velocity Structure at Mount St. Helens Using Earthquake Data, Journal of Geophysical Research 94(B5): 5716-5728.

Liang, C., Song, X. and Huang, J. (2004), Tomographic inversion of Pn travel times in China, Journal of Geophysical Research 109(B11): 1-19.

Luetgert, J. (1988), User manual for RAY84/R83PLT interactive two-dimensional ray tracing/synthetic seismogram pakage, Vol. Technical Report 88-238 of Open File Report, U.S. Geological Survey.

Mainprice, D., Barruol, G. and Ben-Ismail, W. (2000), The seismic anisotropy of the Earths mantle: From single crystal to polycrystal, in S. Karato, A. Forter, R. Liebermann, G. Masters and L. Stixrude (eds), Earths Deep Interior: Mineral Physics and Tomography from the Atomic to the Global Scale, Vol. 117, AGU Geophysical Monograph.

Mainprice, D. and Nicolas, A. (1989), Development of shape and lattice preferred orientations: application to the seismic anisotropy of the lower crust, Journal of Structural Geology 11(1-2): 175-189.

Mainprice, D. and Silver, P. (1993), Interpretation of SKS-waves using samples from the subcontinental lithosphere, Physics of the Earth and Planetary Interiors $78(3-4): 257-280$.

Maunder, D. (2001), New Zealand seismological report, 1999, Vol. E-182 of Seismological Observatory Bulletin, Institute of Geological and Nuclear Sciences Limited.

Montagner, J.-P. (1994), Can Seismology tell us anything about convection in the mantle, reviews of Geophysics 32(2): 115-137. 
Montagner, J.-P. and Tanimoto, T. (1991), Global Upper Mantle Tomography of Seismic Velocities and Anisotropies, Journal of Geophysical Research 96(B12): 20337-20351.

Mooney, H. (1970), Upper mantle inhomogeneity beneath New Zealand: seismic evidence, Journal of Geophysical Research 75(2): 285-309.

Moritz, H. (1972), Advanced least-squares methods, Department of Geodectic Science, Ohio State University, Ohio.

Morley, A. M., Stuart, G. W., Kendall, J. M. and Reyners, M. (2006), Mantle wedge anisotropy in the Hikurangi subduction zone, central North Island, New Zealand, Geophysical Research Letters 33(5).

Mumme, T., Lamb, S. and Walcott, R. (1989), The Raukumara palemognetic domain: constraints on the tectonic rotation of the East Coast, North Island, New Zealand, from paleomagnetic data, New Zealand Journal of Geology and Geophysics 32: 369-392.

Nicholson, T., Gudmundsson, O. and Sambridge, M. (2004), Constraints on earthquake epicentres independant of seismic velocity models, Geophysics Journal International 156: 648-654.

Nicol, A. and Wallace, L. (2007), Temporal stability of deformation rates: Comparision of geological and geodetic observations, Hikurangi subduction margin, New Zealand, Earth and Planetary Science Letters 258(3-4): 397-413.

Nicolas, A. and Christensen, N. (1987), Formation of anisotropy in upper mantle peridotites - a review, in W. D. AGU (ed.), Composition, Structure, and Dynamics of the Lithosphere-Asthenosphere System, AGU.

Paige, C. and Saunders, M. (1982), LAQR: An Algorithm for Sparse Linear Equations and Sparse Least Squares, ACM Transactions on Mathematical Software (TOMS) 8: 43-71. 
Pandey, O. (1981), Terrestrial heat flow in the North Island of New Zealand, Journal of Volcanology and Geothermal Research 10: 309-316.

Parolai, S., Spallaroassa, D. and Eva, C. (1997), Lateral variations of Pn wave velocity in northwestern Italy, Journal of Geophysical research 102: 8369-8379.

Peacock, S. M. (1990), Fluid processes in subduction zones, Science 248(4953): 329337.

Peacock, S. M. (2003), Thermal structure and metamorphic evolution of subducting slabs, Inside the Subduction factory 138: 7-22.

Pei, S., Zhao, J., Rowe, C. A., Wang, S., Hearn, T. M., Xu, Z., Liu, H. and Sun, Y. (2006), ML amplitude tomography in North China, Bulletin of the Seismological Society of America 96: 1560-1566.

Pei, S., Zhoa, J., Sun, Y., Xu, Z., Wang, S., Liu, H., Rowe, C., Toksoz, M. and Gao, X. (2007), Upper mantle seismic velocities and anisotropy in China determined through Pn and Sn tomography, Journal of Geophysical research 112.

Phillips, W., Rowe, C. and Steck, L. (2005), The use of interstation P wave arrival time differences to account for regional path variability, Geophysical Research Letters 32.

Qiu, X., Priestly, K. and McKenzie, D. (1996), Average lithospheric structure of southern Africa, Geophysical Journal International 127(3): 563-587.

Raitt, R., Shor, G., Francis, T. and Morris, G. (1969), Anisotropy of the Pacific upper mantle, Journal of Geophysics Research 74: 3095-3109.

Raitt, R., Shor, G., Morris, G. and Kirk, H. (1971), Anisotropy of the Pacific Ocean, Techtonophysics 12: 173-186.

Rayleigh, J. (1883), Investigation of the character of the equilibrium of an incompressible fluid of variable density, Proceedings of the London Mathematical Society 14: $170-177$. 
Reilley, W. (1990), Horizontal crustal deformation on the Hikurangi Margin, New Zealand Journal of Geology and Geophysics 33: 393-400.

Reilly, W. (1965), Gravity Map of New Zealand 1:4000000 Bouguer Anomalies, New Zealand Department of Scientific and Industrial Research, Wellington.

Reilly, W., Whiteford, C. and Doone, A. (1977), North Island: Gravity map of New Zealand 1:1000000 Bouguer and isostatic anomalies, IDepartment of Science and Industrial Research, Wellintont, New Zealand.

Reyners, M., Eberhart-Phillips, D. and Stuart, G. (1999), A three-dimensional image of shallow subduction: crustal structure of the Raukumera Peninsula, New Zealand, Geophysical Journal Internation 137(3): 873-890.

Reyners, M., Eberhart-Phillips, D., Stuart, G. and Nishimura, Y. (2006), Imaging subduction from the trench to $300 \mathrm{~km}$ depth beneath the central North Island, New Zealand, with $\mathrm{Vp}$ and $\mathrm{Vp} / \mathrm{Vs}$, Geophysical Journal International 165(2): 565-583.

Reyners, M., Robertson, R. and McGinty, P. (1997), Plate coupling in the northern South Island and southernmost North Island, New Zealand, as illuminated by earthquake focal mechanisms, Journal of Geophysical Research B: Solid Earth 102(B7): 15197-15210.

Ribe, N. (1989), Seismic anisotropy and mantle flow, Journal od Geophysical research 94(B4): 4213-4223.

Ribe, N. (1992), On the Relation Between Seismic Anisotropy and Finite Strain, Journal of Geophysical research 97(B6): 8737-8747.

Robinson, R. (1986), Seismicity, structure and tectonics of the Wellington region, New Zealand, Geophysical Journal - Royal Astronomical Society 87(2): 279-409.

SAC (2008), SAC - Seismic Analysis Code, website: http://www.iris.edu/manuals.sac/manual.html . 
Salmon, M. (2007), Crust and Upper Mantle inhomogeneities beneath western North Island, New Zealand: Evidence from seismological and electromagnetic data, $\mathrm{PhD}$ thesis, Victoria University of Wellington.

Salmon, M., Bannister, S., Bibby, H., Savage, M. and Stern, T. (2003), Attenuation and electrical resistivity in an asymmetric back-arc extensional environment, AGU Fall Meeting, Vol. S22B-0450 TI.

Salmon, M., Savage, M. and Stern, T. (2005), Seismic Attenuation, temperature, H2O, mantle melting and rock uplift, central North Island, New Zealand, in E. Trans (ed.), AGU Fall meeting, Vol. 86(52), San Francisco.

Salmon, M., Savage, M. and Stern, T. (2006), Geophysical Evidence of Convectively removed mantle and lower crust behind a continental Backarc, in E. Trans (ed.), AGU Fall meeting, Vol. 87(52), San Francisco.

Sato, H., Sacks, I. and Murase, T. (1989), The use of laboratory velocity data for estimating temperature and partial melt fraction in the low-velocity zone: Comparison with heat flow and electrical conductivity studies, Journal of Geophysical Research 94: 5689-5704.

Savage, M. (1998), Lower crustal anisotropy or dipping boundaries? Effects on receiver functions and a case study in New Zealand, Journal of Geophysical research 103: $15069-15087$.

Savage, M. (1999), Seismic anisotropy and mantle deformation: What have we learned from shear wave splitting?, Reviews of Geophysics 37: 65-106.

Savage, M., Bardout, M., Salmon, M., Greve, S. and Wessel, A. (2007), Seismic anisotropy across the Taranaki-Ruapehu line, in N. M. . L. Wallace (ed.), Geological Society of New Zealand and New Zealand Geophysical Society Joint Annual Conference, Geological Sciety of New Zealand Miscellaneous Publications 123A, Tauranga. 
Savage, M. and Silver, P. (1993), Mantle deformation and tectonics: Constraints from seismic anisotropy in the Western United States, Physics of the Earth and Planetary Interiors 78: 207-228.

Sclater, J. (1972), Heat flow and elevation of the marginal basins of the western Pacific, Journal of Geophysical Research 77(29): 5705-5719.

Sdrolias, M. and Muller, R. (2006), Controls on back-arc basin formation, Geochemistry, Geophysics, Geosystems 7(4).

Sherburn, S. and White, R. (2005), Crustal seismicity in Taranaki, New Zealand using accurate hypocentres from a dense network, Geophysical Journal International 162(2): 494-506.

Sherburn, S., White, R. and Chadwick, M. (2006), Three-dimensional tomographic imaging of the Taranaki volcanoes, New Zealand, Geophysical Journal International 166(2): 957-969.

Silver, P. (1996), Seismic Anisotropy beneath the continents: Probing the Depths of Geology, Annual Reviews of Earth and Planetary Sciences 24: 385-432.

Skinner, D. (1986), Neogene volcanism of the Hauraki Volcanic region, Bulletin of the Royal Society of New Zealand 23: 21-47.

Smith, E. (1977), The theory of multi-earthquake location by least squares and apllications to groups of North Island, New Zealand, mantle earthquakes, PhD thesis, Victoria University of Wellington.

Smith, G. and Ekström, G. (1999), A global study of Pn anisotropy beneath continents, Journal of Geophysical Research 104(B1): 963-980.

Stacey, F. (1977), Physics of the Earth, John Wiley and Sons, New York.

Stein, S. and Wysession, M. (2003), An Introduction to Seismology, Earthquakes, and Earth Science, Blackwell Publishing Ltd., Calton, Victoria, Australia.

Stern, T. (1982), Seismic and Gravity investigations of the central Volcanic Region, North Island, New Zealand, PhD thesis, Victoria University of Wellington. 
Stern, T. and Davey, F. (1987), A seismic investigation of crustal and upper mantle structure within the Central Volcanic region of New Zealand, New Zealand Journal of Geology and Geophysics 30(3): 217-231.

Stern, T., Quinlan, G. and Holt, W. (1992), Basin formation behind an active subduction zone: three dimensional flexural modellingof Wanganui Basin, New Zealand, Basin Research 4: 197-214.

Stern, T., Smith, E., Davey, F. and Muirhead, K. (1987), Crustal and upper mantle structure of the northwestern North Island, New Zealand, from seismic refraction data, Geophysical Journal International 91(3): 913-936.

Stern, T., Stratford, W. and Salmon, M. (2006), Subduction evolution and mantle dynamics at a continental margin: Central North Island, New Zealand, Reviews of Geophysics 44: RG4002.

Stratford, W. (2006), Lithospheric Structure of a Continental Back-arc: Central Volcanic Region, New Zealand, PhD thesis, Victoria University of Wellington.

Stratford, W. R. and Stern, T. A. (2004), Strong seismic reflections and melts in the mantle of a continental back-arc basin, Geophysical Research Letters 31(6).

Stratford, W. R. and Stern, T. A. (2006), Crust and upper mantle structure of a continental backarc: Central North Island, New Zealand, Geophysical Journal International 166(1): 469-484.

Tatsumi, Y. and Eggins, S. (1995), Subduction zone magmatism, Blackwell, Massachusetts.

Thurber, C. and Aki, K. (1987), Three-Dimensional Seismic Imaging, Annual Reviews of Earth and Planetary Science 15: 115-139.

Turcotte, D. and Schubert, G. (2002), Geodynamics, Cambridge University press.

Ulmer, P. (2001), Partial melting in the mantle wedge - The role of H2O in the genesis of mantle-derived 'arc-related' magmas, Physics of the Earth and Planetary Interiors 127(1-4): 215-232. 
Uyeda, S. (1982), Subduction zones: An introduction to comparative subductology, Tectonophysics 81: 133-159.

Uyeda, S. and Kanamori, H. (1979), Bark-arc opening and the mode of subduction, Journal of Geophysical Research 84: 1049-1061.

Verma, R. (1960), Elasticity of some high-density crystals, Journal of Geophysical Research 65(1): 757-766.

Walcott, R. (1987), Geodetic strain and the deformation history of the North Island of New Zealand during the late Cainzoic, Philosophical Transaction of the Royal Society of London A 321: 163-181.

Walcott, R. (1998), Modes of oblique compression: Late Cenozoic tectonics of the South Island of New Zealand, Reviews of Geophysics 36(1): 1-26.

Wallace, L. M., Beavan, J., McCaffrey, R. and Darby, D. (2004), Subduction zone coupling and tectonic block rotations in the North Island, New Zealand, Journal of Geophysical Research B: Solid Earth 109(12): 1-21.

Weins, D. and Smith, G. (2003), Seismological constrints on the structure and flow patterns within the Mantle Wedge, in J. Eiler (ed.), Inside the Subduction Factory, American Geophysical Union, Washington, DC.

Wilson, C., Houghton, B., McWilliams, M., Lanphere, M., Weaver, S. and Briggs, R. (1995), Volcanic and structural evolution of Taupo Volcanic Zone, New Zealand: a review, Journal of Volcanology and Geothermal Research 68(13): $1-28$.

Wittlinger, G., Masson, F., Poupinet, G., Tapponnier, P., Mei, J., Herquel, G., Guilber, J., Achauer, U., Guanqi, X., Danian, S. and Team., L. K. (1996), Seismic tomography of northern Tibet and Kunlun: Evidence for crustal blocks and mantle velocity contrast, Earth and Planetary Science Letters 139(1-2): 263279. 
Xu, Y., Li, Z. and Roeker, S. (2007), Uppermost mantle structure and its relation with seismic activity in the central Tien Shan, Geophysical Research Letters $34(10)$.

Zelt, C. and Barton, P. (1998), Three-dimensional seismic refraction tomography: A comparison of two methods applied to data from the Faeroe Basin, Journal of Geophysical Research 103: 7187-7210.

Zhao, D. (2004), Global tomographic images of mantle plumes and subducting slabs: Insight into deep Earth dynamics, Physics of the Earth and Planetary Interiors 146(1-2): 3-34. 


\section{DERIVATION OF EQUATIONS}

\section{A.1 List of Variables}

\section{A.1.1 Seismic tomography}

$T_{i j}$ ray travel time between event $i$ and station $j$

$\alpha_{i}$ travel time in crust at the source

$\beta_{j}$ travel time in crust at the receiver

$\delta_{i j k}$ travel time of seismic ray between event $i$ and station $j$ in cell $k$ within the mantle $S_{k}$ average slowness in cell $k$

$\gamma_{i j}$ correction for velocity depth gradient

\section{A.1.2 Slowness modelling}

A furthest station from event epicenter in station pairing

B closest station to event epicenter in station pairing

1 vector of observations (travel time differences)

$l_{A B}$ travel time difference between stations $\mathrm{A}$ and $\mathrm{B}$

$M$ matrix differencing station arrival time

$\mathbf{p}$ vector of parameters

$s$ signal measurement

$n$ noise measurement 
$\Delta$ distance between event and station

$S_{a v}$ average mantle slowness

$S^{\prime}(\theta)$ anisotropic mantle slowness

$S_{o}$ azimuthally dependent slowness

$\alpha_{Q}$ travel time in crust at the source

$\theta$ path integrals between event and stations

$\phi$ crustal delay terms beneath stations

$\xi^{\text {meas }}$ measurement uncertainties

$\mathbf{E}$ vector of combined errors

$\mathbf{C}_{\text {meas }}$ covariance of measurements

$\mathbf{C}_{\text {mant }}$ covariance of mantle slowness

$\mathbf{C}_{\text {crust }}$ covariance of crustal slowness

$\mathbf{C}_{\text {tot }}$ sum of measurement, mantle and crustal covariances

$Y_{m}$ amplitude of deflection from average mantle slowness

$Y_{c}$ amplitude of deflection of crustal slowness

$\mathbf{x}$ points in the mantle

$D$ correlation distance

\section{A.1.3 Ray Geometry}

$T_{o}$ event origin time

$\alpha_{o}$ delay time due to crustal neighbourhood about the epicenter

$\delta_{o}$ distance to Moho piercing point from epicentre

$T_{i}$ arrival time at station

$\alpha_{i}\left(\alpha_{A}, \alpha_{B}\right)$ delay time due to crustal neighbourhood beneath stations

$\delta_{i}$ distance to Moho piercing point from station

$\Delta_{i}\left(\Delta_{A}, \Delta_{B}\right)$ distance between epicenter and station

$V_{a i}$ apparent mantle velocity

$t\left(t_{A}, t_{B}\right)$ travel time of ray between event and station 


\section{A.2 Derivation of equation 2.8}

Equation 2.8 calculated the covariance between time measurements at station pair $\mathbf{A}$ and $\mathbf{B}$. The time taken for a ray to arrival at a station, can be expressed as an integral over the path joining the event and the station. For stations $\mathbf{A}$ and $\mathbf{B}$ the travel time can be represented as:

$$
\begin{aligned}
& t_{\mathbf{A}}=\int_{s_{A}}{ }^{q} Z\left(x_{A}\right) d x_{A} \\
& t_{\mathbf{A}}=\int_{s_{B}}{ }^{q} Z\left(x_{B}\right) d x_{B}
\end{aligned}
$$

where $Z(x)$ represents the path between epicenter and station.

The covariance of the above equations is given by:

$$
\begin{aligned}
\left\langle t_{A}, t_{B}\right\rangle & =\left\langle\int_{s_{A}}^{q} Z\left(x_{A}\right) d x_{A} \int_{s_{B}}^{q} Z\left(x_{B}\right) d x_{B}\right\rangle \\
\left\langle t_{A}, t_{B}\right\rangle & =\left\langle\int_{s_{A}}^{q} \int_{s_{B}}^{q} Z\left(x_{A}\right) Z\left(x_{B}\right) d x_{A} d x_{B}\right\rangle \\
\left\langle t_{A}, t_{B}\right\rangle & =\int_{s_{A}}^{q} \int_{s_{B}}^{q}\left\langle Z\left(x_{A}\right) Z\left(x_{B}\right)\right\rangle d x_{A} d x_{B}
\end{aligned}
$$

$\left\langle Z\left(x_{A}\right) Z\left(x_{B}\right)\right\rangle$ is equivalent to the covariance between points $x_{A}$ and $x_{B}$. And $\left\langle t_{A}, t_{B}\right\rangle$ is the covariance of the mantle paths $C_{m p a t h}$

$$
C_{m p a t h}\left(\mathbf{s}_{\mathbf{A}}, \mathbf{s}_{\mathbf{B}}, \mathbf{q}\right)=\int_{s_{A}}^{q} \int_{s_{B}}^{q}\left\langle\operatorname{Cov}\left(x_{A}, x_{B}\right)\right\rangle d x_{A} d x_{B}
$$


APPENDIX B

STATION LIST 


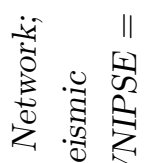

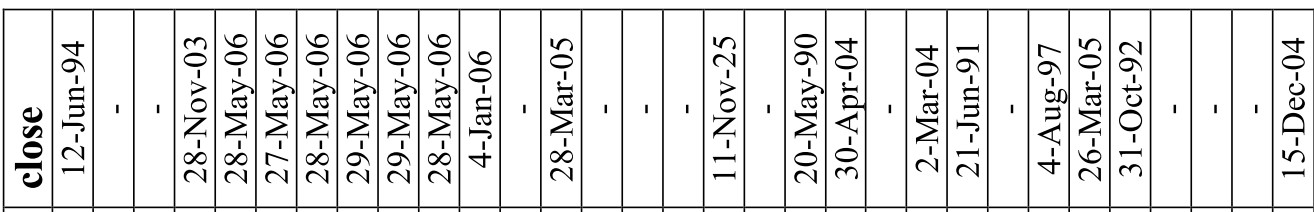

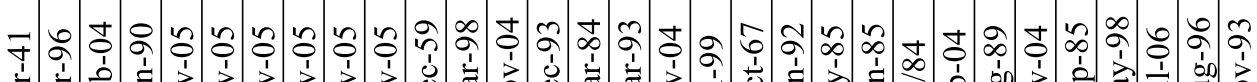

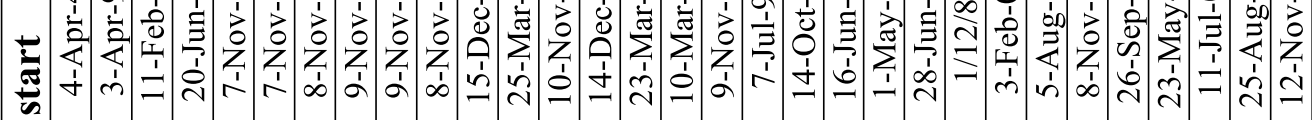

$\therefore>$ क

$\frac{\mathbb{3}}{0} \stackrel{\Xi}{\Xi}$ (1)

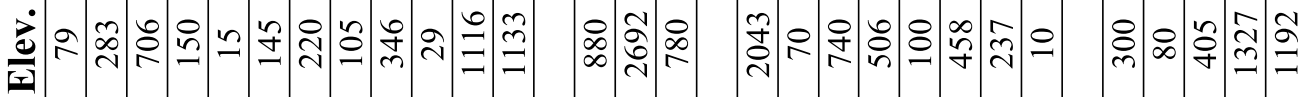

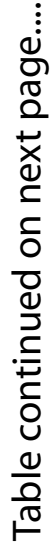

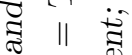

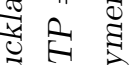
零

||

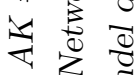
‥ ॠे 过 之.

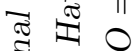

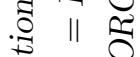
离 00

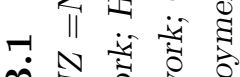

Z1

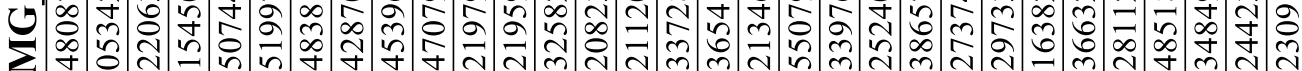
र

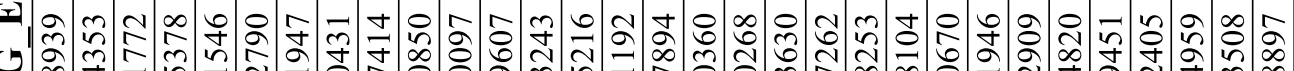

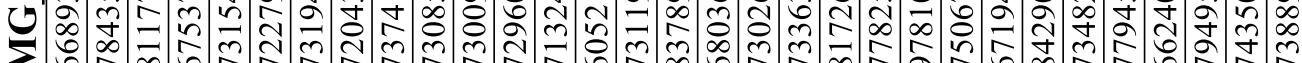

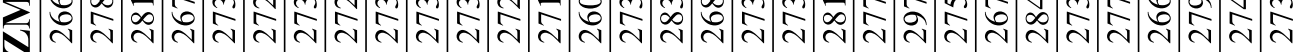

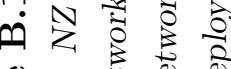
일 $\widetilde{8} \approx$ $\because \underset{ \pm}{\square}$ ปี II 之. ه 蛋

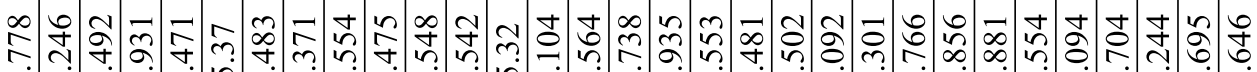

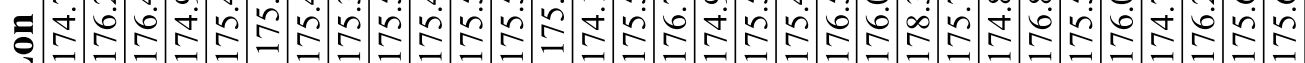
๖.

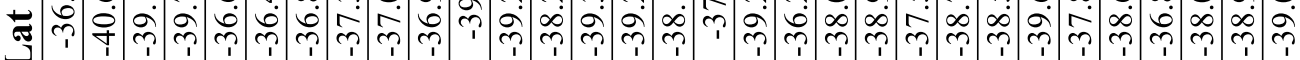

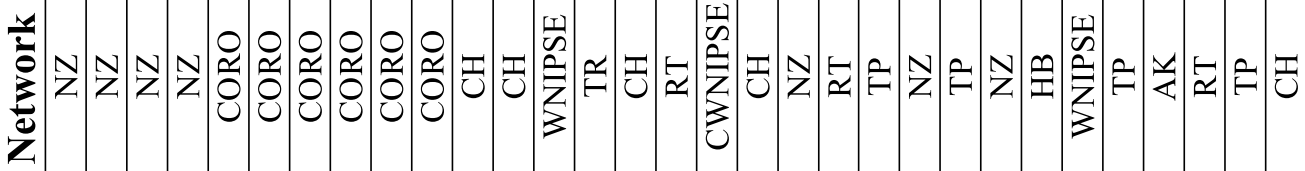
莺 ज)

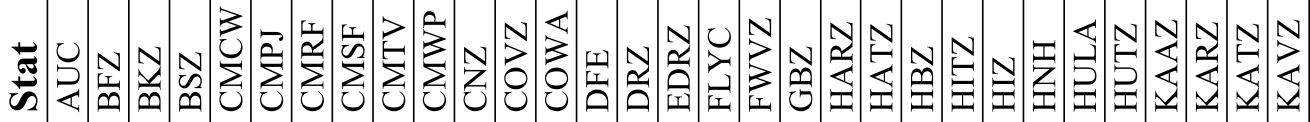
章

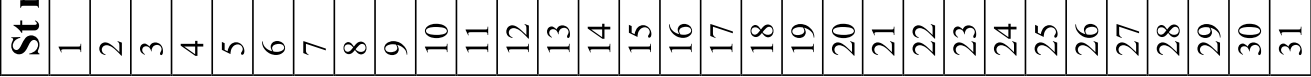




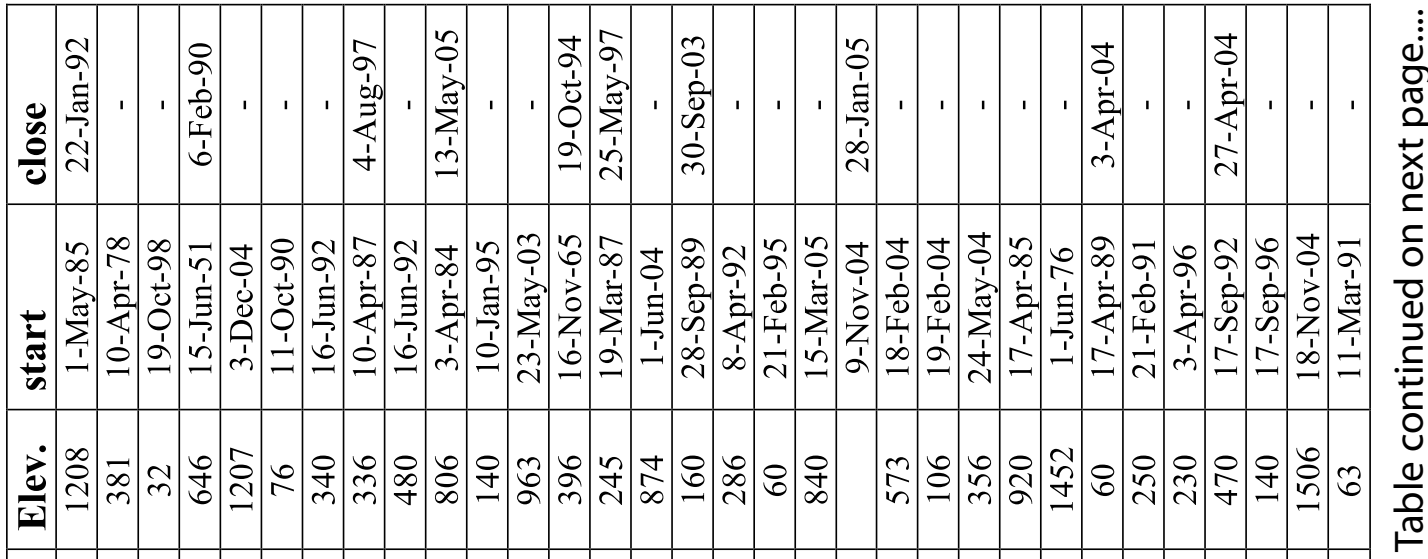

与.

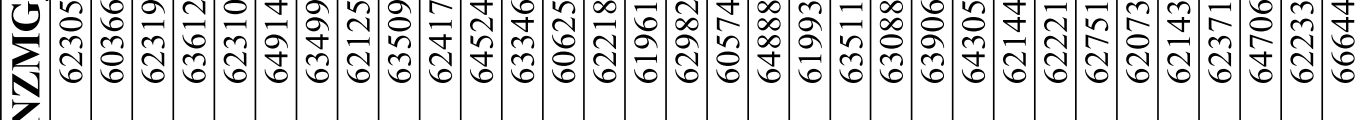

பு

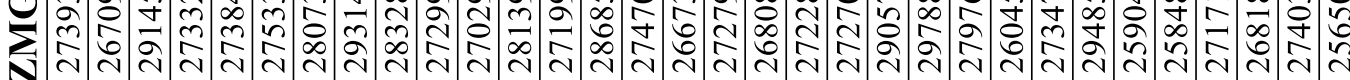

$\mathbf{Z}$

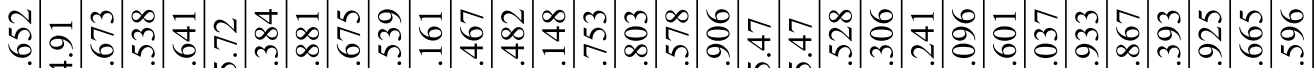
है

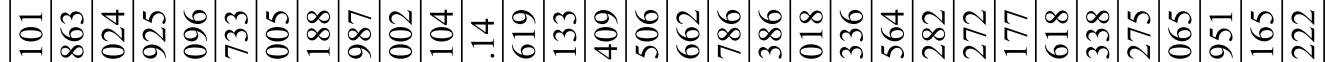
సै

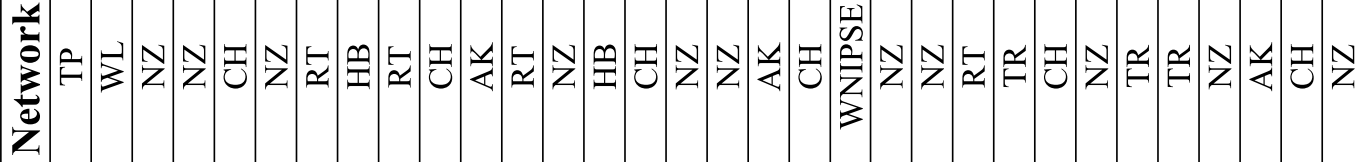

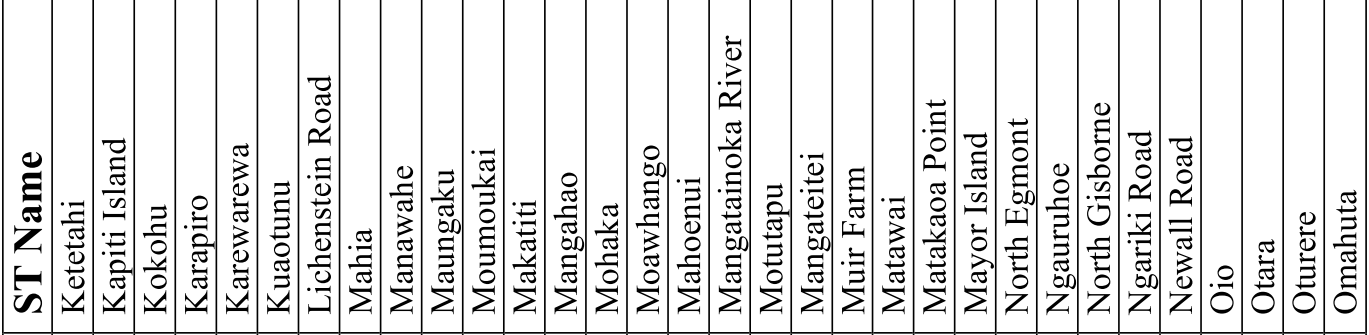

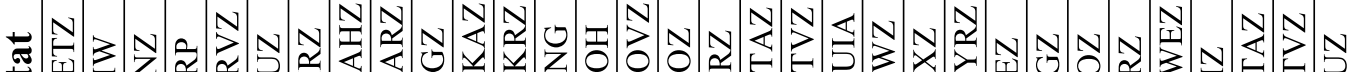

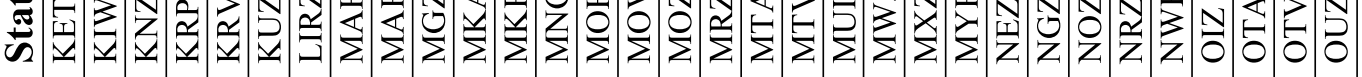

=

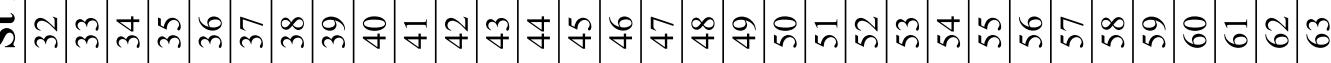




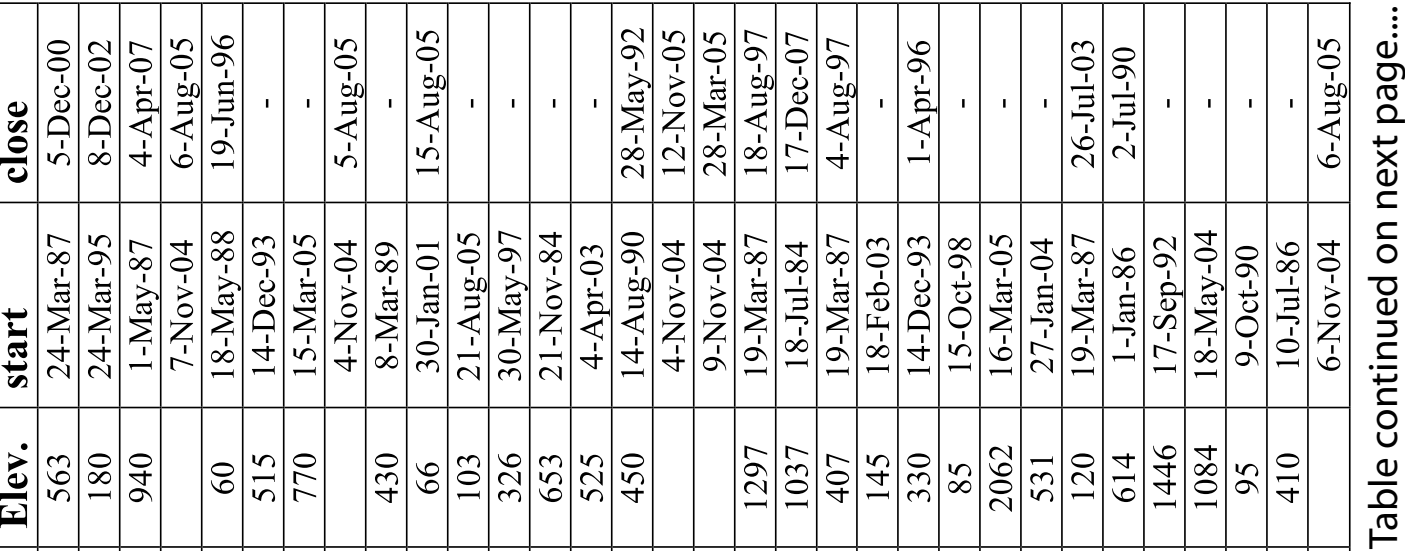

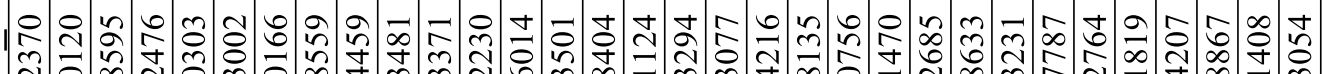

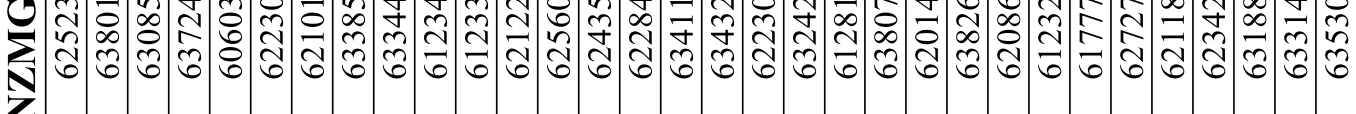

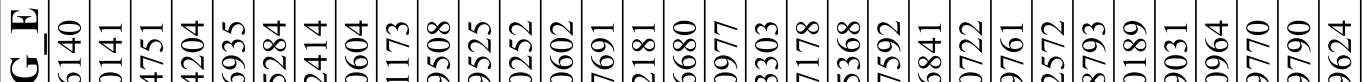

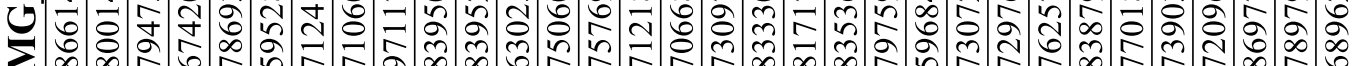

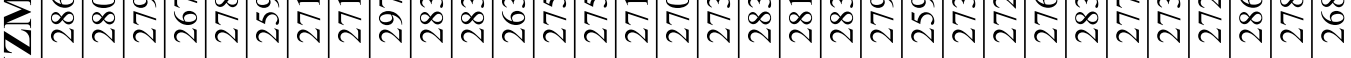

声 సి

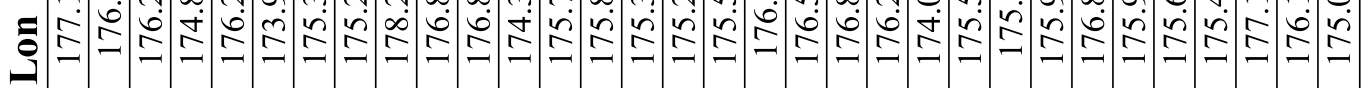

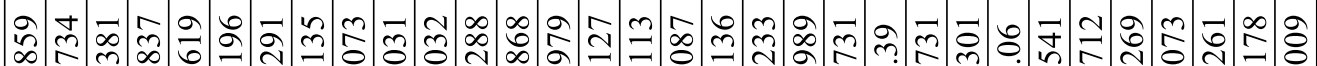

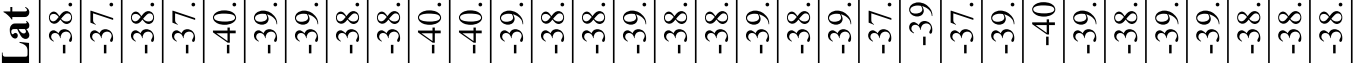

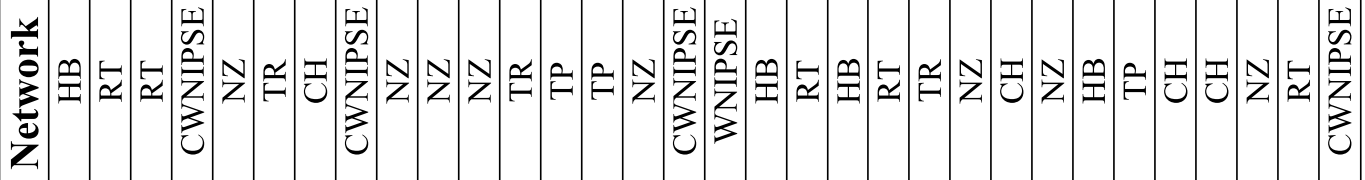

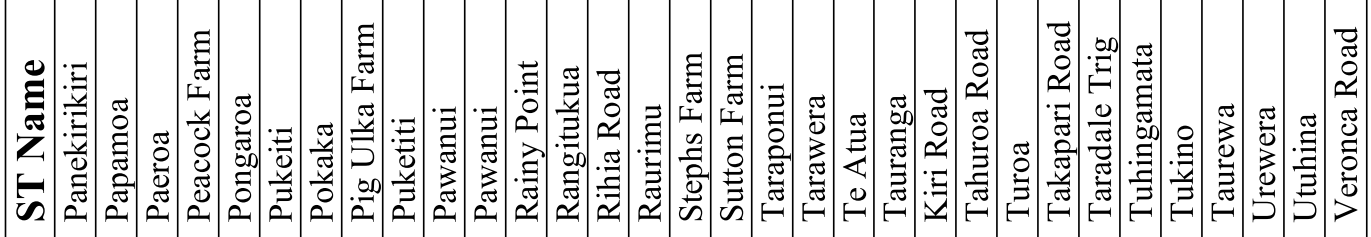

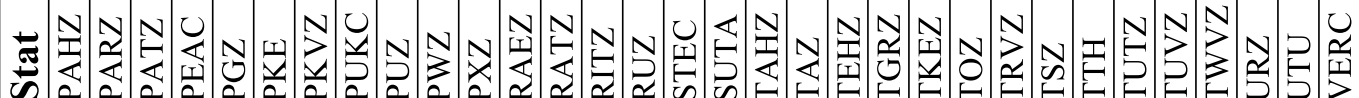

寻

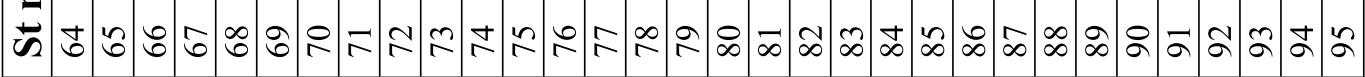




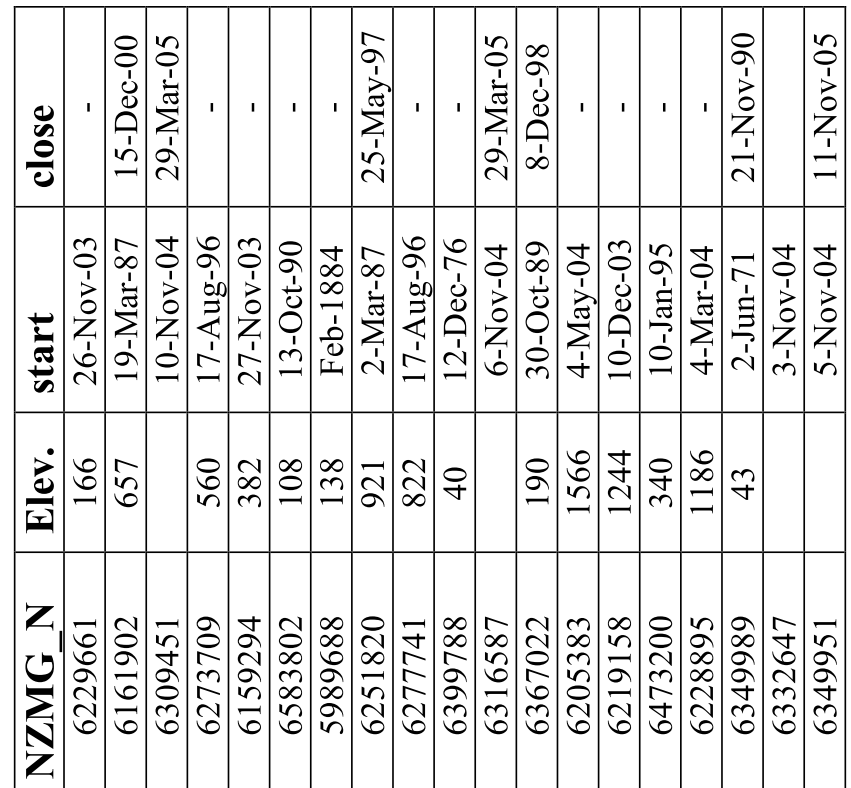

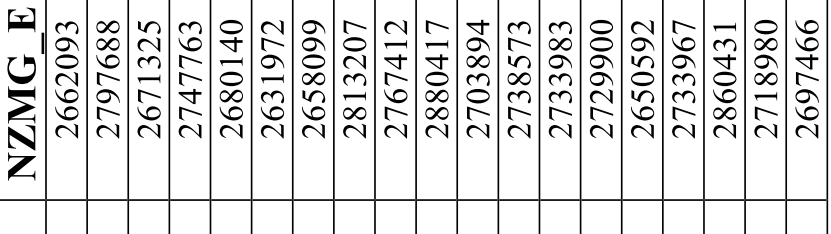

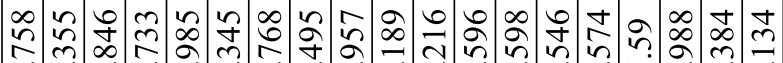
อี

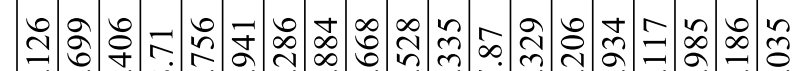
ज्ञ

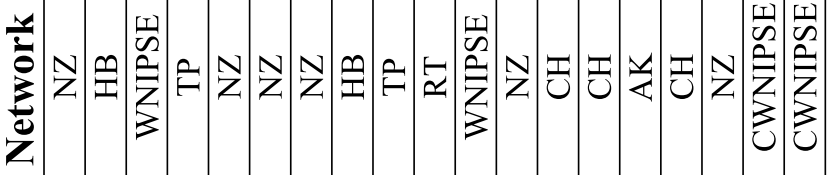

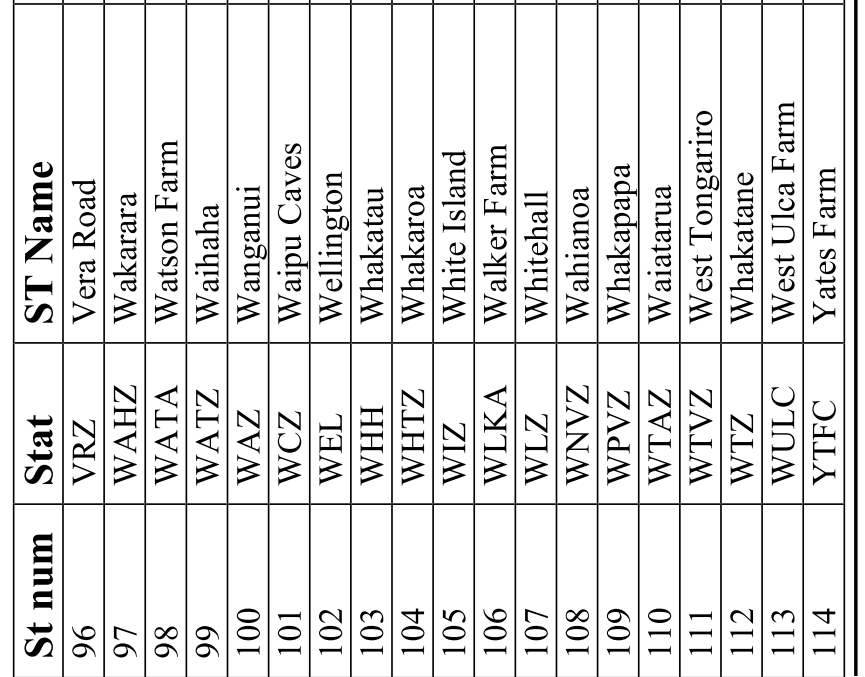


APPENDIX C

\section{FIELDWORK}

\section{C.1 Temporary Deployments}

To sample the uppermantle beneath the central North Island, the NZNSN seismographs in the west of the island were too few for our needs. We deployed two seismograph arrays in the western North Island. The first deployment, WNIPSE (Western North Island Passive Seismic Experiment), was located in the Waikato, central-west North Island, between the latitudes $37.5^{\circ} \mathrm{S}$ and $38.5^{\circ} \mathrm{S}[6380000 \mathrm{~N}-6350000 \mathrm{~N}]$. The second deployment, CORO was located further north, along a north-south line down the eastern coast of the Coromandel Peninsular [6520000 N - 6430000 N].

\section{C.2 Equipment}

Each site was equipped with a sensor (either a Marks Product L4 or a Guralp CMG40T), a GPS antenna, a solar panel, batteries and fencing (when needed). The GPS system ensures that the timing of the data recorder is constantly updated, and that the timing of event arrivals are reliable (to within $\mu$ sec). Solar panels are used to keep the batteries powered to run the seismographs and reduce the need for regular battery changes. Victoria University of Wellington, Institute of Geophysics has designed an Aframe for the short-period stations, which mount the solar panels and have a protruding stem at the top to mount the GPS antenna (fig C.1)

An ideal site for a seismometer would have a clear view of the sky. The reason for 


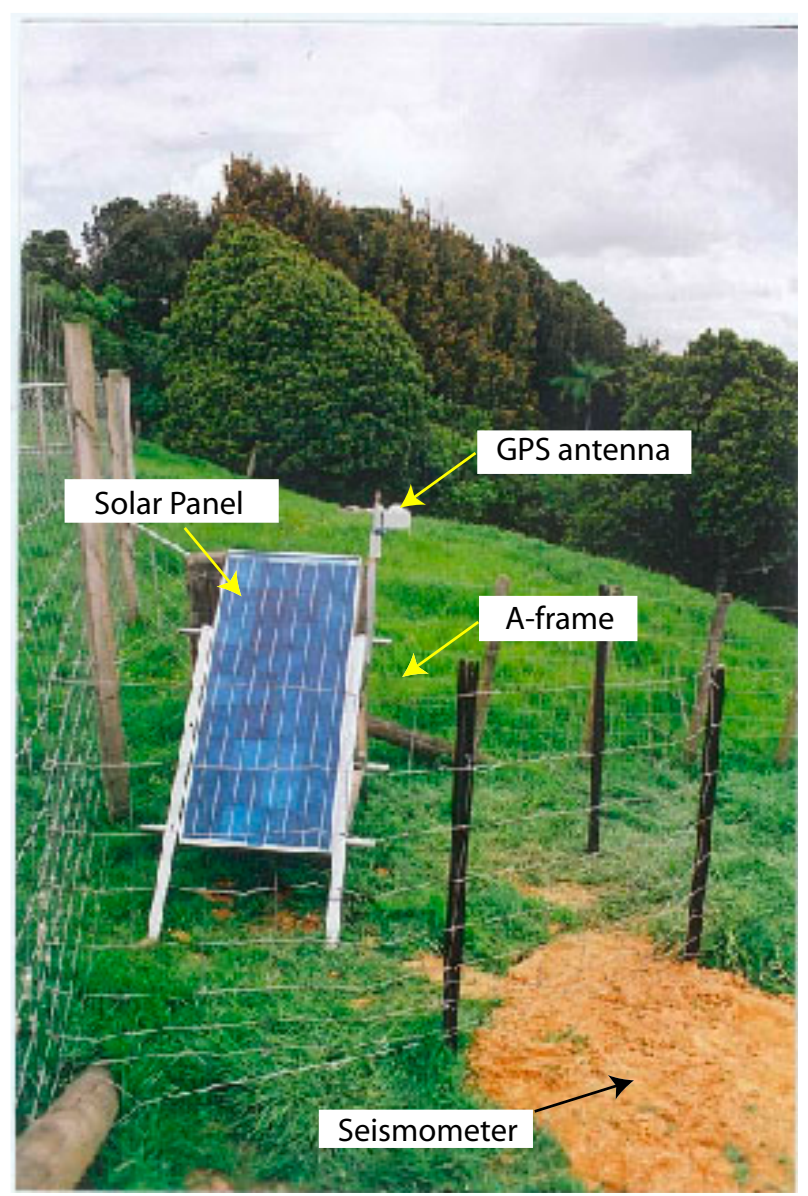

Figure C.1 Photo of the seismograph site consisting of an A-frame supporting a solar panel and GPS antenna.

this is twofold: Firstly, to ensure that sites have adequate sun for the solar panels to keep the batteries charged; secondly, for the GPS antenna to receive signals from a sufficient number of satellites to give accurate timing. The solar panel ideally needs a north facing slope, without trees or buildings obscuring its line-of-sight to the sun.

Seismographs need very accurate timing and all instruments use a GPS antenna to receive time information. When selecting sites, a handheld GPS receiver was carried and if this received the signal from four or more satellites and a position lock was able to be established, then it was considered that the sky coverage was sufficient. 


\section{C.3 Installation and Servicing}

The installation of a seismograph site consists of several steps. Once a site was selected, a hole was dug into the topsoil, in an attempt to reach basement rock. If it was not possible, the hole was stopped at around $70 \mathrm{~cm}$ depth (fig C.2). Typically the top of the sensor was no less than $20 \mathrm{~cm}$ below the surface.

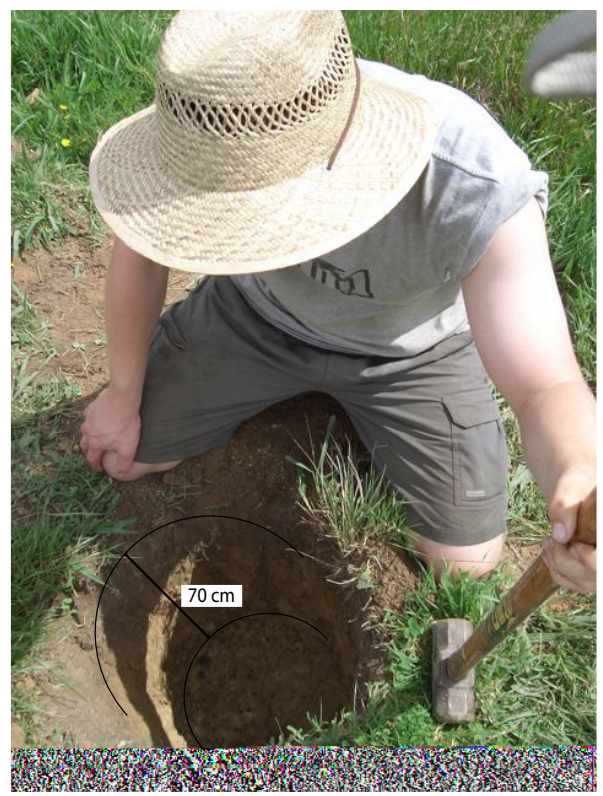

Figure C.2 Photo of the seismograph hole of $70 \mathrm{~cm}$ depth (photo taken by Sonja Greve). This particular site is located on a farm at the top of a hill, where 2 greywake quaries have recently been active.

The sensor is wrapped in a watertight bag, and placed on concrete bases inside a tube casing, to protect the it from the collapse of the soil and, as best it can, water (fig C.3).

Sensors were then aligned to true North.

Once all the equipment was set up at a site, final checks were made for the correct operation of the sensor and GPS antenna. Checking the sensor involved viewing each of the direction components to see if they were picking up a signal, from a stomp-test. The GPS was assured to be working by allowing the position to lock, to at least 4 satellites, before leaving the site. 


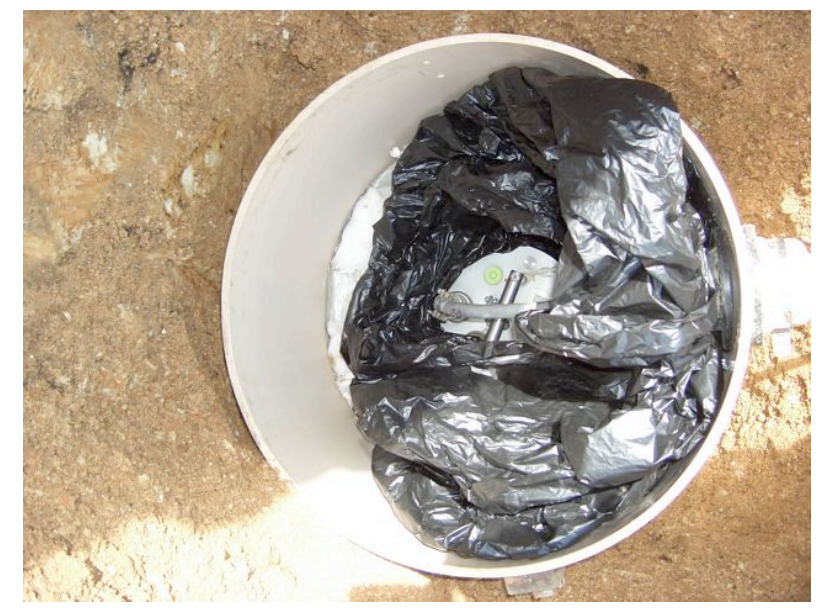

Figure C.3 Photo of the seismograph hole of $70 \mathrm{~cm}$ depth, insulated with a water resistant rubbish bag and a protective tube.

Two weeks after initial installation, sites were revisited to ensure that no problems had been encountered. The equipment was checked to ensure it was still functioning, data was downloaded and checked for unwanted issues with the records. A noise-tosignal ratio was estimated to make sure that the site was worth while. If the noise was too high, the site would be moved. If issues arose, we attempted to fix them while in the field else the faulty components (usually the GPS, storage card or the sensors) were replaced, if spares were available, or else it was brought back to Wellington for servicing. In extreme cases, parts were returned to the manufacturer and new equipment was returned and installed.

If all equipment and records were fine, then new disks were installed and left to record for two months, and then revisited.

\section{C.4 Site selection}

It is preferable for a seismograph to be situated on a solid rock foundation, ideally solid basement rock, to avoid resonance and attenuation of seismic rays. Deployment sites were place directly on the sporadic greywacke outcrops in the both the Waikato (fig C.4) and the Coromandel Peninsular(fig C.5). Those sites not placed directly on bedrock were buried at a depth of a least $70 \mathrm{~cm}$ in soil (fig C.2), in a region which is 
assumed to lie directly above the basement rocks. Concrete was laid at the bottom of the hole to provide a solid flat surface for the sensor.

\section{Geology of the Waikato}

Geologically, the Waikato area lies within the Australian plate, west of the active Australian-Pacific boundary. It predominately consists of silts, sands, gravels and hydrothermally alter Andersites. Basement rocks in this region are mostly marine sandstones (fig C.4) (Edbrooke 2005).

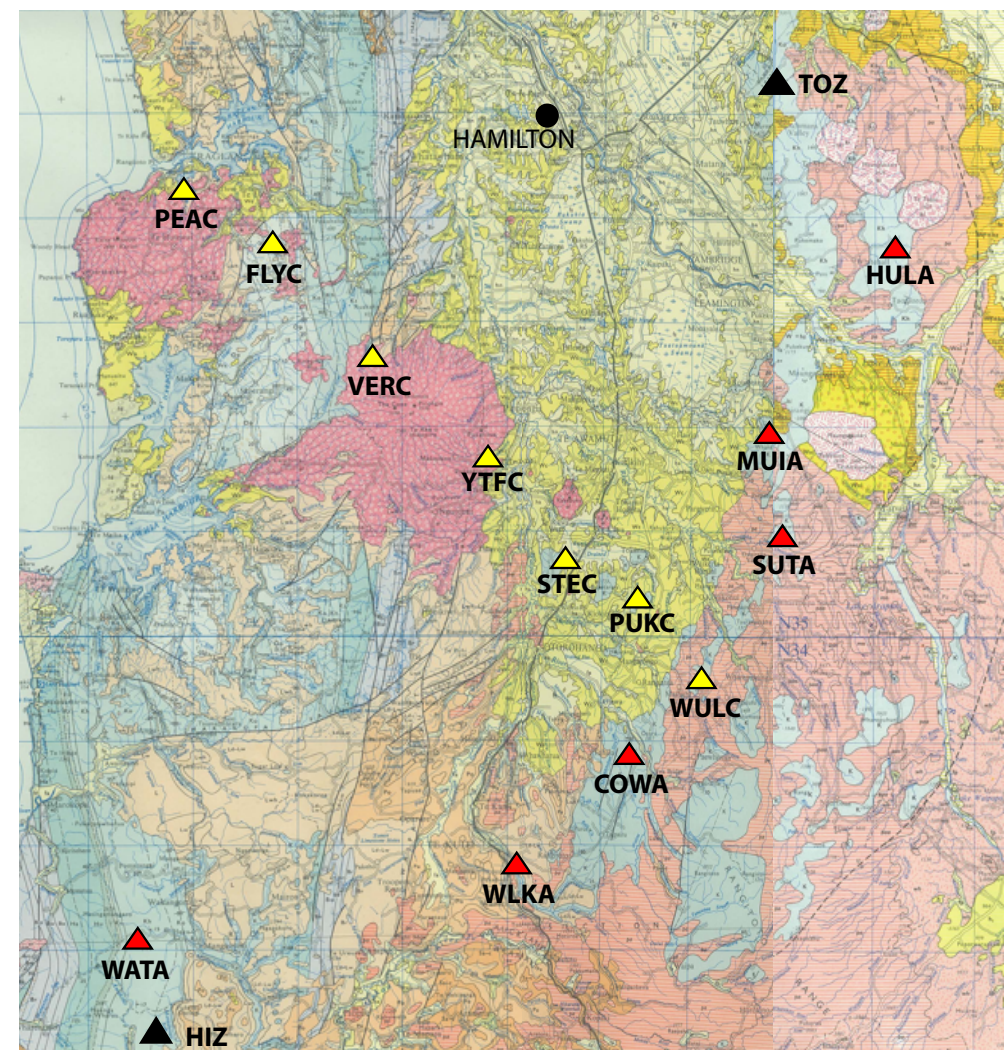

Figure C.4 Geological setting of the Waikato district and the locations of the temporary seismometer deployment. Blue regions indicate marine basement rocks, primarily composed of course sandstone; Pink regions indicate extensively hydrothermally altered Andesites; Yellow regions indicate predominately silts, sands and gravels. (for more details see the Qmap collections (Edbrooke 2005))

Sites are generally chosen to lie in regions of marine basement rocks (fig C.4, table 3.1), to reduce attenuation of seismic waves. Seismograph stations shown in yellow, were primarily located in a straight-line continuation of the CNIPSE-line deployment 
(Henrys et al. 2003), with $10 \mathrm{~km}$ separations, as close to basement rock as possible. Red stations locations, were chosen primarily for their proximity to basement rock.

\section{Geology of the Coromandel}

The Coromandel Peninsula is formed mainly of igneous rocks from volcanic activity that started about 20 Ma. Activity in the Coromandel ceased about $10 \mathrm{Ma}$, and has since moved south to the Rotorua-Taupo region. The oldest rocks in the region are sedimentary rocks consisting of sandstone, siltstone and conglomerate, known collectively as Greywacke. Site are primarily chosen to be located on basement rock (Greywacke).

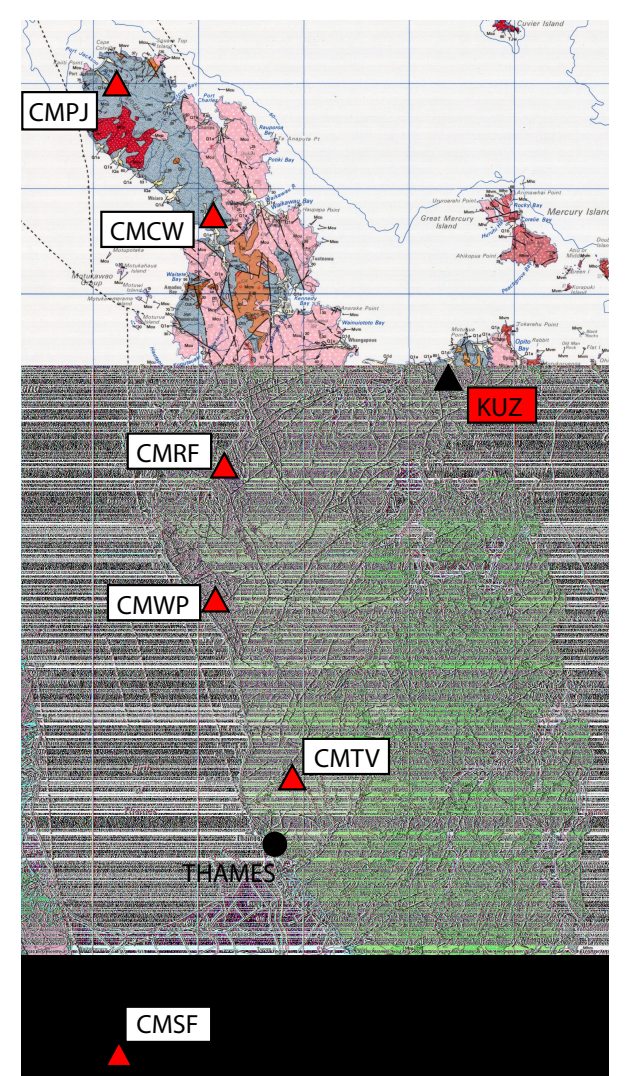

Figure C.5 Geological setting of the Coromandel Peninsular and the locations of the temporary seismometer deployment. Blue regions indicate marine basement rocks, primarily composed of course sandstone; Pink regions indicate extensively hydrothermally altered Andesites; Dark pink represents regions of pumice-rich ignimbrite. (for more details see the Qmap collections (Edbrooke 2001)). 


\section{C.5 Processing of raw data}

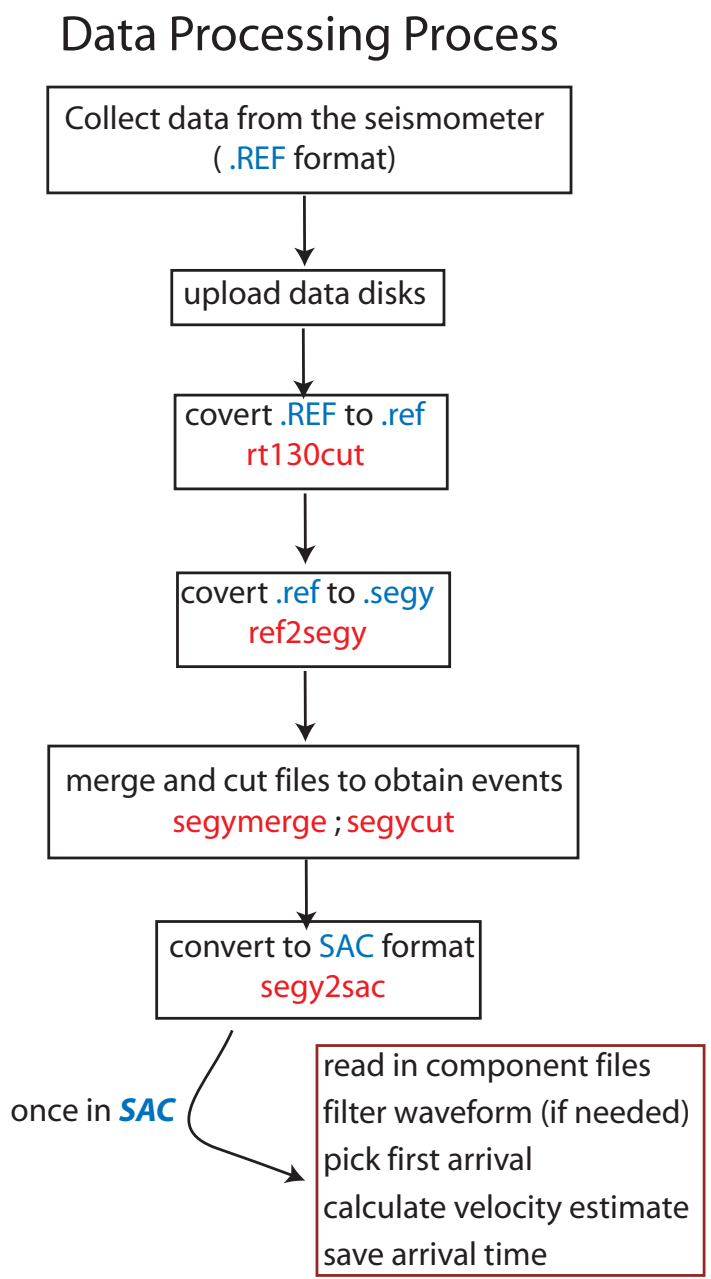

Figure C.6 Flowchart indicating the steps taken to get observations from raw data.

Basic processing of raw seismic data was done to obtain arrival times of events at the deployed sites. Using basic PASSCAL (IRIS 2008) programs, the data was transformed, merged and cut to obtain files containing the earthquake arrival on each component at each station (fig C.6). These files are then converted into .sac format (data format allowing the data to be read into the SAC (Seismic Analysis Code) software (SAC 2008)), to be processed and arrival times picked. Picked times are then used to estimate the average velocity between the event and the receiver. If this velocity is within the range of $5.5-8.5 \mathrm{~km} / \mathrm{s}$ (allowing for the crustal velocity to reduce the 
apparent speed), then it is assumed that the first arrival is a Moho refraction (Pn wave phase).

\section{C.6 List of Events used from temporary deployment}

Table C.1

Relevant events during the WNIPSE deployment

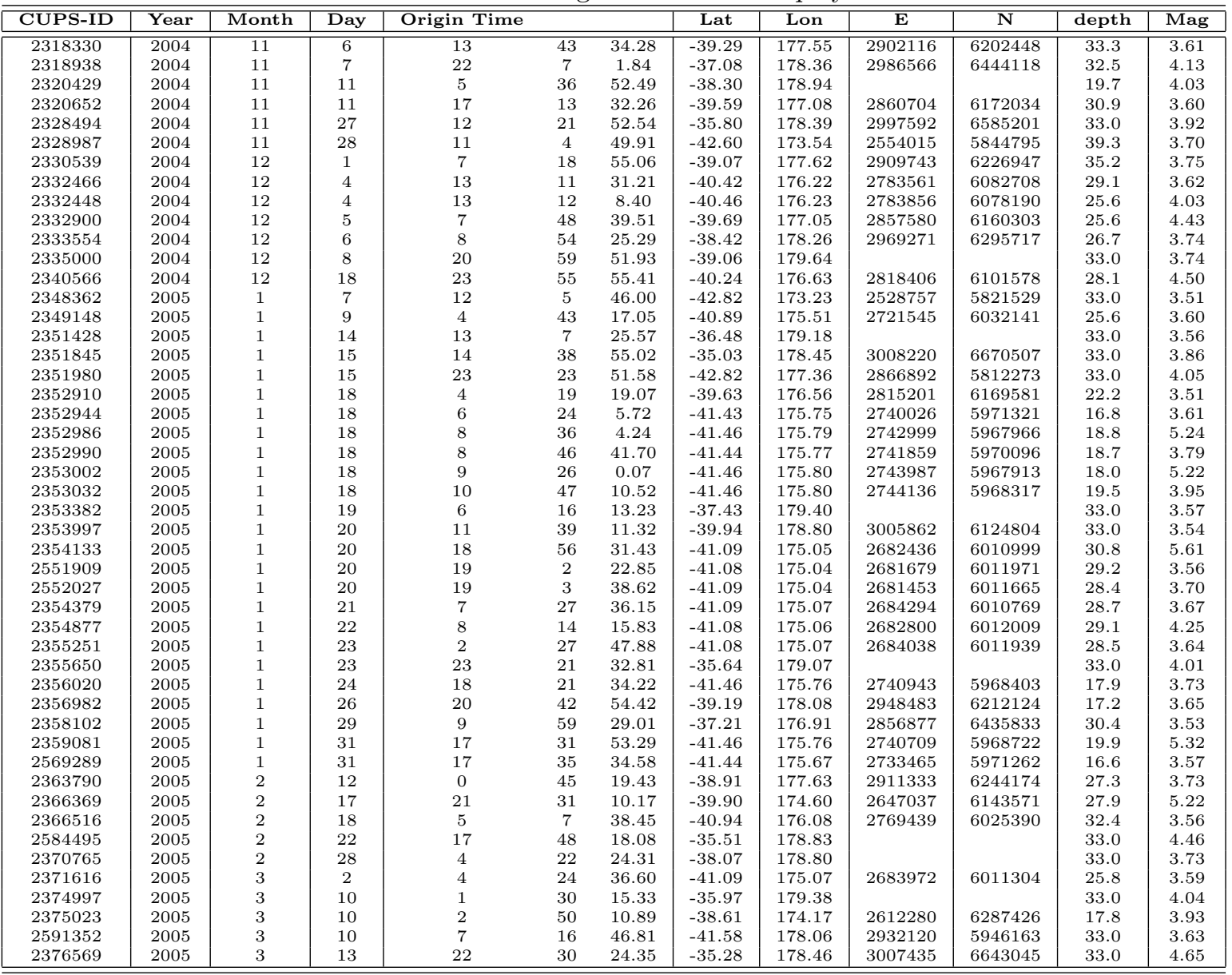


Table C.2

Relevant events during the deployment in the Coromandel Peninsular

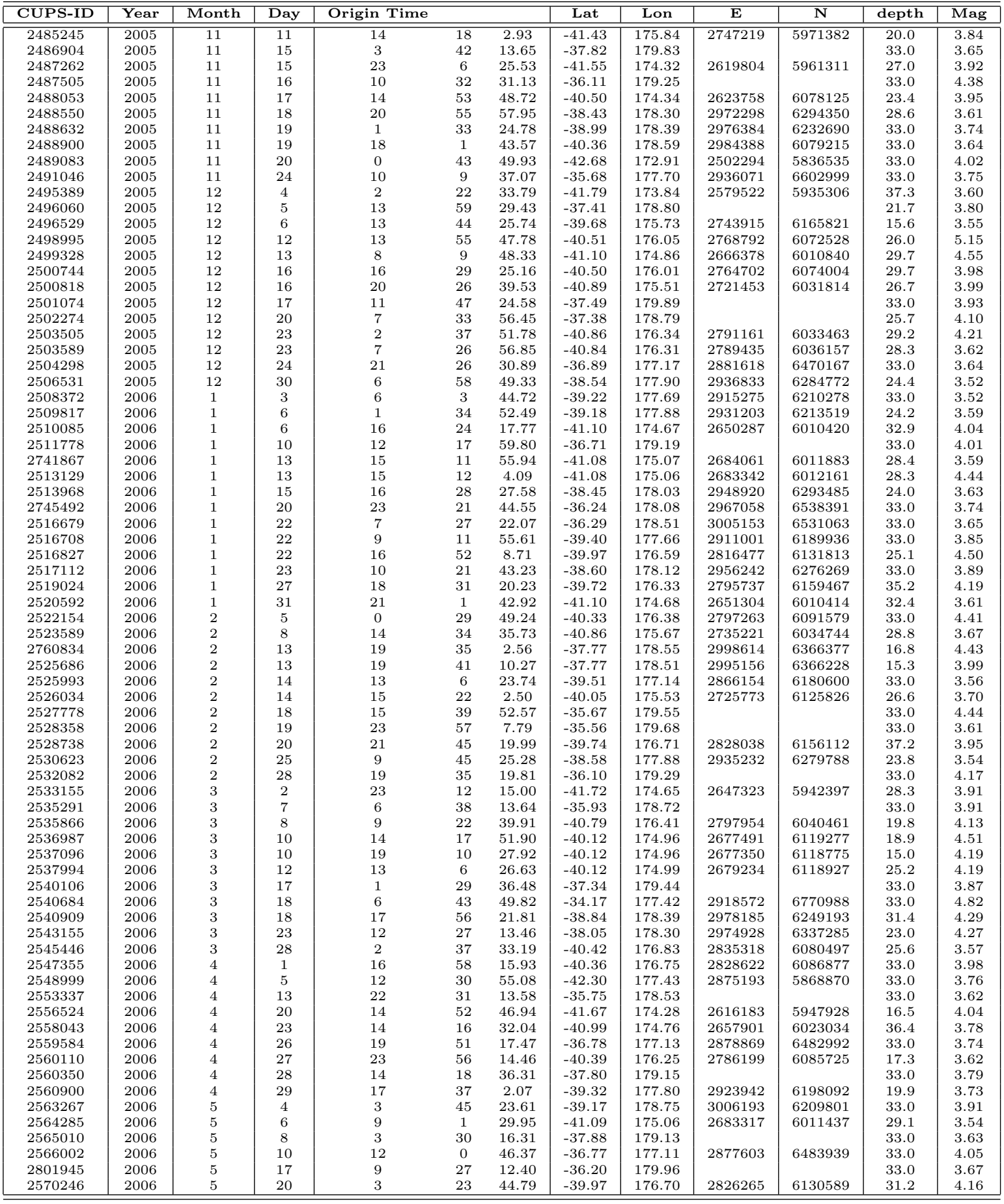


APPENDIX D

PICKING ERRORS 
Table D.1

Differences of re-picked arrival times versus GeoNet arrivals

\begin{tabular}{|c|c|c|c|c|}
\hline$\overline{\text { EQ - CUSP - ID }}$ & Station & GeoNet - pick & $\overline{\text { Re }- \text { picked }}$ & Difference \\
\hline 469232 & $\overline{T A Z}$ & 20.007 & 19.9285 & 0.0785 \\
\hline 1469232 & URZ & 12.364 & 12.247 & 0.117 \\
\hline 1489058 & KATZ & 26.286 & 26.248 & 0.038 \\
\hline 1489297 & CNZ & 48.212 & 48.2965 & -0.0845 \\
\hline 1489297 & MOZ & 54.081 & 54.0355 & 0.0455 \\
\hline 1489297 & URZ & 28.641 & 28.5355 & 0.1055 \\
\hline 1501401 & RATZ & 14.292 & 14.291 & 0.001 \\
\hline 1501401 & WATZ & 15.246 & 15.218 & 0.028 \\
\hline 1528031 & BSZ & 54.668 & 54.594 & 0.074 \\
\hline 1528031 & CNZ & 44.273 & 44.294 & -0.021 \\
\hline 1528031 & EDRZ & 26.937 & 27.0035 & -0.0665 \\
\hline 1528031 & HARZ & 29.764 & 29.727 & 0.037 \\
\hline 1528031 & KAVZ & 42.79 & 42.74 & 0.05 \\
\hline 1528031 & LIRZ & 29.998 & 29.994 & 0.004 \\
\hline 1528031 & MARZ & 26.643 & 26.6265 & 0.0165 \\
\hline 1528031 & MGZ & 43.397 & 43.3885 & 0.0085 \\
\hline 1528031 & MGZ & 43.397 & 43.3885 & 0.0085 \\
\hline 1528031 & MGZ & 43.397 & 43.3885 & 0.0085 \\
\hline 1528031 & MOZ & 48.937 & 48.8535 & 0.0835 \\
\hline 1528031 & NGZ & 43.588 & 43.5465 & 0.0415 \\
\hline 1528031 & NGZ & 43.588 & 43.5465 & 0.0415 \\
\hline 1528031 & OIZ & 45.062 & 45.026 & 0.036 \\
\hline 1528031 & PATZ & 33.377 & 33.3635 & 0.0135 \\
\hline 1528031 & $\mathrm{TAZ}$ & 30.181 & 30.1855 & -0.0045 \\
\hline 1534158 & $\mathrm{CNZ}$ & 46.703 & 46.6035 & 0.0995 \\
\hline 1534158 & URZ & 27.079 & 27.0645 & 0.0145 \\
\hline 1540707 & RATZ & 15.218 & 15.214 & 0.004 \\
\hline 1540707 & URZ & 32.353 & 32.3215 & 0.0315 \\
\hline 1540707 & WATZ & 16.093 & 16.0615 & 0.0315 \\
\hline 1568731 & NGZ & 55.738 & 55.687 & 0.051 \\
\hline 1568731 & URZ & 35.61 & 35.55 & 0.06 \\
\hline 1586439 & CNZ & 47.192 & 47.1915 & 0.0005 \\
\hline 1586439 & NGZ & 46.538 & 46.552 & -0.014 \\
\hline 1598181 & KNZ & 27.592 & 27.591 & 0.001 \\
\hline 1598181 & URZ & 40.09 & 40.09 & 0 \\
\hline 1600244 & CNZ & 47.224 & 47.2505 & -0.0265 \\
\hline 1600244 & FWVZ & 47.845 & 47.819 & 0.026 \\
\hline 1600244 & KAVZ & 45.595 & 45.5525 & 0.0425 \\
\hline 1600244 & NGZ & 46.576 & 46.514 & 0.062 \\
\hline 1600244 & URZ & 26.775 & 26.7425 & 0.0325 \\
\hline 1601222 & CNZ & 46.037 & 46.0395 & -0.0025 \\
\hline 1601222 & FWVZ & 46.404 & 46.33 & 0.074 \\
\hline 1601222 & KAVZ & 44.554 & 44.527 & 0.027 \\
\hline 1601222 & URZ & 25.823 & 25.8015 & 0.0215 \\
\hline 1630864 & MGZ & 22.98 & 22.902 & 0.078 \\
\hline 1630864 & OIZ & 20.738 & 20.749 & -0.011 \\
\hline 1638076 & CNZ & 48.699 & 48.667 & 0.032 \\
\hline 1638076 & NGZ & 47.867 & 47.8385 & 0.0285 \\
\hline 1638076 & URZ & 28.261 & 28.2705 & -0.0095 \\
\hline 1647680 & NGZ & 46.006 & 46.007 & -0.001 \\
\hline 1663531 & BSZ & 51.302 & 51.261 & 0.041 \\
\hline 1663531 & CNZ & 41.8 & 41.8065 & -0.0065 \\
\hline 1663531 & HARZ & 28.482 & 28.456 & 0.026 \\
\hline 1663531 & KATZ & 39.335 & 39.3125 & 0.0225 \\
\hline 1663531 & KNZ & 21.039 & 20.998 & 0.041 \\
\hline 1663531 & MGZ & 40.818 & 40.8155 & 0.0025 \\
\hline 1663531 & MOZ & 47.697 & 47.6835 & 0.0135 \\
\hline 1663531 & NGZ & 41.112 & 41.1125 & -0.0005 \\
\hline 1663531 & OIZ & 42.25 & 42.23 & 0.02 \\
\hline 1663531 & PATZ & 31.412 & 31.401 & 0.011 \\
\hline 1663531 & URZ & 22.332 & 22.306 & 0.026 \\
\hline 1663531 & UTU & 32.048 & 32.049 & -0.001 \\
\hline 1663531 & WHTZ & 35.696 & 35.653 & 0.043 \\
\hline 1663534 & CNZ & 40.935 & 40.914 & 0.021 \\
\hline 1663534 & NGZ & 40.168 & 40.143 & 0.025 \\
\hline
\end{tabular}




\section{MODELLING CODES}

\section{E.1 ImpEQcalc}

ImpEQcalc is a matlab code created to determine all possible station pairings and extract earthquakes from the event list that lie roughly inline with them, and satisfy selection criteria.

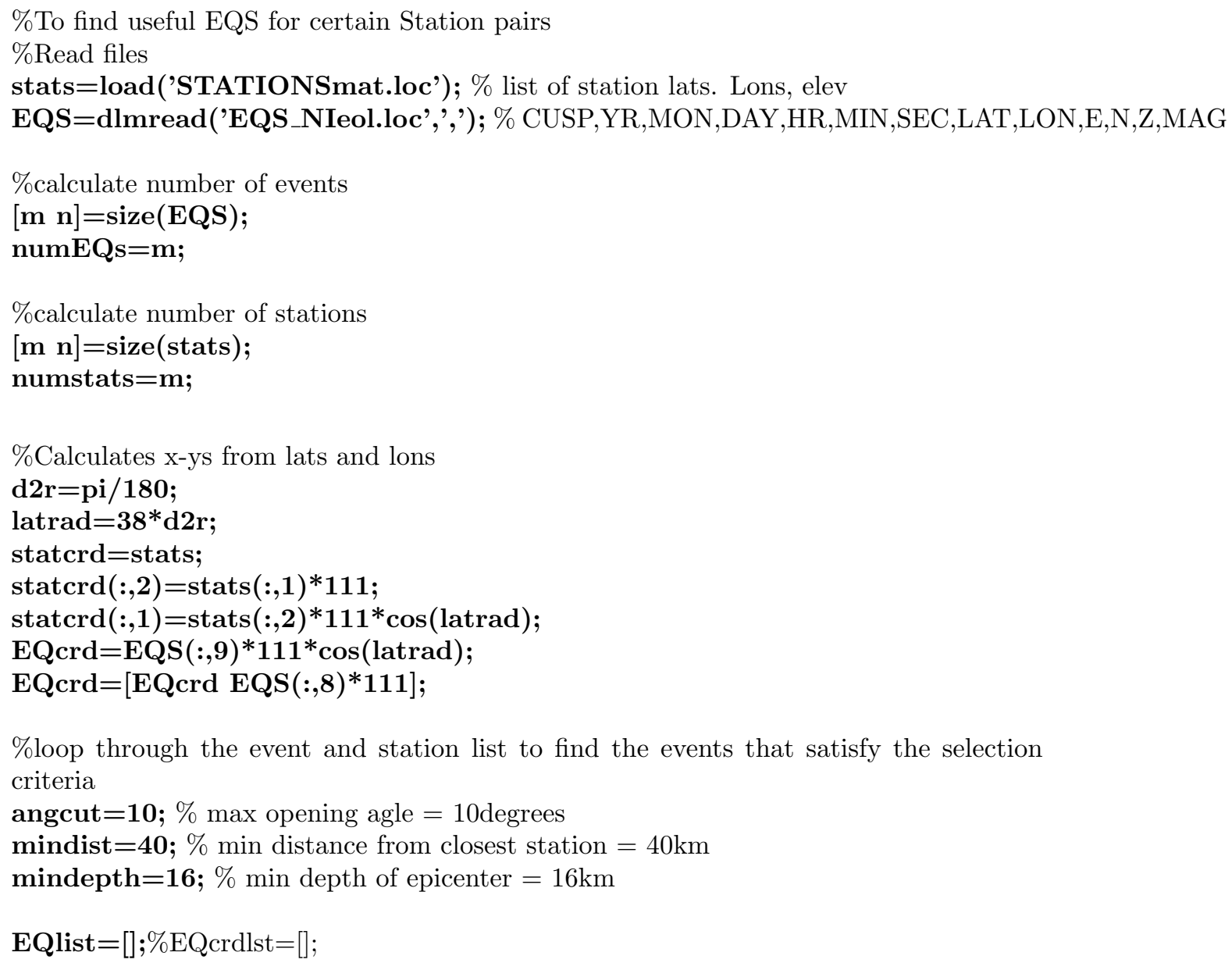




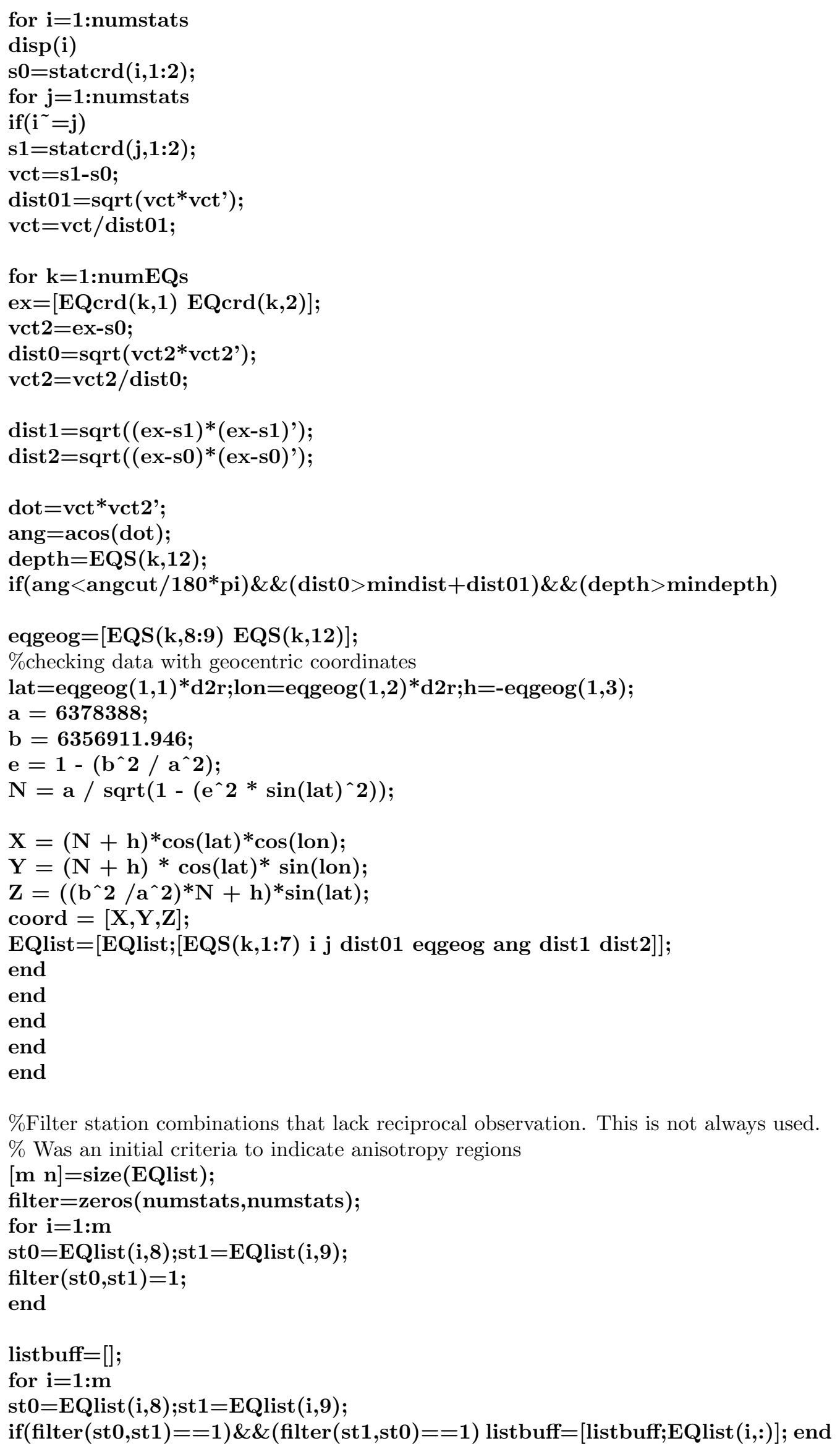




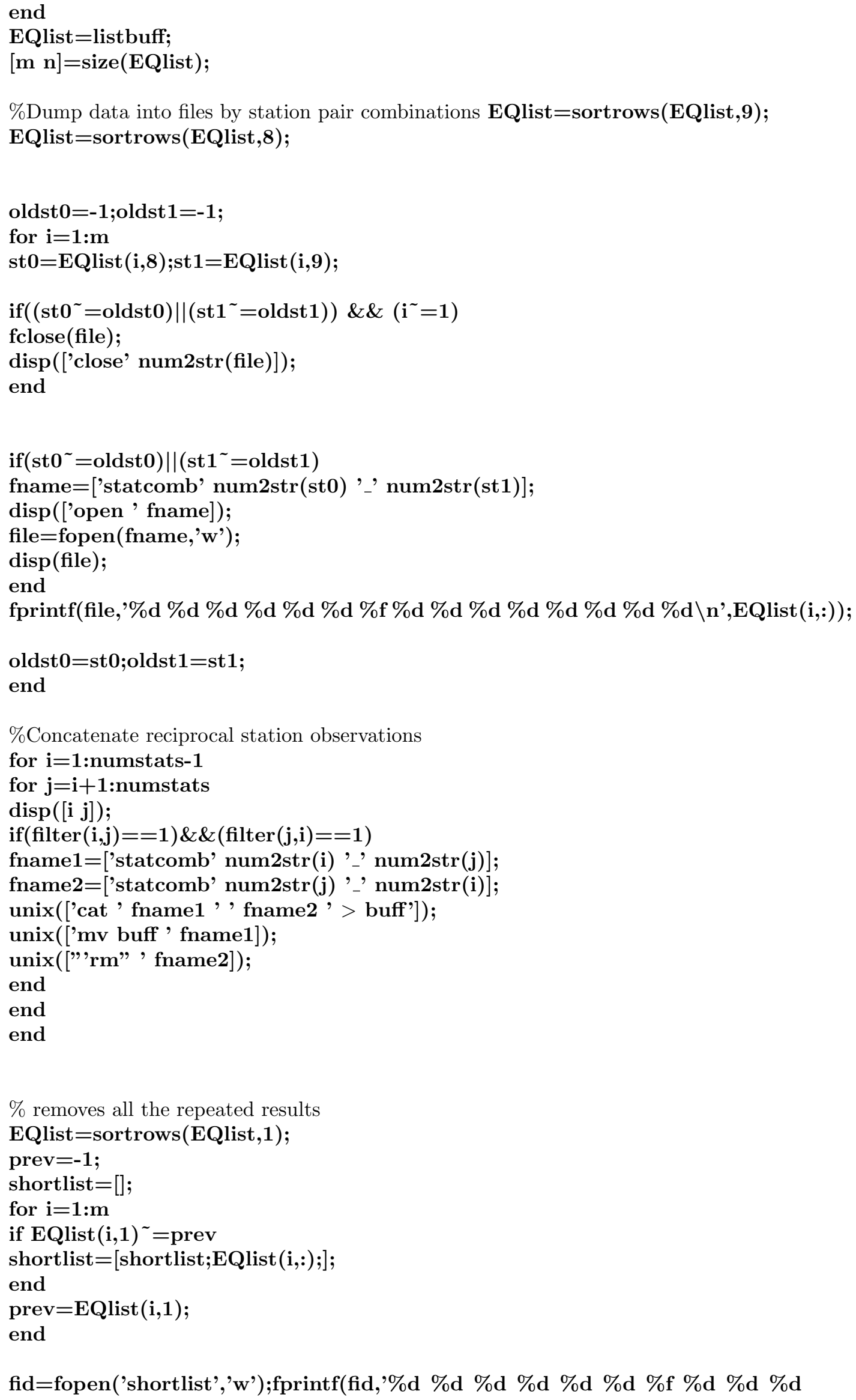


\%d \%d \%d \%d \%d);

fid=fopen('EQlist','w');fprintf(fid,'\%d \%d \%d \%d \%d \%d \%f \%d \%d \%d \%d \%d \%d \%d \%d);

\section{E.2 MARCOV}

MARCOV (Mantle Analysis Routine - Covariance) is a $\mathrm{C}++$ source code that generates a covariance function from event observations and ray-paths. It breaks each ray-path into 32 gaussian-spaced points of covariance and correlates these with each signal point defined on a surface. See attached CD for code.

The classes and functions are described below.

\section{E.2.1 Classes}

$C_{\text {erf }}$ Handles error function reference table.

$C_{\text {paths }}$ Handles all information relavent to paths, including file reading, path redundancy check, and uncertainty filters.

\section{E.2.2 Functions}

Ginteg preforms double Gaussian integration covariance function.

CalcCov calculates the paths covariance

Gsiginteg performs gaussian integration of signal points on a surface.

CalcSigCov calculates covariance of a "signal" point with respect to a pair of paths

GuassQuadCoeff Gaussian quadrature is performed by numerically integrating a function

DumpPars output the Matrices needed 
Main reads input parameters and calls all other routines

\section{E.3 MAR}

MAR is a matlab code which allows various processing options to be selected. It calls up MARCOV to calculate the covariance matrix of observations (see Appendix MARCOV). The velocity estimation can be calculated along with estimates for crustal station terms and anisotropic effects.

\section{E.3.1 Defining parameters:}

This section allows the data files and processing options to be selected.

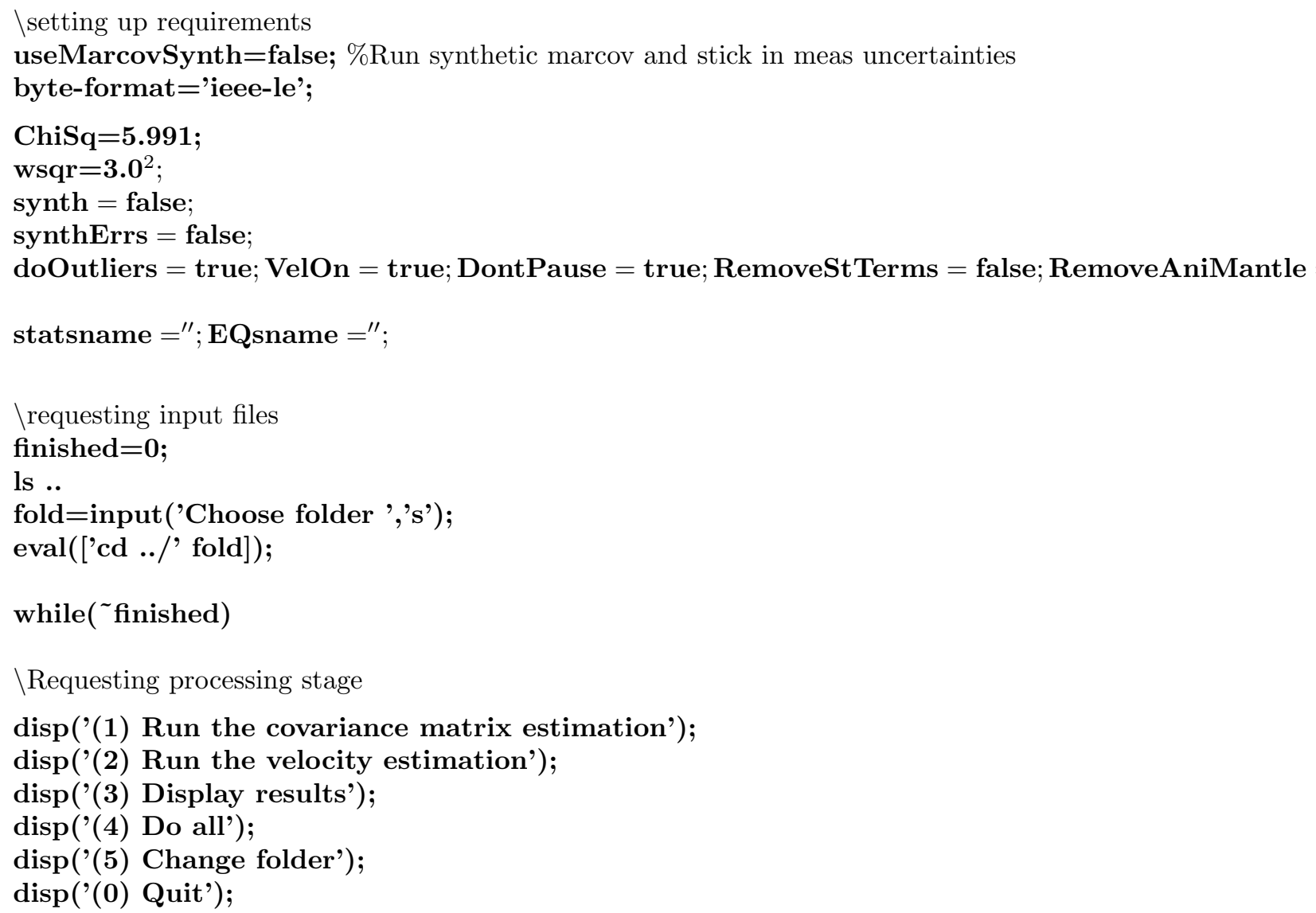


inp=input ('Choice?' ');

if $($ inp $==0$ )

finished $=1$;

end;

\section{E.3.2 Covariance function:}

This section calls up the $\mathrm{C}++$ source code MARCOV to calculate the covariance functions between raypaths and signal points to raypath.

$\backslash$ To calculate the covariance function by calling up MARCOV. if $(\operatorname{inp}==1) \|(\operatorname{inp}==4)$

ls

statsname=input('Stations file name ','s'); \input station list if $($ length $($ statsname $)=0$ )

$\backslash$ call up default file names

statsname='STATS'

EQsname='EQS';

pathsname='PATHS';

else

EQsname=input('Earthquakes file name ','s'); \input EQ list

pathsname=input('Paths file name','s'); \input Path data

end

corrdist =input('Correlation distance','s'); \input station correlation distance (km)

if $($ length $($ corrdist $)=\mathbf{=})$

$\backslash$ set defaults is correlation distance is not stated

corrdist $=$ '100';

bounds='2590 298061506600 10';

locerr $=$ '10';

timecut='0.8';

else

bounds=input('Grid bounds $<$ xmin xmax ymin ymax step $>$ ','s'); \input grid bounds

if $($ length $($ bounds $)==0)$

bounds='2590 298061506600 10';

end

$\backslash$ input mislocation error details

locerr=input('EQ location error (km) ','s');

timecut=input('Cutoff time for EQ location error (seconds) ','s');

end

$\backslash$ calling up MARCOV to calculate the covariance matrix

eval(['!../source/marcov2, statsname ', EQsname', pathsname', corrdist

,' bounds, 'locerr, , timecut]);

end 


\section{E.3.3 Calculation of velocity estimate:}

This section estimates the velocity variations from the covariance functions calculated in MARCOV, allowing for various crustal phenomena such as variation in thickness beneath each station and anisotropy.

$\backslash$ To calculate velocity estimate for Pn wave Phase

$\operatorname{if}(\operatorname{inp}==2) \|(\operatorname{inp}==4)$

$\%$ NOTE - data format: StA StB Azimuth time distance

$\%$ Read all the parameters and paths file name from marpar, which was outputted by marcov

fid=fopen('marpar','r');

marpars $=$ fscanf(fid,' $\%$ f', 7 );

pathsname $=$ fscanf $\left(\right.$ fid, $\left.\% \mathrm{~s}^{\prime}, 1\right)$;

statsname $=$ fscanf $\left(\right.$ fid, $\left.{ }^{\prime} \% \mathrm{~s}^{\prime}, 1\right)$;

fclose(fid);

CheckOutliers $=$ true;

VectorScale=1000; \Scale of anisotropy bars

anidecim=10; \reduces number of anisotropy bars plotted

StParsOn=true;

$\backslash$ input model crustal parameters

MeasErr=input('Measurement error (s) ');

if $($ length $($ MeasErr $)=0$ )

MeasErr $=0.15$;

ScaleCov=0.015; \%squared later

else

\wobbliness of surface through observations (raypath integral)

ScaleCov=input('Modelled wobbliness of surface (s) ')

end

$\backslash$ crustal correlation between each station stcorD=input('Please input the correlation distance between stations $(\mathrm{m})$ ');

$\backslash$ maximum that a time delay can vary from some baseline value

statvar=input('Please enter maximum correlated station delay time (s) ');

statvar $=$ statvar $^{\wedge} \mathbf{2}$

$\backslash$ allows for dipping interfaces resulting in anisotropic measurements at stations

statanivar=input('Please enter the station term anisotropy (s) ');

statanivar $=$ statanivar $^{\wedge} 2$; 


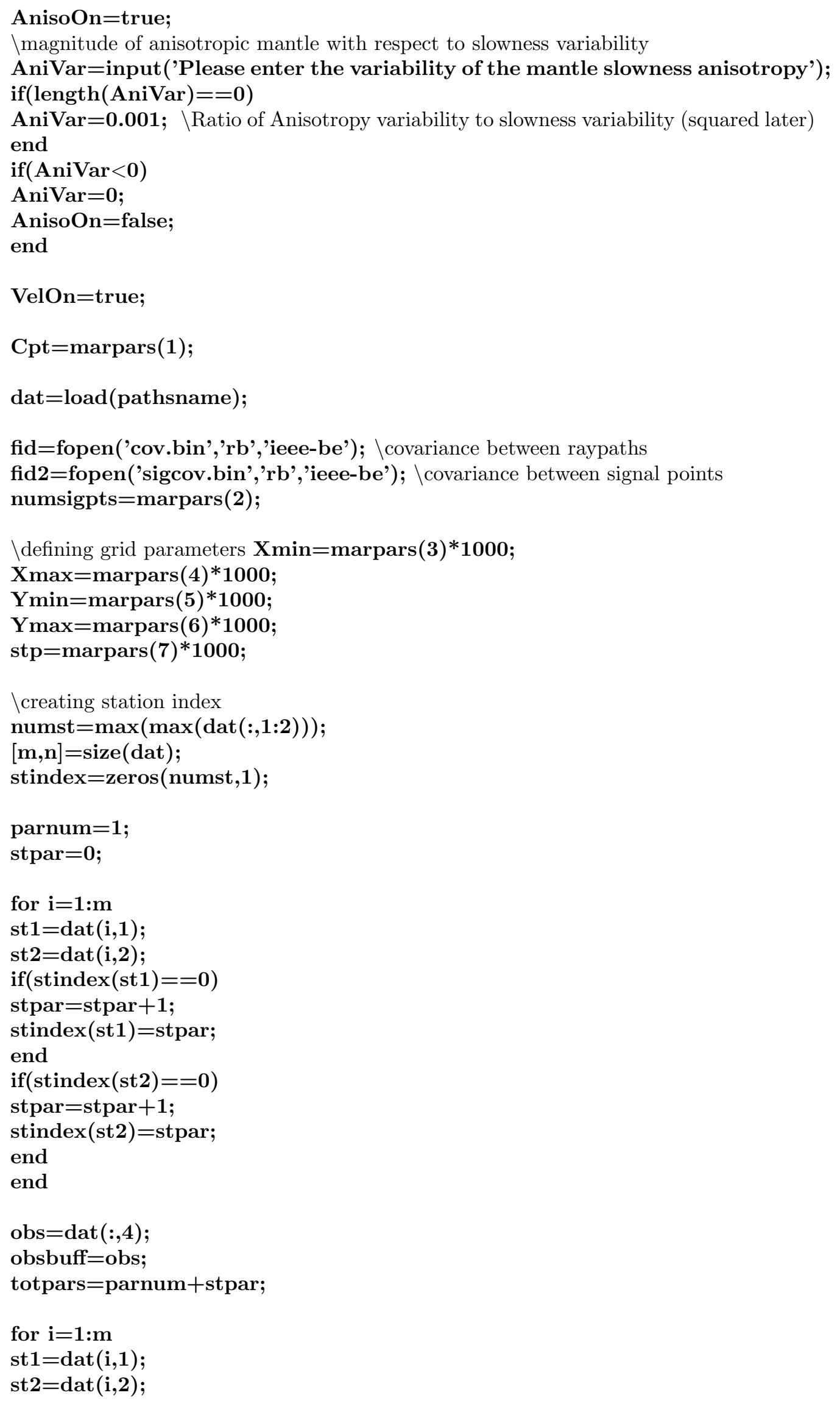




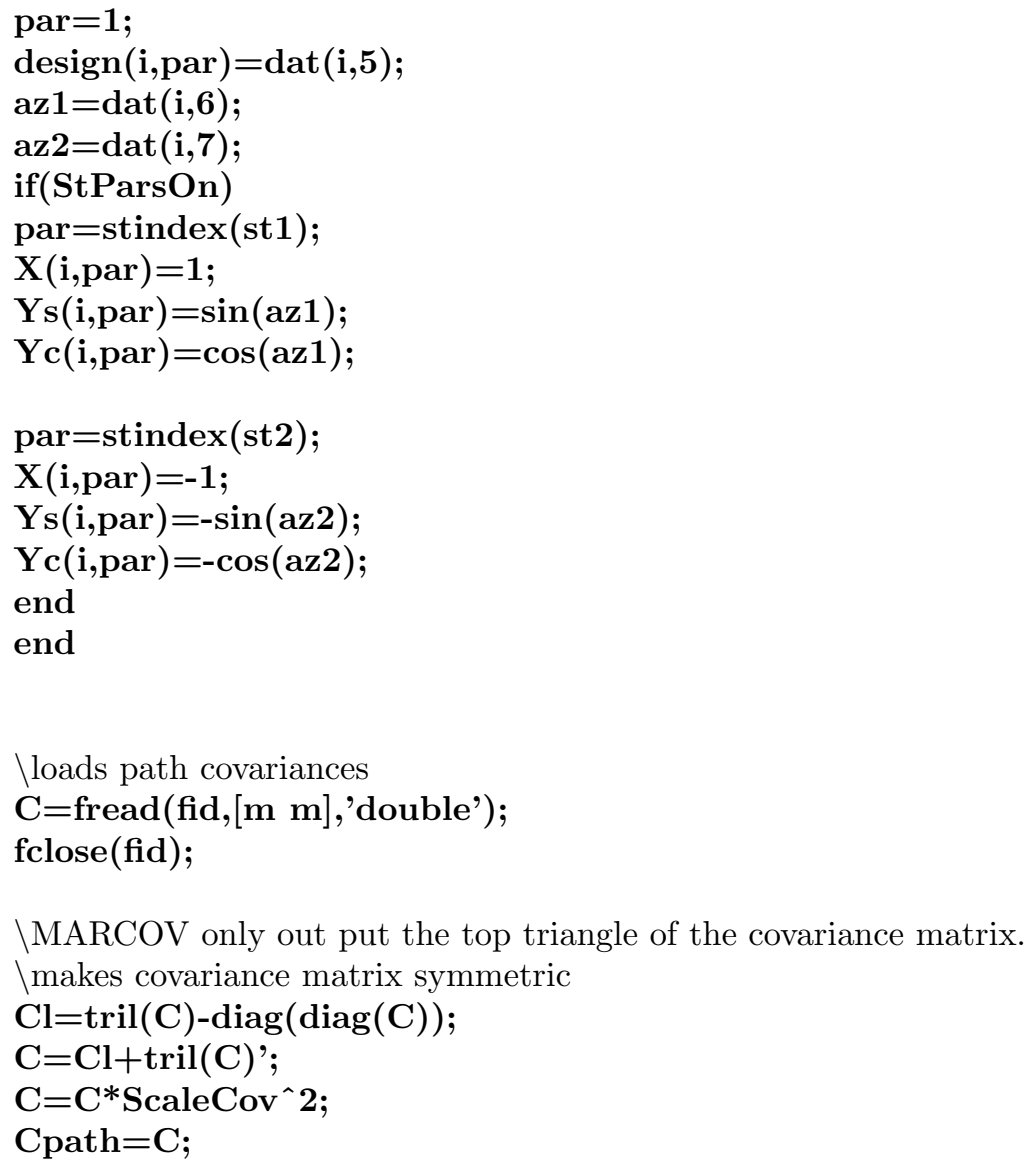




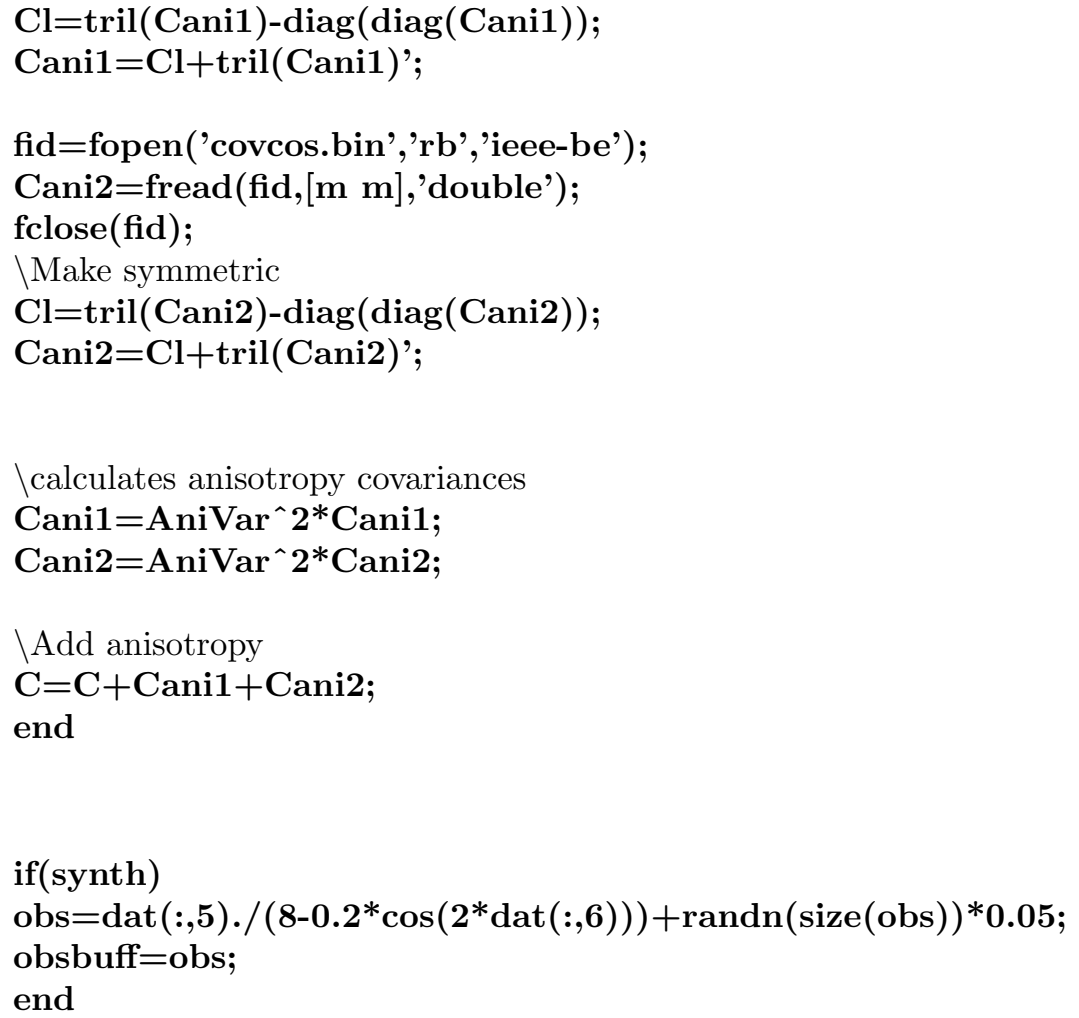

$\backslash$ Add in small extra diagonal cov term to eliminate problem where degenerate station differences exist

$\operatorname{Cerr}=\operatorname{Cerr}+1 \mathrm{e}-10 * \operatorname{eye}(\operatorname{size}(\mathrm{C}))$;

tst $=\operatorname{diag}(\operatorname{chol}(\operatorname{Cerr}))$;

$\backslash$ Downweight degenerate observations. Note that these could be combinations across many observation sets.

tst $=($ tst $<0.01)$;

Cerr $=$ Cerr $+\operatorname{diag}($ tst $) * 100$;

numdeg $=\operatorname{sum}($ tst $)$;

$\mathbf{C}=\mathbf{C}+\mathbf{C e r r}$;

$\% \mathrm{C}=\mathrm{C}+\operatorname{diag}\left(\operatorname{MeasErr} 2^{*}\right.$ ones $\left.(\mathrm{m}, 1)\right)$;

$\backslash$ station covariances

$[\mathrm{AE} \mathrm{BE}]=$ meshgrid(station $)$;

$[\mathrm{AN} B N]=$ meshgrid(stationy);

$\mathrm{Ed}=\mathrm{AE}-\mathrm{BE}$;

$\mathrm{Nd}=\mathrm{AN}-\mathrm{BN}$; 
Edsq=Ed.^ 2;

$\mathrm{Ndsq}=\mathrm{Nd} \cdot{ }^{\wedge} \mathbf{2}$;

Dstat $=(\mathrm{Edsq}+\mathrm{Ndsq}) .^{\wedge} .5$

Cstat $=$ statvar* $\exp (-$ Dstat $/$ stcorD $)$;

Cstat $\mathrm{X}=\left(\mathrm{X}^{*}\right.$ Cstat $\left.^{*} \mathrm{X}^{\prime}\right)$;

$\mathrm{C}=\mathrm{C}+$ Cstat $\mathrm{X}$

$\backslash$ Calculating covariance for station term anisotropy

Cani=statanivar* ${ }^{*} \exp (-D s t a t /$ stcorD $)$;

\% Creating $\mathrm{C}$ (beta) and $\mathrm{C}$ (gamma)

CbetaY $=\left(\right.$ Ys $^{*}$ Cani $\left.^{*} \mathbf{Y} \mathbf{s}^{\prime}\right)$;

CgammaY $=\left(\mathbf{Y c}^{*}\right.$ Cani $\left.^{*} \mathbf{Y c}^{\prime}\right)$;

$\mathrm{C}=\mathrm{C}+$ Cbeta $\mathbf{Y}+$ CgammaY;

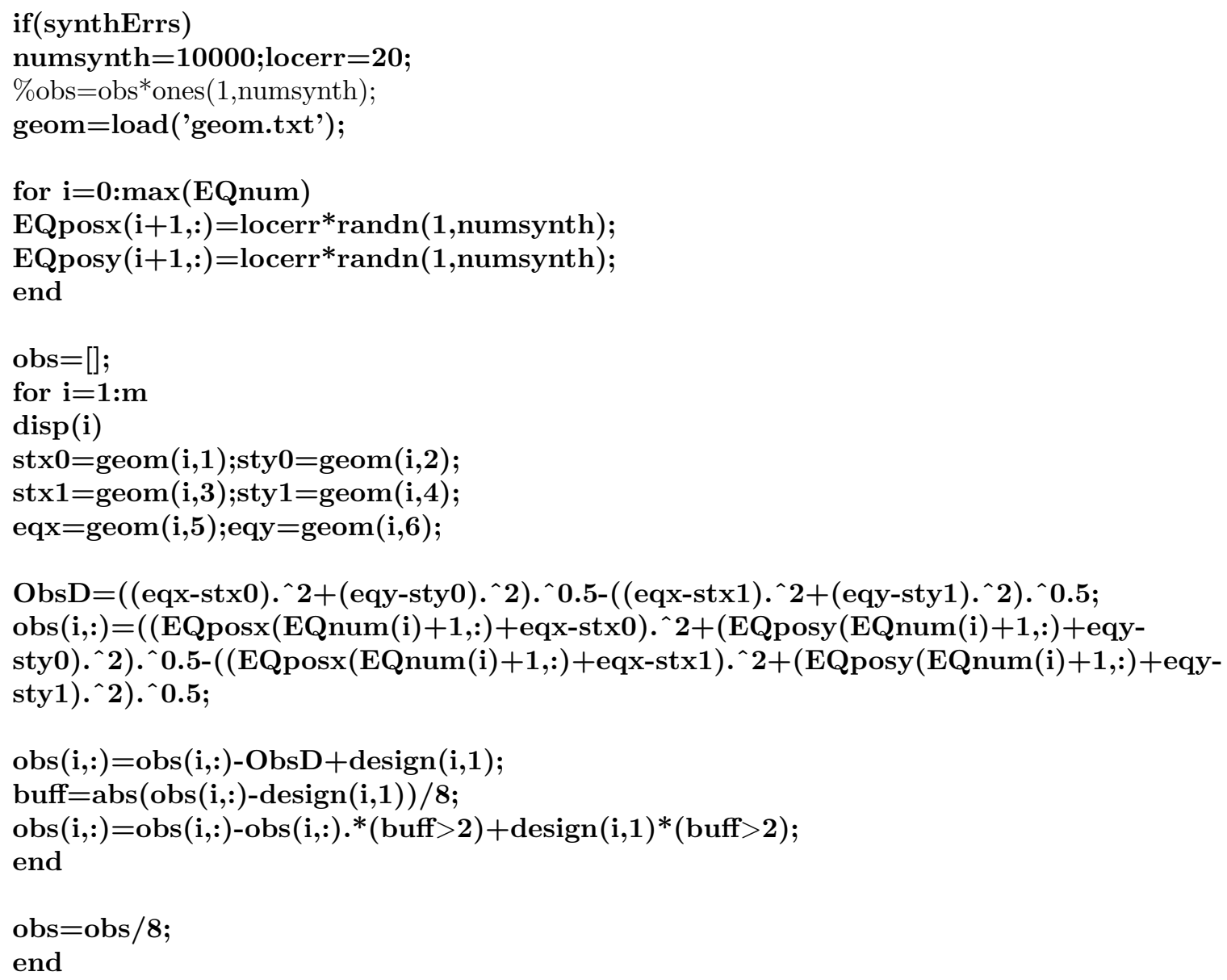




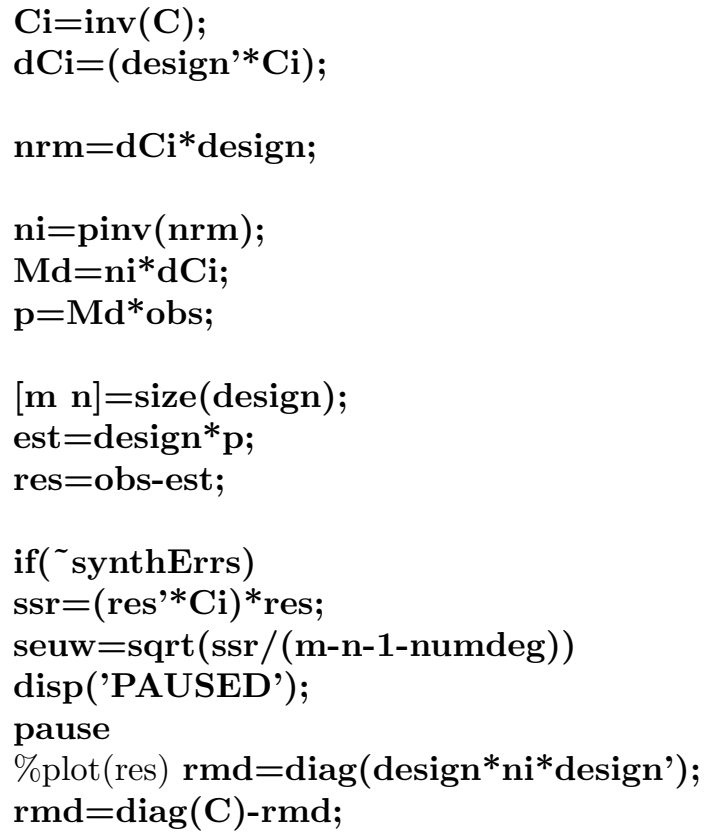

$\backslash$ Calculate Standard deviations for each residual rstd $=$ rmd.` 0.5;

signif $=$ res./rstd;

for $i=1: m$

if $(\operatorname{abs}(\operatorname{signif}(i))>2)$

$\operatorname{disp}([\mathrm{i} \operatorname{dat}(\mathrm{i}, 1: 2) \operatorname{res}(\mathrm{i}) \operatorname{signif}(\mathrm{i})])$;

end

if $(\operatorname{abs}(\operatorname{signif}(\mathrm{i}))>4.0)$

disp('Large Residual!');

$\operatorname{disp}($ 'PAUSED');

pause

end

end

if(CheckOutliers)

$\operatorname{disp}$ ('PAUSED');

pause

end

$[\mathbf{Y}, \mathbf{I}]=\max (\operatorname{abs}($ signif $))$

end

$\mathrm{CiR}=\mathrm{Ci}^{*}$ res;

$\backslash$ Calculate Estimated Apparent velocity from stochastic and deterministic models dist $=\operatorname{dat}(:, 5)$;

$\mathbf{T}=(\mathbf{C p a t h}+\mathbf{C e r r}) * \mathbf{C i R}+\operatorname{dist}^{*} \mathbf{p}$

$\%$ Figure(1)

$\%$ plot(dist,dist./Test,'.');

$\%$ pause

$\%$ Figure (2) 


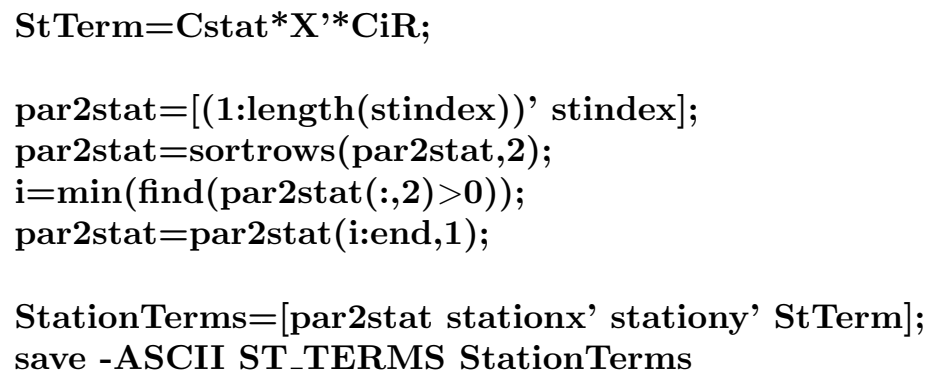

$\backslash$ Calculate covariance signal disp('Calculating Signal');

$\mathrm{Cs}=$ fread(fid2,[m numsigpts],'double');Cs=Cs'; fclose(fid2);

$\mathrm{Cs}=\mathrm{Cs}^{*} \mathrm{ScaleCov}{ }^{\wedge}$;

$[\mathrm{ms}, \mathrm{ns}]=\operatorname{size}(\mathrm{Cs})$;

$\mathrm{v}=\mathrm{Cs}^{*} \mathrm{CiR}+$ ones $(\mathrm{ms}, 1) * \mathrm{p}(1,:)$;

$\operatorname{nis}=\operatorname{fix}((X \max -X \min ) / \operatorname{stp})$;

njs $=\operatorname{fix}((Y \max -Y \min ) / \mathrm{stp})$;

$\mathrm{Xstp}=(\mathrm{Xmax}-\mathrm{Xmin}) / \mathrm{nis}$;

$\mathrm{Ystp}=(\mathrm{Ymax}-\mathrm{Ymin}) / \mathrm{nj}$;

if(synthErrs)

cnt $=1$;

for $\mathrm{i}=\mathbf{0}: \mathrm{nj}$ s

$y=Y \min +i^{*} Y s t p ;$

for $\mathrm{j}=0$ :nis

$\mathrm{x}=\mathrm{Xmin}+\mathrm{j} * \mathrm{Xstp}$;

$\mathrm{sb}=1 . / \mathrm{v}(\mathrm{cnt},:)$;

$\% \operatorname{sb}=\operatorname{sqrt}\left(\operatorname{mean}\left(\mathrm{sb}^{\wedge} 2\right)-\operatorname{mean}(\mathrm{sb})^{\wedge} 2\right)$;

$\% \mathrm{sb}=\operatorname{sqrt}\left(\operatorname{mean}\left(\mathrm{sb}^{\wedge} 2\right)-\operatorname{mean}(\mathrm{sb})^{\wedge} 2\right)$;

$\mathrm{sb}=\operatorname{sort}(\mathrm{sb})$;

$\mathrm{i1}=$ floor $($ numsynth*(1-0.68)/2);

i2=numsynth-i1;

$\mathrm{sb2}=\mathrm{abs}(\mathrm{sb}(\mathrm{i} 1)-\mathrm{sb}(\mathrm{i} 2)) / 2$;

$\operatorname{pts}(\operatorname{cnt}, 1)=x ; \operatorname{pts}(\operatorname{cnt}, 2)=y ; \operatorname{pts}(\operatorname{cnt}, 3)=\mathrm{sb} 2$;

cnt $=$ cnt +1 ;

end

end

save -ASCII estsignal pts;

$\backslash$ Calculate velocity estimations

else

if(VelOn)

disp('Calculating Velocity');

cnt $=1$;

for $i=0: n j s$ 


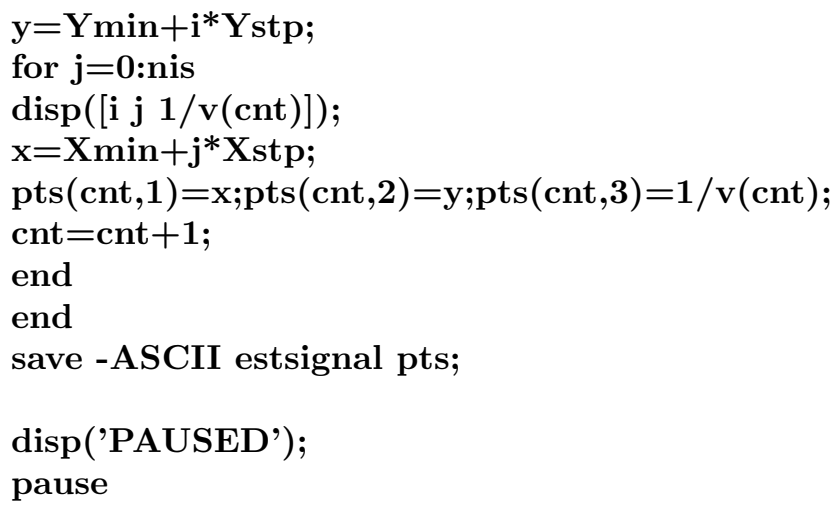

$\backslash$ Calculate velocity uncertainities

disp('Calculating Velocity Uncertainties');

$\mathrm{Q}=$ design'* Ci;

$\mathbf{R}=\mathbf{Q}{ }^{*}$ ni;

$\mathbf{S}=\mathbf{R}^{*}$ design';

$\mathrm{Cpt}=\mathrm{Cpt}^{*}{ }^{\mathrm{ScaleC}} \mathrm{Cov}^{\wedge} \mathbf{2}$

cnt $=\mathbf{1}$;

for $\mathrm{i}=\mathbf{0}: \mathbf{n j}$

$\mathrm{y}=\mathrm{Ymin}+\mathrm{i}^{*} \mathrm{Ystp}$;

$\operatorname{disp}(i)$;

for $\mathrm{j}=0$ :nis

$\mathrm{x}=\mathrm{X} \min +\mathrm{j}^{*} \mathrm{Xstp}$;

$\mathrm{Cxy}=\mathrm{Cs}(\mathrm{cnt},:)$;

Csp=ni(1,1)-ni(1,:)*Q*Cxy'-Cxy*R(:,1)-Cxy*Ci*Cxy'+Cxy*S*Ci*Cxy'+Cpt;

$\% \operatorname{disp}(\operatorname{ni}(1,1))$;

$\% \operatorname{disp}\left(\mathrm{Cpt}-\mathrm{Cxy}^{*} \mathrm{Ci}^{*} \mathrm{Cxy}^{\prime}\right)$

$\%$ pause;

$\operatorname{pts}(\operatorname{cnt}, 1)=x ; \operatorname{pts}(\operatorname{cnt}, 2)=y ; \operatorname{pts}(\operatorname{cnt}, 3)=1 /(\mathrm{v}(\operatorname{cnt})-\operatorname{sqrt}(\operatorname{Csp}))-1 / \mathrm{v}(\operatorname{cnt})$;

$\operatorname{cnt}=\operatorname{cnt}+1$;

end

end

save -ASCII esterrors pts;

end

end

$\backslash$ Calculate anisotropy if(AnisoOn)

disp('Calculating Anisotropy');

fid2=fopen('sigsincov.bin','rb','ieee-be');

aniCs1=fread(fid2,[m numsigpts],'double');aniCs1=aniCs1';

fclose(fid2);

fid2=fopen('sigcoscov.bin','rb','ieee-be'); 
aniCs2=fread(fid2,[m numsigpts],'double');aniCs2=aniCs2';

fclose(fid2);

aniCs1=AniVar^2*aniCs1;

$\operatorname{aniCs2}=$ AniVar` $^{\wedge}{ }^{*}$ aniCs2;

anisig1 $=$ aniCs1 $*$ CiR;

anisig2 $=$ aniCs $2 * \mathrm{CiR}$;

nis $=$ fix $((X \max -X \min ) / \mathrm{stp})$;

$\mathrm{njs}=\mathrm{fix}((\mathrm{Ymax}-\mathrm{Ymin}) / \mathrm{stp})$;

$\mathrm{Xstp}=(\mathrm{Xmax}-\mathrm{Xmin}) / \mathrm{nis}$;

Ystp $=($ Ymax-Ymin $) / n j$;

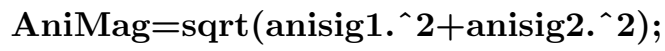

AniPerc $=(1 . /(\mathrm{v}-$ AniMag $)-1 . /(\mathrm{v}+$ AniMag $)) . /(1 . /(\mathrm{v}-$ AniMag $)+1 . /(\mathrm{v}+$ AniMag $))$

AniPerc $=200 *$ AniPerc;

$\operatorname{disp}\left([\text { 'Max anisotropy }=\text { ' num2str( } \max (\text { AniPerc }))^{\prime} \%\right.$ '] $\left.]\right)$;

AniPerc $=$ AniPerc*VectorScale;

$\operatorname{Ani} \mathrm{Az}=\operatorname{atan2}(\operatorname{anisig} 2, \operatorname{anisig} 1) / 2+\mathrm{pi} / 2$;

anifile $=$ fopen ('estaniso','w');

fprintf(anifile, '> $>$ n');

cnt $=1 ;$ plcnt $=1$;

for $\mathrm{i}=\mathbf{0}: \mathrm{njs}$

$\mathrm{y}=\mathrm{Ymin}+\mathrm{i}^{*} \mathbf{Y s t p}$

for $\mathrm{j}=0$ :nis

$\mathrm{x}=\mathrm{X} \min +\mathrm{j}^{*} \mathrm{Xstp}$;

if $(\bmod (i+$ floor $($ anidecim $/ 2)$, anidecim $)==0) \& \&(\bmod (j+$ floor $(\operatorname{anidecim} / 2)$,

anidecim $)==0)$ fprintf $\left(\right.$ anifile, $\% \mathrm{f}, \% \mathrm{f} \backslash \mathbf{n},\left[\mathrm{x}+\operatorname{AniPerc}(\mathrm{cnt}){ }^{*} \sin (\operatorname{AniAz}(\mathrm{cnt}))\right.$,

$\mathrm{y}+\operatorname{AniPerc}(\mathbf{c n t}) * \cos (\operatorname{AniAz}(\mathbf{c n t}))])$;

fprintf(anifile, ${ }^{\%} \%$, $\% f \backslash \mathbf{n}^{\prime},\left[\mathrm{x}-\operatorname{AniPerc}(\mathrm{cnt}){ }^{*} \sin (\operatorname{AniAz}(\mathrm{cnt}))\right.$,

y-AniPerc $(\mathbf{c n t}) * \cos (\operatorname{AniAz}(\mathbf{c n t}))])$;

fprintf(anifile, ' $\left.>\backslash \mathbf{n}^{\prime}\right)$;

$\%$ ani $(2 *$ plcnt $-1,1)=x ; \operatorname{ani}\left(2^{*}\right.$ plcnt- 1,2$)=\mathrm{y} ; \operatorname{ani}(2 *$ plcnt- 1,4$)=$ AniPerc $($ cnt $)$;

ani $(2 *$ plcnt $-1,3)=$ AniAz $($ cnt $)$;

$\% \operatorname{ani}(2 * \operatorname{plcnt}, 1)=\mathrm{x} ; \operatorname{ani}(2 *$ plcnt, 2$)=\mathrm{y} ; \operatorname{ani}(2 * \operatorname{plcnt}, 4)=\operatorname{AniPerc}(\operatorname{cnt}) ;$

$\operatorname{ani}\left(2^{*}\right.$ plcnt, 3$)=\operatorname{AniAz}(\mathrm{cnt})+180$;

plent $=$ plcnt +1 ;

end

cnt $=$ cnt +1 ;

end

end

fclose(anifile);

disp('Calculating Anisotropy Uncertainties');

$\backslash$ Calculate anisotropy uncertainity

$\mathrm{Q}=$ design ${ }^{*} \mathbf{C i}$;

$\mathbf{R}=\mathbf{Q}^{\prime *}$ ni;

$\mathrm{S}=\mathrm{R}^{*}$ design'; 
$\operatorname{cnt}=1$;

anifile $=$ fopen('estanierrors','w');

fprintf(anifile,' $\left.>\backslash \mathbf{n}^{\prime}\right)$;

for $i=0: n j s$

$\mathbf{y}=\mathbf{Y m i n}+\mathbf{i}^{*} \mathbf{Y s t}$;

$\% \operatorname{disp}(\mathrm{i})$;

for $\mathrm{j}=0$ :nis

$\mathrm{x}=\mathrm{Xmin}+\mathrm{j}^{*} \mathrm{Xstp}$;

if $(\bmod (\mathrm{i}+$ floor $(\operatorname{anidecim} / 2)$, anidecim $)=0) \& \&(\bmod (\mathrm{j}+$ floor $(\operatorname{anidecim} / 2)$, anidecim $)==0)$

$\mathrm{Cxy}=[\operatorname{aniCs1}(\mathbf{c n t},:) ; \operatorname{aniCs2}(\operatorname{cnt},:)]$;

$\mathrm{Csp}=\mathrm{AniVar}{ }^{*}{ }^{*} \mathrm{eye}(2)-\mathrm{Cxy}^{*} \mathrm{Ci}^{*} \mathrm{Cxy}^{\prime}$;

Cspi=inv(Csp);

NumSegs $=100$

pts $=[]$;

pts2=[];

jump $=0$;

for $\mathrm{k}=0$ :NumSegs;

ang $=2 *$ pi $/$ NumSegs ${ }^{*} \mathrm{k}$;

$\operatorname{dir}=[\sin ($ ang $) \cos ($ ang $)]$;

$\mathbf{r}=\operatorname{sqrt}\left(\right.$ ChiSq $/\left(\operatorname{dir}^{*}\right.$ Cspi $^{*}$ dir $\left.\left.^{\prime}\right)\right)$;

err $=r^{*}$ dir;

$\operatorname{sig} 1=\operatorname{anisig} 1(\operatorname{cnt})+\operatorname{err}(1)$;

sig2=anisig2 (cnt) $+\operatorname{err}(2)$;

AniMag $=\operatorname{sqrt}\left(\operatorname{sig} 1 .{ }^{` 2}+\operatorname{sig} 2 .{ }^{\wedge} 2\right)$;

AniPerc=(1./(v(cnt)-AniMag)-1./(v(cnt)+AniMag $)) . /(1 . /(v(c n t)-A n i M a g)+1 . /(v(c n t)+$ AniMag $))$;

AniPerc $=200 *$ AniPerc;

AniPerc $=$ AniPerc* VectorScale;

$\operatorname{AniAz}=\operatorname{atan2}(\operatorname{sig} 2, \operatorname{sig} 1)$

$\operatorname{AniAz}=\operatorname{AniAz} / 2+$ pi $/ 2$;

if $(\mathrm{k}=\mathbf{= 0})$

OldAz=AniAz;

end

$\operatorname{AniAz}=A n i A z-j u m p * p i ;$

if $(($ AniAz-OldAz $)>$ pi $/ 2)$

jump $=$ jump +1 ;

AniAz=AniAz-pi;

elseif((AniAz-OldAz) <-pi/2)

jump=jump-1;

$\operatorname{Ani} A z=A n i A z+p i$

end

$\operatorname{OldAz}=A n i A z$

pts $=\left[\right.$ pts;AniAz,x+AniPerc ${ }^{*} \sin ($ AniAz $), y+$ AniPerc $^{*} \cos ($ AniAz $\left.)\right]$;

pts2 $=\left[\right.$ pts2;AniAz,x-AniPerc ${ }^{*} \sin ($ AniAz $), y-A n i P e r c * \cos ($ AniAz $\left.)\right]$;

end

pts $=$ pts';

pts2=pts2';

fprintf(anifile, $\%$ f, $\%$ f $\backslash$ n',pts $(2: 3,:))$;

fprintf(anifile,' $\left.>\backslash \mathbf{n}^{\prime}\right)$;

fprintf(anifile, $\%$ f, $\% f \backslash n ', p t s 2(2: 3,:))$;

fprintf(anifile,' $\left.>\backslash \mathbf{n}^{\prime}\right)$; 


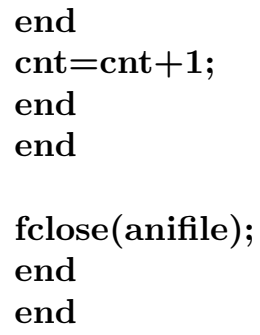

\section{E.3.4 Plotting results:}

The results are best analysed in image form. The raypath coverage is plotted from the epicenter coordinates and station positions. The velocity is plotted as a continuous surface with anisotropy estimations plotted as lines with uncertainty circle, length as an indication of amount of anisotropy. How well the model resolves the data in terns of standard deviations is also shown as continuous surface.

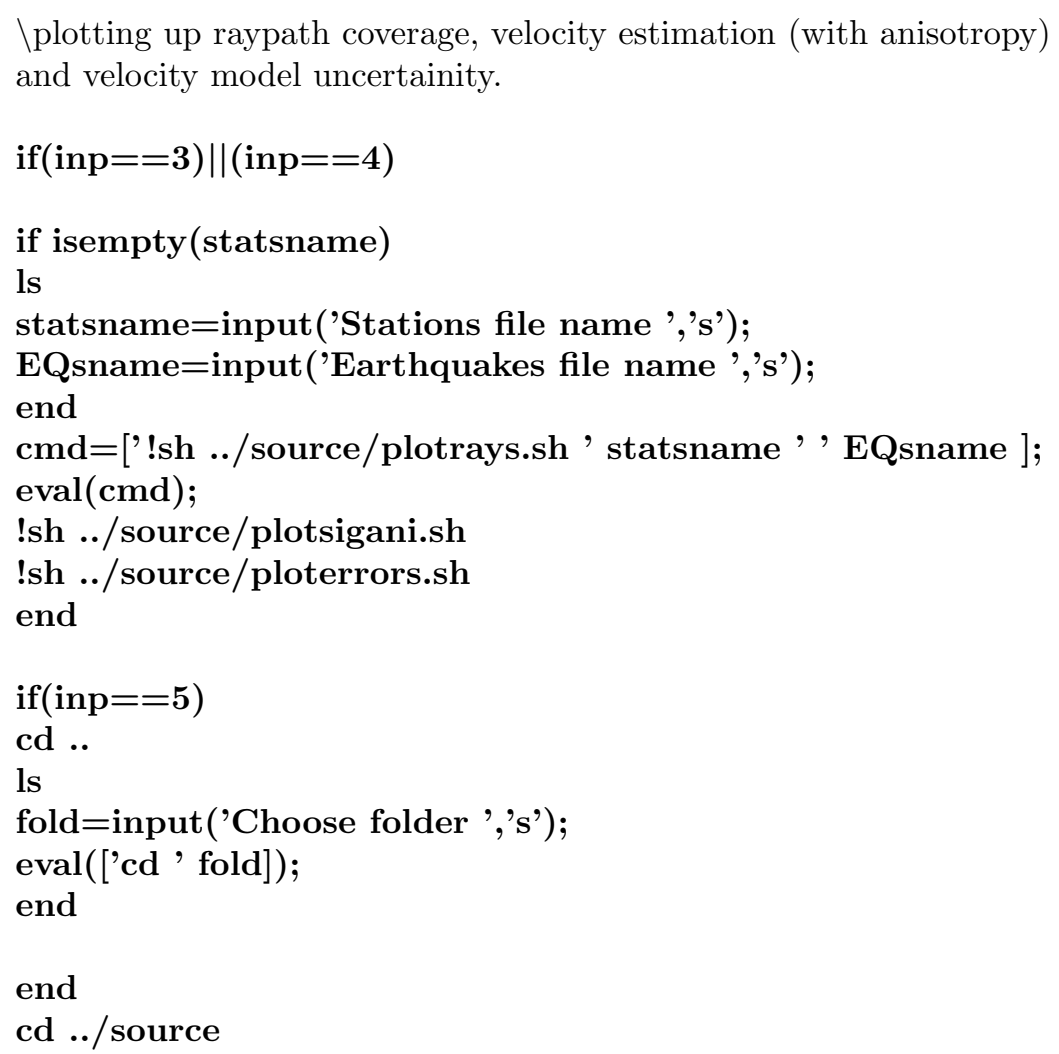


APPENDIX F

\section{STATION TERM ANISOTROPY}

The effect of a sloping Moho boundary and first order crustal inhomogeniety beneath each station is approximated with a station term anisotropy, and is modelled as an azimuthally dependent signal term (EQ F.1). The crustal anisotropy due to aligned cracks and inclusions, will be dependent on $2 \theta$, which is included in the estimation of station term anisotropy, but can not be independently solved for.

$$
C^{\prime}(\theta)=\alpha \sin \theta+\beta \cos \theta+\gamma
$$

where $\theta$ is a column vector of the azimuth with which the ray approaches the station, $\alpha$ and $\beta$ are parameters dependent on the time at various azimuths and $\gamma$ is the average time delay beneath an individual station. $\alpha, \beta$, and $\gamma$ are correlated through a covariance function and then differenced for each ray at each station.

$\gamma$ is the station delay time, where $\alpha$ and $\beta$ indicate the direction of fastest approach. 
Table F.1

Estimation of stationterm anisotropy

\begin{tabular}{|c|c|c|c|c|c|}
\hline Station & $\alpha$ & $\bar{\beta}$ & $\gamma$ & azimuth $\theta$ & Magnitude \\
\hline$\overline{\mathrm{BFZ}}$ & $\overline{-0.289}$ & -0.238 & $\overline{-0.375}$ & 50.52 & 0.374 \\
\hline $\mathrm{BKZ}$ & -0.176 & -0.241 & 4.458 & 36.18 & 0.299 \\
\hline BSZ & -1.280 & -1.001 & -0.397 & 51.98 & 1.625 \\
\hline CMCW & -0.011 & -0.261 & -1.349 & 2.34 & 0.261 \\
\hline CMPJ & 0.043 & -0.132 & -0.731 & -18.03 & 0.139 \\
\hline CMRF & -0.170 & 0.566 & -0.143 & -16.70 & 0.591 \\
\hline CMSF & 0.427 & 0.109 & 0.257 & 75.65 & 0.441 \\
\hline CMTV & -0.977 & 1.026 & 0.183 & -43.60 & 1.417 \\
\hline CMWP & -0.045 & 0.834 & -0.291 & -3.06 & 0.835 \\
\hline CNZ & 0.004 & -0.280 & -0.500 & -0.83 & 0.280 \\
\hline COWA & 0.140 & 0.070 & -1.165 & 63.36 & 0.156 \\
\hline DFE & 0.214 & 0.032 & -1.543 & 81.42 & 0.217 \\
\hline DRZ & -0.170 & -0.217 & -0.233 & 38.03 & 0.276 \\
\hline EDRZ & -0.173 & 0.411 & 0.353 & -22.82 & 0.446 \\
\hline FWVZ & -0.224 & -0.241 & -0.520 & 42.95 & 0.329 \\
\hline HARZ & 0.234 & -0.435 & -0.437 & -28.25 & 0.494 \\
\hline HATZ & 0.214 & -0.685 & -0.489 & -17.35 & 0.718 \\
\hline $\mathrm{HBZ}$ & -1.278 & 0.500 & -0.014 & -68.65 & 1.373 \\
\hline HITZ & 0.157 & 0.711 & -0.397 & 12.48 & 0.728 \\
\hline HIZ & 0.286 & 0.127 & -0.196 & 65.96 & 0.313 \\
\hline $\mathrm{HBH}$ & -1.123 & 0.070 & 0.308 & -86.42 & 1.125 \\
\hline HULA & 0.044 & -0.545 & -0.208 & -4.61 & 0.546 \\
\hline HUTZ & 1.586 & -0.520 & -0.309 & -71.84 & 1.670 \\
\hline KATZ & 0.011 & -0.270 & -0.384 & -2.41 & 0.270 \\
\hline KAVZ & 0.023 & -0.185 & -0.434 & -7.11 & 0.187 \\
\hline KETZ & 0.157 & -0.285 & -0.434 & -28.78 & 0.325 \\
\hline KNZ & 0.865 & 1.003 & 0.993 & 40.77 & 1.324 \\
\hline $\mathrm{KRP}$ & 0.072 & -0.555 & 0.821 & -7.36 & 0.560 \\
\hline KRVZ & 0.075 & -0.187 & -0.510 & -21.84 & 0.202 \\
\hline KUZ & 0.638 & -0.043 & -0.725 & -86.13 & 0.639 \\
\hline LIRZ & 0.101 & -0.577 & -0.667 & -9.93 & 0.586 \\
\hline MAHZ & -0.490 & -0.397 & -0.039 & 50.98 & 0.630 \\
\hline MARZ & 0.470 & -0.616 & -0.827 & -37.32 & 0.775 \\
\hline MGZ & -0.023 & -0.371 & -0.720 & 3.61 & 0.372 \\
\hline MNG & -1.302 & 0.304 & -0.444 & -76.87 & 1.337 \\
\hline $\mathrm{MOH}$ & -0.002 & 0.472 & 0.191 & -0.30 & 0.472 \\
\hline MOVZ & -0.887 & -0.141 & -0.325 & 80.94 & 0.899 \\
\hline MOZ & -0.045 & 0.197 & -0.023 & -12.74 & 0.202 \\
\hline MRZ & -1.349 & 0.449 & -0.320 & -71.60 & 1.422 \\
\hline MTVZ & -0.216 & -0.129 & -1.176 & 59.15 & 0.251 \\
\hline MUIA & 0.146 & -0.418 & 0.033 & -19.25 & 0.442 \\
\hline MWZ & -0.001 & 0.071 & -0.042 & -0.89 & 0.071 \\
\hline MXZ & -0.999 & 0.390 & 0.672 & -68.66 & 1.073 \\
\hline MYRZ & 0.100 & 0.027 & 1.997 & 74.65 & 0.104 \\
\hline NEZ & -0.726 & -0.048 & -0.536 & 86.19 & 0.727 \\
\hline NGZ & 0.022 & -0.271 & -0.490 & -4.62 & 0.272 \\
\hline NOZ & -0.088 & -0.231 & 0.301 & 20.73 & 0.247 \\
\hline NRZ & -0.363 & -0.830 & -0.675 & 23.60 & 0.906 \\
\hline NWEZ & -0.322 & -0.236 & -0.567 & 53.80 & 0.399 \\
\hline OIZ & -0.020 & -0.364 & -0.984 & 3.14 & 0.365 \\
\hline OTVZ & 0.030 & -0.252 & -0.285 & -6.68 & 0.254 \\
\hline
\end{tabular}


Estimation of stationterm anisotropy continued..

\begin{tabular}{|c|c|c|c|c|c|}
\hline \hline Station & $\alpha$ & $\beta$ & $\gamma$ & azimuth $\theta$ & Magnitude \\
\hline \hline PAHZ & -0.641 & 0.508 & 0.928 & -51.64 & 0.818 \\
PARZ & 0.060 & 0.237 & -0.702 & 14.26 & 0.244 \\
PATZ & -0.088 & 0.125 & 0.075 & -34.95 & 0.153 \\
PGZ & -0.460 & 0.390 & -0.551 & -49.67 & 0.603 \\
PKE & -0.398 & 0.284 & -0.594 & -54.48 & 0.489 \\
PKVZ & 0.440 & -0.264 & -0.536 & -59.04 & 0.513 \\
PUKC & 0.021 & -0.142 & 0.232 & -8.37 & 0.143 \\
PUZ & -0.587 & 0.509 & 0.076 & -49.07 & 0.776 \\
RAEZ & -0.218 & -0.266 & -1.254 & 39.32 & 0.344 \\
RATZ & 0.118 & -0.595 & -0.396 & -11.25 & 0.606 \\
RITZ & 0.084 & -0.368 & -0.368 & -12.88 & 0.377 \\
RUZ & -0.090 & -0.443 & -0.929 & 11.51 & 0.452 \\
SUTA & -0.354 & -0.597 & -0.265 & 30.65 & 0.694 \\
TAHZ & -0.489 & 0.079 & 1.005 & -80.86 & 0.496 \\
TAZ & 0.236 & -0.062 & -0.085 & -75.23 & 0.244 \\
TEHZ & -0.945 & 0.079 & -0.402 & -85.21 & 0.948 \\
TGRZ & -0.086 & 0.123 & 1.910 & -34.86 & 0.150 \\
TKEZ & -0.099 & -0.421 & -0.621 & 13.20 & 0.432 \\
TOZ & -0.693 & -0.391 & 0.099 & 60.54 & 0.795 \\
TRVZ & -0.123 & -0.212 & -0.173 & 30.12 & 0.245 \\
TTH & -1.065 & 0.314 & 0.945 & -73.56 & 1.111 \\
TUTZ & 0.348 & 0.282 & 0.120 & 50.93 & 0.448 \\
TUVZ & -0.026 & -0.092 & -0.266 & 15.79 & 0.096 \\
TWVZ & 0.286 & -0.392 & -1.100 & -36.12 & 0.486 \\
URZ & 0.314 & 0.162 & 0.071 & 62.74 & 0.353 \\
UTU & 0.503 & -0.237 & -0.747 & -64.75 & 0.556 \\
VERC & -0.016 & -0.087 & 0.286 & 10.56 & 0.088 \\
VRZ & -0.138 & -0.062 & -0.218 & 65.78 & 0.151 \\
WAHZ & -0.963 & 0.438 & 0.179 & -65.52 & 1.058 \\
WATA & 0.455 & -1.123 & -0.222 & -22.05 & 1.212 \\
WATZ & -0.462 & -0.188 & -0.431 & 67.90 & 0.499 \\
WAZ & -1.112 & -0.673 & -0.488 & 58.84 & 1.300 \\
WEL & 0.222 & -0.482 & -0.534 & -24.72 & 0.531 \\
WHH & -0.297 & -0.059 & 0.742 & 78.82 & 0.303 \\
WHTZ & -0.705 & 0.238 & 0.571 & -71.39 & 0.744 \\
WIZ & 0.546 & -1.091 & -0.398 & -26.57 & 1.220 \\
WLKA & 0.944 & 0.452 & 2.064 & 64.41 & 1.047 \\
WLZ & 0.111 & -0.525 & -0.748 & -11.90 & 0.536 \\
WPVZ & -0.010 & -0.287 & -0.353 & 1.94 & 0.287 \\
WTVZ & -0.077 & -0.278 & -0.510 & 15.56 & 0.289 \\
WTZ & -1.041 & 1.187 & 0.488 & -41.25 & 1.578 \\
WULC & -0.126 & -0.034 & -0.111 & 74.90 & 0.131 \\
\hline \hline & & & & &
\end{tabular}




\section{DEPTH MODELLING}

\section{G.1 Ray Paths through a medium with a depth dependent velocity gradient}

\section{G.1.1 Linear change of velocity with Depth - Circular Ray-paths}

If we start off with a simple model, a ray travelling through a single medium of a constant, non-zero, linear velocity gradient, normal to the Earth's surface, we can use Snell's Law of Refraction to find equations for travel-time and coordinates of the raypath. Snell's Law of Refraction dictates that a ray will refract at an interface between different velocities. The raypath through a medium of linearly increasing velocity will be circular (Stacey 1977). The equation of the circle depends on three parameters.

(1) The initial velocity at the boundary from which the ray departs, $V_{o}$

(2) The velocity gradient within the material, $V_{g}$

(3) The initial take-off angle with which the ray departs the overlaying boundary, $\theta$

The circle radius can be calculated by (Dobrin and Savit 1988):

$$
R=\frac{V_{o}}{V_{g} \sin (\theta)}
$$

The equation of the circle can also be expressed as:

$$
R \sin (\theta)=z+z_{0}
$$




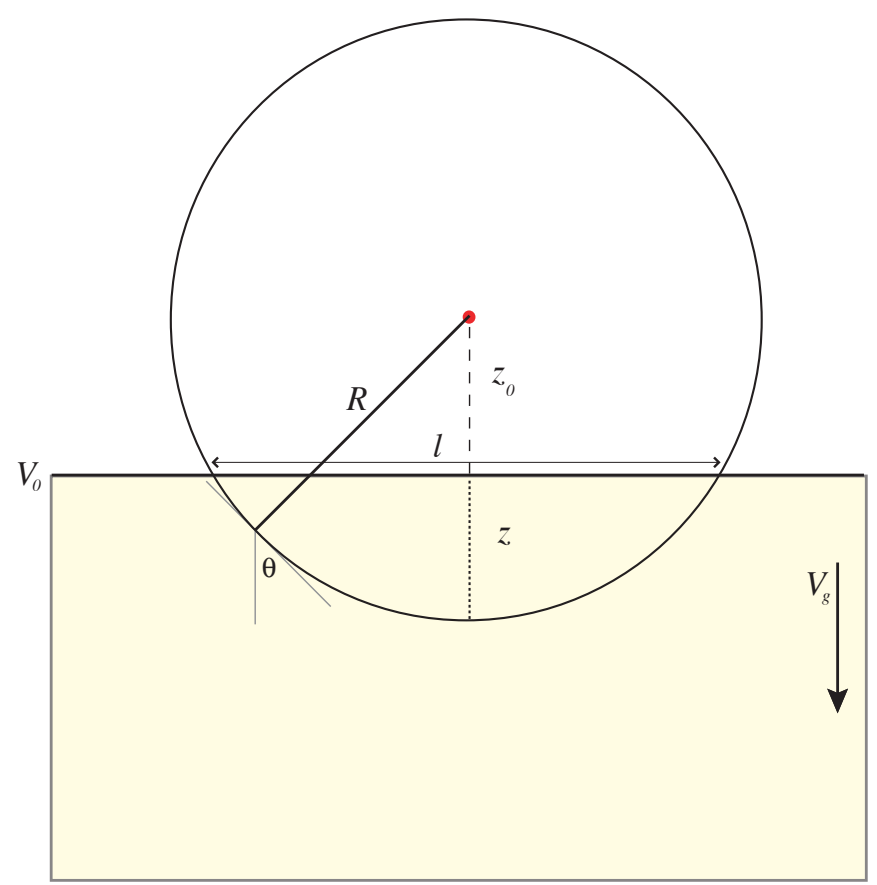

Figure G.1 Schematic of the propagation of a circular ray path, through a medium with constant, non-zero, velocity gradient. Illustrating the equation of a circle with a centre of curvature located above the interface.

where $z_{0}$ is the distance of the centre of curvature above the boundary surface, $z$ is the distance below the interface that the ray propagates (fig G.1).

By comparing Snell's Law and equation G.2, we see that $z_{o}$ is dependent on only the initial velocity $V_{0}$ and the velocity gradient within the layer $V_{g}$.

$$
z_{o}=\frac{V_{0}}{V_{g}}
$$

The ray-path will be sharply curved for a large velocity gradient and almost straight for a small one. If the initial angle of incidence is small, the ray descends steeply to a large depth and returns to the surface at a greater offset than if the initial angle is large (i.e. a shallow angle). 


\section{G.1.2 Depth penetration estimation}

The depth to which a ray penetrates a medium can be calculated from the circular raypath. If we assume that the crust is a single layer with a constant average velocity of $6 \mathrm{~km} / \mathrm{s}$ (Stratford 2006) and offset, the depth to which a ray reaches is dependent on the uppermost mantle velocity (assumed to be between $7.4-8.2 \mathrm{~km} / \mathrm{s}$ for the North Island) and the vertical velocity gradient within the mantle $\left(0.005-0.01 s^{-1}\right)$ Gradients are estimated from velocity observations beneath the North Island from Stratford (2006) and Reyners et al. (2006).

It can be seen (fig G.2) that assuming a crustal thickness of $22 \mathrm{~km}$ with an average velocity of $6 \mathrm{~km} / \mathrm{s}$, no matter what the uppermost mantle velocity in the range of 7.4 - $8.0 \mathrm{~km} / \mathrm{s}$, the ray will not reach depths of more than $75 \mathrm{~km}$ for events offset of less than $615 \mathrm{~km}$.

For the dataset used in the MAR algorithm (modelling code, see Appendix E), there are no epicentral locations more than $610 \mathrm{~km}$ from the furthest station used. Therefore, from the dataset used here, we will not be able to say that the low velocity zone seen in the central North island reaches depths greater than $75 \mathrm{~km}$. 
(a)

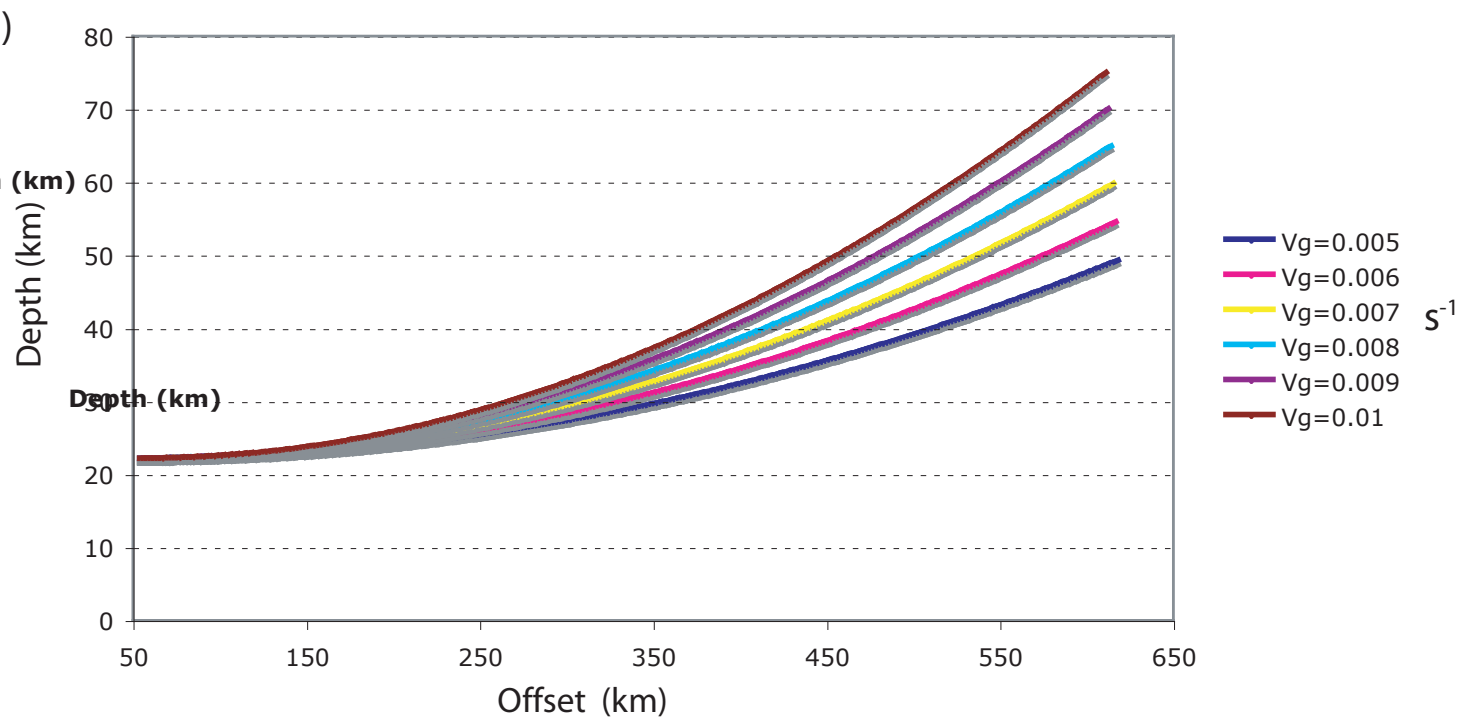

(b)

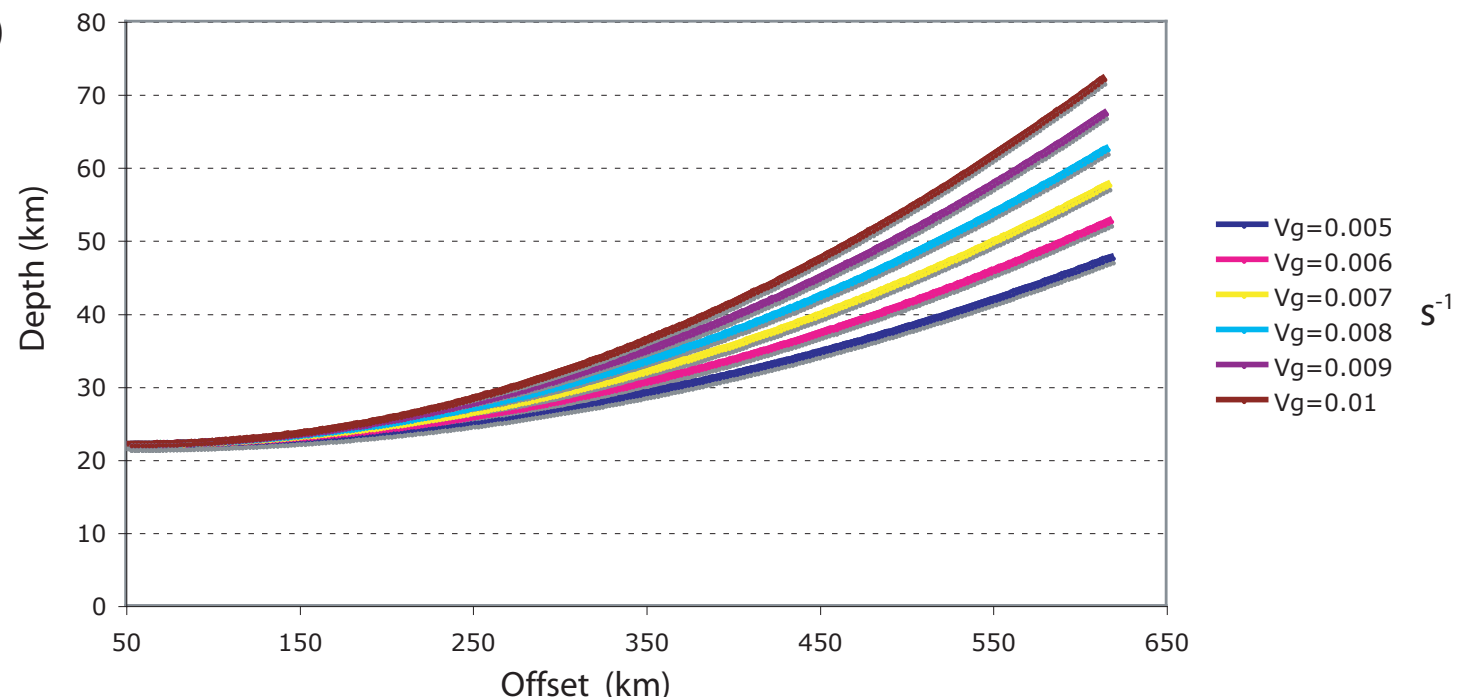

(c)

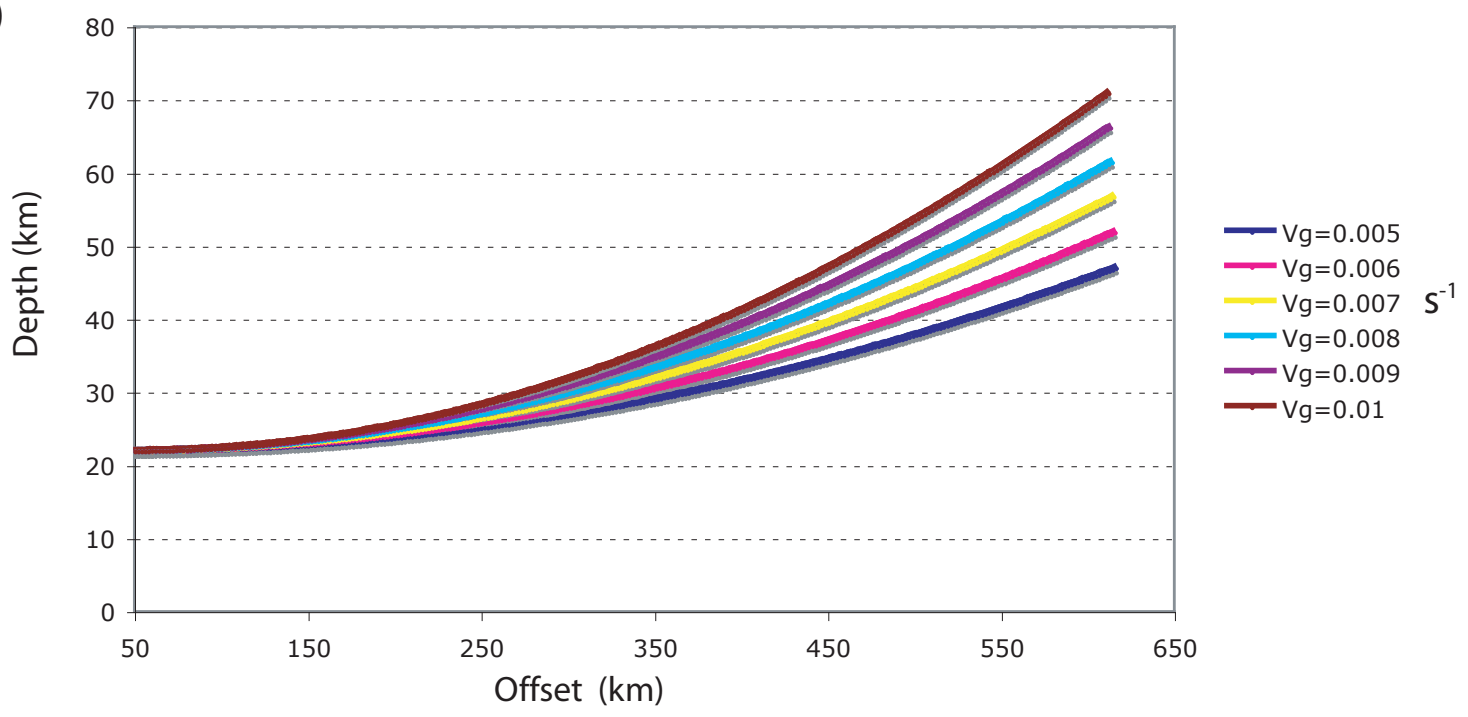

Figure G.2 Estimates of depth penetration with linearly varying vertical velocity gradient. (a) with initial mantle velocity of $7.4 \mathrm{~km} / \mathrm{s}$, (b) with initial mantle velocity of $7.8 \mathrm{~km} / \mathrm{s}$, and (c) with initial mantle velocity of $8.0 \mathrm{~km} / \mathrm{s}$. 


\section{JGR - PAPER}

H.1 Models of the upper mantle beneath the central North Island, New Zealand, from speeds and anisotropy of subhorizontal P-waves (Pn)

Journal of Geophysical Research (JGR - solid earth), vol 114, B01301, doi:10.1029/2008JB005805, 2009 